\title{
Organizing for Business Digitalization and Innovation - Theoretical Perspectives and Empirical Evidence on the Role of Top Managers and Inter-organizational Networks
}

\author{
DISSERTATIONSSCHRIFT \\ (kumulative Dissertation) \\ zur Erlangung des akademischen Grades Doctor rerum politicarum (Dr. rer. pol.) \\ der Fakultät für Sozial- und Wirtschaftswissenschaften \\ der Otto-Friedrich-Universität Bamberg \\ vorgelegt von \\ Fabian Thomas Reck, M.Sc. (Wirtschaftsingenieurwesen) \\ am Lehrstuhl für Betriebswirtschaftslehre, insb. Innovationsmanagement
}

\section{Promotionskommission:}

1. Kommissionsmitglied Univ.-Prof. Dr. Alexander Fliaster (Erstgutachter/Sprecher)

Lehrstuhl für Betriebswirtschaftslehre, insbesondere Innovationsmanagement, Otto-Friedrich-Universität Bamberg

2. Kommissionsmitglied Univ.-Prof. Dr. Björn Ivens (Zweitgutachter)

Lehrstuhl für Betriebswirtschaftslehre, insbesondere Marketing, Otto-Friedrich-Universität Bamberg

3. Kommissionsmitglied Univ.-Prof. Dr. Dr. habil. Wolfgang Becker

Lehrstuhl für Betriebswirtschaftslehre, insbesondere Unternehmensführung \& Controlling, Otto-Friedrich-Universität Bamberg

Datum der mündlichen Prüfung: 12.04.2021 


\section{Summary}

Especially in times of digitalization and digital transformation, firms need to generate and commercialize innovations in order to reinvent their business model, to build and expand their competence base, and to secure their long-term survival. Questions of how firms should "organize for innovation" and which organizational factors determine firms' innovation performance have for long been subject to academic discussion. Most prominently, past research has identified factors such as "top management and leadership", "strategy", "structures and processes", "organizational culture", "resources, skills, and expertise", or "networks and external partners" as major determinants of organizational innovation. However, the pervasiveness of digital technologies and innovations entails two major challenges that will most likely dictate the rules of the "innovation game" in years to come: (1) business digitalization entails holistic organizational transformation; (2) distributed and combinatorial innovation are the major modes of digital innovation. In the light of those challenges, especially the factors "top management and leadership" and "networks and external partners" might be crucial differentiators between innovation leaders and laggards. Hence, my cumulative dissertation centers around those two focus areas. In this thesis, I first identify pressing research gaps with regard to the dominant theoretical perspectives on both topics (upper echelon/strategic leadership theory for "top management and leadership"; strategic network perspective for "networks and external partners"). Then, I present five empirical studies that each address a specific set of the identified limitations in theory and research literature. In all, my work advocates the use of either multi-level research models or typological/taxonomic frameworks as core elements for theoretical reasoning in innovation management research. Doing so, I aim to help overcome theoretical fragmentation in both focus areas and support the development of mid-range theories that adequately reflect the complex and interdependent nature of organizations and of the causal mechanisms at play.

Dieses Werk ist als freie Onlineversion über das Forschungsinformationssystem (FIS; https://fis.uni-bamberg.de) der Universität Bamberg erreichbar. Das Werk steht unter der CC-Lizenz CC-BY-NC.

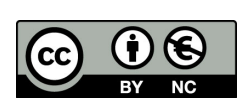

URN: urn:nbn:de:bvb:473-irb-500234

DOI: https://doi.org/10.20378/irb-50023 


\section{Outline}

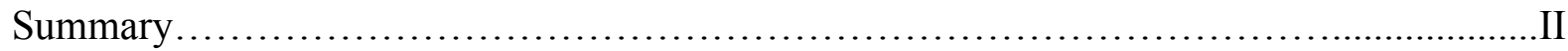

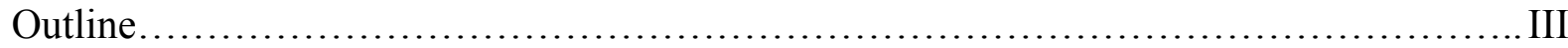

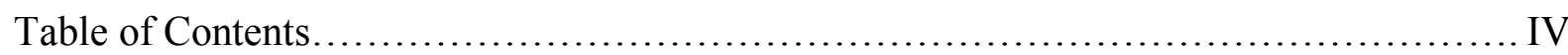

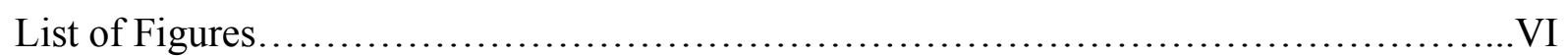

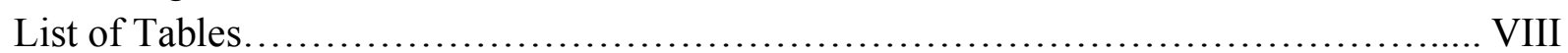

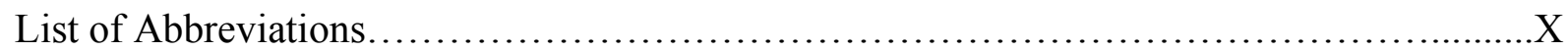

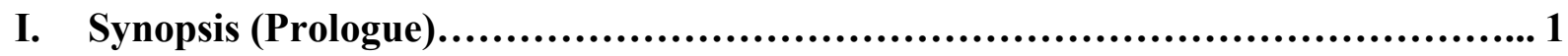

1. Strategic Importance and Organizational Challenges of Innovation.................. 2

2. Research on the Determinants of Organizational Innovation........................ 4

3. Determinants of Organizational Innovation in the Digital Age..................... 11

4. Selection of Focus Areas for Empirical Investigation............................... 17

5. Focus Area I: Top Management and Leadership.................................21

6. Focus Area II: Networks and External Partners................................ 32

7. Overall Structure of the Dissertation........................................ 47

II. Publications in Focus Area I: Top Management and Leadership......................48

1. Publication 1: How New Top Management Roles Drive Business Digitalization - A Configurational Analysis on CDOs' Effectiveness and Failure..................49

2. Publication 2: Toward a Taxonomy of Innovation Leadership on the C-Level An Exploratory Study on the Leadership Behaviors of Senior Executives........... 86

III. Publications in Focus Area II: Networks and External Partners...................133

1. Publication 3: Innovation Networks in the German Energy Industry An Empirical Analysis of Inter-organizational Knowledge Transfer.

2. Publication 4: Management of Knowledge Networks in Industry Clusters and Product Innovation Performance - Development and Test of a Mediation Model....168

3. Publication 5: Firms' Network Profiles and Product Innovation Performance A Configurational Perspective...................................................206

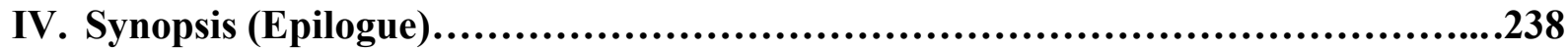

1. Key Findings and Implications in Focus Area I: Top Management and Leadership..238

2. Key Findings and Implications in Focus Area II: Networks and External Partners.. .245

3. Concluding Remarks: Implications for "Organizing for Innovation" in the Digital Age.........................................................251

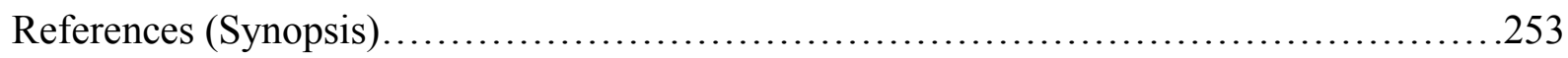




\section{Table of Contents}

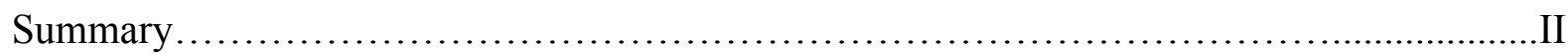

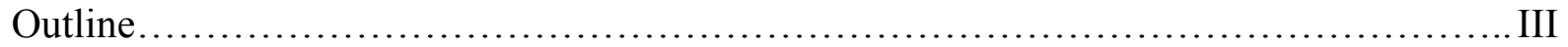

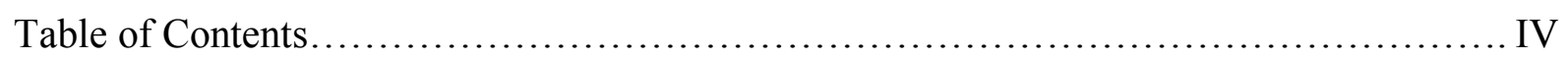

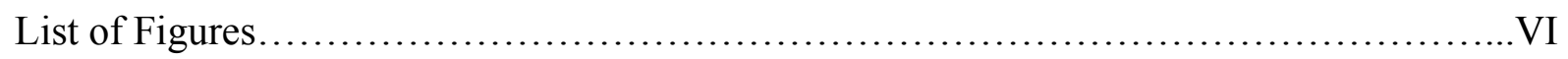

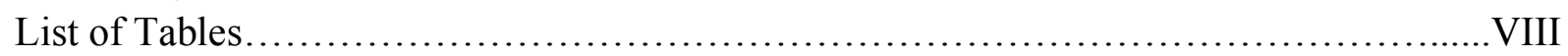

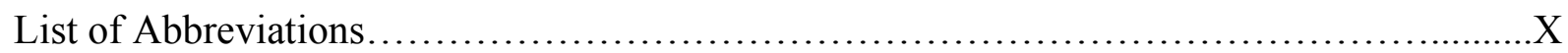

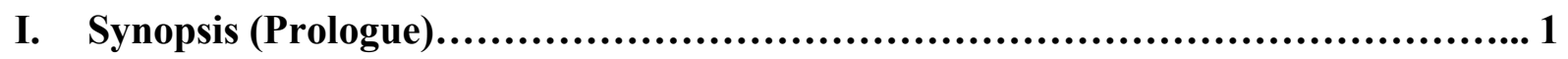

1. Strategic Importance and Organizational Challenges of Innovation.................. 2

2. Research on the Determinants of Organizational Innovation......................... 4

2.1. Determinants of Organizational Innovation According to Observations of "Best Practice"...........................................................

2.2. Determinants of Organizational Innovation According to Reviews of Research Literature..................................................... 7

2.3. Summary of Current Insight on the Determinants of Organizational

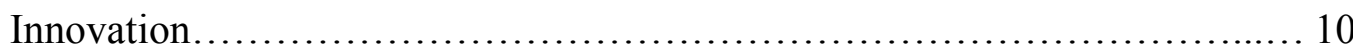

3. Determinants of Organizational Innovation in the Digital Age..................... 11

3.1. Specific Features of Digital Innovations and Consequences for Innovation Management...................................................... 12

3.2. Digital Transformation and the Importance of Top Management and Leadership.

3.3. Distributed Innovation, Combinatorial Innovation, and the Importance of Inter-organizational Networks and External Partners...................... 15

4. Selection of Focus Areas for Empirical Investigation.............................. 17

5. Focus Area I: Top Management and Leadership.................................21

5.1. Previous Research and Baseline Theories....................................21

5.2. Research Gaps........................................................ 24

5.3. Summary of Publications in Focus Area I............................... 28

6. Focus Area II: Networks and External Partners.................................... 32

6.1. Previous Research and Baseline Theories.......................................32

6.2. Research Gaps........................................................... 35

6.3. Summary of Publications in Focus Area II...................................... 39

7. Overall Structure of the Dissertation........................................ 47 
II. Publications in Focus Area I: Top Management and Leadership .48

1. Publication 1: How New Top Management Roles Drive Business Digitalization -

A Configurational Analysis on CDOs' Effectiveness and Failure...................49

1.1. Note on Submitted Paper.................................................49

1.2. Academic Paper....................................................... 50

1.3. References............................................................... 80

2. Publication 2: Toward a Taxonomy of Innovation Leadership on the C-Level An Exploratory Study on the Leadership Behaviors of Senior Executives........... 86

2.1. Note on Submitted Paper................................................ 86

2.2. Academic Paper........................................................ 87

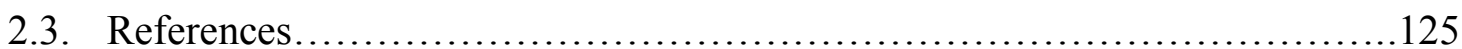

III. Publications in Focus Area II: Networks and External Partners...................133

1. Publication 3: Innovation Networks in the German Energy Industry -

An Empirical Analysis of Inter-organizational Knowledge Transfer................134

1.1. Note on Submitted Paper................................................. 134

1.2. Academic Paper.................................................... 135

1.3. References........................................................... 163

2. Publication 4: Management of Knowledge Networks in Industry Clusters and

Product Innovation Performance - Development and Test of a Mediation Model....168

2.1. Note on Submitted Paper................................................. 168

2.2. Academic Paper..................................................... 169

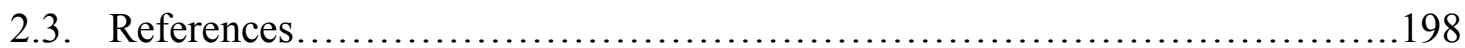

3. Publication 5: Firms' Network Profiles and Product Innovation Performance -

A Configurational Perspective...............................................206

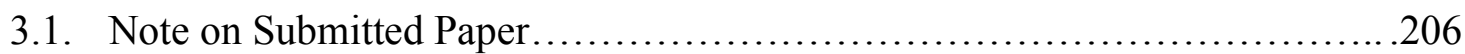

3.2. Academic Paper........................................................... 207

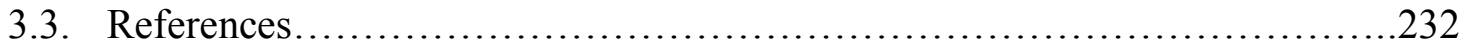

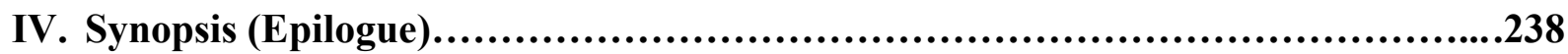

1. Key Findings and Implications in Focus Area I: Top Management and Leadership..238

1.1. Research Gaps and Key Findings....................................238

1.2. Theoretical Implications............................................... 243

1.3. Limitations and Further Research.......................................244

2. Key Findings and Implications in Focus Area II: Networks and External Partners.. .245

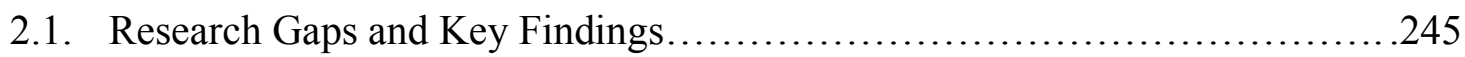

2.2. Theoretical Implications............................................... 249

2.3. Limitations and Further Research......................................250

3. Concluding Remarks: Implications for "Organizing for Innovation" in the

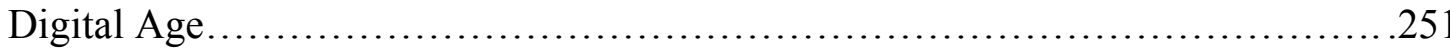

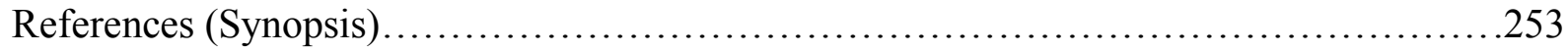




\section{List of Figures}

Figure I-1

Figure I-2

Figure I-3

Figure I-4

Figure I-5

Figure I-6

Figure I-7

Figure I-8

Figure I-9

Figure I-10

Figure I-11

Figure I-12

Figure I-13

Figure I-14

Figure I-15

Figure I-16

Figure I-17

Figure I-18

Figure I-19

Figure II-1-1

Figure II-1-2

Figure II-1-3

Figure II-2-1

Figure III-1-1

Figure III-1-2

Figure III-1-A1

Figure III-1-A2

Figure III-1-A3

Figure III-1-A4

Figure III-2-1

Figure III-3-1

Figure III-3-2

Figure III-3-3

Figure IV-1

Figure IV-2

Figure IV-3

Figure IV-4
Annual R\&D spendings of “Global Innovation 1000” firms by industry....................................................... 2

Annual R\&D spendings of "Global Innovation 1000” firms by

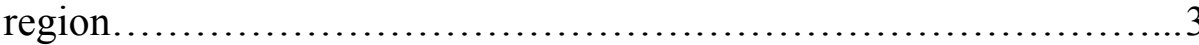

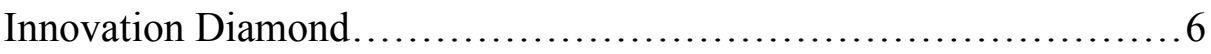

OCI framework.............................................. 7

Multi-dimensional framework of organizational innovation............ 8

Components of RPI capability................................. 10

Strategic relevance of different areas of innovation................. 12

Conceptual framework for the management of business

digitalization.............................................. 14

Six dimensions of digital innovation............................. 16

Selection of focus areas for my doctoral research................... 19

Summary of research variables employed in empirical studies on CEOs, TMTs, and the CEO-TMT interface.........................23

Leadership influence on organizational innovation..................24

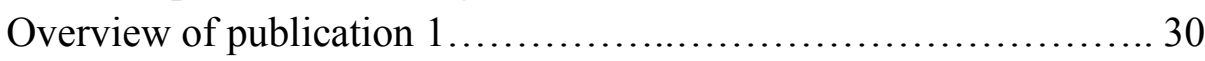

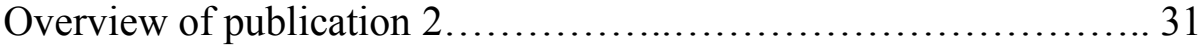

Overview of network-related variables employed in empirical studies on inter-organizational networks and innovation.............. 34

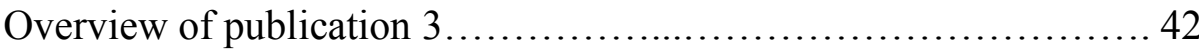

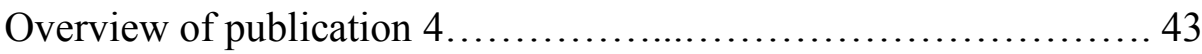

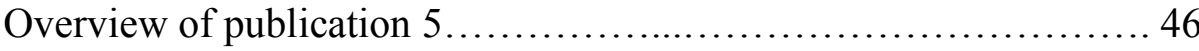

Structure of the dissertation...................................... 47

Research framework......................................... 58

Distribution and calibration of the variable internal network ...........65

Distribution and calibration of the variable external network.......... 65

Innovation leadership behaviors at the c-level ......................95

Knowledge exchange volume in all four dimensions.................147

Profiles of high performing firms................................. 156

Network of technological knowledge transfer......................159

Network of market knowledge transfer........................... 160

Network of managerial knowledge transfer....................... 160

Network of regulatory knowledge transfer........................161

Hypothesized model......................................... 177

Research framework......................................... 214

Distribution of network size................................... 222

Summary of innovation-fostering configurations..................229

Key findings in focus area I with regard to research gaps 1 and 2.. 240

Key findings in focus area I with regard to research gaps 3 and 4... 241

Key findings in focus area I with regard to research gap 5......... 242

Key findings in focus area II with regard to research gaps 1 and 2... 247 
I. Synopsis (Prologue)

Figure IV-5 Key findings in focus area II with regard to research gaps 3 and $4 \ldots 248$ 


\section{List of Tables}

Table II-1-1

Table II-1-2

Table II-1-3

Table II-1-4

Table II-1-5

Table II-1-6

Table II-1-7

Table II-1-8

Table II-2-1

Table II-2-2

Table II-2-3

Table II-2-4

Table II-2-5

Table II-2-6

Table II-2-7

Table II-2-8

Table II-2-9

Table II-2-10

Table II-2-11

Table III-1-1

Table III-1-2

Table III-1-3

Table III-1-4

Table III-1-5

Table III-1-6

Table III-1-7

Table III-1-8

Table III-1-9

Table III-1-A1

Table III-2-1

Table III-2-2

Table III-2-3

Table III-2-4

Table III-3-1

Table III-3-2

Table III-3-3
Means, standard deviations, and correlations. 59

Construct specification and item loadings. 60

Construct specification and item loadings (continued)............... 61

Construct specification and item loadings (continued)................6 62

Sufficient solutions for high levels of business digitalization.......... 68

Sufficient solutions for low levels of business digitalization........... 69

Demographics and professional backgrounds of the identified CDO types................................................ 70

Solutions for high levels of business digitalization: Contingency perspective. 71

Means, standard deviations, and correlations...................... 101

Construct specification and item loadings........................... 102

Construct specification and item loadings (continued)............... 103

Construct specification and item loadings (continued)................ 104

Construct specification and item loadings (continued)................ 105

Statistical cluster description.................................. 108

Verbal cluster description........................................ 109

Cluster membership for managerial positions....................... 110

Discriminant analysis results................................... 112

Results of classification analysis................................ 113

Covariate cluster means, standard deviations, and results of

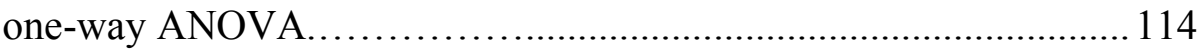

Questionnaire items for knowledge exchange dimension............. 144

Descriptive data on networks.................................... 146

Significance test for density and exchange volume differences........147

Guttman scale analysis results................................ 149

Analysis for exchange multiplexity........................... 150

Correlations between knowledge exchange

networks (original data).

Correlations between knowledge exchange

networks (adjusted data)

OLS regression result for different types of innovation............... 154

$t$-test for profile differences between high and low performers........ 155

Significance test for correlation differences among the four

knowledge exchange networks................................ 162

Construct specification and item loadings........................... 187

Construct specification and item loadings (continued)............... 188

Convergent and discriminant validity............................189

PLS-SEM results.............................................. 192

Means, standard deviations, and correlations.....................218

Construct specification and item loadings..........................219

Sufficient solutions for high product innovation performance.........224 
I. Synopsis (Prologue)

Table III-3-4 Sufficient solutions for low product innovation performance

.225

Table III-3-5 Solutions for high product innovation performance: Contingency

perspective. 
I. Synopsis (Prologue)

\section{List of Abbreviations}

ABS

AGFI

ANOVA

AVE

avg.

BCG

CB

$\mathrm{CDO}$

CEO

CFI

$\mathrm{CFO}$

CI95\%

CIO

CHRO

$\mathrm{CMO}$

COMPL

$\mathrm{COO}$

$\mathrm{CR}$

CR

CS

$\mathrm{CSO}$

CTO

$\mathrm{CxO}$

D-A-CH

df

DIVERS

e.g.

EBITDA

ED

ed./Ed.

ed./eds./Ed./Eds.

EGOS

EnBW

ES

et al.

etc.

EXNW

fsQCA

GE

HR
Association of Business Schools

Adjusted Goodness of Fit Index

Analysis of Variance

Average Variance Extracted

average

Boston Consulting Group

Covariance-based

Chief Digital Officer

Chief Executive Officer

Comparative Fit Index

Chief Financial Officer

$95 \%$ confidence interval

Chief Information Officer

Chief Human Resources Officer

Chief Marketing Officer

partner complementarity

Chief Operating Officer

Coefficient of Reproducibility

Composite Reliability

Coefficient of Scalability

Chief Strategy Officer

Chief Technology Officer

C-Level Executive

Deutschland, Österreich, \& Schweiz (German); Germany, Austria, \& Switzerland

degrees of freedom

partner diversity

exempli gratia (Latin); for example

Earnings before Interest, Taxes, Depreciation, and Amortization

Euclidian Distance

edition

editor/editors

European Group for Organizational Studies

Energie Baden-Württemberg

Effective Size

et alii/et aliae (Latin); and others, amongst others

et cetera (Latin); and so on

external network

fuzzy-set Qualitative Comparative Analysis

General Electric

Human Resource(s) 
I. Synopsis (Prologue)

HRM

i.e.

ibid.

INNO

INNO

INNW

IT

$\log$

Mgmt

MgtK

MIT

MktK

MSCI

MV

no.

NNFI

NPD

NWSIZE

OCI

OLS

ONA

$\mathrm{P} \& \mathrm{G}$

p.

PDMA

PLS

POLS

pp.

PRI

QAP

R\&D

$\mathrm{RE}$

Reg

RK

RMSEA

ROA

ROI

ROS

RPI

RTA

RWE

S. D./SD

SAS

SEM

sig.
Human Resource Management

id est (Latin); this is

ibidem (Latin); in the same place

innovative role behavior

partner innovativeness

internal network

Information Technology

logarithmic

management

managerial knowledge

Massachusetts Institute of Technology

market knowledge

Morgan Stanley Capital International

missing value

number

Non-normed Fit Index

New Product Development

network size

Outstanding Corporate Innovator

Ordinary Least Squares

Organizational Network Analysis

Procter \& Gamble

page

Product Development Management Association

Partial Least Squares

political skills

pages

Proportional Reduction in Consistency

Quadratic Assignment Procedure

Research \& Development

Renewable Energy

regulatory

regulatory knowledge

Root Mean Square Error of Approximation

Return on Assets

Return on Investments

Return on Sales

radical product innovation

Revealed Technological Advantage

Rheinisch-Westfälisches Elektrizitätswerk

standard deviation

Statistical Analysis System

Structural Equation Modelling

significance 
I. Synopsis (Prologue)

SITK

SME

SNA

SPSS

SRMSR/SRMR

std.

STEAG

SUPP

Tech/techn.

THÜGA

TIESTR

TK

TMT

US

USA

VAF

VHB

VP

vs. strategic IT knowledge

Small and Medium-sized Enterprise

Social Network Analysis

Statistical Package for the Social Sciences

Standard Root Mean Square Residual

standard

Steinkohlen-Elektrizität AG

supportive role behavior

technological

Thüringer Gasgesellschaft

tie strength

technological knowledge

Top Management Team

United States

United States of America

Variance Accounted For

Verband der Hochschullehrer für Betriebswirtschaft

(German); German Academic Association for Business

Research

Vice President

versus (Latin); versus, in comparison to 


\section{Synopsis (Prologue)}

This cumulative dissertation altogether comprises five publications. These five publications cover different aspects of the overall topic examined in two focus areas: (1) top management and leadership; and (2) networks and external partners. The five publications are encompassed by a synopsis which is structured dichotomously. In the beginning, the initial chapter contains an introductive prologue that provides an introduction as well as a depiction of the overall thematic frame that links the individual publications of this dissertation to the overall research topic (chapter I). At the end, the concluding chapter holds an epilogue that provides a summary of all the publications included in this dissertation, the overall findings, and how they contribute to the prevailing state of research regarding the overall topic (chapter IV). Furthermore, I highlight implications and limitations of my doctoral research. In between the prologue and the epilogue, the five publications included in this thesis are presented in chapters II ("Focus Area I - Top Management and Leadership") and III ("Focus Area II - Networks and External Partners"). For complementary information, a note on the current state of the submission as well as previous conference presentations of each paper is provided.

The following prologue starts with a general introduction on organizational innovation, firmlevel innovation performance, and their effect on firms' competitive advantage and overall performance (section I.1). In section I.2, I summarize previous research on which factors determine organizational innovation and present four models that aimed to depict comprehensively the major organizational components that influence firm-level innovation outcomes. Section I.3 describes the challenges for innovation management that stem from an increasing digitalization of society and business environments. Thereby, I discuss the issues that arise from the holistic transformational task firms are confronted with due to digitalization as well as the issues that stem from the general features that distinguish digital from analog technologies. Based on this insight, I reevaluate the findings of previous research on the determinants of organizational innovation. Because of this reevaluation, I select two focus areas for my empirical research and substantiate this choice in section I.4. Section I.5 provides an overview of the first focus area ("top management and leadership"), summarizes previous research, identifies gaps in the current state of knowledge, and presents the publications 1 and 2 of this dissertation. Analogously, section I.6 deals with the second focus area ("networks and external partners"), illustrating publications 3 to 5. Finally, section I.7 concludes the prologue and outlines the overall structure of publications within the scope of this dissertation. 


\section{Strategic Importance and Organizational Challenges of Innovation}

In the present era of digitalization, "innovation" is one of the highest-ranking issues on firms' strategic agendas. In 2010, when the advent of the fourth industrial revolution, mobile computing, big data analytics, and artificial intelligence became apparent in most traditional industries (Becker \& Pflaum, 2018), the Boston Consulting Group (BCG) reported based on a senior executive innovation survey that $71 \%$ of companies named innovation as one of their top 3 strategic priorities, $70 \%$ of the surveyed firms considered "new-to-the-world" products as "important" or "very important" for future business performance (Andrew, Manget, Michael, Taylor, \& Zablit, 2010). More recently, the top management consultancy Strategy\& presented data indicating that from 2005 on, the amount of R\&D spending of the 1,000 publicly held companies that invested most in innovation (the "Global Innovation 1000") grew continuously to an all-time high of 782 billion US-Dollar (Jaruzelski, Chwalik, \& Goehle, 2018). Breaking the numbers down with regard to sectoral and regional contexts, this trend is evident across almost all major industries and most world regions (see Figure 1 and 2).

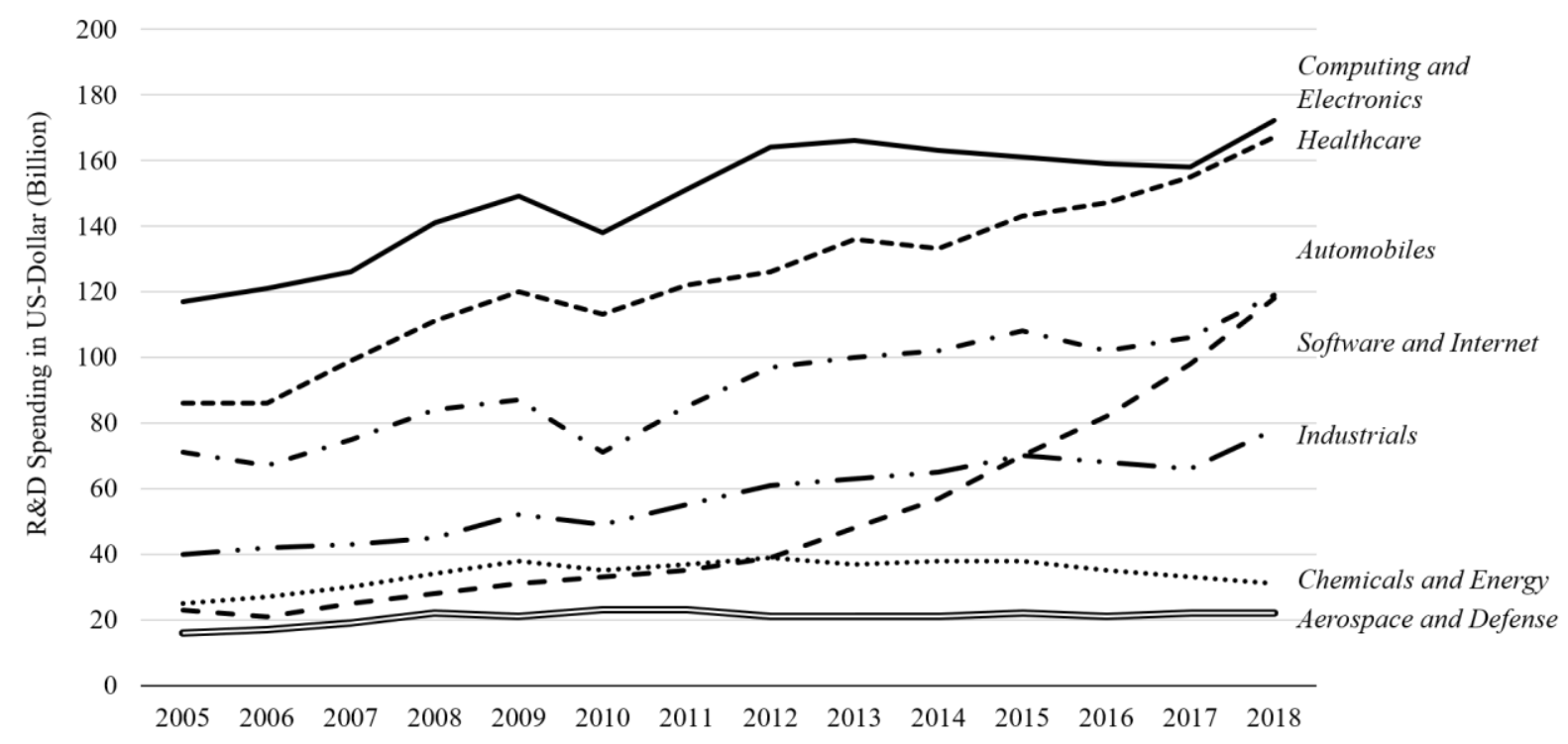

Figure I-1. Annual R\&D spending of "Global Innovation 1000" firms by industry (own illustration, based on Jaruzelski et al., 2018) 


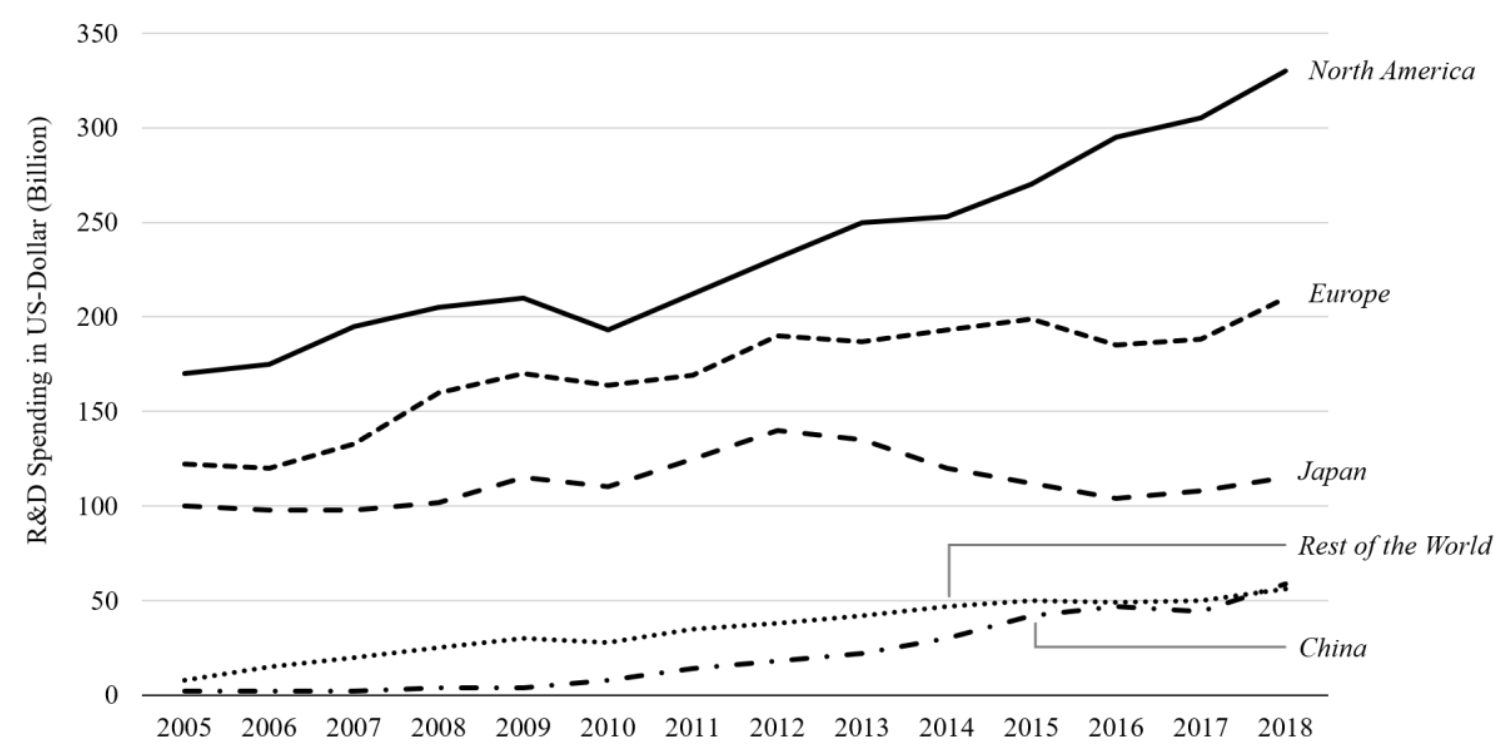

Figure I-2. Annual R\&D spending of "Global Innovation 1000" firms by region (own illustration, based on Jaruzelski et al., 2018)

Reflecting the continuously growing importance of innovation in the view of top managers and strategic decision-makers in firms across industries and regions, organizational innovation, i.e., "the introduction of new processes, products, or ideas in the organization" (Hult, Hurley, \& Knight, 2004, p. 429), seems to be a major predictor of competitive advantage and market performance. For instance, data from Thomson Reuters indicates that in 2015 the Top 100 innovators (in terms of the number, financial return, and influence of granted patents) outperformed the MSCI World Index by 6.01 percentage points in revenue growth and 4.09 percentage points in employment growth (Thomson Reuters, 2015). This empirical data is well in line with the results of academic research. Calantone, Cavusgil, and Zhao (2002) for instance find that innovation in the firm was a strong predictor of overall profitability and financial returns (ROI, ROA, and ROS). Li and Calantone (1998) demonstrate that the introduction of superior new products is linked to increased market performance in terms of EBITDA, ROI, pre-tax margins, and market share. Additionally, Klomp and van Leeuwen (2001) provide evidence that not only new products but also other forms of innovation such as new processes can provide a basis for competitive advantage and result in increased sales performance and employment growth.

Still, despite high levels of awareness on the issue it is evident that many firms struggle with the task of developing and implementing innovations that meet the aspired business goals. In the McKinsey Global Survey 2010, only $6 \%$ of the surveyed senior executives were satisfied with their firm's innovation performance though $84 \%$ reported innovation as critical for their business (Capozzi, Gregg, \& Howe, 2010; McKinsey, 2019). Similarly, the American Productivity \& Quality Center reports based on senior executive survey data that while top managers across industries name "enhancing innovation abilities" as the most crucial factor for competitive advantage and firm prosperity, in only $13 \%$ of firms the overall internal innovation efforts hit market, cost, and time objectives (Cooper, 2017; Edgett, 2011). Cooper (2013) 
consequently states that "[ $\mathrm{t}]$ he central role of product [and other forms of] innovation in business strategy coupled with the poor innovation performance results in many firms has resulted in a quest for the factors that drive performance and lead to product innovation success" (p. 4).

The reason why firms and senior managers often fail to install adequate means for improving in innovation and $R \& D$ is that innovation is not just a strategic investment decision, but a much more complex problem of organization (e.g. Crossan \& Apaydin, 2010; Damanpour, 1991; Fiol, 1996). Among others, innovation in the firm entails "the organizing challenges of iterating between diverse activities, working around barriers, combining insights, and resolving the conflicts of seemingly opposing forces" (Dougherty, 1999, p. 175). In order to meet those challenges, firms must on the one hand configure useful skills, resources, and competencies (Eisenhardt \& Martin, 2000; Slater, Mohr, \& Sengupta, 2014). On the other hand, firms need adequate organizational structures and processes that enable the effective deployment of those resources (Lam, 2005; O'Connor \& Ayers, 2005; O'Connor \& DeMartino, 2006) as well as proactive technology and business strategies to guide innovative efforts (Cooper, 2013; Mugge \& Markham, 2013). In other words, firms must find ways to "organize for innovation", i.e., set up adequate organizational structures, processes, roles, norms and values to enable the successful development and commercialization of new products, services, processes, or business models (e.g. Chesbrough \& Teece, 2009; Dougherty, 1999; Hauser, Tellis, \& Griffin, 2006; Lam, 2005; Tushman \& Nadler, 1986; Yoo, Boland, Lyytinen, \& Majchrzak, 2012).

While "organizing for innovation" by itself is a complex and difficult task, the increasing digitalization of the business world brings forth a number of new challenges for firms (Benner \& Tushman, 2015; Nambisan, Lyytinen, Majchrzak, \& Song, 2017; Yoo et al., 2012). As research has just begun to understand those new challenges, the question of how firms should manage business digitalization and innovation is largely unanswered. In this thesis, I aim to shed light on this issue by providing theoretical explanations and empirical evidence on how two important organizational factors ("top management and leadership", "networks and external partners") influence innovation in the firm. In the rest of this prologue, I first reflect previous research on the determinants of organizational innovation. Then, I outline the current state of academic research on what distinguishes innovation in the digital age from innovation in the analog age. I use this insight to discuss the selection of the two focus areas of this dissertation. Finally, I address prevailing theories as well as research gaps in both focus areas, and provide a brief overview of the research papers included in this dissertation.

\section{Research on the Determinants of Organizational Innovation}

The ability to effectively "organize for innovation" is widely regarded as one of the most valuable organizational capabilities a firm can possess. Consequently, a large share of innovation research aims to uncover the determining factors of organizational innovation or other synonymously used constructs reflecting firm-level innovation performance (Crossan \& Apaydin, 2010; Wolfe, 1994). Thereby, research has discussed the effects of a broad range of different variables on the inter-organizational level, the firm level, and the micro level (i.e., teams and individuals in the firm). Among others, innovation research examined causal 
relations between organizational innovation and the structure and composition of ecosystems and firm networks (e.g. Ahuja, 2000; Phelps, 2010; Powell, Koput, \& Smith-Doerr, 1996), inter-organizational collaboration and knowledge transfer (e.g. Rothaermel \& Hess, 2007; Tiwana, 2008; Tortoriello \& Krackhardt, 2010), organizational structure and design (e.g. Blindenbach-Driessen \& Van den Ende, 2014; Damanpour, 1992; Teece, 1998), strategic orientations of the firm (e.g. Atuahene-Gima \& Ko, 2001; Kraft \& Bausch, 2016; Zhou, Yim, $\&$ Tse, 2005), cultures, norms, and values (e.g. Chua, Roth, \& Lemoine, 2015; Kitchell, 1995; Sarros, Cooper, \& Santora, 2008), innovation processes and management tools (e.g. Cooper \& Edgett, 2012; Ettlie \& Elsenbach, 2007; Sethi \& Iqbal, 2008), the firm's resource endowment (e.g. O’Brien, 2003; Parthasarthy \& Hammond, 2002; Voss, Sirdeshmukh, \& Voss, 2008), human and social capital (e.g. Grigoriou \& Rothaermel, 2014; Maurer, Bartsch, \& Ebers, 2011; Subramaniam \& Youndt, 2005), or top management and leadership (e.g. Elenkov, Judge, \& Wright, 2005; Makri \& Scandura, 2010; Yadav, Prabhu, \& Chandy, 2007).

Just by looking at this short sample of examined influence factors, it is evident that "organizing for innovation" is a multi-faceted and complex problem. In order to enable innovation within the firm, managers and strategic decision-makers must thus build adequate systems of plans, activities, resources, tools, and techniques (Dougherty, 1999; Hauser et al., 2006; Van de Ven, Polley, Garud, \& Venkatraman, 2007). As demonstrated above, innovation literature is quite extensive and provides many important insights and explanations on different aspects of this task. However, despite the clear need for subsumption that stems from the multiplicity of variables and theoretical perspectives in innovation research, surprisingly few attempts exist that review innovation management research, aggregate previous findings, and develop overarching frameworks on what distinguishes innovative from less innovative firms (Crossan \& Apaydin, 2010; Lam, 2005; O'Connor, 2012). Notably, the first models and frameworks to this end have not been developed based on theory-driven academic works but rather by an analysis of "best practice" anecdotes and experiences. Advancing chronologically, I will therefore first discuss the models that stem from such more practice-oriented approaches before reflecting the models that were derived from systematic reviews of empirical research literature.

\subsection{Determinants of Organizational Innovation According to Observations of "Best Practice"}

The first holistic frameworks on the determinants of organizational innovation were not developed based on extensive reviews of research findings, but on managerial experience, practical anecdotes, and observed or surveyed "best practices" (e.g. Barczak et al., 2009; Cooper \& Kleinschmidt, 1995b; Wheelwright \& Clark, 1992). Among the most prominent of those frameworks is the "Innovation Diamond" (Cooper, 2005). The "Innovation Diamond" is a derivative of the "New Product Performance Triangle" developed by Cooper and Kleinschmidt (1995a) and aims to outline the factors that are fundamental for successful new product development (NPD) in the firm. In their first model, Cooper and Kleinschmidt (1995a) postulate three organizational factors influencing firms' product innovation output: (1) a company-wide strategy for innovation with adequate control systems; (2) a purposeful resource planning that allocates money, people, materials, and tools across a portfolio of innovation projects; (3) a formalized and sequential innovation process to ensure that critical tasks in innovation projects are completed and resources are employed efficiently. Based on further 
studies on best practices of NPD (Cooper, Edgett, \& Kleinschmidt, 2004a; Cooper, Edgett, \& Kleinschmidt, 2004b; Cooper, Edgett, \& Kleinschmidt, 2004c) as well as on lessons learned from the implementation of the "New Product Performance Triangle" at the consumer goods enterprise Procter \& Gamble (P\&G) (Cooper \& Mills, 2005), Cooper (2005) added a fourth dimension to the model to create the "Innovation Diamond": (4) an innovation-friendly company culture and climate, effective cross-functional teams, and senior management leadership (see Figure 3). Most recently, Cooper (2017) published an update of the "Innovation Diamond" model in which some of the elements are framed towards recent developments and trends in innovation management (for instance, element (3) "innovation process" was extended in order to incorporate more agile process models such as design thinking). Overall, the core elements of the innovation diamond model remained the same. In all, the four dimensions proposed by Cooper $(2005,2017)$ cover a quite exhaustive range of organizational elements that affect firm-level innovation performance, including both "hard" and "soft" factors as well as both "strategic" and "operational" aspects of the task of "organizing for innovation".

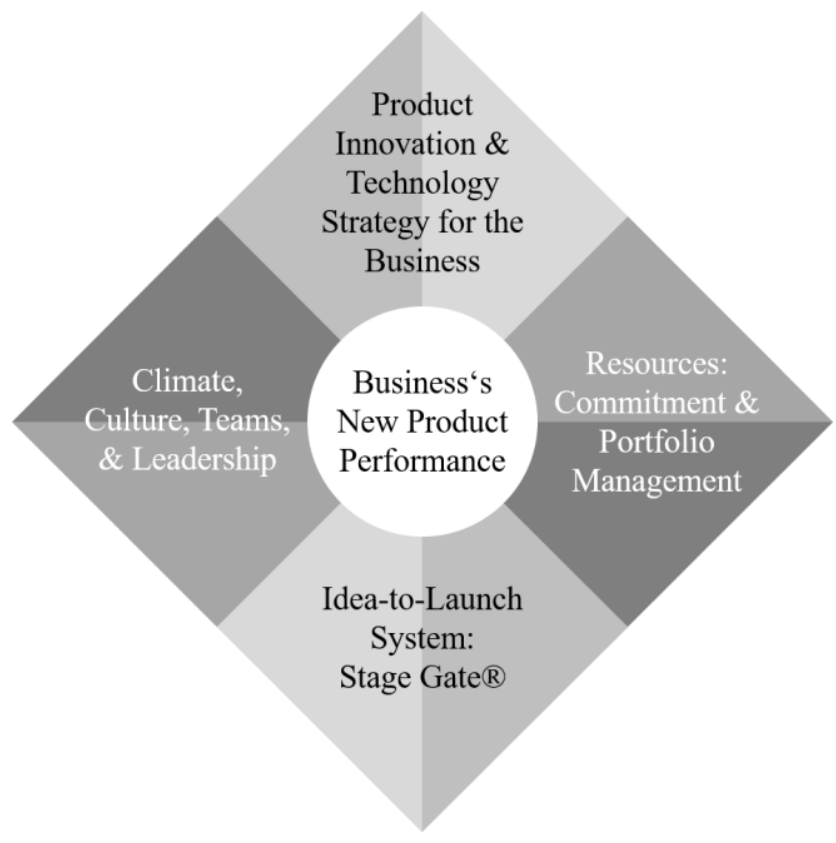

Figure I-3. Innovation Diamond (Cooper \& Mills, 2005; minor design modifications to match the formatting style of the thesis)

In an approach similar to the one of Cooper $(2005,2017)$, the Product Development \& Management Association (PDMA) developed a framework of determinants of organizational innovation (Kay et al., 2013). This framework explicitly aims to update previous models that largely employed insight from the 1980s and 1990s (such as the first version of the "Innovation Diamond" (Cooper, 2005)) and to reflect the arising challenges for innovation management in the 21 st century. The involved scholars and practitioners argue for the need of such an update as "it is clear that innovation best practices are not stagnant and that to be successful, companies must adapt their practices to changing global trends and market conditions" (Kay et al., 2013, p. 388). 
For the development of the framework, the researchers identified and evaluated best practices of the winners of PDMA's annual "Outstanding Corporate Innovators" (OCI) award in the 1988-2003 period and the 2004-2010 period. Based on the best practices identified and a comparison of the earlier and the time period, the "OCI Framework" was developed (see Figure 4). This framework comprises five factors: (1) corporate strategic commitment to innovation; (2) innovation strategy as core element of corporate strategy; (3) open innovation and collaborative development; (4) intense focus on the front end; (5) comprehensive innovation management toolkits. While there is some conceptual overlap between the 1988-2003 version of the framework and the current version, some important elements emerged that did not seem to be of relevance earlier. The authors reason that "innovation has also increased in complexity, as evidenced by the proliferation of toolkits, the need for extensive knowledge at the front end, and the increasing role of external collaboration throughout the innovation process" (Kay et al., 2013, p. 388).
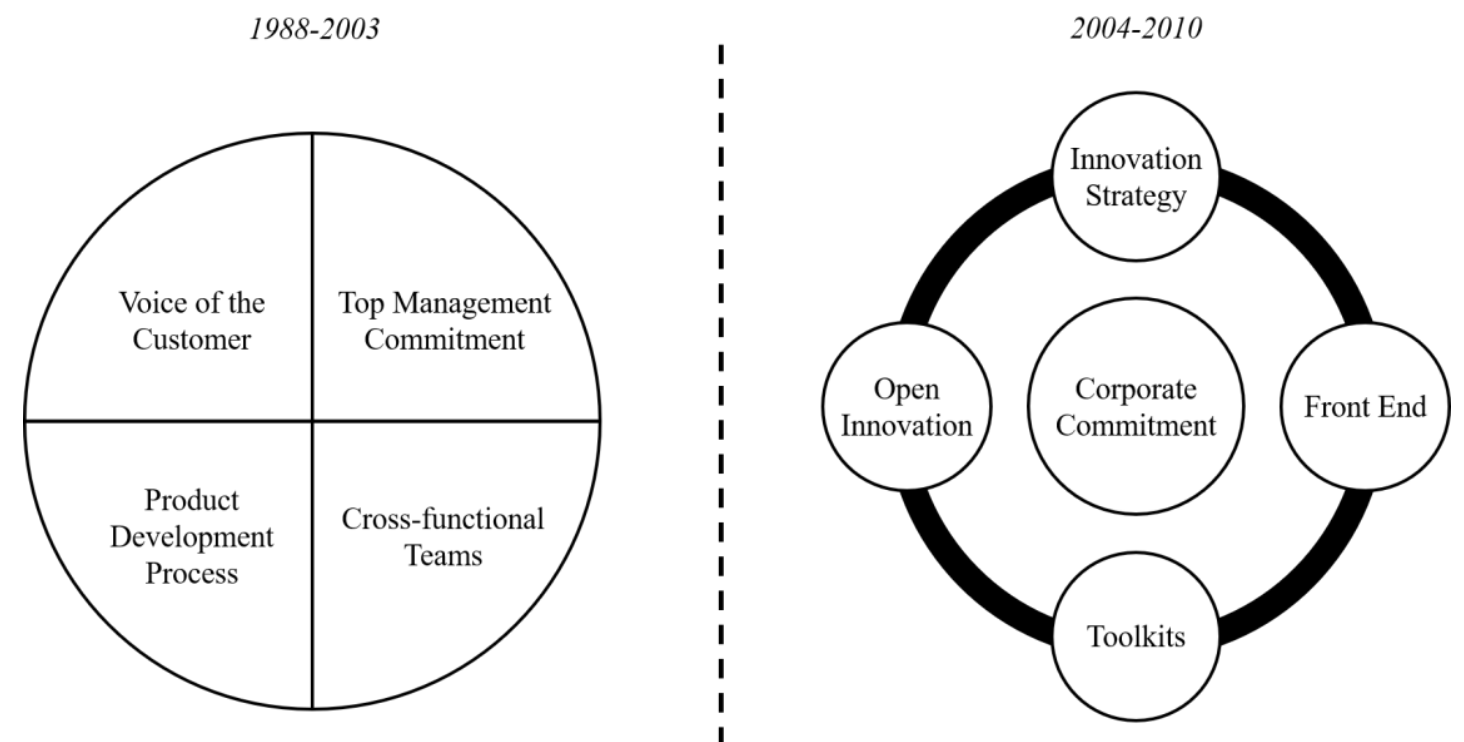

Figure I-4. OCI framework (own illustration, based on Kay et al., 2013)

\subsection{Determinants of Organizational Innovation According to Reviews of Research Literature}

While the practice-oriented discussion thus had produced comprehensive models of firm-level innovation performance since the early 1990s, research just recently has begun to develop overarching frameworks with the goal of capturing the organizational determinants of innovation holistically. From its beginning on, innovation management research was fragmented as most studies focused only on one aspect of the problem of "organizing for innovation" (Damanpour \& Aravind, 2006; Fiol, 1996; Hauser et al., 2006; Lam, 2005; O’Connor, 2012; Wolfe, 1994). There was little discourse between the different streams of innovation research and works that examined innovation performance as dependent variable rather positioned themselves with regard to the independent variables employed, e.g. in literature streams such as network or leadership research (Anderson, Potočnik, \& Zhou, 2014; Crossan \& Apaydin, 2010). 
To this day, the arguably most comprehensive and most scientifically grounded framework of organizational innovation is the one by Crossan and Apaydin (2010). Based on a systematic review of literature published between 1981 and 2009 (in total 524 papers), the authors develop a multi-dimensional framework depicting the major influence factors on innovation in the firm (see Figure 5). The framework consolidates "the determinants of innovation into three theoretically distinct meta-constructs (leadership, managerial levers, and business processes)" (Crossan \& Apaydin, 2010, p. 1165). Each of the three meta-constructs is thereby linked to an overarching theory that can serve as an explanatory lens on the effects of variables related to the meta-construct on innovation performance.

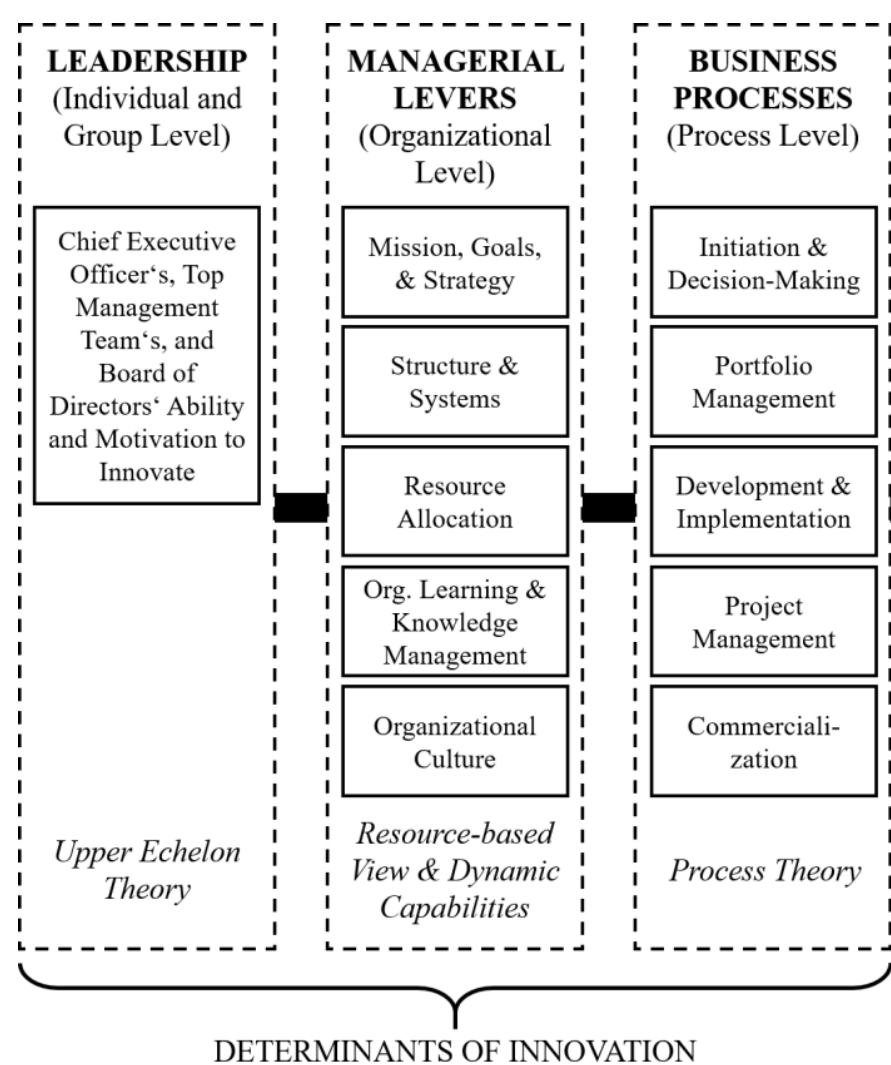

DETERMINANTS OF INNOVATION

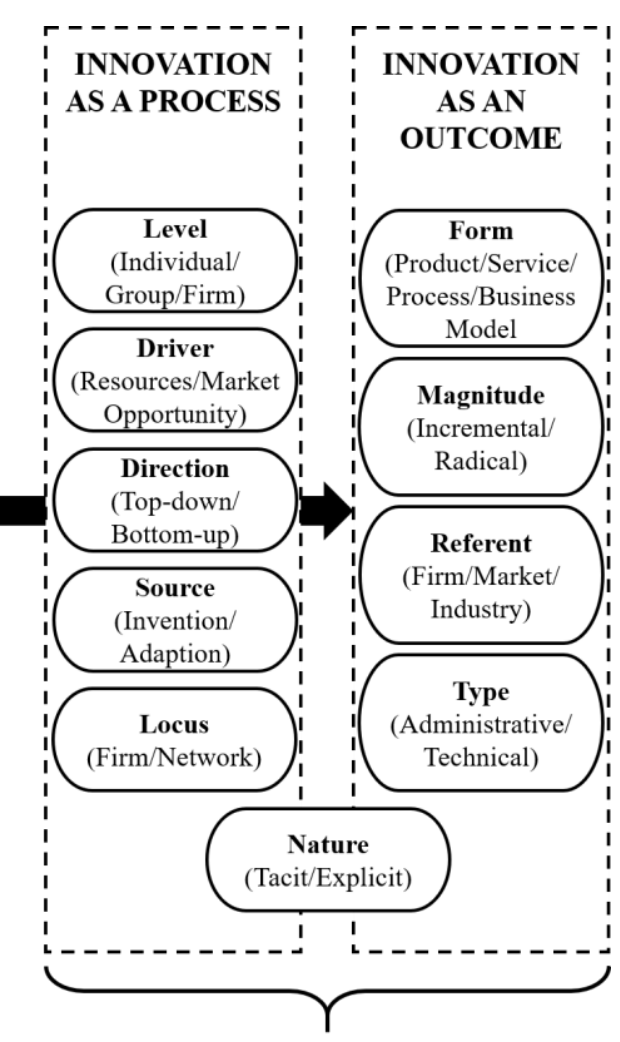

DIMENSIONS OF INNOVATION

Figure I-5. Multi-dimensional framework of organizational innovation (Crossan \& Apaydin, 2010; minor design modifications to match the formatting style of the thesis)

First, the influence of leadership can be explained by upper echelon theory (Hambrick \& Mason, 1984; Hambrick, 2007). As members of the top management team (TMT) hold positions of unique strategic influence and hierarchical power, their motivation and ability to support and guide innovative efforts across the organization is vital for firms' innovation performance (Deschamps, 2008; Makri \& Scandura, 2010; Mumford \& Licuanan, 2004). Second, the managerial levers construct reflects the resource-based view (Barney, 2001; Kraaijenbrink, Spender, \& Groen 2010) and the dynamic capabilities view (Eisenhardt \& Martin, 2000; Teece, 2007). According to those two related theories, differences in firms' resources, procedures, policies, and routines will account for variation in innovation outcomes. The five managerial levers identified by Crossan and Apaydin (2010) in previous research 
(mission, goals, and strategy; structure and systems; resource allocation; organizational learning and knowledge management tools; and organizational culture) represent such organizational resources and capabilities and enable the firm to coordinate individual- or grouplevel innovative efforts and align them toward overall strategic targets. Third, process theory explains the impact of business processes on organizational innovation (Van de Ven \& Poole, 1995). Process theory argues that firm-level outcomes are generated by a sequential pattern of events and actions, such as workflows, information exchange, and decision-making (Tsoukas, 1989). Following process theory, firms thus must ensure that they accomplish critical activities such as innovation initiation, portfolio management, development \& implementation, project management, and commercialization in order to innovate successfully (Van de Ven et al., 2007). Finally, Crossan and Apaydin (2010) acknowledge that the task of "organizing for innovation" might also require firms to aim to influence innovation determinants on higher levels of analysis such as institutions, regional systems, and especially inter-organizational networks. However, as the authors chose to focus on the firm level and the micro level, those determinants are not included in their framework.

Besides Crossan and Apaydin (2010), no further works have been published in top-tier management journals that aimed to develop comprehensive theoretical models that cover the determinants of organizational innovation. Still, the work of Slater et al. (2014) comes close to this endeavor as the authors review innovation management literature to develop a model of firm's capability for radical product innovations (RPI). Radical innovations represent a conceptual subset of the broader innovation term and are defined as new products, services, processes, and business models that offer unprecedented performance benefits, substantial cost reductions, or the ability to create new businesses (Leifer, O'Connor, \& Rice, 2001; Simon, McKeough, Ayers, Rinehart, \& Alexia, 2003). In their "Components of RPI capability" model, Slater et al. (2014) argue that "RPI capability is a complex configuration of components that requires juggling an array of seemingly paradoxical skills" (p. 563). Based on a literature review, they identify five major groups of organizational factors that are conducive to innovation performance: (1) senior leadership; (2) organizational culture; (3) organizational characteristics; (4) product development process; and (5) product launch strategy (see Figure $6)$. The authors suggest that "the various components in the model affect each other, implying a complex interplay between and among them" (Slater et al., 2014, p. 564). Thus, in line with the other models presented in this chapter, the "Components of RPI capability" framework also promotes the notion of innovation as a multi-faceted organizational problem that requires firms to configure various organizational elements in order to be successful. 
I. Synopsis (Prologue)

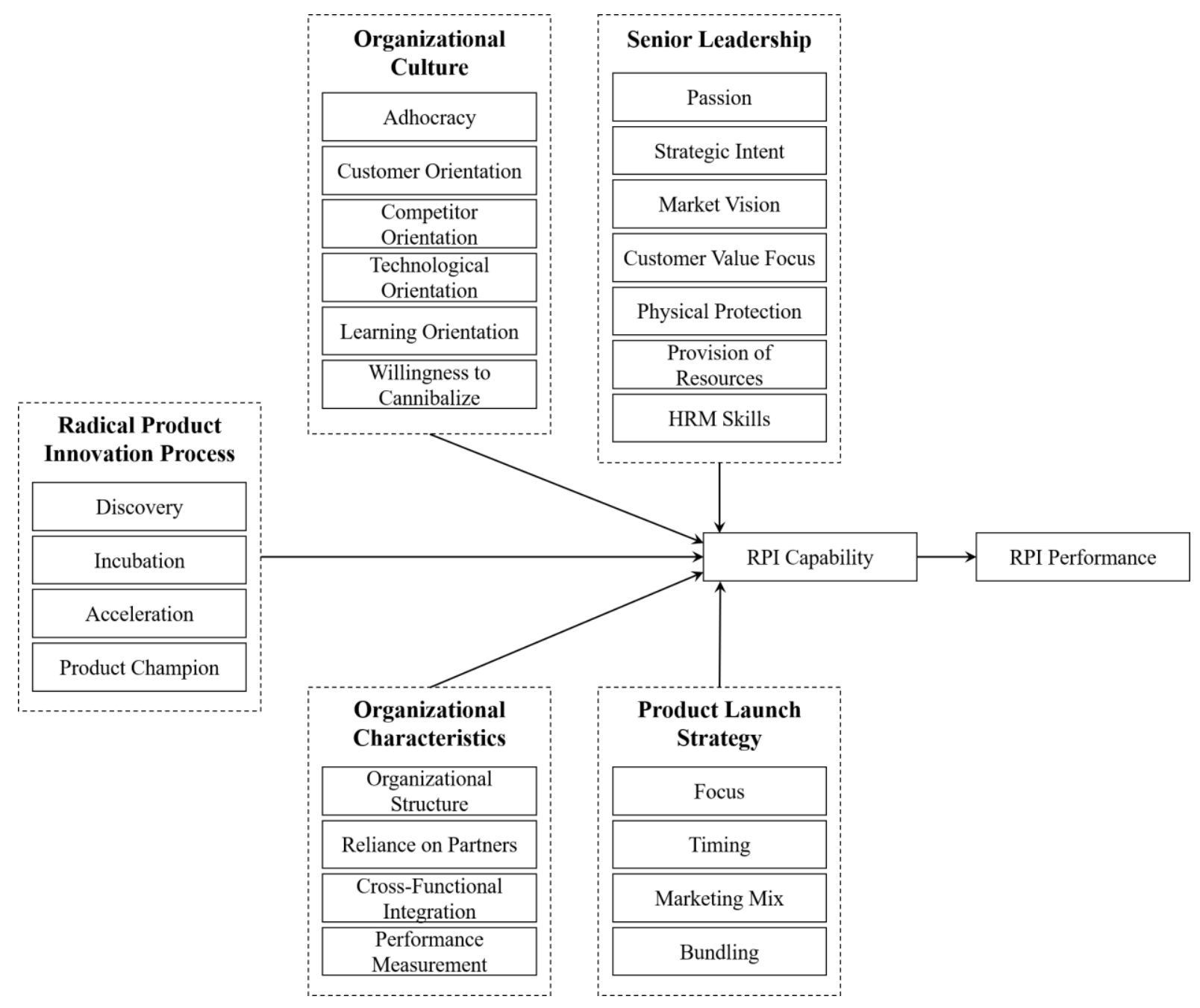

Figure I-6. Components of RPI capability (Slater et al., 2014; minor design modifications to match the formatting style of the thesis)

\subsection{Summary of Current Insight on the Determinants of Organizational Innovation}

To sum up this short overview of determinants of organizational innovation, it can be stated that there is much conceptual overlap between the presented models, irrespective if they were developed based on practice experiences or reviews of empirical research studies. All four models include both operational and strategic, both "hard" and "soft" factors. Though there are differences in the depth and detail to which concepts are elaborated on, all models name leadership, strategy, process, culture, and resources as main determinants of innovation in the firm.

A further insight that can be derived from the models is that there seems to be a temporal component. Hence, over time the factors that distinguish highly innovative from less innovative firms seem to differ. Such differences are especially noticeable in the OCI framework and Cooper's (2017) updated version of the "Innovation Diamond", but also in the literature reviews. The authors of the OCI framework explain this phenomenon as with time current best practices become state-of-the-art so that they do no longer serve as differentiating factors (Kay et al., 2013). Additionally, technological developments and other macro-trends lead to the 
emergence of new challenges and practices such as open innovation, crowd-based innovation, or data-driven innovation (Majchrzak \& Malhotra, 2013; Rindfleisch, O'Hern, \& Sachdev, 2017; West \& Bogers, 2014). As digital technologies are among the major drivers behind such developments (Nambisan et al., 2017; Rijsdijk \& Hultink, 2012; Yoo et al., 2012), I will discuss the features of innovation in the digital age (compared to the analog age) in the next chapter and provide implications for research on the determinants of organizational innovation.

\section{Determinants of Organizational Innovation in the Digital Age}

The ever-increasing perpetration of digital technologies into physical objects and artefacts is widely seen as one of the most strategically relevant trends in today's business world (Downes $\&$ Nunes, 2014). In order to prevent being cannibalized by this trend and to remain competitive, firms must engage in business digitalization, i.e., employ current and emergent information technologies, such as data analytics and artificial intelligence with the aim of enabling major business improvements like better fulfillment of customer needs or more efficient operations (Fitzgerald, Kruschwitz, Bonnet, \& Welch, 2014). First and foremost, business digitalization is an innovative task as it requires firms to radically adapt or change the nature and structure of their products, services, processes of value creation and appropriation, and organizing principles (e.g. Iansiti \& Lakhani, 2014; Nambisan et al., 2017; Nylén \& Holmström, 2015; Porter \& Heppelmann, 2014).

The strategic importance of business digitalization and related topics is widely evident in management practice. The BCG argued in the 2018 version of their annual global innovation survey that for "leading innovators, R\&D and new-product development have become digital endeavors" (Ringel \& Zablit, 2018, URL). In the most recent 2019 version of the same study (see Figure 7), issues related to business digitalization were among the most relevant areas of innovation named by the surveyed senior managers in terms of the expected mid-term impact on the industry and their prominence in the firm's innovation strategy (Ringel, Grassl, Baeza, Kennedy, \& Manly, 2019). However, despite the strategic importance of business digitalization, most firms still fail to achieve the desired results. For instance, a recent poll of Chief Information Officers (CIOs) and Chief Digital Officers (CDOs) conducted by Strategy\& found that only $10 \%$ of companies were able to generate at least $5 \%$ of their revenues from digital initiatives (Niebuhr et al., 2019). 


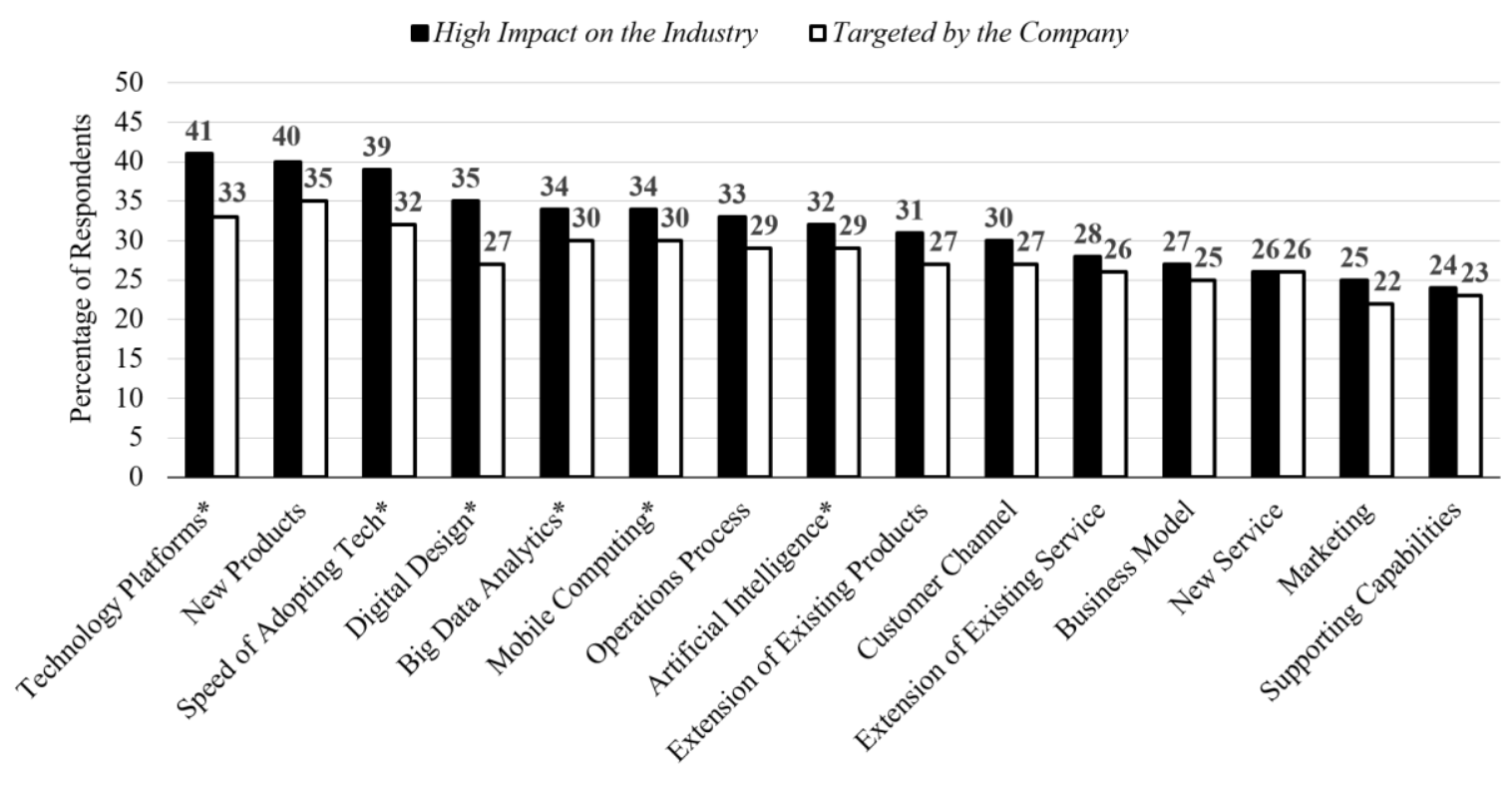

Notes: * denotes areas of innovation/product development that are directly linked to business digitalization

Figure I-7. Strategic relevance of different areas of innovation (Ringel et al., 2019; minor design modifications to match the formatting style of the thesis)

\subsection{Specific Features of Digital Innovations and Consequences for Innovation Management}

Corresponding to the evident struggles of companies to develop and implement digital innovations and achieve the desired levels of business digitalization, innovation management scholars are confronted with new challenges and problems "because of the shift in the locus of innovation and because some of our core organizing axioms may be challenged or fundamentally changed by the digital revolution" (Benner \& Tushman, 2015, p. 2). Digital technologies possess several characteristics that make them fundamentally different from their analog, non-digital counterparts (Yoo, Henfridsson, \& Lyytinen, 2010b). For instance, digital technologies are programmable, i.e., they are able to incorporate new sets of instructions and adapt their behaviors accordingly to those instructions, and senseable, i.e., they are contextaware and able to respond to changes in their environment of operation (Yoo et al., 2010a).

Features such as programmability and senseability allow digital technologies to act "smart", i.e., to complete complex tasks autonomously, test and refine different courses of action, and connect and coordinate themselves with a range of other technological or human actors (e.g. Barrett, Oborn, Orlikowski, \& Yates, 2012; Dougherty \& Dunne, 2012; Rijsdijk \& Hultink, 2009). However, besides the "smart" functionality of digital artifacts, the features of digital technologies also entail fundamental differences in the nature, development, and diffusion of innovation in a largely digitized compared to a largely analog world (e.g. Henfridsson, Mathiassen, \& Svahn, 2014; Porter \& Heppelmann, 2014; Yoo et al., 2010a; Yoo et al., 2012).

To instruct firms on how to cope with the challenge of "organizing for innovation in the digitized world" (Yoo et al., 2012, p. 1398) as well as to provide explanations for the mechanisms at play, leading scholars advocate that the theories and findings of previous 
innovation management research must be reevaluated in the light of the features of digital innovation (Barrett, Davidson, Prabhu, \& Vargo, 2015; Nambisan et al., 2017; Rindfleisch et al., 2017). This applies in particular for research on the determinants of organizational innovation. In order to determine which of the factors identified in past innovation management research might be of particular importance or which new factors might arise, I will first take a quite narrow focus and describe the challenge of business digitalization from the perspective of established firms. Subsequently, I will take a broader look and discuss the general features of digital innovation and how those features might affect the way firms should "organize for innovation".

\subsection{Digital Transformation and the Importance of Top Management and Leadership}

From the perspective of established firms, business digitalization entails the need to create value by employing digital technologies to incorporate new functionalities into physical products and processes (e.g. Rijsdijk \& Hultink, 2009; Yoo et al., 2010b), a shift in revenue generation from transactional buyer-seller interactions to service-oriented long-term relations (e.g. Barrett et al., 2015; Lusch \& Nambisan, 2015), and an increased competitive relevance of data and data analytics (e.g. George, Haas, \& Pentland, 2014; Iansiti \& Lakhani, 2014). This provides firms with a range of interesting business opportunities but also requires them to engage in holistic change and organizational transformation. This transformation goes beyond the traditional scope of innovation management that most often merely deals with the coordination of single product, process, or service development initiatives to better serve a comparably stable market environment (e.g. Nylén \& Holmströn, 2015; Svahn, Mathiassen, \& Lindgren, 2017; Yoo et al., 2012). In contrast, business digitalization challenges essential values, worldviews, and business logics, especially in firms in traditionally non-digital industries (e.g. Fitzgerald et al., 2014; Svahn et al., 2017).

In the course of business digitalization, firms are thus confronted with an extensive transformation journey as it is for instance depicted in the framework by Becker (2018) (see Figure 8). This journey starts with the firm's decision to engage in business digitalization, which leads to a transformation of the business model and the core mechanisms of how the firm creates value. Rather than using digital technologies to merely leverage existing business logics, business digitalization might thereby radically alter the configuration of organizational skills, resources, structures, and procedures (e.g. Hess, Matt, Benlian, \& Wiesböck, 2016; McDonald \& Rowsell-Jones, 2012; Yoo et al., 2010b). This transformation does not only affect the traditionally technology-oriented organizational functions such as IT, R\&D, and manufacturing, but also other functional areas like sales, finance, strategy, and HR (Matt, Hess, $\&$ Benlian, 2015). Digital transformation initiatives thus tend to span the whole organization so that their launch and implementation requires considerable cross-functional coordination (e.g. Hess et al., 2016; Haffke, Kalgovas, \& Benlian, 2017). 


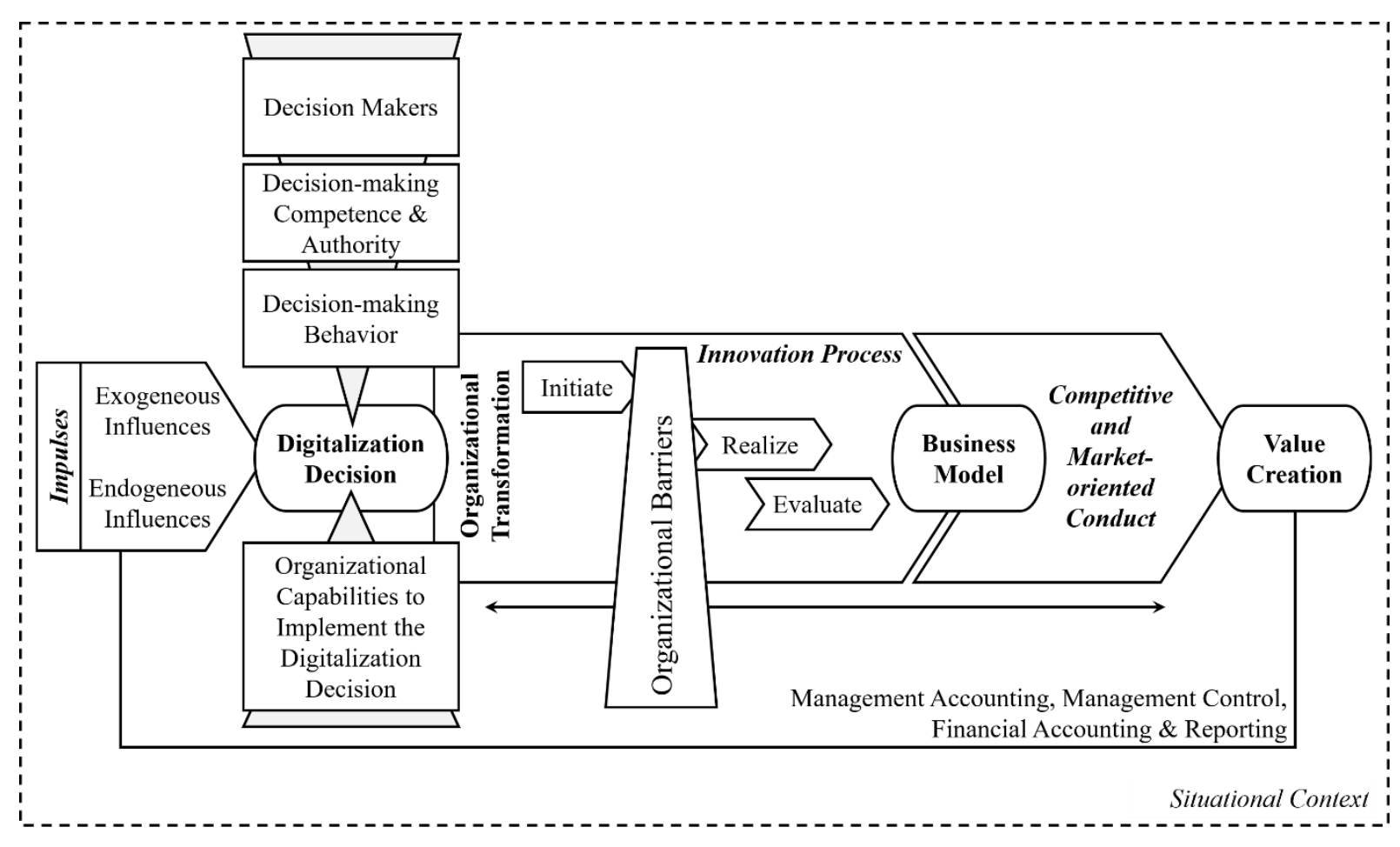

Figure I-8. Conceptual framework for the management of business digitalization (Becker, 2018; minor design modifications to match the formatting style of the thesis)

Drawing on this insight about the transformation process induced by business digitalization, it is likely that factors linked to strategy and leadership will be of particular importance for effective innovation management in the digital age. Strategic management research on the basis of the related theory streams of evolutionary economics, resource-based view, and dynamic capabilities view has argued that the more a change effort affects a firm's resource and activity system as a whole, the more coordination in the form of c-level leadership is required (e.g. Milgrom \& Roberts, 1995; Teece, 2007). In contrast to bureaucracy in which coordination is provided by central formalized rules of conduct, c-level leadership describes the active engagement of senior managers to advice lower organizational levels, to provide overarching narratives and visions, and to align different innovation or change initiatives in different organizational departments toward a common goal (Stieglitz \& Heine, 2007).

If the firm's top management fails to provide such strategic direction, business digitalization might still emerge locally in various departments of the firm (Haffke et al., 2017; Levinthal \& Warglien, 1999; Winter, 2000). However, due to the lack of coordination the firm likely would struggle to integrate the different initiatives across the firm, realize complementarities between digital innovation efforts, and reestablish a coherent and consistent system of organizational skills, resources, structures, and procedures that allows for effective value creation (Milgrom \& Roberts, 1995; Rivkin, 2000; Stieglitz \& Heine, 2007). In line with these theoretical considerations, a substantial part of business digitalization research highlighted the crucial role of top management (e.g. Fitzgerald et al., 2014; Hess et al., 2016; Matt et al., 2015). 
The argument that top management and leadership are essential factors that most likely will differentiate between the successful and non-successful innovators in the digital age is furthermore supported by the emerging practical phenomenon that many firms have created a new executive position - the CDO (e.g. Singh \& Hess, 2017; Tumbas, Berente, \& vom Brocke, 2018). In 2018, of the 2,500 largest publicly listed companies worldwide about $21 \%$ had already appointed a CDO, even 39\% of the largest European firms had created a CDO position (Péladeau, Acker, \& Müller, 2019). CDOs are intended to be the main leader of business digitalization in their respective company and to ensure the coordination, prioritization, and implementation of digitization initiatives all across the firm (Matt et al., 2015; Haffke et al., 2017). They are expected to act as change agents in order to establish digital technology on the strategic agenda of their firms (Singh \& Hess, 2017). By creating the CDO position, firms seem to acknowledge the need for c-level leadership when it comes to business digitalization (Fitzgerald et al., 2014). It is thus reasonable to assume that in the light of the holistic transformational task of business digitalization, top management and leadership will be essential influence factors on a firm's innovation performance and a central element in a firm's ability to "organize for innovation" in the digital age.

\subsection{Distributed Innovation, Combinatorial Innovation, and the Importance of Inter- organizational Networks and External Partners}

Besides confronting firms with new opportunities and threats, digital technologies also entail profound changes in the rules and mechanisms of how innovations emerge and diffuse (Nambisan et al., 2017; Zammuto, Griffith, Majchrzak, Dougherty, \& Faraj, 2007). In an interdisciplinary research workshop titled "Digital Challenges in Innovation Research" in October 2008, 42 leading international scholars from information systems, computer science, organization science, and economics met in order to provide a first theoretical framework on the new principles of digital innovation (Yoo et al., 2010a). Thereby, the underlying theme was how the "properties of digital materiality and the emergence of loosely-coupled digital service architectures have stimulated waves of digitalization that are fundamentally re-shaping innovations in products, services and organizational forms" (Yoo et al., 2010a, p. 13).

During the workshop, a framework comprising six dimensions of digital innovation was developed. Two of those six dimensions ("Convergence" and "Digital Materiality") describe digital innovation from an object perspective (Garcia \& Calantone, 2002), i.e., they explain the specific characteristics of digitized products, services, processes, or business models in comparison to their analog counterparts (Kolloch \& Reck, 2018; Yoo et al., 2010a). The other four characteristics ("Heterogeneity", "Generativity", "Locus of Innovation", "Pace”) reflect the process perspective of innovation (Garcia \& Calantone, 2002) and explain differences in the generation and diffusion procedure of innovation in the digital vs. the analog age (Kolloch \& Reck, 2018; Yoo et al., 2010a). Figure 9 presents the six dimensions of digital innovation and provides a short explanation on each of the dimensions. 
Outcome-related Characteristics of Digital Innovations

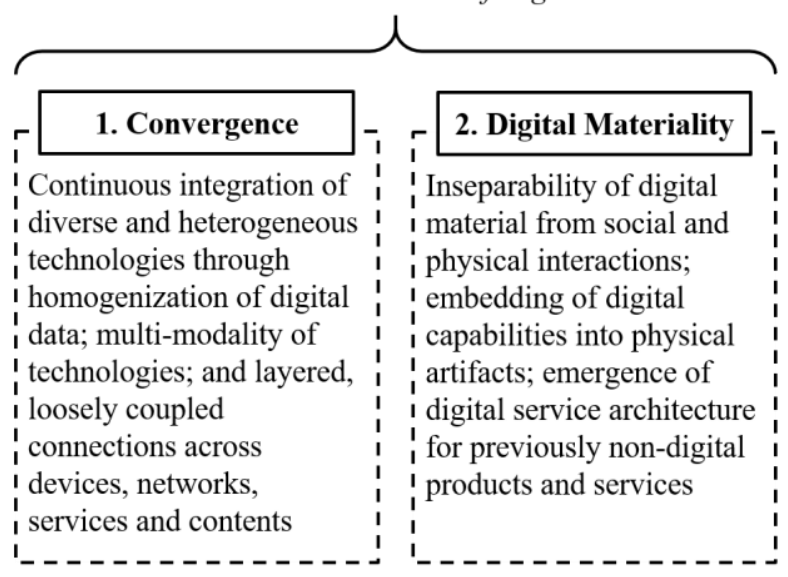

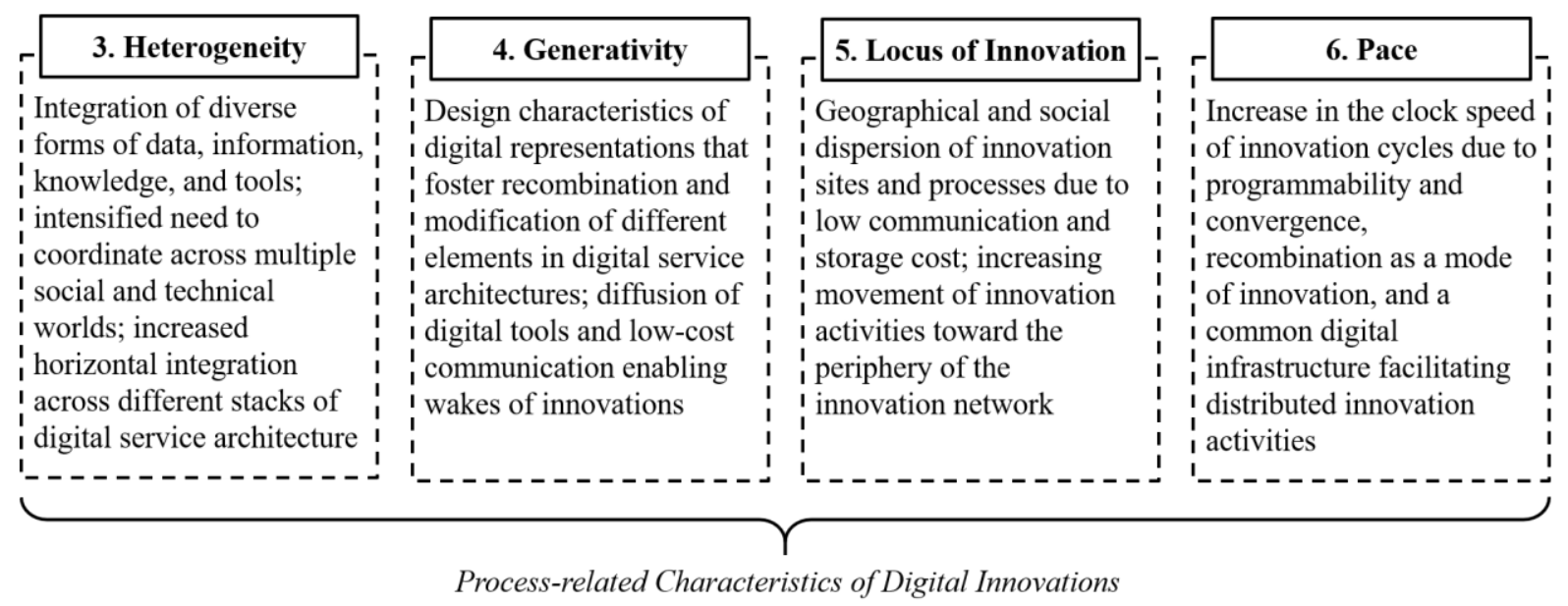

Figure I-9. Six dimensions of digital innovation (own illustration, based on Kolloch \& Reck, 2018; Yoo et al., 2010a)

Based on those considerations, Yoo et al. (2012) further subsumed the specific characteristics of digital innovation and inferred two major implications for how to "organize for innovation in the digitized world". First, Yoo et al. (2012) name the "emergence of distributed innovations" (p. 1400) as a major influence on innovation management. Innovation activities become more dispersed as information technology decreases the costs of communication and coordination. Consequently, innovation processes become more and more "democratized" and control over innovation activities is shared across multiple organizations (e.g. Chesbrough, Vanhaverbeeke, \& West, 2006; Dhanaraj \& Parkhe, 2006; West \& Bogers, 2014).

Further, Yoo et al. (2012) outline the "prevalence of combinatorial innovation" (p. 1400) as the second important implication for the management of digital innovation. Given that adequate standard interfaces exist, software-based digital modules can be combined with each other, but also with physical objects, in a nearly infinite number of different ways (Lessig, 2008). Describing this phenomenon, Arthur (2009) speaks of "limitless recombination" as a new source of innovation. For firms, this increase in combinatorial innovation enables new forms of creativity and new potentials of customization (e.g. Austin, Devin, \& Sullivan, 2012; Boland, Lyytinen, \& Yoo 2007; Faraj, Jarvenpaa, \& Majchrzak, 2011). Still, to realize those 
opportunities, firms need to be able to exploit the "serendipitous behavior" of innovators inside and outside the firm by building vibrant environments that enable those "third-party innovators" to take part in the process of combinatorial innovation (Yoo et al., 2012).

Summing up these notions, it can be concluded that in an increasingly digitized world innovation is less and less happening in linear processes within the firm's boundaries, but more and more in cooperative activities between a variety of different organizations and innovation actors (Boland et al., 2007; Brynjolfsson, Hu, \& Smith, 2010; Lyytinen, Yoo, \& Boland, 2016; Nambisan et al., 2017; Tilson, Lyytinen, \& Sørenson, 2010; Tiwana, Konsynski, \& Bush, 2010; Yoo et al., 2010b). Scholars in the field of digital innovation thus argue that "no innovation is born out of a single idea of a single innovator, which gradually diffuses to a market after its invention" (Lyytinen et al., 2016, p. 50). In contrast, innovation in the digital age should be perceived as "emerging from the ebb and flow of fragile, heterogeneous and dynamic knowledge [...] assembled through the interaction of diverse actors into new knowledge combinations of resources" (ibid., p. 50). Because of this notion of digital innovation "as a collective action" (Nambisan et al., 2017, p. 230), scholars reason, "control is changing in organizations and it's fundamentally changing increasingly into network-based organizations" (Yoo et al., 2010a, p. 13). Innovation initiatives thus no longer remain under the control of individual firms, but are accomplished in open, boundary-spanning, and decentral forms of organization such as innovation networks, ecosystems, or technology platforms (Adner \& Kapoor, 2010; Lee \& Berente, 2012; Lyytinen et al., 2016; Tiwana et al., 2010).

As network-based forms of organizations are the locus of most digital innovations, a firm's innovation performance will strongly depend on the ability to establish cooperative relationships with a range of diverse external partners and to orchestrate value co-creation and value appropriation in inter-organizational networks (Lyytinen et al., 2016; Nambisan et al., 2017; Svahn et al., 2017). Digital leaders like Facebook, Amazon, Apple, or Google who also are constantly perceived as among the most innovative firms in the world (Ringel et al., 2019), for instance, managed to create vibrant networks of complementors that provide add-ons or modifications to their core products and services from their very outset (Yoo et al., 2010a). Moreover, those firms set in place elaborate mechanisms for enabling their partner firms to autonomously contribute their expertise to the "wake of innovation" generated by the network but also for guaranteeing an adequate degree of alignment between their partners' efforts (Boland et al., 2007; Gawer \& Cusumano, 2014; Weill \& Woerner, 2015). Participation in innovation networks as well as the capabilities related to developing and orchestrating those networks are thus likely to differentiate between successful innovators and less innovative firms in the digital age and play a crucial role in determining organizational innovation.

\section{Selection of Focus Areas for Empirical Investigation}

In this section, I will outline the selection of focus areas for my empirical research and substantiate the reasons why those focus areas were chosen. In the previous sections, I first summarized research literature on the determinants of organizational innovation. In addition, I gave a brief overview of theoretical frameworks and models that capture the most relevant factors that explain differences in firms' effectiveness to generate and commercialize 
innovation outputs. Afterwards, I reviewed literature on digital innovation, highlighted the challenges for innovation management that stem from the specific features of digital innovations, and discussed how this might influence the way in which firms "organize for innovation" in a more and more digitized world. In order to determine the focus areas of my research, I synthesized the insights from both the literature on the determinants of organizational innovation and the literature on digital innovation (see Figure 10). As a result, I argue that two factors discussed in innovation management research will be of particular importance for "organizing for innovation" in the digital age: (1) top management and leadership; and (2) networks and external partners. Hence, those two factors will constitute the focus areas of this doctoral dissertation.

First, the influence of top management and leadership on organizational innovation has received much interest in previous research, but still holds several unsolved conundrums for innovation management scholars (e.g. Deschamps, 2008; Felekoglu \& Moultrie, 2014; Makri \& Scandura, 2010; Yadav et al., 2007). Research largely agrees on the importance of top managers for firms' innovation performance. Accordingly, the frameworks presented above all include the domain of top management and outline the importance of top-level leadership for making innovation a strategic priority, for aligning innovation initiatives, and for providing direction and sense of purpose to employees across the firm (Cooper \& Mills, 2005; Crossan \& Apaydin, 2010; Kay et al., 2013; Slater et al., 2014). Due to the holistic and transformational nature of the business digitalization task, the importance of top management as an enabler of innovation will most likely increase even more (e.g. Fitzgerald et al., 2014; Hess et al., 2016; Matt et al., 2015). Still, in order to provide comprehensive insight on the role of top management and leadership for "organizing for innovation" in the digital age, further research is needed. Thereby, major gaps in current literature are on the one hand the fragmentation and theoretical endogeneity present in top management research (e.g. Bromiley \& Rau, 2016; Busenbark, Krause, Boivie, \& Graffin, 2016), as well as the apparent lack of studies that explicitly address the role of top managers and new managerial positions (such as the CDO) in business digitalization (e.g. Haffke et al., 2017; Singh \& Hess, 2017; Tumbas et al., 2018). 


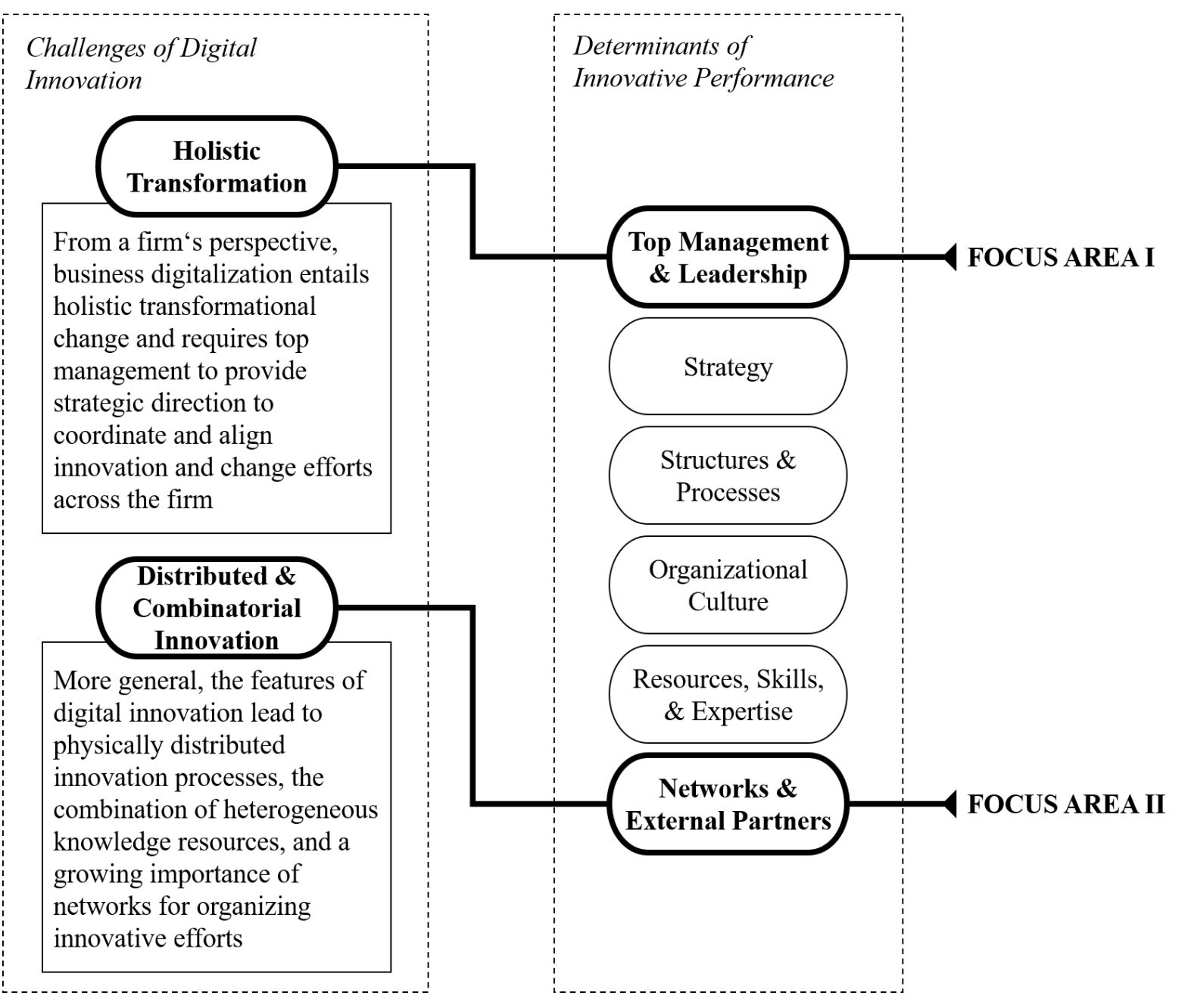

Figure I-10. Selection of focus areas for my doctoral research (own illustration)

Second, external partners and the network-based forms of organization in which those partners coordinate their activities will likely be an essential factor, distinguishing winners from losers in the digital innovation game. In the frameworks of innovation determinants presented above, the factor "networks and external partners" does not seem to play a major role at first glance but is actually mentioned explicitly in all four models. Kay et al. (2013) outline "Open Innovation" as a major driver of innovation performance and name external partnerships and inter-organizational networks as main conduits for incorporating external ideas into own innovative outputs. Similarly, Slater et al. (2014) discuss firms' reliance on partners as an important determinant of radical innovation performance. Finally, as both Crossan and Apaydin (2010) and Cooper (2017) focus on organizational and micro-level factors, they do not include networks and external partnerships in their frameworks. However, in an extended model in the Appendix of their paper, Crossan and Apaydin (2010) highlight the importance of networks and explicitly refer to networks as a major influence factor and network theory as one of the most used theoretical lenses for explaining firms' innovation performance. In a similar vein, Cooper (2017) explicitly outlines collaborative development and open innovation as "critical drivers of success" (p. 388) and "proven ways to create big, bold innovation ideas" (p. 390). 
As digital innovation scholars stress the importance of networks as main form of organization and locus of innovation in the digital age, networks and external partners are widely seen as one of the most promising areas for future innovation research (e.g. Lyytinen et al., 2016; Nambisan et al., 2017; Yoo et al., 2012). Still, most previous research examining the link between inter-organizational relations and innovation performance regards networks and external partnerships as exogenous and stable elements of the firm's structural environment (e.g. Phelps, Heidl, \& Wadhwa, 2012; Rowley \& Baum, 2008; Salancik, 1995). As this assumption opposes the notion of top innovators as proactive network "actors", there is a need of further research that examines how firms can proactively configure, shape, and exploit their position in network-based forms of organization as well as initiate, develop, and cultivate external partnerships (e.g. Capaldo, 2007; Dhanaraj \& Parkhe, 2006; Lorenzoni \& Lipparini, 1999).

The publications in this dissertation thus cover two highly relevant factors in the management of innovation and business digitalization in commercial enterprises. The first focus area ("Top Management and Leadership") places special emphasis on the challenges of the intra-firm organization of innovation and business transformation. The second focus area ("Networks and External Partners") deals with the task of how firms organize innovation in cooperative relationships. In the rest of this prologue, I will take a closer look at previous research in both focus areas, specify major research gaps, describe the empirical studies and research publications in both focus areas, and explain how those studies contribute to research literature.

While the main focus of the research publications in this dissertation will be on these two areas, it is important to state that the other organizational factors identified in innovation management literature still may play a major role in determining firms' innovation outcomes. "Organizing for innovation" challenges firms with a multi-faceted and complex problem that requires them to configure different organizational elements and build a coherent system in which components such as leadership, strategy, organizational structures and processes, culture, resources, and external partnerships complement each other (e.g. Crossan \& Apaydin, 2010; Fiol et al., 1996; Slater et al., 2014). Though the focus of each paper in my work will lie on a specific research question related to "top management and leadership" or "networks and external partners", a central theme of this dissertation will be that the included papers take a rather comprehensive approach by trying to put the effects of top management or network-related variables in context with other organizational factors that might influence innovation outcomes. In particular, the study designs will draw on configurational theory (publications 1, 2, and 4) or consider multiple levels of analysis in their research questions, empirical designs, and statistical models (publications 3 and 5). Doing so, this dissertation answers calls in innovation and business digitalization research that ask for a better understanding of how patterns and combinations of different organizational factors cause certain outcomes to occur instead of the rather reductionist variance explanations that dominate most management research (e.g. El Sawy, Malhotra, Park, \& Pavlou, 2010; Nambisan et al., 2017). 


\section{Focus Area I: Top Management and Leadership}

The term "top management" defines the group of senior executives in the firm that are on the top of the hierarchical pyramid and make the core strategic decisions (Carpenter, Geletkanycz, $\&$ Sanders, 2004). Research literature assigns the label "top manager" to executives in the ranks of the Chief Executive Officer (CEO) and his/her direct reports (Boeker, 1997; Guadalupe, Li, \& Wulf, 2014; Tushman \& Rosenkopf, 1996) respectively to the top two tiers of an organization's management (usually managers above the level of vice president) (Carpenter \& Fredricksson, 2001; Ferrier, 2001; Geletkanycz \& Hambrick, 1997). Together, those senior executives form the top management team (TMT) which represents the firm's "dominant coalition" (Cyert \& March, 1963). The TMT are the group of people in the firm are at the interface between the firm and its environment, that hold most of the power, and who's choices and actions are most likely to affect the organization as a whole (Hambrick, Finkelstein, \& Mooney, 2005). Due their unique position, top managers essentially influence the strategic priorities and resource allocations in the firm and thus are ultimately responsible for the firm's financial, market, social, and especially innovation performance (Carpenter et al., 2004; Young, Charns, \& Shortell, 2001).

\subsection{Previous Research and Baseline Theories}

Though studies on the influence of top managers on organizational innovation take a variety of different explanatory approaches, the bulk of them explicitly refer to upper echelon theory (Hambrick, 2007). Upper echelon theory interprets "the organization as a reflection of its top managers" (Hambrick \& Mason, 1984, p. 193). This perspective builds on three central assumptions:

"(1) strategic choices made in firms are reflections of the values and cognitive bases of powerful actors, (2) the values and cognitive bases of such actors are a function of their observable characteristics like education or work experience, and as a result (3) significant organizational outcomes will be associated with the observable characteristics of those actors " (Carpenter et al., 2004, pp. 750-752).

Applying upper echelon theory to the context of innovation management, scholars consequently argue that top managers' unique position allows them to allocate critical resources to innovation initiatives (Balkin, Markman \& Gomez-Mejia, 2000) and move forward the realization and implementation of such initiatives (Lubatkin, Simsek, Ling \& Veiga, 2006). Therefore, depending on their attention and efforts a firm's upper echelons can considerably influence organizational innovation outcomes, either positively (e.g. Elenkov et al., 2005; Papadakis \& Bourantas, 1998; Yadav et al., 2007) or negatively (e.g. Khurana, 2002; Tripsas \& Gavetti, 2000). As top managers' motivation and ability to support or get involved in organizational innovation is assumed to be determined by factors related to the top manager's person and his/her position (e.g. Damanpour \& Schneider, 2009; Gerstner, König, Enders, \& Hambrick, 2013; Hoffman \& Hegarty, 1993), executives' characteristics will most likely explain large shares of variance in firms' innovation performance (Hambrick, 2007). 
Research on the basis of the upper echelon theory is quite extensive (Bromiley \& Rau, 2016; Busenbark et al., 2016). Concerning firm-level performance outcomes, previous studies examined the effects of various variables including observable characteristics like demographics or education, underlying psychological characteristics like personality or personal values, and top manager's interactions with other people such as social ties or power relations (see Figure 11 for an overview). In specific, research links top managers' age (Barker \& Mueller, 2002), gender (Damanpour \& Schneider, 2009), education (Garms \& Engelen, 2019), diversity of functional background (Hoffman \& Hegarty, 1993), social skills (Baron \& Markman, 2000), over-confidence (Galasso \& Simcoe, 2011), narcissism (Gerstner et al., 2013), locus of control (Boone, De Brabander, \& Hellemans, 2000), Big Five personality traits (Lin \& Tan, 2013), personal value system (Berson, Oreg, \& Dvir, 2008), or social network (Cao, Simsek \& Jansen, 2015) organizational innovation.

Following the notion of top managers as major factors for organizational innovation, research over the years has extended upper echelons theory into a more comprehensive perspective, the strategic leadership theory (Cannella et al., 1997). Instead of limiting itself to top managers' demographics and personal characteristics, strategic leadership theory explains firm-level outcomes by top managers' characteristics and their choices, actions, and behaviors. Upper echelon theory has been criticized for not directly studying actual behaviors of organizational leaders (e.g. Cannella \& Monroe, 1997; Carpenter et al., 2004; Elenkov et al., 2005; Geletkanycz \& Boyd, 2011). Strategic leadership theory aims to overcome those shortcomings by opening up the "black box" of top managers' actions and behaviors and providing insight on this "missing link" between the personal characteristics of organizational leaders and their impact on firm-level outcomes (e.g. Antonakis \& House, 2014; Elenkov et al., 2005; Makri et al., 2010). Thereby, strategic leadership theory does not merely infer top managers' behaviors on the basis of personal characteristics, but seeks to examine "what they do, how they do it, and particularly, how they affect organizational outcomes" (Finkelstein et al., 2009, p. 4). While upper echelon theory just assumes certain types of behaviors to emanate from top managers' demographics, experiences, and personalities (Carpenter et al., 2004; Hambrick, 2007; Hambrick \& Mason, 1984), strategic leaderships theory discusses the actual nature of top managers' behaviors and examines their effects on firm-level outcomes (e.g. Boal \& Hooijberg, 2000; Elenkov et al., 2005; Li \& Patel, 2019; Makri \& Scandura, 2010). 


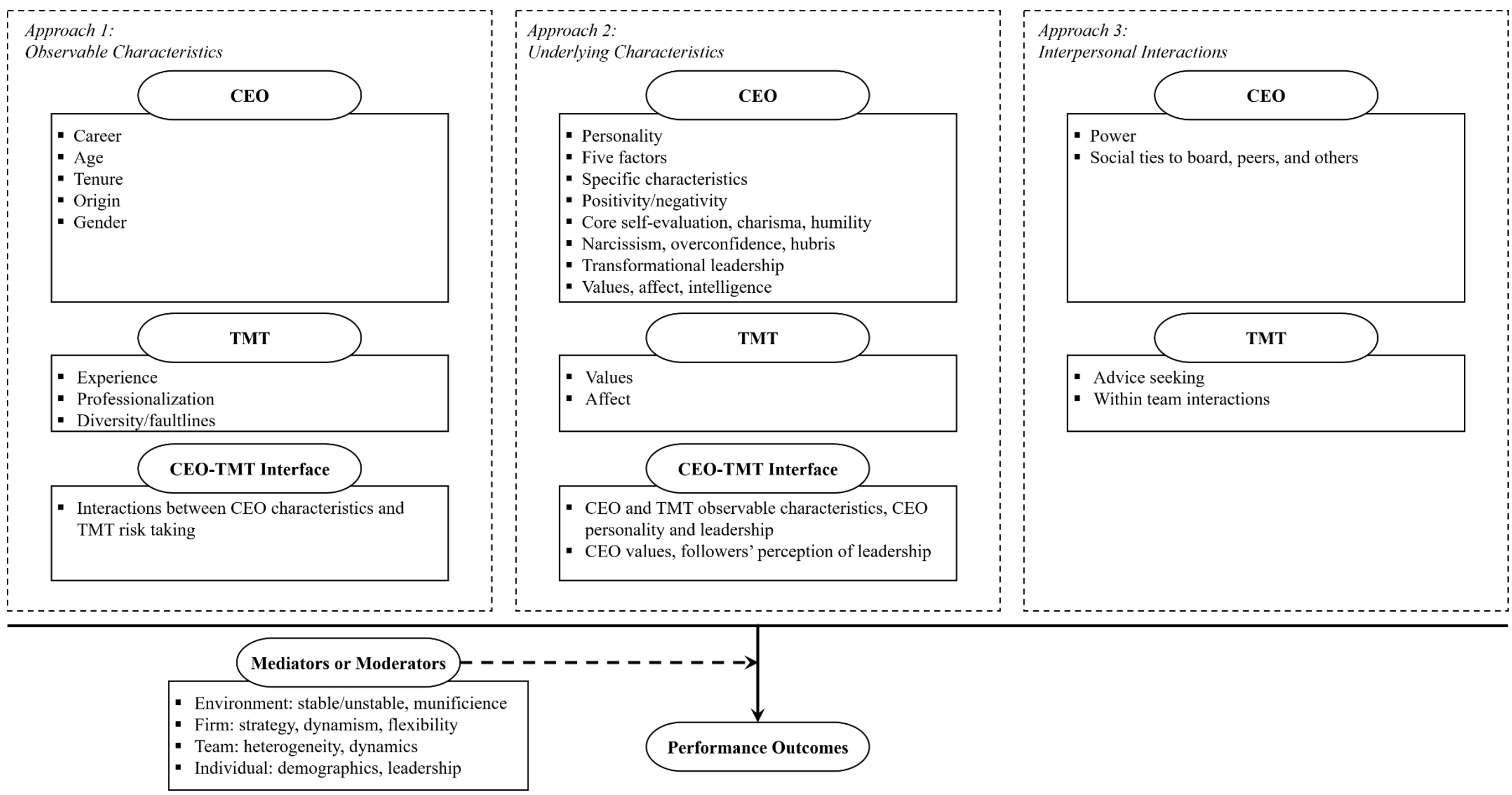

Figure I-11. Summary of research variables employed in empirical studies on CEOs, TMTs, and the CEO-TMT interface (Bromiley \& Rau, 2016; minor design modifications to match the formatting style of the thesis) 
Previous research on strategic leadership in the context of innovation management has found that the behaviors of top managers impact innovation outcomes significantly. Those studies found that organizational leaders influence innovation either directly by searching for new ideas, allocating resources, and formulating innovation strategies (e.g. Elenkov et al., 2005; Li, Magitti, Smith, Tesluk \& Katila, 2013; Yadav et al., 2007) or indirectly by providing subordinates with guidance and social support (e.g. Makri \& Scandura, 2010; Mumford \& Licuanan, 2004; Mumford, Scott, Gaddis, \& Strange, 2002). For instance, Hunter and Cushenbery (2011) provide an overview of the different ways in which top managers' behaviors influence innovation and creativity on the individual, the team, and the firm level (see Figure 12). In general, the bulk of studies from the strategic leadership theory perspective thereby treat visionary, charismatic, and transformational behaviors (e.g. Elenkov et al., 2005; Jung, Wu, \& Chow, 2008; Ling, Simsek, Lubatkin, \& Veiga, 2008; Mumford \& Licuanan, 2004) as the "alpha and omega of leadership" (Antonakis \& House, 2014, p. 751). Consequently, most studies in the context of innovation employ a conceptualization of leadership that highlights idealism, inspiration, intellectual stimulation, and individualized consideration as core factors for enabling organizational innovation (Bass, 1985).

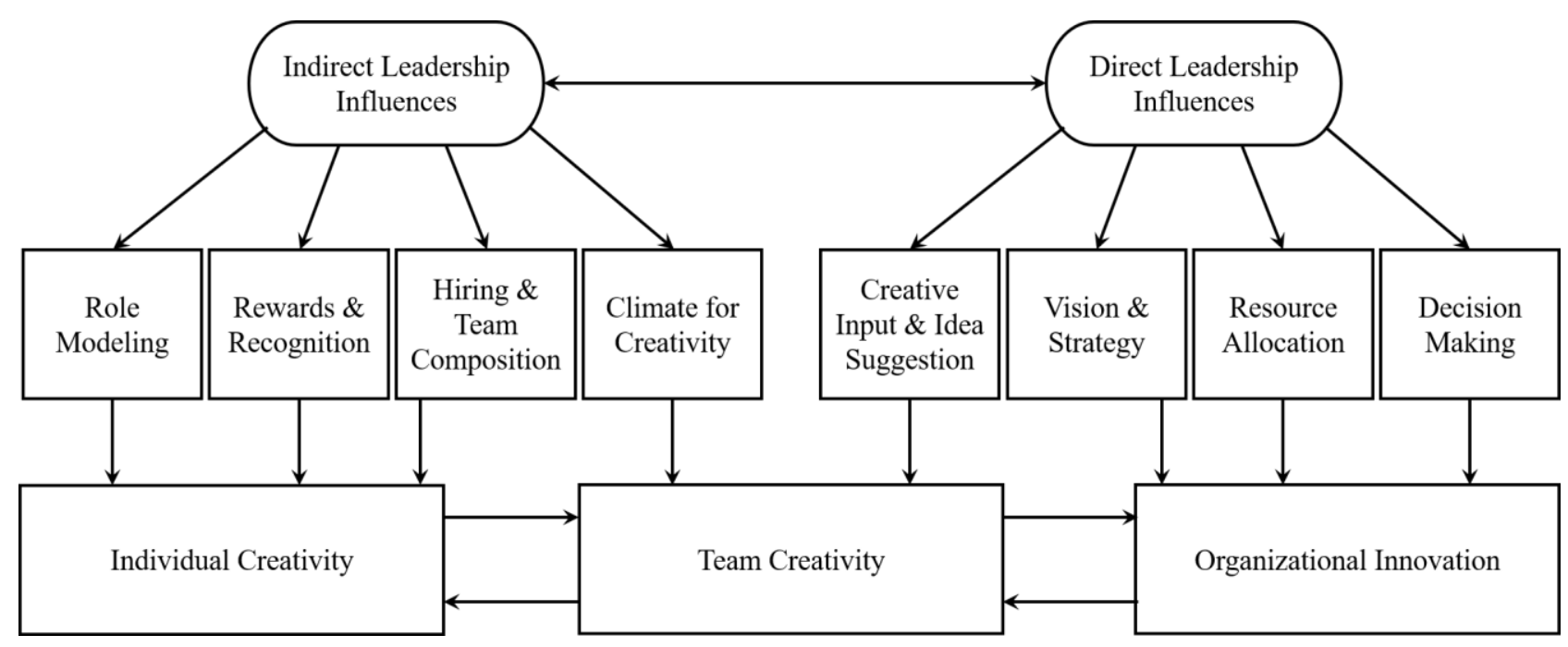

Figure I-12. Leadership influence on organizational innovation (Hunter \& Cushenbery, 2011; minor design modifications to match the formatting style of the thesis)

\subsection{Research Gaps}

In spite of the large number of studies on the impact of top management on innovation, still several major research gaps demand for further examination. The large majority of studies on the issue stick closely to the seminal perspectives of upper echelon theory (e.g. Hambrick \& Mason, 1984) and strategic leadership theory (e.g. Finkelstein et al., 2009). As a consequence, those works delate similar conceptual limitations, focus on similar empirical settings, neglect the same aspects of top managers' innovation leadership, and thus only partially provide a comprehensive and realistic perspective on the impact of top managers on innovation (Antonakis \& House, 2014; Cannella \& Monroe, 1997; Carpenter et al., 2004). For the context 
of my research, I identified five important limitations that I will address by the publications in this focus area of my dissertational research: (1) prevailing theoretical endogeneity; (2) focus on isolated net effects of individual variables rather than causal complexity; (3) lack of knowledge on what top managers "actually do" to promote innovation; (4) lack of research on the relations between top managers' personal characteristics and leadership behaviors; (5) neglect of top management positions besides the CEO.

Research gap 1: Prevailing theoretical endogeneity. Up to this point, plenty of studies investigated how certain characteristics, skills, contacts, behaviors, or experiences might help managers promote organizational innovation and increase the firm's innovation performance (e.g. Berson et al., 2008; Damanpour \& Schneider, 2009; Galasso \& Simcoe, 2011; Gerstner et al., 2013; Hoffman \& Hegarty, 1993). However, this plethora of examined factors and significant effects observed entails a serious problem: theoretical endogeneity. Theoretical endogeneity describes a situation in which two or more different theoretical perspectives provide alternative plausible explanations on the same issue but there are only few attempts to integrate those different streams (Busenbark et al., 2016). Consequently, most studies on the issue are fraught with the risk of having omitted key variables so that results must be interpreted with caution. Busenbark et al. (2016) diagnose such theoretical endogeneity for research on CEOs, but also on top managers in general:

"As we have stated above, the theoretical fault lines separating each of the domains have fragmented the literature such that we know much about how individual CEO attributes and circumstances relate to firm performance, but we have little integrated knowledge specifically about CEOs, each of whom represents one particular configuration of these attributes and circumstances" (p. 259).

First attempts have been made to consolidate this state of theoretical endogeneity. Several recent works argue that that organizational outcomes such as innovation will be explained by a complementary interaction between the human capital (i.e., personal skills and expertise) that a top manager can deploy, the social capital (i.e., personal relationships and interactions), and by how he/she makes use of those skills and relationships by making innovation-related strategic choices and engaging in innovation-related leadership behaviors (e.g. Adner \& Helfat, 2003; Bromiley \& Rau, 2016; Li \& Patel, 2019). Still, detailed theoretical explanations and empirical evidence on those interactions is lacking. Hence, there is a clear need for further research that seeks to integrate the findings of different streams of top management research and examines how factors from different conceptual domains combine to affect firm-level innovation outcomes (Busenbark et al., 2016).

Research gap 2: Focus on isolated net effects of individual variables rather than causal complexity. Exacerbating the issue of theoretical endogeneity, most studies on top management and innovation do not include variables from different domains (such as demographics, education, professional background, personality, networks, and position (Bromiley \& Rau, 2016; Busenbark et al., 2016)) but focus on a limited set of explanatory variables, mostly all from the same domain. Most research on top management relies on variance theory (Van de Ven \& Huber, 1990) for representing relations between research variables. Variance theory 
holds the potentially problematic assumption that explanatory variables in a research model are independent (Vis, 2012). Furthermore, variance theory is unable to provide meaningful evidence on complex interaction effects (Fiss, 2011). Consequently, almost all studies on top management and innovation test isolated net effects of top managers' characteristics (e.g. Barker \& Mueller, 2002; Berson et al., 2008; Galasso \& Simcoe, 2011) or one-way interactions between those characteristics (e.g. Damanpour \& Schneider, 2009; Gerstner et al., 2013; Hoffman \& Hegarty, 1993).

Most recently, top management scholars have started to question the validity of this conceptual and empirical approach and call for research that aims at exploring complex interplays between different variables related to top managers and their positions in the firm (e.g. Bromiley \& Rau, 2016; Busenbark et al., 2016; Helfat \& Martin, 2015; Lewellyn \& Fainshmidt, 2017). Those scholars advocate a configurational perspective that allows for representing more complex causal relations and acknowledges that "parts of a social entity take their meaning from the whole and cannot be understood in isolation" (Meyer, Tsui, \& Hinings, 1993, p. 1178). Based on the assumptions of configurational theory, top management research would thus be able to examine how top managers' demographics, education, professional background, personality, networks, and position affect organizational innovation in conjunction rather than in isolation and provide "causal recipes" for improving innovation performance (Fiss, 2011).

Research gap 3: Lack of research on what top managers "actually do" to promote innovation. As outlined above, most works that study top managers' innovation-related behaviors examine the effects of transformational/charismatic/visionary leadership (e.g. Elenkov et al., 2005; Jung et al., 2008; Ling et al., 2008). Those concepts were originally developed in traditional "supervisory" leadership research with the aim to better explain the outcomes of leader/follower relations or, in other words, leadership “in” organizations (Boal \& Hooijberg, 2000). However, while interpersonal and relational issues undoubtedly are of importance for top managers, leading scholars argue that strategic leadership or, in other words, leadership "of" organizations cannot be reduced to such social aspects (e.g. Antonakis \& House, 2010; Finkelstein et al., 2009; Ireland \& Hitt, 1999; Makri \& Scandura, 2010). Makri and Scandura (2010) thus argue that when seeking to understand by which behaviors top managers influence innovation, concepts adapted from traditional "supervisory" leadership research (such as transformational leadership) are unsuitable as such concepts do not "capture the behaviors of a CEO [and in a broader sense other top managers] which are most associated with the dimensions of the innovation value chain" (p. 77). Instead, they argue that "the concept of strategic leadership in the context of high-technology firms calls for constructs reflective of the CEO's overall effectiveness in spearheading invention, innovation and commercialization" (ibid., p. 75).

In the context of organizational innovation, top managers thus do not just make an impact by inspiring, stimulating, or motivating employees (Deschamps, 2008). Among others, top managers can contribute to innovation by generating ideas and initiating innovation projects (e.g. Barker \& Mueller, 2002; Hunter \& Cushenbery, 2011; Yadav et al. 2007), by planning and setting-up adequate organizational structures and processes (e.g. Christensen, Kaufman, \& Shih, 2008; Deschamps, 2008; Makri \& Scandura, 2010), by making decisions for portfolio management and resource allocation (e.g. Cooper \& Mills, 2005; Hoffman \& Hegarty, 1993; 
Pisano, 2015), or by advocating employees' ideas and clearing barriers in the implementation of innovation initiatives (e.g. Dutton, Ashford, O’Neill, \& Lawrence, 2001; Rost, Hölzle, \& Gemünden, 2007; Watts \& Henderson, 2006).

However, due to the focus on transformational leadership and related concepts, academic research provides surprisingly little insight on those aspects of top managers' innovation leadership. Only few works actually operationalized and measured innovation leadership behaviors on the c-level, let alone attempted to structure different innovation leadership behaviors into an overarching framework. Hence, we know little about how top managers "instigate, sponsor, and steer innovation in their organization" (Deschamps, 2008, p. 19). Literature thus fails to provide adequate information on a number of important issues such as (1) what top managers "actually do" to promote innovation, (2) which leadership behaviors constitute innovation leadership on the c-level, and (3) if different top managers exert and combine different types of innovation leadership behaviors and thus contribute to organizational innovation in different ways.

Research gap 4: Lack of research on the relations between top managers' personal characteristics and innovation leadership behaviors. When providing answers to what managers "actually do" to promote organizational innovation, the question of if and how personal characteristics or the context of a top manager's position in the firm influence such innovation leadership behaviors is almost a logical consequence. Following the assumptions of upper echelon theory and strategic leadership theory, demographics, experiences, personality, and job demands will substantially determine a top manager's motivation and ability to engage in organizational innovation (e.g. Damanpour \& Schneider, 2009; Gerstner et al., 2013; Hoffman \& Hegarty, 1993). However, empirical evidence for this assumption is limited. Research on the basis of upper echelon theory has for long been criticized for using personal characteristics as a proxy for an assumed tendency to get involved in organizational innovation instead of directly observing top managers' actions and behavior (e.g. Cannella \& Monroe, 1997; Carpenter et al., 2004; Elenkov et al., 2005; Geletkanycz \& Boyd, 2011). Research on the basis of strategic leadership theory, on the other hand, has mainly used leadership behaviors as independent variables predicting innovation without discussing how personal characteristics might lead top managers to engage in such leadership behaviors (e.g. Elenkov et al., 2005; Makri et al., 2010). Hence, linking personal characteristics of top managers with their engagement in observable leadership behaviors bears the potential to fill black spots in the causal explanations of upper echelon and strategic leadership theory, and in sum to strengthen some central claims underlying top management research.

Research gap 5: Neglect of top management positions besides the CEO. Finally, the bulk of previous studies on top management and innovation focuses on the position of the CEO (e.g. Berson et al., 2008; Galasso \& Simcoe, 2011; Gerstner et al., 2013; Yadav et al., 2007) or the TMT as a whole (e.g. Alexiev, Jansen, Van den Bosch, \& Volberda 2010; Collins \& Clark, 2003; Talke, Salomo, \& Kock, 2011). Still, functional managers like the Chief Information Officer (CIO) (Watts \& Henderson, 2006), the Chief Technology Officer (CTO) (Garms \& Engelen, 2019), the Chief Marketing Officer (CMO) (Nath \& Mahajan, 2008), or the Chief Strategy Officer (CSO) (Menz \& Scheef, 2014), as well as departmental managers that have 
profit and loss responsibility for one or more business units of the firm (Guadalupe et al., 2014) might make valuable contributions to innovation initiatives in the firm. Thus, those managers are likely to be an important but up-to-now largely neglected factor for successful organizational innovation (Menz, 2012). Due to the immense strategic importance of business digitalization, especially the new managerial role of the CDO provides a promising field for further research, both from an academic and a practice-oriented standpoint (e.g. Haffke et al., 2017; Singh \& Hess, 2017; Tumbas et al., 2018).

\subsection{Summary of Publications in Focus Area I}

Addressing the research gaps outlined above, this dissertation comprises two publications in focus area I. Both publications are based on data generated from a research project aiming to understand the impact of top management on innovation and business digitalization in manufacturing firms in Germany, Austria, and Switzerland. The data was collected in a number of surveys addressing different members of top management teams including CEOs, CDOs, CIOs, CTOs, CMOs, COOs, CFOs, and CHROs. The surveys were conducted between December 2017 and April 2018. Publication 1 examines how different configurations of individual attributes and behaviors explain the effectiveness and failure of CDOs in different situational contexts. The publication addresses research gaps 1, 2, and 5, in particular. Publication 2 develops a taxonomy of top managers based on their innovation leadership behaviors and analyses if demographics, professional background, managerial position, and personality predict the role a top manager takes in promoting organizational innovation. Within the scope of this paper, I tackle the research gaps 2, 3, 4, and 5 outlined above. Figures 13 and 14 provide an overview on research questions, theoretical foundations, methodology, and the results of each publication.

Publication 1: How new top management roles drive business digitalization - A configurational analysis on CDOs' effectiveness and failure. In 2018, 21\% of the 2,500 worldwide largest publicly listed companies (in the European subsample even 39\%) had appointed a top-level executive responsible for business digitalization at the corporate level (Péladeau, Acker, \& Müller, 2019). Despite the high strategic relevance of this new position, only little is known about when and why CDOs are effective in their task and are able to foster business digitalization as an organizational performance outcome. In order to address this lack of research, this study draws on upper echelon theory and configuration theory to link CDOs' skills (strategic IT knowledge, political skills), networks (internal, external), and role behaviors (innovative, supportive) in a comprehensive research framework. Based on data from 211 CDOs, we employ fuzzy-set qualitative comparative analysis (fsQCA) to identify profiles of successful and non-successful CDOs.

As a result, the publication identifies four effective types of CDOs: (1) "process promotor" CDOs with strong political skill and a large internal network who engages in supportive role behavior; (2) "local" CDOs with strong political skills, profound strategic IT knowledge, and a large internal network; (3) "evangelist" CDOs who have considerable experience in other firms and industries, possess strong political skills and a valuable external network, and demonstrate strong innovative role behavior but lack strategic IT knowledge; and (4) "icebreaker" CDOs 
who are characterized by strong strategic IT knowledge, a large and diverse external network, strong engagement in innovative role behavior, and, surprisingly, weak political skills. Moreover, our findings indicate that those four types of CDOs are effective in different situational contexts. Concerning CDO failure, the analysis yields three different profiles: (5) technology-oriented CDOs that spent most of their career in IT \& infrastructure departments and miss out on most of the skills, networks, and behaviors examined; (6) CDOs that resemble the "evangelist" type but lack political skills, internal network, and hierarchical influence; and (7) CDOs that resemble the "icebreaker" type, but operate in a different context that might deteriorate the benefits and unveil the negative aspects of this profile. In all, the results provide important implications to research on CDOs, but also to upper echelon theory in general.

Publication 2: Toward a taxonomy of innovation leadership on the c-level-An exploratory study on the leadership behaviors of senior executives. While research provides broad evidence for the significant impact of top managers on organizational innovation, only few studies conceptualize and measure observable and problem-oriented actions by which top managers might influence innovation outcomes (Elenkov et al., 2005; Geletkanycz \& Boyd, 2011; Makri \& Scandura, 2010). Therefore, there is a lack of knowledge on what top managers "actually do" to promote organizational innovation (Deschamps, 2008; Mumford \& Licuanan, 2004). Publication 2 aims to provide insight on this issue by drawing on configuration theory and a classification approach in order to enrich the perspective of strategic leadership theory. In particular, I first develop a conceptual component model that serves to determine top managers' innovation leadership behaviors along four dimensions: (1) involvement in idea creation and innovation projects; (2) sponsoring innovators and innovation projects; (3) formulation and implementation of an innovation strategy; (4) establishing a climate for innovation. Second, I employ cluster analysis in order to identify groups of managers that share similar patterns of innovation leadership behaviors. Finally, I conduct a discriminant analysis to test if personal and job characteristics influence the likelihood of top managers displaying a certain pattern of innovation leadership behaviors. 


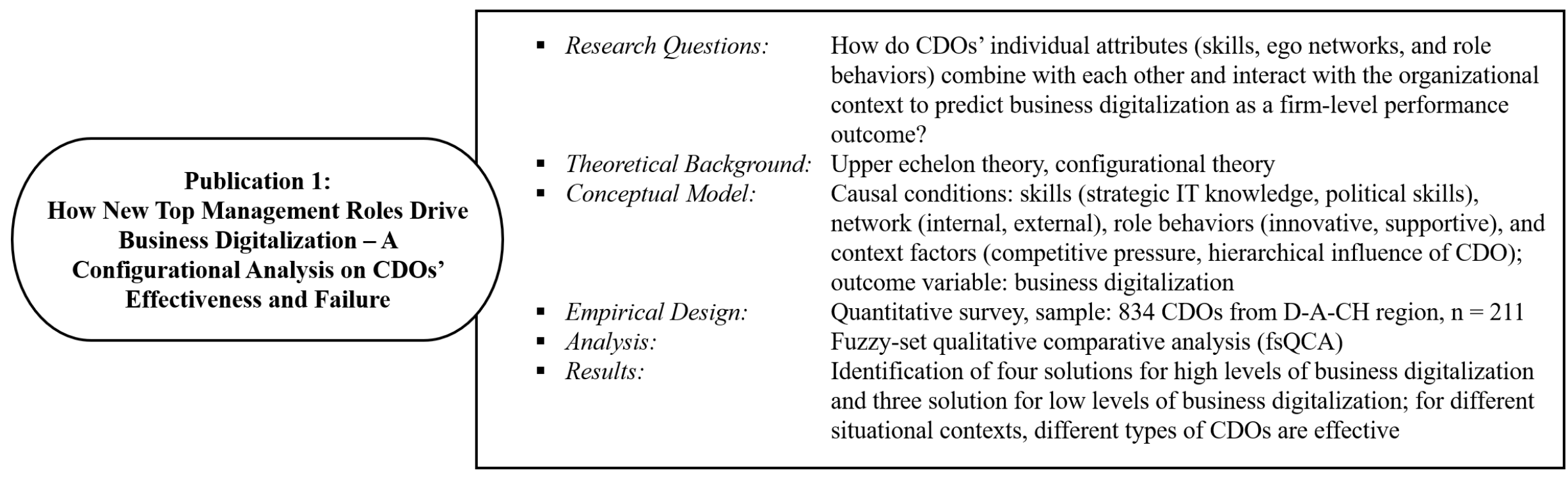

Figure I-13. Overview of publication 1 (own illustration) 


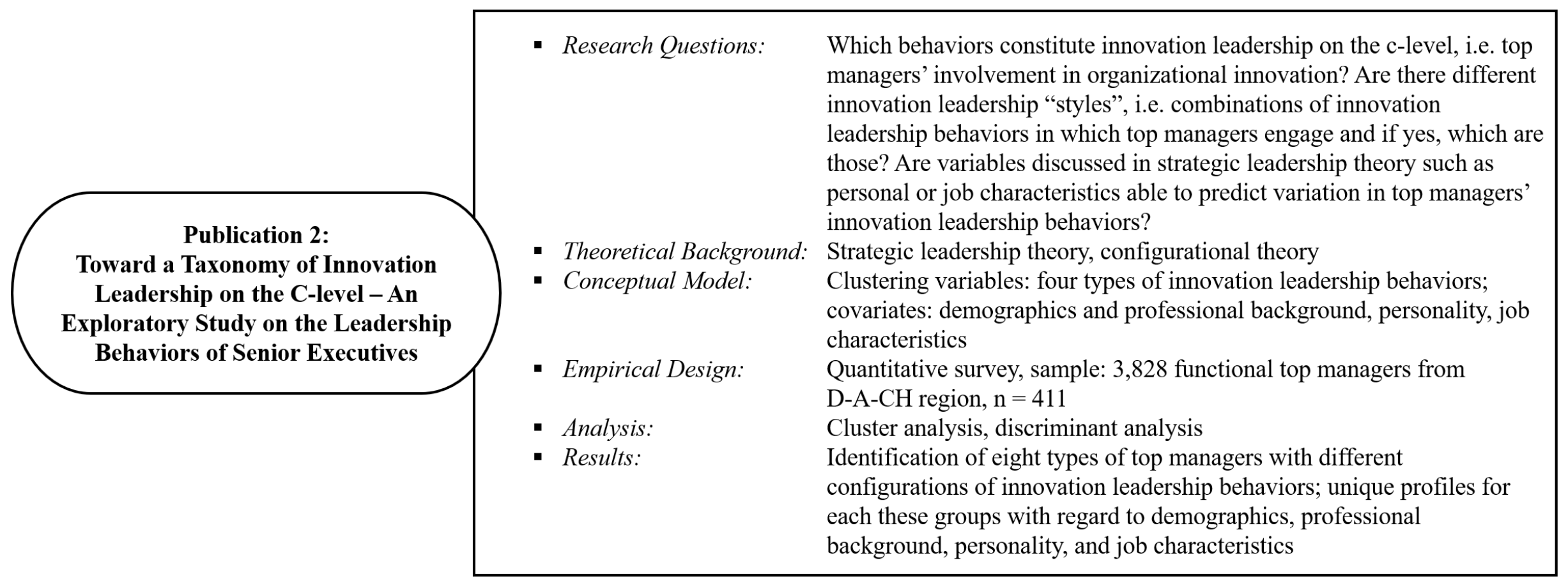

Figure I-14. Overview of publication 2 (own illustration) 
Based on survey data from 411 functional top managers, cluster analysis identifies eight groups of top managers: (1) lightweights (low engagement in all four leadership behaviors); (2) inventors (high engagement in "involvement in idea creation and innovation projects" only); (3) hands-on innovators (high engagement in "involvement in idea creation and innovation projects" and "sponsoring of innovators and innovation projects"); (4) entrepreneurs (high engagement in "involvement in idea creation and innovation projects" and "formulation and implementation of an innovation strategy"); (5) headcoaches (high engagement in "sponsoring of innovators and innovation projects" and "formulation and implementation of an innovation strategy"); (6) gardeners (high engagement in "sponsoring of innovators and innovation projects" and "establishing a climate for innovation"); (7) evangelists (high engagement in "formulation and implementation of an innovation strategy" and "establishing a climate for innovation"); and (8) superheroes (high engagement in all four leadership behaviors). Furthermore, discriminant analysis demonstrates that for each of these types, there is a distinct profile of demographic, professional background, positional, and personality characteristics describing the type of manager. In all, the findings contribute to research on top managers' influence on organizational innovation as well as to strategic leadership theory.

\section{Focus Area II: Networks and External Partners}

In the field of innovation management research, the network concept becomes increasingly popular as there is considerable empirical evidence that cooperation and knowledge exchange between firms foster innovation performance (e.g. Ahuja, 2000; Baum, Calabrese, \& Silverman, 2000; Pullen, de Weerd-Nederhof, Groen, \& Fisscher, 2012; Ritter \& Gemünden, 2003; Rothwell, 1991). The term "inter-organizational network" describes a loosely-coupled system of autonomous firms that at least to some degree share a common goal, interact, and cooperate (Dai, Goodale, Byun, \& Ding, 2018). From the perspective of an individual firm that is embedded in such a network, the network is "the sum total of ties it has with others" (Gulati, 2007, p. 55). From a more overarching perspective, networks represent collaborative forms of organization of which there are different types such as strategic alliances (e.g. Baum et al., 2000; Degener, Maurer, \& Bort, 2018; Ozer \& Zhang, 2015), industry clusters (e.g. Bell, 2005; Boschma \& ter Wal, 2007; Inkpen \& Pien, 2006), or ecosystems (e.g. Adner, 2017; Adner \& Kapoor, 2010; Rohrbeck, Hölzle, \& Gemünden, 2009). In the context of innovation management, networks usually represent sets of collaborative agreements between three or more firms that aim at sharing resources and know-how, exploring technological and business opportunities, and/or joint development of new products, services, processes, or business models (e.g. Baker, Grinstein, \& Harmancioglu, 2016; Heidenreich, Landsperger, \& Spieth, 2016; Thornton, Henneberg, Leischnig, \& Naudé, 2019).

\subsection{Previous Research and Baseline Theories}

The majority of scholars explain the positive effect of networks on firms' innovation performance on the basis of the strategic network perspective. The strategic network perspective is based on the assumption that "networks potentially provide a firm with access to information, resources, markets, and technologies; with advantages from learning, scale, and scope economies; and allow firms to achieve strategic objectives, such as sharing risks and 
outsourcing value-chain stages and organizational functions" (Gulati, Nohria, \& Zaheer, 2000, p. 203). The central element in the causal logic portrayed by the strategic network perspective is the concept of "network resources" (Gulati, Nohria, \& Zaheer, 2000). Network resources are obtained from the ties that connect the firm to external partners such as customers, suppliers, or even competitors (Gulati, 1999; Gulati, 2007; Lavie, 2006). By highlighting that organizational performance to a significant degree is influenced by such network resources, the strategic network perspective extends rather "atomistic" management theories like the resourcebased view (Barney, 2001) and the knowledge-based view (Grant, 1996) of the firm that explain performance differences mainly by variance in firms' internal resource base.

According to the strategic network perspective, the benefits provided by access to network resources especially come into effect in the context of organizational innovation (Ahuja, 2000; Bell \& Zaheer, 2005). Innovation is a resource- and knowledge-intensive activity that requires a broad scope of heterogeneous resources, expertise, and skills (Bierly, Damanpour, \& Santoro, 2009; Lyytinen et al., 2016; Nambisan et al., 2017; Yoo et al., 2012). As the development of diverse resources and knowledge is costly and bears risks, it is seen as beneficial for innovative performance when the firm can access "a network of knowledgeable contacts that provide a reliable source of information about options for enhancing competitive capabilities" (McEvily \& Zaheer, 1999, p. 1136). By the help of external partners, firms can overcome fundamental limitations in the scope of resources they are able to generate and deploy on their own (Baum et al. 2000; Dyer \& Nobeoka, 2000).

Network resources are not under the control of the focal firm but are embedded in the relationships and the overarching social structure in which the firm operates (Gulati, Madhavan, \& Lavie, 2011). Therefore, the quantity and quality of the network resources that a firm can acquire depends on the structural, compositional, and relational characteristics of its network (Borgatti \& Foster, 2003; Borgatti \& Halgin, 2011; Hoffmann, 2007; Wassmer, 2010; Zaheer, Gözübüyük, \& Milanov, 2010). Accordingly, such network characteristics can be depicted as "conduits" (Gulati, 1999) or "loci" (Gnyawali \& Madhavan, 2001) of network resources that determine the firm's access to the desired assets, information, or status provided by other firms (Thornton et al., 2019). As variance in network characteristics thus is assumed to translate into differences in innovation performance (e.g. Galaskiewicz \& Zaheer, 1999; Gulati et al., 2011; Pullen et al., 2012), research on inter-organizational networks has examined the effects of a number of different network variables reflecting differences in the structure, composition, and relations with firms' networks (Wassmer, 2010). Figure 15 provides an overview on some of the most prominent network variables that have been employed in previous empirical research. 

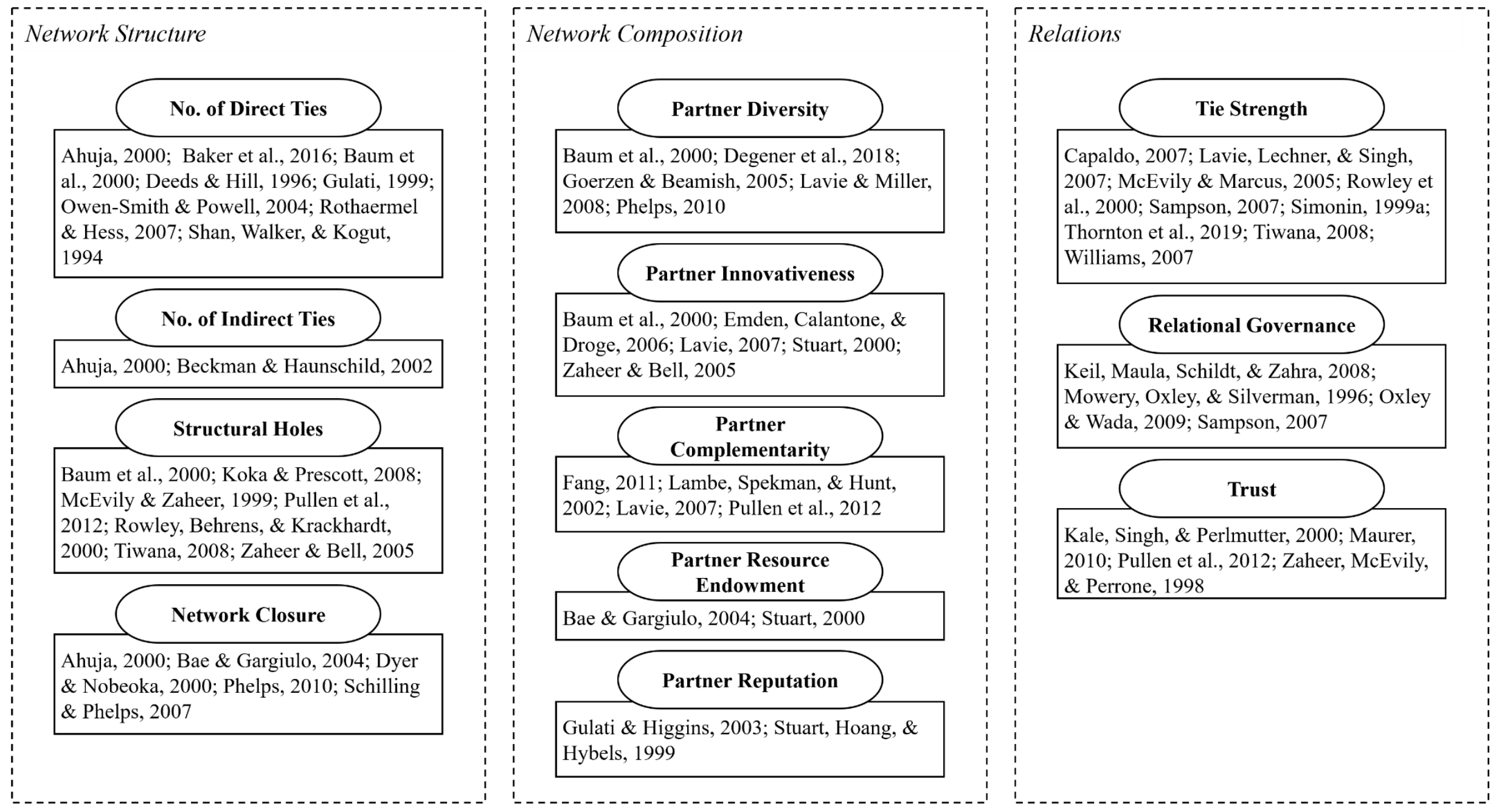

Figure I-15. Overview of network-related variables employed in empirical studies on inter-organizational networks and innovation (own illustration, based on Phelps et al., 2012; Wassmer, 2010) 
Though research has produced extensive evidence for the profound impact of networks on firms' performance, most network literature has one serious limitation: networks and relationships between firms are largely perceived as static social entities (Salancik, 1995). Consequently, research on the basis of the strategic network perspective most often "portrays network nodes [i.e. firms and organizations] in their role as transmitters of information and knowledge as being empty vessels with no strategic interests" (Phelps et al., 2012, p. 1149). Only recently, network scholars have begun to acknowledge that resource and performance advantages stem "not merely from opportunity structures embedded in networks but also from the distribution of ability and motivation among firms" (Madhavan, Caner, Prescott, \& Koka, 2008, p. 457). Hence, rather than network characteristics alone, also the activities, routines, and practices by which a firm positions itself in inter-organizational networks, develops and alters collaborative relationships to other firms, or capitalizes on the accessed resources, will most likely play a major role in determining organizational outcomes such as innovation performance (e.g. Ford \& Mouzas, 2013; Ritter \& Gemünden, 2003; Thorelli, 1986; Thornton, Henneberg, \& Naudé, 2015).

While most research on inter-organizational networks originates from the "structuralist heritage" of network theory (Borgatti \& Foster, 2003, p. 1000) and thus does not elaborate on firms' strategic motivations and abilities to shape their network environment, a second stream of literature within the strategic network perspective has recently developed that might help to fill this academic void. This stream of research establishes the concept of "network management", i.e., the set of identifiable and specific routines and processes by which firms aim to purposefully initiate, maintain, and utilize relationships with external partners (e.g. Anand \& Khanna, 2000; Lorenzoni \& Lipparini, 1999; Vesalainen \& Hakala, 2014; Walter, Auer, \& Ritter, 2006). Studies have shown that network management represents an important organizational capability (Ireland, Hitt, \& Vaidyanath, 2002). It has been found that network management on the firm's behalf improves the outcomes of collaborative partnerships with other firms (e.g. Heimeriks \& Duysters, 2007; Kale \& Singh, 2007; Mitrega \& Pfajfar, 2015; Schilke \& Goerzen, 2010; Schreiner, Kale, \& Corsten, 2009), innovation performance (e.g. Leischnig, Geigenmueller, \& Lohmann, 2014; Mu \& Di Benedetto, 2012; Ritter \& Gemünden, 2003; Rothaermel \& Deeds, 2006), and overall organizational performance (e.g. Sarkar, Echambadi, \& Harrison, 2001; Walter et al., 2006). Hence, this "managerial perspective" provides a valid theoretical viewpoint that complements the widely established "structural perspective" on inter-organizational networks (Faems, Janssens, \& Neyens, 2012).

\subsection{Research Gaps}

Though research literature provides important insights on how inter-organizational networks foster firms' innovation performance, there are still several white spaces in our current understanding of the causal mechanisms and effects at play. Concerning the theoretical approach, most inter-organizational network research relies on structural perspectives (e.g. Borgatti \& Foster, 2003; Borgatti \& Halgin, 2011; Phelps et al., 2012; Salancik, 1995) and employs variance theory for the specification of effect directions and effect sizes (e.g. Hofman, Faems, \& Schleimer, 2017; Leischnig et al., 2014; Meuer, 2014; Xie, Fang, \& Zeng, 2016). Concerning the methodological approach, the use of archival data dominates large parts of 
research on inter-organizational networks (e.g. Phelps et al., 2012; Pittaway, Robertson, Muni, Denyer, \& Neely, 2004). Though both the prevailing theoretical and methodological approaches are well-justified and helped to advance the academic knowledge on firm networks, they also entail several limitations. In the following, I will discuss four important limitations in more detail: (1) focus on the effect of single network characteristics and neglect of the interplay and fit between different network resources; (2) neglect of firm characteristics and the interplay and fit between network resources and internal resources; (3) missing link between structural and managerial perspectives on inter-organizational networks; (4) focus on a limited set of network and network resource types.

\section{Research gap 1: Focus on the effect of single network characteristics and neglect of the} interplay and fit between different network resources. Previous studies examined the impact of various different network characteristics and revealed several positive effects on innovation performance. Among others, inter-organizational network research found network size (e.g. Ahuja, 2000; Baum et al., 2000; Rothaermel \& Hess, 2007), partner innovativeness (e.g. Emden et al., 2006; Stuart, 2000; Zaheer \& Bell, 2005), partner diversity (e.g. Degener et al., 2018; Goerzen \& Beamish, 2005; Phelps, 2010), partner complementarity (e.g. Fang, 2011; Pullen et al., 2012; Sampson, 2007), and tie strength (e.g. Capaldo, 2007; Thornton et al., 2019; Tiwana, 2008) to be beneficial for innovation outcomes. Thereby, most research literature at least implicitly seems to assume that those network characteristics affect innovation performance independently (Pullen et al., 2012). Scholars evaluate this independence assumption increasingly as problematic because studying different network characteristics in separation "is meaningful only if their effects are orthogonal" (Gulati et al., 2011, p. 210). However, the independence assumption is unlikely to hold true when "(1) real-life organizations and networks consist of multiple characteristics simultaneously; and (2) the combined effect of these characteristics might be to some extent different from analyzing characteristics separately" (Pullen et al., 2012, p. 921). Hence, the core assumption that underlies most theoretical and empirical approaches towards studying inter-organizational networks must be considered as a form of reductionism (Van de Ven \& Drazin, 1985) and consequently be called into question.

Gulati et al. (2011) thus note that "approaches that focus exclusively either on network structure, relational properties of ties, or organizational attributes offer incomplete theoretical and empirical treatment" (p. 208) and most research on the performance effects of interorganizational networks might have "offered incomplete interpretations at best and misleading recommendations at worst” (ibid., p. 220). To remedy those shortcomings, scholars call for a perspective of "fit" on inter-organizational networks that examines and explains if and how different network characteristics and resources complement or substitute each other (e.g. Gulati et al., 2011; Phelps et al., 2012; Pittaway et al., 2004; Pullen et al., 2012; Wassmer, 2010; Zaefarian, Henneberg, \& Naudé, 2013).

Pullen et al. (2012) and Zaefarian et al. (2013), for instance, advocate a configurational perspective on the effect of firms' networks on organizational performance based on a systems approach to the "fit" concept. "Fit" thereby describes that in order to yield superior performance, consistency across multiple dimensions of an organization's design and context is required (Doty, Glick, \& Huber, 1993). Following this line of reasoning, configurations of 
network characteristics that display such consistency may be perceived as "ideal profiles" (Van de Ven \& Drazin, 1985), i.e., "combinations of network characteristics that fit together (i.e., are internally consistent) and are related to high performance" (Pullen et al., 2012, p. 919). In a similar vein, Gulati et al. (2011) call for theoretical models and empirical approaches that explain interaction effects between different network characteristics based on how well the resource benefits stemming from those characteristics complement each other. Such models should simultaneously consider structural, relational, and actor attributes as determinants of innovation performance to provide a more "comprehensive view on the mechanisms whereby networks affect organizational performance" (Gulati et al., 2011, p. 222).

\section{Research gap 2: Neglect of firm characteristics and the interplay and fit between network} resources and internal resources. Similar to the lack of research on the interplay and fit between different network resources, most literature also neglects that different types of firms might profit from different types of networks. Past research has been criticized for perceiving firms as "black boxes" and treating firm-level differences as a source of empirical noise that should be controlled for or ignored completely (Phelps et al., 2012). Especially in the closely related contexts of innovation, knowledge creation, and knowledge transfer, only few studies have examined how differences across firms interact with network characteristics to influence innovation outcomes (Phelps et al., 2012; Wassmer, 2010). Indeed, a small but growing number of studies demonstrates that the value of network characteristics and corresponding network resources depends on firms' business strategies (Zaefarian et al., 2013), organizational characteristics (Huggins \& Johnston, 2010), and particularly on internal resources and expertise (e.g. Gesing, Antons, Piening, Rese, \& Salge, 2015; Rothaermel \& Hess, 2007; Ritala \& Hurmelinna-Laukkanen, 2013; Rupietta \& Backes-Gellner, 2019). However, further insight is needed on the causal mechanisms that underlie the interaction between networks on the one hand and firms' characteristics (especially internal resources) one the other hand (Gulati et al., 2011; Phelps et al., 2012).

Analogous to the question of how different network characteristics and resources interact to influence organizational outcomes, configuration theory and the "fit" concept have also been suggested to serve as the basic theoretical lenses for examining and explaining the interplay between networks and firm characteristics (Gulati et al., 2011; Pullen et al., 2012). Besides "internal fit" (i.e., fit between different network characteristics and resources), those works advocate the role of "external fit" and posit, "that for each set of network characteristics, there exists an 'ideal' set of organizational characteristics dynamically fitting with the organizations' context that yields superior performance" (Pullen et al., 2012, p. 919). Thereby, following the notion that an organization needs sufficient internal resources to create value from its network (Gulati et al., 2011), the organizational characteristics and internal resources are seen to be important determinants of firms' capacity to absorb and learn from externally acquired resources (Cohen \& Levinthal, 1990; Lane, Salk, \& Lyles, 2001). On the other hand, Gulati et al. (2011) expect complementing and substituting effects between organizational structures and resources so that "one must take into account possible synergies that can emerge by combining its [i.e., the firm's] internal resources with those available via external ties to partners" (Gulati et al., 2011, p. 214). Hence, in order to dissolve the "black box" and examine the 
interdependencies between networks and firms, more comprehensive and holistic approaches towards theory development and research methodology are needed, as well.

\section{Research gap 3: Missing link between structural and managerial perspectives on inter-} organizational networks. As outlined above, there are two major streams within the strategic network perspective that explain the effects of inter-organizational networks on organizational performance in general and innovation performance in specific (e.g. Faems et al., 2012; Phelps et al., 2012; Thornton et al., 2015). On the one hand, the structural perspective explains the effects of network characteristics and the corresponding network resources. On the other hand, the managerial perspective links firms' activities, routines, and processes to differences in innovation performance. Though structural and managerial perspective put forth potentially complementary explanations for why firms in inter-organizational networks succeed or fail to foster innovation performance by the help of external partners, both streams largely ignore each other up to this point. For instance, concerning alliance networks, an important subtype of interorganizational networks, Faems et al. (2012) note that though "existing alliance portfolio studies provide valuable insights into the structural properties or managerial aspects of alliance portfolios, they largely ignore the interactions between them" (p. 242). Only few studies include both network characteristics and network management in their theoretical models and their empirical research designs (e.g. Degener et al., 2018; Naudé, Zaefarian, Tavani, Neghabi, \& Zaefarian, 2014; Sarkar, Aulakh, \& Madhok, 2009; Schreiner et al., 2009).

This mutual neglect of the other perspective entails serious limitations for the explanatory power of both streams. For instance, Wang and Rajagopalan (2015) argue in their literature review on alliance management capabilities that the lack of integrating network structures into research models is a major reason that there is little knowledge on the causal mechanisms that link network management to superior organizational performance. Similarly, research from the network structure perspective calls for further research to "study not only the performance implications of alliance portfolios from a structural perspective, but also examine in more detail firms' capabilities to actually manage their alliance portfolio" (Degener et al., 2018, p. 1389). Doing so, research could provide answers to the question of how firms can actively shape their position in inter-organizational networks and their relations to external partners in order to improve their innovation performance (Gulati et al., 2011).

Research gap 4: Focus on a limited set of network and resource types. Finally, the contextual scope of extant network research is unduly narrow (Gulati et al., 2011). As empirical literature mostly draws on the use of archival data (e.g. Phelps et al., 2012; Pittaway et al., 2004), studies tend to focus mainly on publicly documented types of networks and resource exchanges. Concerning the network and relationship types examined, this means that most research operationalizes network ties as formal contracts and alliances between two or more firms (e.g. Degener et al., 2018; Owen-Smith \& Powell, 2004; Rothaermel \& Deeds, 2006). While alliance networks are undoubtedly a highly relevant subtype of inter-organizational networks, this type of network is characterized by comparably high clarity in goal formulation, governance, and division of work between partners (Inkpen \& Tsang, 2005). Other types of networks that are also very important in the innovation context such as regional clusters (e.g. Bell, 2005) or industry associations (e.g. Dalziel, 2006) are mostly less structured and more informal. In such 
contexts, inter-firm collaboration does not necessarily require written formal agreements such as a business contract but may also result from informal exchange between organizational actors (McEvily, Soda, \& Tortoriello, 2014). Hence, I argue that a comprehensive theory of the effects of inter-organizational networks on innovation performance should acknowledge such substantial differences between different forms of inter-organizational networks, and formulate and test propositions that reflect the specific idiosyncrasies of different types of interorganizational relationships.

Concerning the types of network resources examined, a large share of empirical studies relies on patent data to represent exchanges of resources and expertise between firms (Brenner, 2007). Due to this form of operationalization, most empirical studies "recognize innovation networks [...] on the base of the exchange of technological knowledge" (Alberti \& Pizzurno, 2015, p. 264). Only few studies examined the exchange of other types of resources and expertise such as market knowledge and managerial knowledge (e.g. Alberti \& Pizzurno, 2015; Boschma \& Ter Wal, 2007; Sammarra \& Biggiero, 2008; Schulz, 2001; Tanriverdi \& Venkatraman, 2005). Still, those studies found that indeed, different types of knowledge such as technological, market, or managerial knowledge possess clearly different characteristics, are exchanged in different patterns, and provide firms with different benefits (Alberti \& Pizzurno, 2015, Sammarra \& Biggiero, 2008; Simonin, 1999b). The predominant focus on technological knowledge thus "overlooks the role of market and managerial knowledge in fostering the innovation process" (Sammarra \& Biggiero, 2008, p. 805). Consequently, further research on how different types of network resources (especially different types of knowledge) are exchanged and how different patterns of exchange relate to firms' innovative performance is required.

\subsection{Summary of Publications in Focus Area II}

Focus area II of this dissertation comprises three publications that address the research gaps outlined above. The publications are based on two survey datasets. Publications 3 and 4 draw on a quantitative survey of the member firms in the largest cluster network of German energy providers. Publication 3 thereby includes the first wave of survey (November 2015 till January 2016) and mainly draws on the sociometric part of the questionnaire that elicits data on the knowledge transfer relations between the cluster member firms and the structure of the intracluster knowledge network. Publication 4 furthermore includes the second wave of survey which was conducted between March and May 2016 to extend the research sample. Besides the sociometric part of the questionnaire, publication 4 mainly draws on the sections in the questionnaire that employ item-based measures to capture network management activities in the respondent firms. Publication 5 employs data from another survey of the 300 largest municipal utilities in Germany outside of the cluster network analyzed in publications 3 and 4. This additional survey was conducted in autumn 2016.

Publication 3 seeks to provide a more fine-grained examination of the multi-dimensional nature of knowledge exchange in inter-organizational networks. This publication specifically addresses research gap 4. Publication 4 aims to build a conceptual bridge between literature on the basis of the structural perspective on inter-organizational networks that explains the effects 
of network characteristics and literature on the basis of the managerial perspective that explains the effects of firm-level network management capabilities. To this end, a mediation model is proposed that explains how network management capabilities help firms to improve their networks of knowledge exchange relations inside an industry cluster and how in turn the network mediates the effect of network management on product innovation performance. This paper tackles the research gaps 3 and 4 outlined above. Finally, publication 5 examines the interplay between different network and firm characteristics in determining innovation performance by developing a configurational model and testing the model via fsQCA. Therefore, this paper addresses research gaps 1 and 2. Figures 16, 17, and 18 provide an overview on research questions, theoretical foundations, methodology, and the results for each of the three publications in focus area II.

Publication 3: Innovation networks in the German energy industry - An empirical analysis of inter-organizational knowledge transfer. Being confronted with a number of external challenges, such as liberalization, decarbonization, decentralization, and digitalization (e.g. Bhattacharyya, 2007; Dusonchet \& Telaretti, 2010; Müller, Steinert, \& Teufel, 2008), especially smaller firms in the energy sector such as municipal utilities increasingly deploy various forms of inter-firm collaboration and engage in knowledge exchange with industry peers (Jacobsson \& Bergek, 2004). Thereby, innovation in the energy industry goes beyond the mere development of novel technologies and largely involves the creation of novel business models (Richter, 2013). As a consequence, utilities cannot just rely on exchanging technological expertise, but must also engage in the transfer of other forms of knowledge such as market, managerial, or regulatory knowledge (e.g. Edwards, 2008; Horbach, Rammer, \& Rennings, 2012; Kolloch \& Golker, 2016). However, to this point research literature does not provide adequate explanations on how different types of knowledge are exchanged in interorganizational networks and on how firms can profit from acquiring different knowledge types from external partners (e.g. Alberti \& Pizzurno, 2015; Sammarra \& Biggiero, 2008).

Therefore, this paper examines and compares patterns of knowledge exchange on network-, dyad- and firm-level with regard to four types of knowledge (technological, market, managerial, regulatory) that is conducive to innovation in the energy sector. Drawing on network theory (Borgatti \& Halgin, 2011) and the knowledge-based view of the firm (Grant, 1996), we explore density, hierarchy, and multiplexity patterns based on data from 54 municipal utilities and 7 service intermediaries in the largest cluster network in the German energy industry. Furthermore, we test how the patterns of exchange affect firm-level outcomes by examining the effects of firms' propensity to form multiplex instead of uniplex ties as well as the composition of externally acquired knowledge concerning the four types on organizational innovativeness. Our findings indicate that there are clearly different exchange patterns for technological, market, managerial, and regulatory knowledge. Still, our findings also demonstrate that transfer relationships involving these four types of knowledge are interdependent displaying non-hierarchical relations of complementarity. Furthermore, the study provides evidence for the existence of "ideal profiles" with regard to the knowledge types that firms acquire. In particular, highly innovative firms tend to acquire less regulatory knowledge relative to the other three knowledge types. 
Publication 4: Management of knowledge networks in industry clusters and product innovation performance - Development and test of a mediation model. Research has demonstrated that industry clusters benefit innovation by providing a social infrastructure for mobilizing knowledge flows between member firms (e.g. Arikan, 2009; Bell, 2005; Boschma \& Ter Wal, 2007; Dhanaraj \& Parkhe, 2006). However, research also found that while some firms seem to gain considerable benefits from cluster membership and foster their own capacity for innovation, other companies fail to do so (e.g. Boschma, 2005; McCann \& Folta, 2011; Pouder \& St. John, 1996). One theoretical lens for explaining such differences is the strategic network perspective (e.g. Gulati et al., 1999; Gulati et al., 2011; Zaheer \& Bell, 2005). Extending the resource-based view of the firm, the strategic network perspective assumes that the structure, content, and quality of a firm's relationships and ties within an industry cluster network determine the firm's access to external resources (e.g. Boschma \& Ter Wal, 2007; McCann \& Folta, 2011; Owen-Smith \& Powell, 2004; Zhang \& Li, 2010; Zaheer \& Bell, 2005). However, up to this point due to the limiting assumption that inter-firm ties and network structures are exogeneous (Stuart \& Sorenson, 2007) research does not explain why some firms achieve to build a beneficial ego-network of knowledge sources in the cluster and others do not (e.g. Phelps et al., 2012; Rowley \& Baum, 2008; Salancik, 1995). 


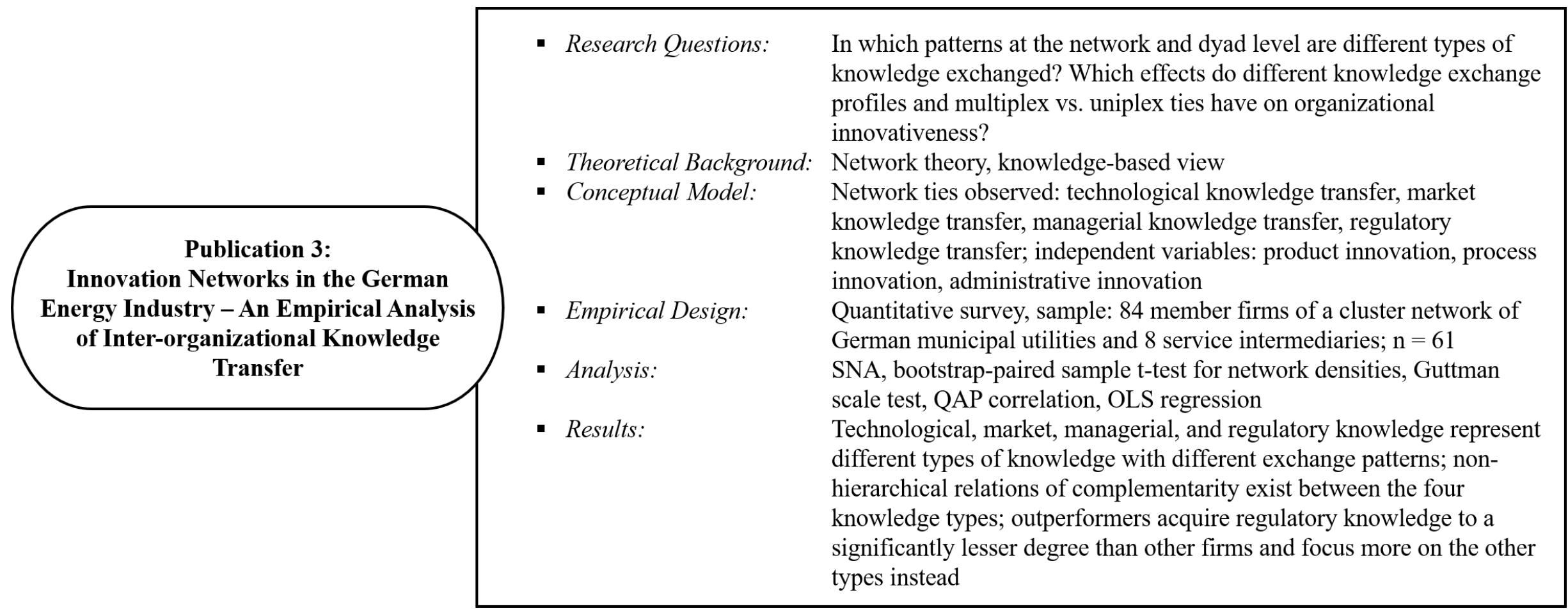

Figure I-16. Overview of publication 3 (own illustration) 


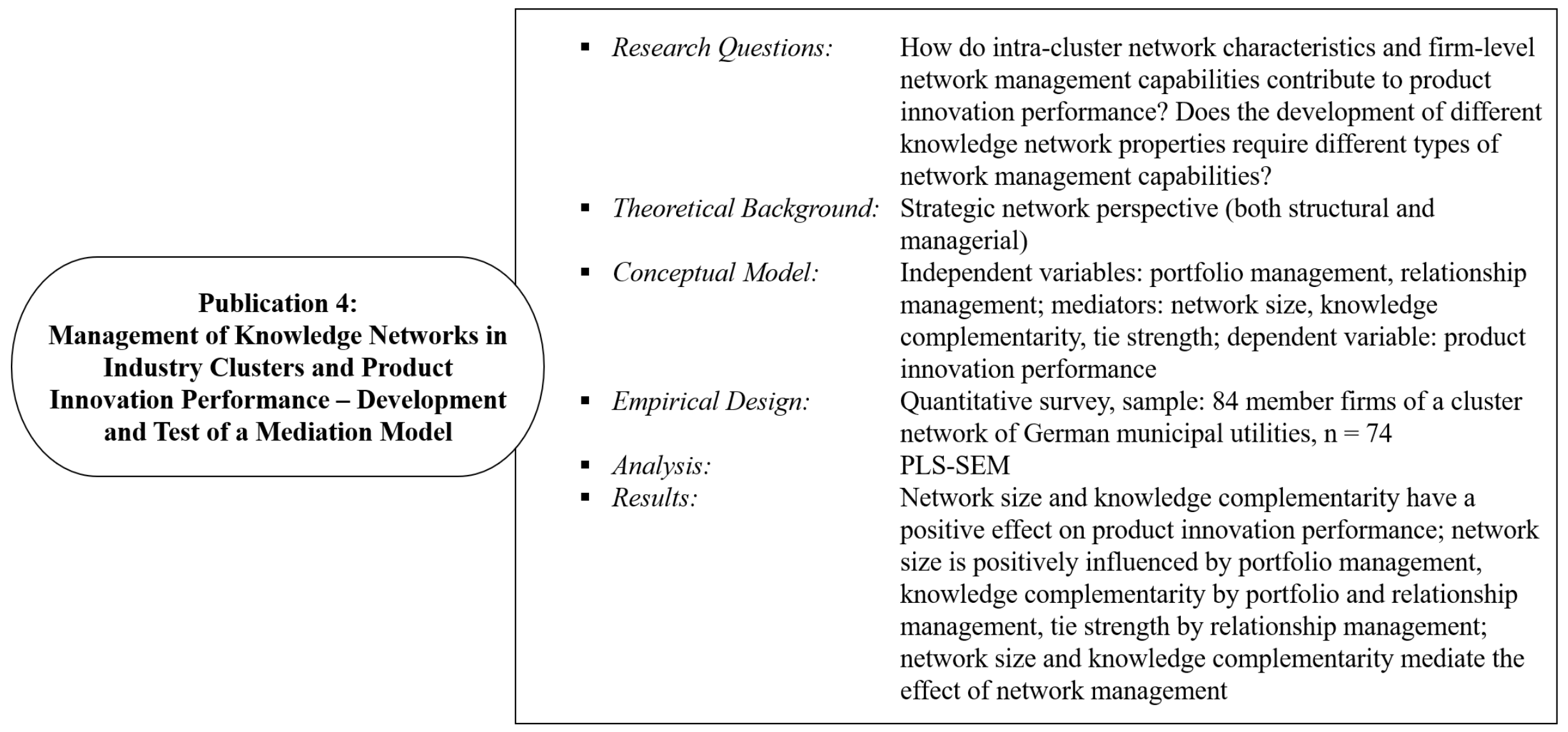

Figure I-17. Overview of publication 4 (own illustration) 
In this paper, we shed light on this important issue. To this end, we integrate two previously separate streams of literature within the inter-organizational network research: (1) the structural perspective that links resource benefits to network characteristics and has been the dominant theoretical perspective in most research on inter-organizational networks (e.g. Ahuja, 2000; Baum et al., 2000; McEvily \& Zaheer, 1999); (2) the managerial perspective that examines the network-related actions, routines, and processes of firms and has grown popular only recently (e.g. Anand \& Khanna, 2000; Lorenzoni \& Lipparini, 1999; Thornton et al., 2015; Vesalainen $\&$ Hakala, 2014). Based on these two streams of literature, we develop a mediation model that explains the effects of network characteristics and firm-level network management on the product innovation performance of cluster member firms. We test our propositions based on relational as well as traditional socio-empirical data from a cluster network in the German energy industry. As a result, we find that network characteristics mediate the positive effect of network management on product innovation performance. Hence, network management helps firms to improve the quality of their intra-cluster network. Moreover, we find that in order to achieve different types of network characteristics (structural, compositional, relational), network management capabilities on different levels of analysis are required (portfolio management, relationship management).

Publication 5: Firms' network profiles and product innovation performance - A configurational perspective. Among innovation scholars, there is broad agreement that the partner network of a firm is an essential source of valuable information, know-how, and skill, and thus an important enabler of innovation performance (e.g. Crossan \& Apaydin, 2010; Phelps et al., 2012; Pittaway et al., 2004). Consequently, research on firms' partner networks in the context of innovation management is quite extensive and the effects of various structural, relational, and compositional network characteristics on innovation performance have been examined (e.g. Ahuja, 2000; Baum et al., 2000; Fang, 2011; Rothaermel \& Hess, 2007; Stuart, 2000; Thornton et al., 2019; Zaheer \& Bell, 2005). However, most of those works at least implicitly follow the "independence assumption" (Gulati et al., 2011) by treating various network characteristics as independent determinants of innovation performance and not as "complex, multidimensional constellations of interrelated, complementary and mutually reinforcing attributes" (Zaefarian et al., 2013, p. 261). Therefore, research does not provide adequate insight on which combination of network characteristics fosters high innovation performance (Pullen et al., 2012).

Following research calls that advocate a perspective of "fit" on inter-organizational networks (e.g. Gulati et al., 2011; Phelps et al., 2012; Pittaway et al., 2004; Pullen et al., 2012; Wassmer, 2010; Zaefarian et al., 2013), this paper integrates the strategic network perspective (Gulati, 1999) and configuration theory (Meyer et al., 1993). Based on data from 93 municipal energy providers in Germany, we examine a configurational research model that combines five network characteristics (network size, partner innovativeness, partner complementarity, partner diversity, and tie strength) and two organizational characteristics (firm size, human capital). The results indicate that there are four "ideal" network profiles that explain high levels of product innovation performance: (1) a network with strong ties to partners with complementary resources, (2) a network with strong ties to highly innovative partners, (3) a large network 
composed of many complementary partners, and (4) a large network composed of many innovative partners. Furthermore, we demonstrate that those four networks are effective for different types of firms. While large firms benefit more from a broad-range network, small firms benefit more from strong relationships. While firms with high levels of internal human capital profit more from innovative partners, firms with rather low levels of human capital are better off with partners providing complementary resources. Based on those results, the paper contributes to the strategic network perspective, but also to broader theoretical streams like organizational learning and the resource-based view of the firm. 


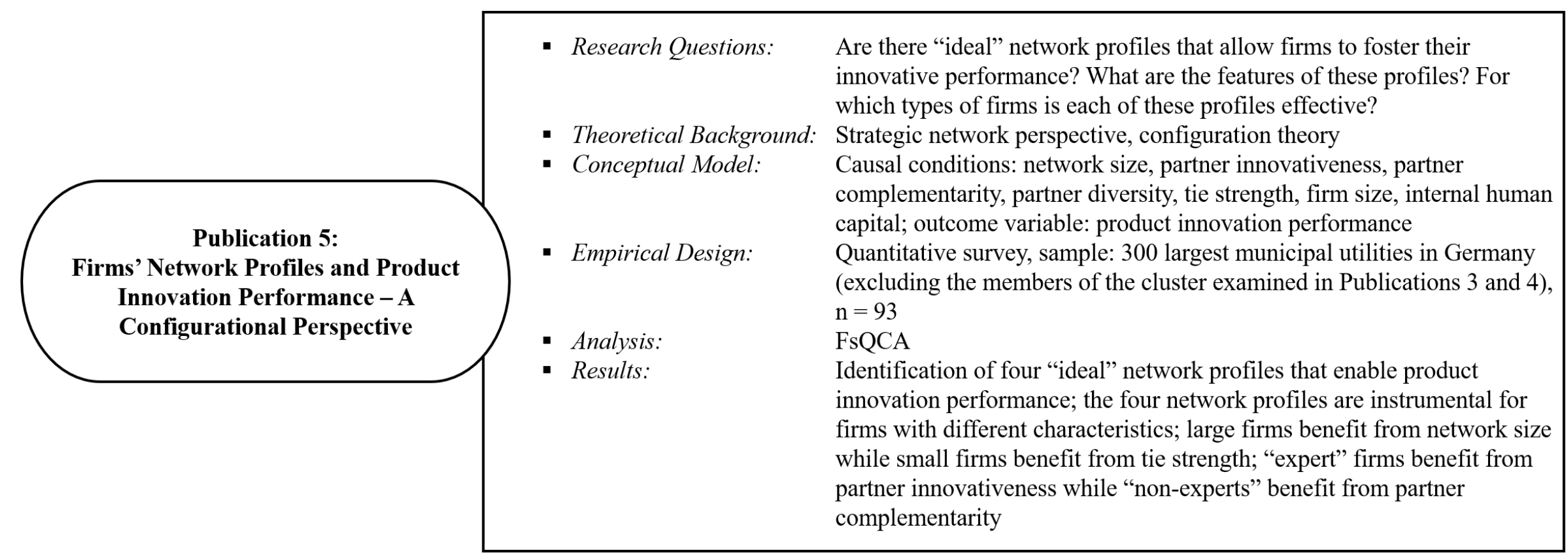

Figure I-18. Overview of publication 5 (own illustration) 


\section{Overall Structure of the Dissertation}

The chapter structure of this dissertation is outlined in Figure 19. As outlined above, the thesis comprises five publications, two in the focus area "Top Management and Leadership" (chapter II) and three in the focus area "Networks and External Partners" (chapter III). Besides the academic papers, the chapters II and III also include supplementary information on the journal submission, the authors involved, and the dataset employed. As academic journals have different style guidelines, the five publications apply the formatting and citation style required for the journal they were submitted to. Chapters II and III are framed by a synopsis consisting of prologue (chapter I) and epilogue (chapter IV). Those two chapters apply citation style proposed by the American Psychological Association (APA; 6th edition).

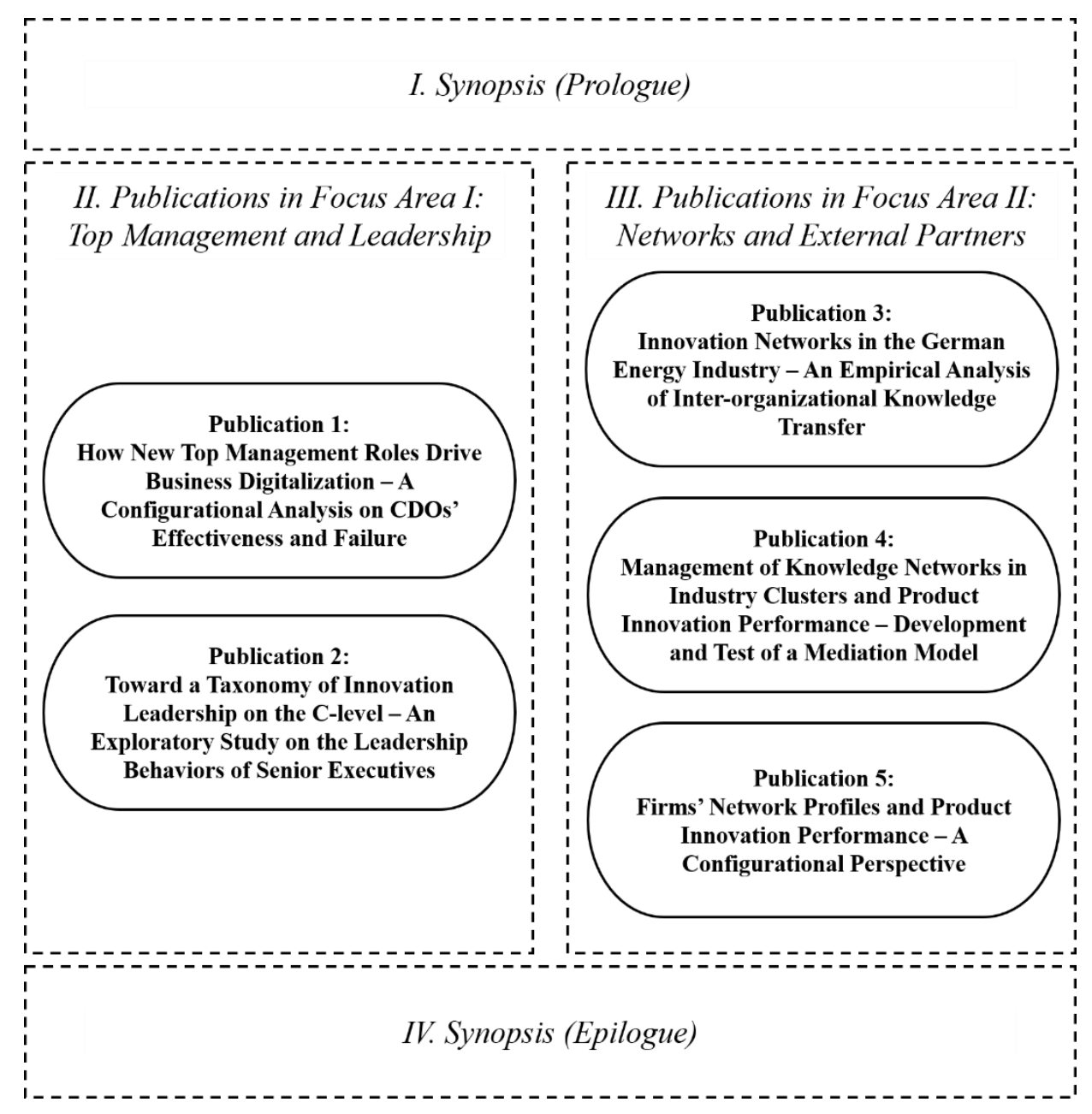

Figure I-19. Structure of the dissertation (own illustration) 
II. Publications in Focus Area I: Top Management and Leadership

II. Publications in Focus Area I: Top Management and Leadership 


\section{Publication 1: How New Top Management Roles Drive Business Digitalization - A Configurational Analysis on CDOs' Effectiveness and Failure}

\subsection{Note on Submitted Paper}

The following paper on "How New Top Management Roles Drive Business Digitalization A Configurational Analysis on CDOs' Effectiveness and Failure" was co-authored by my PhD supervisor Prof. Dr. Alexander Fliaster and myself. As corresponding author, I submitted the paper to a leading international academic journal (VHB: A; ABS: 4) where it is currently under review. Earlier versions of the paper were accepted for presentation at the 34th European Group for Organizational Studies (EGOS) Colloquium in Tallinn, Estonia (date of presentation: July $7^{\text {th }}, 2018$ ) as well as at the 78th Annual Meeting of the Academy of Management in Chicago, USA (date of presentation: August $14^{\text {th }}, 2018$ ) after double-blind peer-review processes. A practice-oriented summary of some of the paper's key findings with the title "Four profiles of successful digital executives" was submitted to the international academic journal MIT Sloan Management Review (VHB: C; ABS: 3), accepted for publication, and published in 2019.

Publication details:

Reck, F., \& Fliaster, A. (2019). Four profiles of successful digital executives. MIT Sloan Management Review, 60(3), 1-7.

https://sloanreview.mit.edu/article/four-profiles-of-successful-digital-executives/ 


\title{
1.2. Academic Paper
}

\begin{abstract}
Recently, the Chief Digital Officer (CDO) as a specific top management role in charge of digital transformation has attracted the interest of organization and management scholars. However, research fails to provide insights on when and why CDOs are effective in helping firms cope with challenges of the digital age. In this paper, we draw on configuration theory to explore CDOs' effectiveness as well as reasons for failure. In doing so, we link CDOs' skills, networks, and role behaviors in a comprehensive research framework and conduct a fuzzy-set Qualitative Comparative Analysis (fsQCA) on survey data from 211 CDOs. The results reveal four equifinal configurations that lead to high and three configurations that lead to low levels of business digitalization. Moreover, our results demonstrate that the effect of the particular configuration is contingent upon contextual factors, namely the competitive pressure towards digitalization and the CDO's strategic influence in the firm.
\end{abstract}

\section{Keywords}

Business digitalization, Chief Digital Officer, configuration theory, fsQCA, top management 


\section{Introduction}

From a corporate perspective, business digitalization entails a bulk of new challenges, such as the emergence of digital ecosystems and platform business models (e.g. Gawer \& Cusumano, 2014; Weill \& Woerner, 2015), increased competitive relevance of data and data analytics (e.g. George, Haas, \& Pentland, 2014; Iansiti \& Lakhani, 2014), and increased rates of innovation and environmental change (e.g. Arthur, 2009; Nambisan, Lyytinen, Majchrzak, \& Song, 2017). In attempt to tackle these challenges, various organizations have created a new top management role, designating a Chief Digital Officer (CDO) to drive business digitalization (Haffke, Kalgovas, \& Benlian, 2017). A recent study by the consultancy Strategy\& shows that across the 2,500 worldwide largest publicly listed companies in 2018 about $21 \%$ had already appointed a top-level executive whose main charge was to lead business digitalization at the corporate level; remarkably in the European subsample this number was even higher at 39\% (Péladeau, Acker, \& Müller, 2019).

By creating the CDO role, companies hope to develop a means to handle the inherent complexity of digital transformation. Digitalization often requires firms to adjust not only their products and services, but also their core logic of operating, as well as the corporate vision, norms, and cultural values (Bharadwaj, El Sawy, Pavlou, \& Venkatraman, 2013). CDOs are responsible for taking on this leadership task by coordinating, prioritizing, and implementing transformation initiatives across the company (Matt, Hess, \& Benlian, 2015). They are expected to act as connecting agents in order to establish digital technology on the strategic agenda of their firms and initiate digitalization initiatives in various fields (Singh \& Hess, 2017). Thus, the CDO is perceived as "transformer in chief" (Rickards, Smaje, \& Sohoni, 2015) who plays a decisive role in adjusting the company to the challenges of the digital age.

Despite the practical relevance of the CDO position, current research takes only first steps toward an understanding of "digital leadership". Past empirical studies have rather descriptively addressed CDOs' fields of action (Singh \& Hess, 2017), different archetypes of CDOs (Tumbas, Berente, \& vom Brocke, 2017), and the division of labor between the CDO and the Chief Information Officer (CIO) (Haffke, Kalgovas, \& Benlian 2016). However, much remains to be understood about when and why CDOs are effective in their task. As a result of the lack of empirical insight, business leaders, consultants, and executive education either praise CDOs as "new heroes" (Teerlink, Sigmon, Gow, \& Banerjee, 2014) or criticize the advent of CDOs as the creation of just "another organizational silo" (Sealey, 2015). For now, organization research falls short in delivering theoretically rigorous and empirically supported insights that explain whether and how this specific top management role helps companies cope with the challenges of digitalization.

To close this important research gap, our study seeks to illuminate the key characteristics that make an effective CDO, and on the flipside, the characteristics of CDOs that failed to achieve the objectives of business digitalization. Moreover, addressing these characteristics we aim to explain CDOs' effectiveness across different situational contexts, that is, whether the factors that determine effectiveness differ according to the contextual contingencies that a CDO faces in his/her managerial position. Thus, our interest is in "causal recipes" (Ragin, 2008), i.e., how 
the CDO's individual attributes (in particular, his/her skills, ego networks, and role behaviors) combine with each other and interact with the organizational context, that predict digital transformation as a firm-level performance outcome.

In doing so, we apply a configurational perspective (Misangyi, Greckhamer, Furnari, Fiss, Crilly, \& Aguilera, 2017) with the goal of developing a middle-range theory on CDOs' effectiveness in driving business digitalization. We first review current research literature on the role of CDOs and, more broadly, literature on upper echelons, especially functional top management team (TMT) members, and their impact on organizational strategy and firm-level outcomes. Second, we present the assumptions of configuration theory and integrate CDOs' skills, networks, behaviors, as well as positional and environmental context into a comprehensive research framework. Third, based on survey data from 211 CDOs, we use fuzzyset Qualitative Comparative Analysis (fsQCA) to unravel configurations that are sufficient for a firm's accomplishments in business digitalization as well as configurations associated with digitalization failure. Finally, we discuss our empirical results and their theoretical and managerial consequences and develop propositions to spur additional research.

By taking this approach, we contribute to research on both the organization of digitalization and top management roles. Concerning the former, we are able to identify four specific configurations of skills, networks, and behaviors of CDOs that contribute to successful business digitalization and three configurations that lead to failure. Concerning the latter, past research called for a theoretical perspective on top managers' contribution to organizational performance that goes beyond net effects of isolated variables (Busenbark, Krause, Boivie, \& Graffin, 2016; Lewellyn \& Fainshmidt, 2017). Our paper examines multifaceted configurations of variables related to functional executives and considers the interplay of these configurations with situational contingencies. Thus, we provide a more comprehensive explanation of top managers' positive and negative impact on firm-level outcomes. In doing so, we directly answer calls that outline the importance of further research on the question of "How do multiple contingencies (and their interactions) affect the benefits of functional TMT member presence?" (Menz, 2012, p. 68).

\section{Theoretical Background}

\section{The Chief Digital Officer as a new top management role}

The CDO is a functional manager who deals with the strategic and operational issues related to incorporating digital technologies in a firm's products, services, processes, and business models (Tumbas et al., 2017). Commonly, he/she oversees the development, refinement, and execution of the corporate digital strategy, the development of digital capabilities, and the necessary change management efforts (Haffke et al., 2016). By creating this new top management role, firms acknowledge that existing organizational departments often do not possess the capabilities to deal with digital technologies that "demand different mindsets and skill sets than previous waves of transformative technology" (Fitzgerald, Kruschwitz, Bonnet, \& Welch, 2014, p. 6). 
In sum, the task of the CDO is integrative, transformational, and strategic (Yoo, Boland, Lyytinen, \& Majchrzak, 2012). First, implementing digital technologies for business applications affects various functional areas like sales, finance, production, and HR (Matt et al., 2015). This implies the need for an effective launch and coordination of transformation initiatives across the boundaries of organizational units and connect them to an organization's business model. Second, firms from traditionally non-digital industries must master a transformation journey that may alter their fundamental values and worldviews (Fitzgerald et al., 2014). Rather than a mere improvement of the existing business logics via digital technologies, CDOs must initiate a profound process of organizational innovation entailing radically changed structures and procedures (Yoo et al., 2012). Third, with regard to their ultimate objectives, CDOs cannot confine themselves just to introducing digital technologies, but have to focus on economic performance outcomes in the form of increased revenues and profits or lowered costs (McDonald \& Rowsell-Jones, 2012).

\section{Determinants of CDOs' effectiveness}

In order to be effective in his/her role, the CDO must foster business digitalization in the firm. Often used interchangeably with the term "digital transformation" (Haffke et al., 2016), business digitalization describes the use of current and emergent information technologies, such as data analytics and artificial intelligence with the aim of enabling major business improvements like better fulfillment of customer needs or more efficient operations (Fitzgerald et al., 2014). The term comprises the establishment of digitized sales and communication channels, the augmentation of existing physical products or services by digitized offerings, and the automation of internal processes, among others (Bharadwaj et al., 2013).

As previous research on the top management role of the CDO is scarce, we base our considerations on the tenets of the upper echelon theory (Hambrick \& Mason, 1984). This research stream assumes that due to their hierarchical power, top-level executives represent the appropriate unit of analysis for examining the emergence of organizational outcomes (Hambrick, 2007), especially transformational and strategic change (Helfat \& Martin, 2015). Previous studies revealed that functional TMT members, defined as "senior executives in the TMT responsible for one or more functional areas in their organizations" (Menz, 2012, p. 46), play a key role in strategic decision-making and thus considerably determine the direction of a firm's future development and its competitive performance (Hambrick \& Cannella, 2004; Marcel, 2009; Menz \& Scheef, 2014). Past studies within this literature stream investigated the effects of a broad variety of variables related to top managers and their immediate social environment (see Bromiley \& Rau (2016), Helfat \& Martin (2015), Menz (2012) for overviews).

Based on previous studies, we argue first that the effectiveness of a CDO with regard to business digitalization is particularly affected by six key factors that refer to the CDO as an actor. These factors that we describe below represent the skills, ego networks, and role behaviors of a CDO. Second, we theorize that the impact of these personal characteristics of the CDO is likely to be contingent upon the situational context in which the CDO is embedded, namely external 
competitive pressure for digitalization and CDOs' influence in their organizations (Haffke et al., 2016; Haffke et al, 2017; Singh \& Hess, 2017).

Skill component: strategic IT knowledge. First, past research has shown that deep expertise, i.e., experience, skills, and knowledge (Hoffman \& Hegarty, 1993) in the own functional area can have a positive influence on TMT members' effectiveness. Such functional expertise represents a key intellectual resource on which a top manager can draw in order to make strategic plans and evaluate and select management initiatives (Garms \& Engelen, 2019). In line with this, previous works on chief strategy officers (CSOs; Angwin, Paroutis, \& Mitson, 2009), chief technology officers (CTOs; Medcof, 2008), and chief information officers (CIOs; Smaltz, Sambamurthy, \& Agarwal, 2006) outlined the importance of function-related skills and knowledge. Taking into account the role of the $\mathrm{CDO}$, our conceptualization of functional expertise should reflect his/her knowledge on digital technologies as well as on business opportunities that emerge from technology applications (Singh \& Hess, 2017). Hence, we argue that a CDO's functional expertise is represented by his/her strategic IT knowledge, i.e., his/her awareness and understanding of current and emergent information technologies and how to use them to increase the firm's competitive capability, nurture its business strategies and achieve economically valuable outcomes (Armstrong \& Sambamurthy, 1999; Sambamurthy, Bharadwaj, \& Grover, 2003; Smaltz et al., 2006).

Skill component: political skills. Besides strategic IT knowledge, we expect political skills to be a valuable asset for CDOs. Political skills reflect the ability to sell and negotiate issues, to persuade others, and to influence their decisions and actions (Ferris et al., 2005; Hambrick \& Mason, 1984). Previous research has indicated that in order to be effective, functional TMT members need to collaborate with other key decision makers in the firm - particularly when their position is new and legitimacy is not fully established yet (Menz, 2012). Accordingly, previous works found interpersonal skills to be essential across different functional TMT positions (Angwin et al., 2009; Feeny, Edwards, \& Simpson, 1992; Knight \& Paroutis, 2017; Medcof, 2008). For CDOs, such skills are also likely to be of high relevance, especially in catalyzing transformational change and educating other organizational members about digital technologies (Singh \& Hess, 2017; Tumbas et al., 2017).

Network component: internal network. Besides his/her skills, the value of a top manager for the respective company lies in his/her social connections (Cao, Maruping, \& Takeuchi, 2006). Adopting a social capital perspective (Nahapiet \& Ghoshal, 1998), previous research demonstrated that social relations are highly relevant assets as they provide executives with information and support. Thereby, literature distinguishes between top managers' internal network and external network (Cao et al., 2006; Collins \& Clark, 2003; Heyden et al., 2013). The internal network represents a top managers' ties to other c-level executives, middle managers, and employees within the organization (Cao, Simsek, \& Janssen, 2015). Previous research on CIOs, for instance, has demonstrated the importance of internal networks for ensuring the performance of the IT function (Feeny et al., 1992; Johnson \& Lederer, 2005; Karahanna \& Preston, 2013). Applied to our study, we assume that personal interactions within the firm, across organizational functions and hierarchical levels, provide a CDO with access to key experts, internal stakeholders, and decision-makers (Heyden et al., 2013). On the one hand, 
this may benefit the CDO as he/she can draw on a broader range of different perspectives when formulating a digital strategy and initiating digitalization initiatives (Haffke et al., 2017; Saldanha \& Krishnan, 2011). On the other hand, the internal network may help recognize and localize potential resistance for business digitalization across the organization, so that the CDO might be able to anticipate barriers for transformation efforts and develop appropriate countermeasures (Singh \& Hess, 2017; Tumbas et al., 2017). Thus, we argue that the CDO's internal network is likely to influence his/her effectiveness.

Network component: external network. Beyond a CDO's personal interactions within the firm, also his/her external network might determine his/her impact on organizational outcomes. A top manager's external ties serve as conduits for novel information, best practices, or customer preferences (Alexiev, Janssen, van den Bosch, \& Volberda, 2010; Cao et al., 2015; Collins \& Clark, 2003). While the research on external relationships of functional TMT members is still scarce (Menz, 2012), studies on CEOs demonstrate that external ties significantly affect the quality of top managers' decisions and ultimately the performance of the firm (Cao et al., 2006; Cao et al., 2015; Geletkanycz \& Hambrick, 1997). Transferring this insight to the context of CDOs, we argue that a large network of external contacts, such as customers, suppliers, competitors, or service providers is also likely to benefit CDO's awareness of novel digital technologies (Alexiev et al., 2010; Cao et al., 2015) and his/her ability to explore emerging business opportunities (Cao et al., 2015; Hargadon \& Sutton, 1997).

Behavioral component: innovative role behavior. Research on top management found that firmlevel outcomes are influenced by how top managers exert their managerial role, i.e., by their behaviors and actions (Carpenter, Geletkanycz, \& Sanders, 2004; Gottschalk, 1999; Grover, Jeong, Kettinger, \& Lee, 1993; Smaltz et al., 2006). We argue that due to the innovative character of digital transformation, role behaviors that are related to innovation and change management are most likely to affect CDOs' effectiveness (Haffke et al., 2016; Matt et al., 2015; Rickards et al., 2015). Such innovative role behavior includes the range of activities from starting an innovative effort to commercializing the innovative output (Makri \& Scandura, 2010; Yadav, Prabhu, \& Chandy, 2007). Hence, top managers exert innovative role behavior when they actively search for new ideas and useful solutions to business problems (Li, Magitti, Smith, Tesluk, \& Katila, 2013), select new technologies and market opportunities to explore (Gerstner, König, Enders, \& Hambrick, 2013), engage in the development of concepts and prototypes (Deschamps, 2008), and champion the implementation of developed solutions (Howell \& Boies, 2004). Accordingly, a CDO can be termed as innovation leader if he/she actively and directly takes part in the major digital transformation initiatives, plays a key role in selecting and implementing new ideas, and designs a clear strategic roadmap for the future development of the firm (e.g. Haffke et al., 2016; Haffke et al., 2017; Matt et al., 2015; Tumbas et al., 2017).

Behavioral component: supportive role behavior. In addition, CDOs might also effectively contribute to digitalization by taking a more indirect role and acting as enablers rather than "authors" of digital transformation (Singh \& Hess, 2017; Tumbas et al., 2017). In other words, rather than personally generating and implementing organizational change initiatives, the CDO might foster digitalization by creating an innovation-friendly work environment for other 
organizational change agents (Makri \& Scandura, 2010; Deschamps, 2008). Core activities that refer to this supportive role behavior are, for instance, encouragement and social support of innovators (Mumford, Scott, Gaddis, \& Strange, 2002), establishing communication links between innovating employees and key decision-makers (Makri \& Scandura, 2010), promoting transformation projects to stakeholders inside and outside the firm (Knight \& Paroutis, 2017), securing and allocating resources and manpower (Gottschalk, 1999), giving advice and feedback (Watts \& Henderson, 2006), and helping innovators align their efforts to the broader company strategy (Rost, Hölzle, \& Gemünden, 2007). We argue that besides being directly involved in digitalization initiatives, these supportive activities represent another option for the CDO to exert considerable influence on the accomplishment of digitalization.

Environmental context: competitive pressure. Pressure for digitalization may stem from increased competition because of new market entrants (Iansiti \& Lakhani, 2014), technological progress and changing customer demands (Nambisan et al., 2017), or competitors' investment in digital technologies (Haffke et al., 2016). Research has found that competitive pressure on the functional area of a top manager affects how other actors in the firm evaluate his/her leadership efforts and how willing they are to accept his/her influence on core strategic decisions (Kearns \& Sabherwal, 2007; Medcof, 2008). In the context of business digitalization, studies have shown that the strength of pressure influences an organization's attention and positivity towards digital transformation (Andersen et al., 2016). Hence, we assume that lowand high-pressure contexts might demand for different skills, networks, and role behaviors (Yukl, 2012). The effects of these variables are thus likely to be influenced by the level of competitive pressure for digitalization.

Positional context: hierarchical influence of CDO. The CDO's influence that we define as his/her involvement in strategic decisions and authority over resources (Singh \& Hess, 2017) is the second contextual factor that we include in the theoretical framework. Research on other functional executives has found that the hierarchical influence a manager possesses is positively associated with the impact that the manager has on organizational outcomes (Smaltz et al., 2006). The stronger hierarchical power, the more directly a top manager can influence the strategic course of his/her firm; the weaker the power, the more he/she must interact with other decision-makers for achieving outcomes on the firm-level (Garms \& Engelen, 2019; Greve \& Mitsuhashi, 2007; Medcof, 2008). In line with this, we expect the hierarchical influence of CDOs to be an important contextual variable for determining their effectiveness in their managerial role as digital leaders.

\section{Toward a configurational perspective on CDOs' effectiveness}

Past research has mainly addressed the above factors as independent predictors of functional TMT members' effectiveness. However, top management scholars increasingly call for an approach that allows for exploring complex interplays between these variables (e.g. Bromiley \& Rau, 2016; Busenbark et al., 2016; Helfat \& Martin, 2015; Lewellyn \& Fainshmidt, 2017). The configurational perspective is well suited to depict such causal complexity (Misangyi et al., 2017) as the main assumption of configurational theory is that "parts of a social entity take 
their meaning from the whole and cannot be understood in isolation" (Meyer, Tsui, \& Hinings, 1993, p. 1178).

Following this line of reasoning, we argue that the effectiveness of a CDO depends on his/her skills, networks, and behaviors in conjunction. For example, we assume that a CDO who is very busy designing several digital innovation activities might bring no economic benefits or even harm the company, if this CDO does not possess adequate technical or business-related knowledge. On the contrary, this particular CDO may deliver a more positive contribution to digitalization being focused on supportive role behavior and creating better, innovation-friendly work conditions for actual digitalization experts. Hence, when trying to explain the CDOs' effectiveness it is likely that "variables found to be causally related in one configuration may be unrelated or even inversely related in another" (Meyer et al., 1993, p. 1178).

In the configurational theory, theoretical propositions are formulated as "causal recipes" capturing overall configurations of factors that predict an outcome of interest (Misangyi et al., 2017). Those recipes may be equifinal, i.e., different configurations may lead to similar positive or negative outcomes (Fiss, 2011). For instance, in most managerial tasks there is no single recipe for success but a number of ways to reach a goal at hand (Ketchen, Thomas, \& Snow, 1993). Moreover, causal recipes allow for causal asymmetry, which means that if a configuration predicts the presence of an outcome the negation of this configuration does not necessarily predict the absence of this outcome (Fiss, 2011; Ragin, 2008).

We argue that a configurational perspective is well suited to improve existing theories on top managers' impact on organizational outcomes by providing a holistic spot on causation and helping to overcome theoretical fragmentation (Busenbark et al., 2016; Misangyi \& Acharya, 2014). To this end, we develop a theoretical framework that serves as a basis for guiding empirical data collection as well as the further elaboration of the theory (Greckhamer, Furnari, Fiss, \& Aguilera, 2018). This framework must comprise the most relevant causal conditions for the outcome of interest (i.e., accomplishments of business digitalization), be exhaustive in terms of covering the major facets of the research topic at hand and parsimonious enough to allow for meaningful interpretation (Wagemann \& Schneider, 2010).

In this theoretical framework, we include the variables described above: strategic IT knowledge, political skills, internal network, external network, innovation role behavior, supportive role behavior, competitive pressure, and hierarchical influence of the CDO. We argue that taken together, the skills, networks, and change-related role behaviors build an adequately exhaustive profile of the factors that might determine a CDO's effectiveness as well as the causal mechanisms that may be at play (Busenbark et al., 2016). Furthermore, we consider these profile-shaping factors to be mutually exclusive as each of them covers clearly different aspects concerning the abilities, personal resources, and behaviors of a top manager (Menz, 2012; Yukl, 2012). The interdependent nature of these variables is depicted in the center of Figure 1. Furthermore, the research framework includes two variables that describe the positional and environmental context in which the CDO operates. This allows us to examine whether certain configurations of skills, networks, and behaviors are instrumental for different contexts, and 
control for contingency effects that might enhance or diminish the effectiveness of a certain type of CDO.

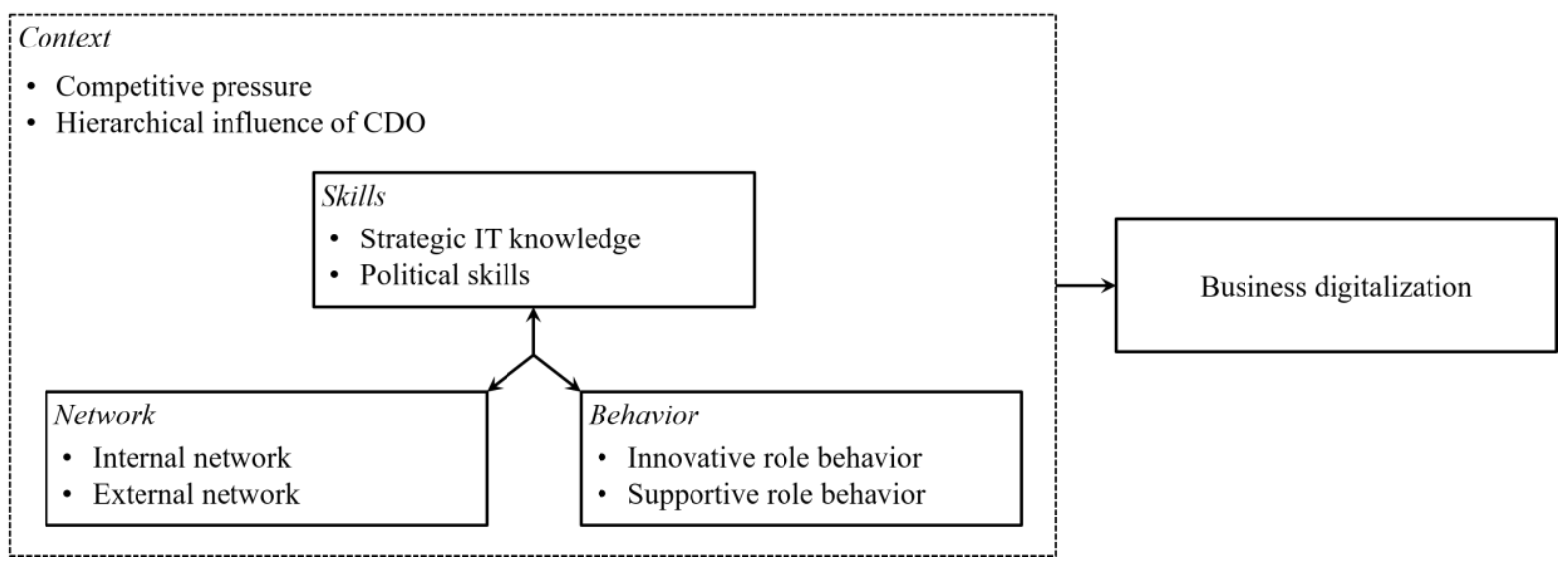

Figure II-1-1. Research framework (own illustration)

\section{Methodology}

\section{Sample and data collection}

To collect data, we conducted a quantitative survey of executives from manufacturing firms in Germany, Austria and Switzerland. Thereby, we randomly drew a sample of 1,500 firms from the industry register on "Wer liefert was", a database of over 540,000 firms from these three countries. To determine the top executive that leads digital transformation in the firm, we followed a comprehensive multi-step approach. First, we manually scanned the company pages in the business network XING for contacts who occupy a position in the ranks of vice presidents, directors or top management and describe their task content as "digital transformation", "digitalization", "digital business models", or similar. Second, we searched company websites for the presentation of top management. Third, we scanned press releases and annual reports for topics related to business digitalization looking for top managers mentioned or quoted in these publications. Fourth, in case that the previous steps did yield no or more than one potential contact, we reached out to the company via e-mail or telephone and asked for the manager in authority of digital transformation. In the process, we were able to identify $834 \mathrm{CDOs}$ to whom we mailed an invitation with a link to the online questionnaire.

In total, we received 227 completed questionnaires. In order to assure that the respondents actually assume the role of a CDO we used three verification questions: 1) the respondent had to confirm that he/she was the person responsible for the firm's digital transformation; 2) the respondent had to indicate his/her level of hierarchy in the firm and be positioned within the top three levels; and 3) the respondent had to name the title of his/her position which we checked for plausibility. In addition, the respondent had to be in the position of the CDO for at least one year in order to ensure that differences in business digitalization could be attributed to his/her presence. In this process, we had to exclude 16 respondents who did not meet the above criteria. Ultimately, 211 questionnaires were usable, yielding an effective response rate of $25.3 \%$. We 
tested for non-respondent bias by comparing early and late respondents for differences in the study variables (Armstrong \& Overton, 1977). There were no significant differences. The respondents had a mean age of 43.4 years and 6.8 years of tenure in their position. With respect to firm size, 83 of the CDOs in the final sample came from firms with 30-99 employees $(39.3 \%)$, 59 from firms with 100-499 employees (28.0\%), 59 from firms with 500-4999 employees (28.0\%), and 10 from firms with 5000 or more employees $(4.7 \%)$. The industry sectors that were most present in our sample were machinery (45.0\%), automotive (23.7\%), and electric equipment (19.9\%).

\section{Measurement}

Except for the network measures, data on all research variables were collected via multiple items that were rated on seven-point Likert scales ranging from $1=$ "completely disagree" to 7 = "completely agree". The formulation of the measurement items followed previous works. The questionnaire was pretested and discussed with both managers and academics. Our outcome variable that reflects business digitalization accomplishment was created analogously to previous studies on technology adoption and deployment (e.g. Brown \& Svenson, 1988; Gerstner et al., 2013; Lenox \& King, 2004; Yadav et al., 2007) and reflected the successful adoption, implementation, and commercialization of contemporary digital technologies in the firm. The measurement scale comprised five items. Competitive pressure was measured by three items based on Andersen et al. (2016) and Haffke et al. (2016). Hierarchical influence of $C D O$ used three items based on Spreitzer (1995). Our measure of strategic IT knowledge encompassed four items adapted from Smaltz et al. (2006). Political skills used a shortened version (six items) of Ferris et al.'s (2005) scale. The measurement scale for innovative role behavior followed Scott and Bruce (1994) containing seven items. Finally, a six-item scale for supportive role behavior was created based on Watts and Henderson (2006) and Gottschalk (1999). Table 1 depicts construct means, standard deviations and correlations; Tables 2, 3, and 4 summarize the items used.

Table II-1-1. Means, standard deviations, and correlations

\begin{tabular}{|c|c|c|c|c|c|c|c|c|c|c|}
\hline Variable & Mean & S. D. & 1 & 2 & 3 & 4 & 5 & 6 & 7 & 8 \\
\hline 1. Business digitalization & 4.02 & 1.36 & & & & & & & & \\
\hline 2. Competitive pressure & 4.38 & 1.47 & $.16^{*}$ & & & & & & & \\
\hline 3. Hierarchical influence of CDO & 4.21 & 1.49 & $.21^{* *}$ & -.01 & & & & & & \\
\hline 4. Strategic IT knowledge & 4.62 & 1.31 & $.23^{* *}$ & $.15^{*}$ & -.06 & & & & & \\
\hline 5. Political skills & 4.19 & 1.34 & $.31 * * *$ & .00 & .02 & -.08 & & & & \\
\hline 6. Internal network & 4.33 & 2.60 & $.36^{* * *}$ & -.04 & .12 & $.14 *$ & $.27 * * *$ & & & \\
\hline 7. External network & 5.55 & 4.09 & $.24^{* *}$ & -.03 & $.21^{* *}$ & .08 & $.21 * *$ & -.12 & & \\
\hline 8. Innovative role behavior & 4.25 & 1.42 & $.33^{* * *}$ & .08 & $.29 * * *$ & $.29 * * *$ & .03 & .07 & $.29 * * *$ & \\
\hline 9. Supportive role behavior & 4.08 & 1.32 & $.22 * *$ & -.03 & .10 & .01 & $.18^{* *}$ & .09 & .02 & -.01 \\
\hline
\end{tabular}


Table II-1-2. Construct specifications and item loadings

\begin{tabular}{|c|c|c|c|c|}
\hline & Item & Load & Mean & S.D. \\
\hline \multirow{5}{*}{$\begin{array}{l}\text { Business } \\
\text { digitalization } \\
(\alpha=.89 \\
\mathrm{CR}=.90 \\
\mathrm{AVE}=.64)\end{array}$} & $\begin{array}{l}\text { We started numerous initiatives and innovation projects for digitizing our products, processes and } \\
\text { business models. }\end{array}$ & .705 & 4.32 & 1.62 \\
\hline & $\begin{array}{l}\text { We use external growth strategies concerning digitization, e.g. acquisitions, joint ventures, or } \\
\text { patent licencing. }\end{array}$ & .747 & 3.82 & 1.60 \\
\hline & Digital products and services account for a large share of our sales. & .832 & 4.00 & 1.58 \\
\hline & $\begin{array}{l}\text { We considerably improved the effectiveness and efficiency of our internal processes through the } \\
\text { application of digital technologies. }\end{array}$ & .852 & 4.05 & 1.67 \\
\hline & Digital technologies highly benefit our operating results. & .857 & 3.91 & 1.62 \\
\hline \multirow{3}{*}{$\begin{array}{l}\text { Competitive } \\
\text { pressure } \\
(\alpha=.79 \\
\mathrm{CR}=.79 \\
\mathrm{AVE}=.56)\end{array}$} & Our direct competitors invest heavily in digital transformation initiatives. & .719 & 4.53 & 1.69 \\
\hline & Digital technologies threaten our revenues and profits. & .755 & 4.32 & 1.81 \\
\hline & $\begin{array}{l}\text { There is a considerable number of start-ups and new competitors entering our industry with new } \\
\text { digital offerings that are received well by the customer. }\end{array}$ & .771 & 4.29 & 1.74 \\
\hline Hierarchical & I am strongly involved in strategy formulation and selection. & .713 & 4.40 & 1.72 \\
\hline influence of CDO & I have a great deal of control over what happens in our company. & .769 & 4.20 & 1.85 \\
\hline $\begin{array}{l}(\alpha=.77 \\
\mathrm{CR}=.77 \\
\mathrm{AVE}=.53)\end{array}$ & I have a significant influence on decisions and activities in our company. & .693 & 4.01 & 1.86 \\
\hline
\end{tabular}

Note: $\alpha=$ Cronbach's $\alpha$; CR = composite reliability; AVE = average variance extracted. 
Table II-1-3. Construct specifications and item loadings (continued)

\begin{tabular}{|c|c|c|c|c|}
\hline & Item & Load & Mean & S.D. \\
\hline Strategic IT & I possess profound knowledge about the current and future value offerings of our firm. & .659 & 4.61 & 1.57 \\
\hline knowledge & I understand the core factors that determine our competitive capabilitites. & .663 & 4.47 & 1.60 \\
\hline $\begin{array}{l}(\alpha=.82 \\
\mathrm{CR}=.82\end{array}$ & $\begin{array}{l}\text { I have a good overview on new digital technologies and know how these might help our company } \\
\text { in the future. }\end{array}$ & .759 & 4.66 & 1.66 \\
\hline $\mathrm{AVE}=.59)$ & I have a clear plan on how our company should develop, acquire and deploy digital technologies. & .834 & 4.72 & 1.65 \\
\hline Political skills & I understand how to use my personal relationships for increasing my success at work. & .794 & 4.33 & 1.60 \\
\hline$(\alpha=.89$ & I continuously develop my network and excel in building trusting relationships fast. & .751 & 4.08 & 1.76 \\
\hline $\mathrm{CR}=.89$, & I keep track of my personal contacts and evaluate the value of my relationships regularly. & .735 & 4.14 & 1.72 \\
\hline \multirow[t]{3}{*}{$\mathrm{AVE}=.57)$} & I feel comfortable in the company of others. & .708 & 4.26 & 1.61 \\
\hline & I seem to instinctively know the right things to say to influence others. & .752 & 4.07 & 1.63 \\
\hline & I am able to quickly understand and correctly evaluate political or social situations. & .789 & 4.28 & 1.67 \\
\hline
\end{tabular}

Note: $\alpha=$ Cronbach's $\alpha$; $\mathrm{CR}=$ composite reliability; AVE = average variance extracted. 
Table II-1-4. Construct specifications and item loadings (continued)

\begin{tabular}{|c|c|c|c|c|}
\hline & Item & Load & Mean & S.D. \\
\hline \multirow{7}{*}{$\begin{array}{l}\text { Innovative role } \\
\text { behavior } \\
(\alpha=.93 \\
\mathrm{CR}=.93 \\
\mathrm{AVE}=.67)\end{array}$} & I identify potentials for improvement and generate new ideas. & .836 & 4.40 & 1.56 \\
\hline & I develop new solutions for current business problems. & .791 & 4.27 & 1.57 \\
\hline & $\begin{array}{l}\text { I actively search for new and useful information, technologies, and procedures that may be useful } \\
\text { for developing and improving solutions to business problems. }\end{array}$ & .834 & 4.30 & 1.78 \\
\hline & I mobilize support for my ideas. & .858 & 4.20 & 1.76 \\
\hline & I secure resources for the implementation of my ideas. & .812 & 4.10 & 1.68 \\
\hline & I look for ways of applying new ideas in our business. & .802 & 4.07 & 1.74 \\
\hline & I evaluate the usefulness of my ideas and improve them based on user feedback. & .798 & 4.41 & 1.64 \\
\hline \multirow{6}{*}{$\begin{array}{l}\text { Supportive } \\
\text { role behavior } \\
(\alpha=.88 \\
\mathrm{CR}=.88 \\
\mathrm{AVE}=.56)\end{array}$} & $\begin{array}{l}\text { I give advice to innovators based on my functional expertise and inform them on current } \\
\text { developments and politics in the firm. }\end{array}$ & .802 & 4.15 & 1.60 \\
\hline & $\begin{array}{l}\text { I help in composing project teams for the development of new concepts and solutions and for the } \\
\text { implementation of novel ideas. }\end{array}$ & .712 & 4.19 & 1.69 \\
\hline & $\begin{array}{l}\text { I evaluate the quality and usefulness of project resources and help to gather further ones if } \\
\text { necessary. }\end{array}$ & .710 & 4.06 & 1.64 \\
\hline & $\begin{array}{l}\text { I help innovators in putting their ideas in the broader organizational context and thus realizing and } \\
\text { improving the value potential from said ideas. }\end{array}$ & .695 & 4.04 & 1.63 \\
\hline & $\begin{array}{l}\text { I monitor the progress of projects, evaluate the quality of work results, set schedules and provide } \\
\text { suggestions for improvements. }\end{array}$ & .749 & 3.99 & 1.76 \\
\hline & $\begin{array}{l}\text { I support innovators in communicating and implementing their ideas, establish contact between } \\
\text { innovators and decision makers and try to persuade important stakeholders }\end{array}$ & .810 & 4.08 & 1.68 \\
\hline
\end{tabular}

Note: $\alpha=$ Cronbach's $\alpha$; $\mathrm{CR}=$ composite reliability; $\mathrm{AVE}=$ average variance extracted. 
In order to measure CDOs' internal and external networks, we followed Cao et al. (2015) and asked the respondents to report the number of individuals in each of the categories described below with whom they interacted within the last year for work-related information and advice. The variable internal network referred to the CDO's ties across departments or functional units within the company. We followed previous research in operationalizing this variable as the product between the total number of intra-firm ties and the diversity of ties. We asked CDOs to identify the number of contacts they had in the following five groups: "employees in own department", "middle managers in own departments", "managers and employees in other departments", "top management", "board of directors". Diversity of ties was calculated using Blau's (1977) index of diversity. The measure for external network was calculated analogously. Here, CDOs assigned ties to seven groups: "customers", "suppliers", "competitors", "government and administrative agencies", "consultants and service providers", "research institutes", "companies from other industries". For both networks, we followed Cao et al. (2015) in adjusting the number of ties by the square root of the firm's size.

We used conventional methods to validate our measurement instrument. Cronbach's alpha, composite reliability, average variance extracted as well as all factor loadings were above the required thresholds (Bagozzi \& Yi, 1988). Confirmatory factor analysis in AMOS indicates a good fit of our measurement model $\left(\chi^{2} / d f=1.16, p<0.01, R M S E A=0.028, C F I=0.98, N N F I\right.$ $=0.97, S R M S R=0.047, A G F I=0.83)$. Discriminant validity was assessed via the criterion by Fornell and Larcker (1981). AVE of each latent variable is greater than the squared correlation between the concerned and the other constructs, so that discriminant validity can be stated. Finally, we conducted Harman's one-factor test to examine the common-method bias (Podsakoff, MacKenzie, Lee, \& Podsakoff, 2003). The unrotated factor solution resulted in seven factors explaining $67.0 \%$ of the variance $(20.2 \%$ was the largest variance explained by one factor). Thus, we are confident that common method bias is unlikely to be a problem.

As our outcome variable business digitalization is measured via self-report, there might be several potential respondent biases, including CDOs' over- or underestimation of the firm's accomplishments. In order to control for this bias, we sent an additional questionnaire to the CEOs of each respondent's firm and asked them to rate the firm's business digitalization accomplishments on the scales explained above. In the process, we received 143 responses, so that for $67.7 \%$ of our research cases, two independent ratings of business digitalization have been obtained. Based on this, we computed inter-rater agreement by following the procedure described by Kotha and Vadlamani (1995) and Schilke and Goerzen (2010). First, we calculated the share of item ratings on which both managers were within one interval or less on the Likert scale. Both respondents agreed in $75.2 \%$ of the ratings. Second, we calculated the Pearson correlation across the questionnaire items for each pair of respondents. Mean correlation across all pairs was .64 $(p<.01)$. In all, there was high agreement between CDOs and CEOs on the variable business digitalization so that we are confident in the validity of the CDOs' self-report.

\section{Set-theoretic analysis}

In order to extract configurations leading to high levels of business digitalization, we applied fsQCA methodology - a set-theoretic method of analysis that treats cases as combinations of 
causal conditions and outcomes (Meuer, 2014). All steps of configurational analysis were done in fsQCA software version 3.0 (Ragin \& Davey, 2016). In contrast to regression analysis and other variance-based approaches that prevail in management science, fsQCA conducts a Boolean analysis procedure for identifying high- and low-performing configurations (Ragin, 2008). In this procedure, the empirical values of research variables are not treated as absolute numbers, but as an indicator of set membership (e.g. if a given CDO is a member in the set of CDOs with high levels of strategic IT knowledge or not). By linking the membership of cases in sets of causal conditions to their membership in the outcome set, it can be assessed if configurations of causal conditions are necessary and/or sufficient causes for said outcome (Fiss, 2011; Ragin, 2008). In order to do so, the fsQCA procedure encompasses three-steps that are described in detail: calibration, truth table refinement and truth table analysis.

Calibration. We followed calibration guidelines for survey measurement for all our multi-item scales (Misangyi \& Archarya, 2014). In doing so, we used the minimum, midpoint and maximum of the seven-point Likert scale as anchors for calibration $(1=$ full non-membership; 4 = cross-over point; 7 = full membership). Based on these anchors, we used the formula by Fiss (2011) to assign fuzzy membership scores to each research case for each research variable.

For our network variables, the absence of comparable benchmarks for CDO networks prohibited such an approach. Hence, we needed to rely on sample statistics for determining reasonable calibration anchors. Under such circumstances, previous studies usually used the mean, maximum and minimum values observed in the sample as calibration anchors assuming an approximately normal distribution of the data (e.g. Greckhamer et al., 2018). However, research has shown that due to inequalities in activity and popularity, the distribution of egonetwork size and diversity typically follows a power law (Stephen \& Toubia, 2009). In a power law distribution, most of the observed individuals in an empirical sample should possess only a small number of rather homogeneous contacts ("tail" of the distribution), a smaller amount possesses a medium number of contacts ("body"), whereas only very few individuals possess a large and heterogeneous network ("head") (Albert \& Barabàsi, 2002).

Based on these theoretical insights on the nature of the distribution of interpersonal networks as well as on previous works that rank individuals in professional contexts by quantiles in the network distribution (e.g. Grigoriou \& Rothaermel, 2014; Tushman \& Scanlan, 1981), we used two indications for defining calibration anchors: 1) the peaks and valleys in the observed distribution; and 2) the cumulated number of observations in the given interval in the distribution. Figures 2 and 3 show the distributions of internal networks and external networks as well as the assigned calibration anchors. 
II. Publications in Focus Area I: Top Management and Leadership

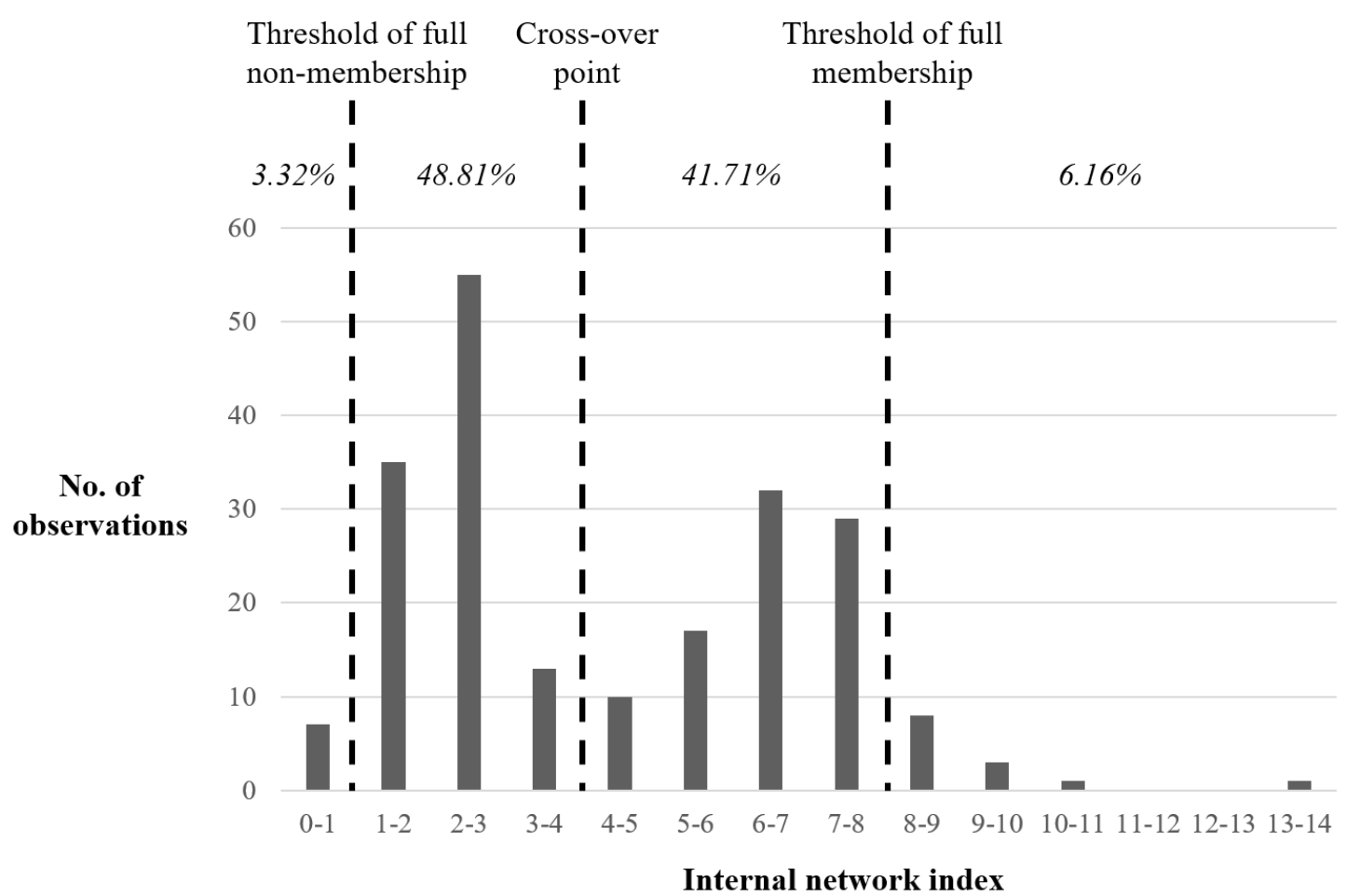

Figure II-1-2. Distribution and calibration of the variable internal network (own illustration)

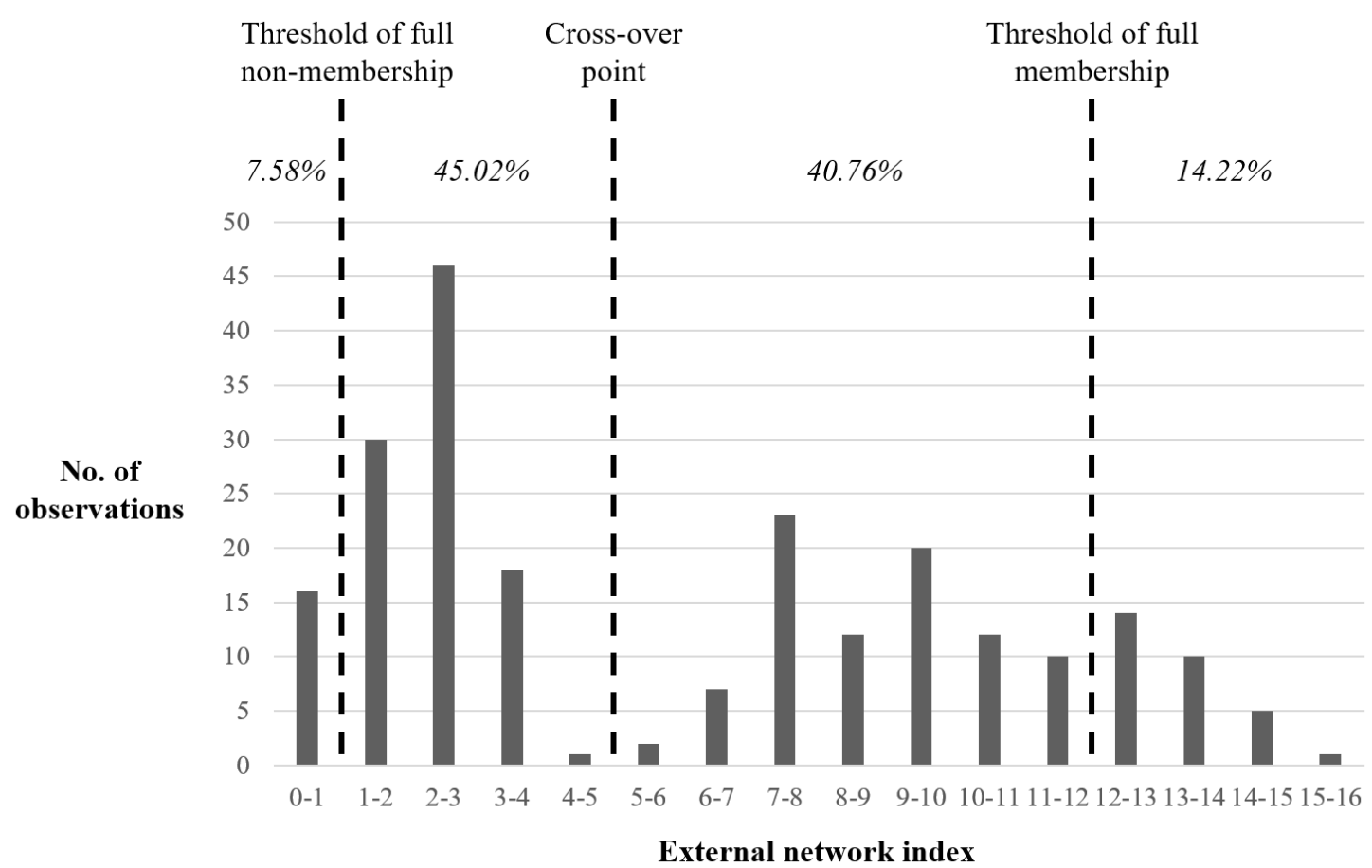

Figure II-1-3. Distribution and calibration of the variable external network (own illustration) 
First, as most individuals in professional contexts are likely to seek advice and support only from a quite focused group of people that emerges organically either through the coordination needs of their work task or by a long-term personal attachment (Cross, Borgatti, \& Parker, 2001; Gargiulo \& Benassi, 2000), we argued that the cross-over point should be located after the tail peak of the distribution. Also, the majority of observations (i.e., at least 50\%) should fall below that cross-over point. Hence, we specified the cross-over point for the variable internal network at the value of 4.00 and for external network at 5.00. Second, the threshold for full nonmembership should denote "isolates" who do not even possess a "normal" organically grown network (Tichy, Tushman, \& Fombrun, 1979). In the power law distribution, those cases should represent the interval before the steep slope of the "tail" peak and account only for a small share of observations (which we defined as less than 15\%). Based on these considerations, we set the threshold for full non-membership to the value of 1.00 for both internal and external network. Finally, the threshold of full membership should denote the small number of "relational stars" that occupy the most central positions in interpersonal information networks (Grigoriou \& Rothaermel, 2014). Those research cases should be above the "body" peak in the power law distribution that stands for "rather large and diverse" networks and again represent only a small share of observations (here again 15\%). Therefore, we set the threshold for full membership to the value of 8.00 for internal network and 12.00 for external network. As we did with the Likert scale ratings, we used these anchors to compute the fuzzy membership scores.

Truth table refinement. Following the calibration procedure, the research cases can be structured in a truth table that depicts all potential combinations of causal conditions (i.e., $2^{k}$ combinations with $k=$ number of causal conditions) (Ragin, 2008). For the further steps of analysis, this truth table must be refined based on frequency and consistency thresholds. As our sample size is rather large $(N>150)$, we set the frequency threshold to 3 , making sure that the analysis only includes configurations of empirical relevance in order to reduce the complexity of the obtained results (Greckhamer, Misangyi, \& Fiss, 2013). The consistency criterion should be at least .80 for raw consistency and .75 for PRI consistency (Misangyi \& Acharya, 2014). We used both these values for assigning high-performing and low-performing configurations.

Truth table analysis. In the final step of fsQCA, the refined truth table is used to extract causally relevant configurations by applying the Quine-McCluskey algorithm (Ragin, 2008). Thereby, fsQCA produces two different types of solutions (Fiss, 2011). Based on these two solutions, one can assess the causal relevance of all conditions in a given configuration. "Core conditions" appear in both parsimonious and intermediate solutions, are backed by stronger evidence relative to the outcome of interest and are seen to be causally essential for the particular solution's effect (Fiss, 2011). "Peripheral conditions" appear only in the intermediate solution, support the effect of core conditions, but are rather expandable or exchangeable when it comes to explaining the outcome of interest (Fiss, 2011). By this procedure, fsQCA identifies and delineates all the configurations that consistently lead to a particular outcome. 


\section{Results}

\section{Sufficient solutions}

Tables 5 and 6 illustrate the results of the fsQCA in the notation developed by Ragin and Fiss (2008). Table 5 shows four major solutions that are sufficient for high levels of business digitalization. Solution 1 has three neutral permutations (solutions 1a, 1b, and 1c), solution 2 and 3 have two neutral permutations (solutions $2 \mathrm{a}$ and $2 \mathrm{~b}$ respectively $3 \mathrm{a}$ and $3 \mathrm{~b}$ ). These permutations only differ in peripheral, but not in core elements (Fiss, 2011). The consistency of the single solutions ranges between .97 and .99. Hence, empirical instances of these solutions strongly agree in predicting business digitalization (Ragin, 2008). The consistency of the combined solution is .96 . Raw coverage values that indicate the size of the overlap between solution set and outcome set vary between .24 and .36 whereas unique coverage that controls for overlapping configuration sets ranges between .01 and .07. Thereby, solutions 4 and $1 \mathrm{c}$ have the highest scores of unique coverage, which is to say that these configurations occur most frequently in the sample. Overall solution coverage is .64 which demonstrates that the four solutions have a high explanatory power in terms of representing the majority of empirical observations' membership in the outcome (Ragin, 2008).

On the flipside, Table 6 demonstrates three sufficient solutions for low levels of business digitalization (solutions 5, 6, and 7). The consistency values of the single permutations range between .96 and .99 , the consistency of the combined solution is .95 . Coverage values range between .24 and .29 (raw coverage) respectively .01 and .06 (unique coverage). Overall solution coverage for low levels of business digitization is .46 ; this value means that compared to the case of high business digitization a considerable share of empirical observations is not explained by the solution term.

\section{Sensitivity analyses}

In line with previous works (e.g. Fiss, 2011; Ordanini, Parasuraman, \& Rubera, 2014), we conducted several robustness checks on our results. First, we applied changes to our calibration. Instead of using 1 as a threshold for full non-membership and 7 for full membership, we changed these scores to 2 respectively 6 and reran the analysis. Thereby, we also varied the cross-over point to 3.5 and 4.5. Furthermore, we also tested another calibration for the network variables: we set the calibration anchors for internal network and external network to the median, 90\%-quantile, and 10\%-quantile respectively to the mean, maximum, and minimum of the distribution. Second, we used frequency thresholds of 1 and 2 in the truth table refinement and repeated the analysis. Finally, we varied the threshold of raw and PRI consistency. In these steps, we observed only minor variations concerning the number of solutions and neutral permutations, but the general patterns in the results remained unchanged. The results of these robustness checks are available on request. 
Table II-1-5. Sufficient solutions for high levels of business digitization

\begin{tabular}{|c|c|c|c|c|c|c|c|c|}
\hline & \multicolumn{8}{|c|}{ Solution } \\
\hline & 1a & $1 b$ & $1 \mathrm{c}$ & $2 \mathbf{a}$ & $2 \mathbf{b}$ & $\mathbf{3 a}$ & $\mathbf{3 b}$ & 4 \\
\hline \multicolumn{9}{|l|}{ Context } \\
\hline Competitive pressure & $\otimes$ & $\otimes$ & $\bullet$ & & $\bullet$ & $\otimes$ & $\otimes$ & $\bullet$ \\
\hline Hierarchical influence of CDO & $\otimes$ & $\bullet$ & $\bullet$ & $\otimes$ & $\otimes$ & & & \\
\hline \multicolumn{9}{|l|}{ Skills } \\
\hline Strategic IT knowledge & 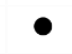 & $\otimes$ & $\bullet$ & & & $\otimes$ & $\otimes$ & \\
\hline Political skills & & & & & & & & $\otimes$ \\
\hline \multicolumn{9}{|l|}{ Network } \\
\hline Internal network & & & & O & O & $\otimes$ & $\bullet$ & $\otimes$ \\
\hline External network & $\bullet$ & - & & $\otimes$ & $\otimes$ & & & 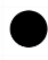 \\
\hline & & & & & & & & \\
\hline \multicolumn{9}{|l|}{ Behavior } \\
\hline Innovative role Behavior & & $\otimes$ & $\bullet$ & $\otimes$ & $\bullet$ & & 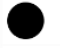 & \\
\hline Supportive role Behavior & & & & $\bullet$ & & $\bullet$ & $\otimes$ & \\
\hline Consistency & .99 & .98 & .98 & .98 & .98 & .98 & .99 & .97 \\
\hline Raw coverage & .27 & .24 & .36 & .30 & .30 & .24 & .25 & .30 \\
\hline Unique coverage & .04 & .01 & .06 & .04 & .03 & .02 & .02 & .07 \\
\hline Overall solution consistency & \multicolumn{8}{|l|}{.96} \\
\hline Overall solution coverage & \multicolumn{8}{|l|}{.64} \\
\hline
\end{tabular}

Note: Black circles indicate the presence of a condition, circles with " $x$ " indicate its absence. Large circles indicate core conditions, small ones indicate peripheral conditions. Blank spaces indicate that the condition may be either present or absent. 
Table II-1-6. Sufficient solutions for low levels of business digitization

\begin{tabular}{|c|c|c|c|c|c|c|c|}
\hline & \multicolumn{7}{|c|}{ Solution } \\
\hline & $5 \mathbf{a}$ & $\mathbf{5 b}$ & $5 c$ & 6a & $\mathbf{6 b}$ & $7 \mathbf{a}$ & $7 \mathbf{b}$ \\
\hline \multicolumn{8}{|l|}{ Context } \\
\hline Competitive pressure & & $\bullet$ & $\otimes$ & & $\otimes$ & $\otimes$ & $\bigotimes$ \\
\hline Hierarchical influence of $\mathrm{CDO}$ & $\otimes$ & $\otimes$ & $\otimes$ & $\otimes$ & $\otimes$ & $\otimes$ & $\bullet$ \\
\hline \multicolumn{8}{|l|}{ Skills } \\
\hline Strategic IT knowledge & $\otimes$ & $\bullet$ & $\bullet$ & $\bullet$ & & $\bullet$ & $\bullet$ \\
\hline Political skills & $\otimes$ & $\otimes$ & $\bullet$ & $\otimes$ & $\otimes$ & $\otimes$ & $\bigotimes$ \\
\hline \multicolumn{8}{|l|}{ Network } \\
\hline Internal network & $\otimes$ & $\otimes$ & $\bigotimes$ & $\otimes$ & $\bigotimes$ & $\otimes$ & $\otimes$ \\
\hline External network & $\otimes$ & $\bullet$ & $\otimes$ & $\bullet$ & $\bullet$ & $\bullet$ & $\otimes$ \\
\hline \multicolumn{8}{|l|}{ Behavior } \\
\hline Innovative role behavior & $\otimes$ & & $\otimes$ & $\otimes$ & $\otimes$ & & $\bullet$ \\
\hline Supportive role behavior & $\otimes$ & $\otimes$ & $\bigotimes$ & $\bullet$ & $\bullet$ & $\bullet$ & $\bullet$ \\
\hline Consistency & .98 & .96 & .99 & .98 & .98 & .98 & .97 \\
\hline Raw coverage & .29 & .25 & .25 & .25 & .24 & .25 & .26 \\
\hline Unique coverage & .06 & .02 & .02 & .01 & .01 & .01 & .03 \\
\hline Overall solution consistency & .95 & & & & & & \\
\hline Overall solution coverage & .46 & & & & & & \\
\hline
\end{tabular}

Note: Black circles indicate the presence of a condition, circles with " $\mathrm{x}$ " indicate its absence. Large circles indicate core conditions, small ones indicate peripheral conditions. Blank spaces indicate that the condition may be either present or absent.

\section{Discussion}

\section{Interpretation of the identified configurations}

Our empirical analysis displays several relevant patterns that need to be interpreted with regard to the role of CDOs in business digitalization as well as in the broader context of the existing theory on TMT members' influence on organizational outcomes. The examination of the individual variables shows that none of them is a stand-alone predictor of success or failure in business digitalization. Instead, four distinct configurations that explain high levels of business digitalization and three configurations that explain low levels of business digitalization were identified in the empirical data analysis. To interpret the seven CDO profiles in a more comprehensive way, we also considered various demographic data and data on the professional background as well as professional and organizational tenure of these executives collected in 
our survey (Table 7). Finally, we considered various contexts in which these CDOs may operate (Table 8).

Table II-1-7. Demographics and professional backgrounds of the identified CDO types

\begin{tabular}{|c|c|c|c|c|c|c|c|c|}
\hline \multirow[b]{2}{*}{ Variable } & \multicolumn{7}{|l|}{ Solution } & \multirow{2}{*}{$\begin{array}{l}\text { Overall } \\
\text { Sample } \\
(n=211)\end{array}$} \\
\hline & $\begin{array}{l}1 \\
(n=21)\end{array}$ & $\begin{array}{l}2 \\
(n=16)\end{array}$ & $\begin{array}{l}3 \\
(n=8)\end{array}$ & $\begin{array}{l}4 \\
(n=13)\end{array}$ & $\begin{array}{l}5 \\
(n=21)\end{array}$ & $\begin{array}{l}6 \\
(n=10)\end{array}$ & $\begin{array}{l}7 \\
(n=10)\end{array}$ & \\
\hline \multicolumn{9}{|l|}{ Demography } \\
\hline Gender & $\begin{array}{l}\text { M: } 85.71 \% \\
\text { F: } 14.29 \%\end{array}$ & $\begin{array}{l}\text { M: } 93.75 \% \\
\text { F: } 6.25 \%\end{array}$ & $\begin{array}{l}\text { M: } 87.50 \% \\
\text { F: } 12.50 \%\end{array}$ & $\begin{array}{l}\text { M: } 84.62 \% \\
\text { F: } 15.38 \%\end{array}$ & $\begin{array}{l}\text { M: } 95.24 \% \\
\text { F: } 4.76 \%\end{array}$ & $\begin{array}{l}\text { M: } 80.00 \% \\
\text { F: } 20.00 \%\end{array}$ & $\begin{array}{l}\text { M: } 70.00 \% \\
\text { F: } 30.00 \%\end{array}$ & $\begin{array}{l}\text { M: } 92.89 \% \\
\text { F: } 7.11 \%\end{array}$ \\
\hline \multicolumn{9}{|l|}{ Education level } \\
\hline University degree & $61.90 \%$ & $87.5 \%$ & $100.00 \%$ & $84.62 \%$ & $66.67 \%$ & $90.00 \%$ & $80.00 \%$ & $78.67 \%$ \\
\hline $\mathrm{PhD}$ & $9.52 \%$ & $12.5 \%$ & $0.00 \%$ & $15.38 \%$ & $9.52 \%$ & $0.00 \%$ & $0.00 \%$ & $9.00 \%$ \\
\hline \multicolumn{9}{|l|}{ Subject of study } \\
\hline $\begin{array}{l}\text { Engineering \& } \\
\text { science }\end{array}$ & $57.41 \%$ & $62.50 \%$ & $62.50 \%$ & $84.62 \%$ & $80.95 \%$ & $60.00 \%$ & $90.00 \%$ & $72.51 \%$ \\
\hline $\begin{array}{l}\text { Business } \\
\text { administration \& } \\
\text { economics }\end{array}$ & $66.67 \%$ & $56.25 \%$ & $87.50 \%$ & $30.77 \%$ & $38.10 \%$ & $80.00 \%$ & $60.00 \%$ & $54.50 \%$ \\
\hline Others & $0.00 \%$ & $6.25 \%$ & $0.00 \%$ & $7.69 \%$ & $4.76 \%$ & $10.00 \%$ & $0.00 \%$ & $5.69 \%$ \\
\hline Dual degree & $23.81 \%$ & $25.00 \%$ & $50.00 \%$ & $23.08 \%$ & $23.81 \%$ & $50.00 \%$ & $50.00 \%$ & $31.75 \%$ \\
\hline \multicolumn{9}{|l|}{$\begin{array}{l}\text { Functional background } \\
\text { (years of experience } \\
\text { in.../years of service) }\end{array}$} \\
\hline $\begin{array}{l}\text { Research \& } \\
\text { development }\end{array}$ & 0.25 & 0.06 & 0.15 & 0.28 & 0.28 & 0.20 & 0.25 & 0.22 \\
\hline $\begin{array}{l}\text { Production \& } \\
\text { operations }\end{array}$ & 0.19 & 0.46 & 0.30 & 0.31 & 0.25 & 0.30 & 0.28 & 0.25 \\
\hline IT \& infrastructure & 0.44 & 0.40 & 0.30 & 0.65 & 0.61 & 0.50 & 0.47 & 0.47 \\
\hline $\begin{array}{l}\text { Finance, auditing \& } \\
\text { controlling }\end{array}$ & 0.09 & 0.12 & 0.52 & 0.12 & 0.11 & 0.20 & 0.07 & 0.16 \\
\hline Marketing \& sales & 0.26 & 0.08 & 0.43 & 0.25 & 0.09 & 0.14 & 0.20 & 0.19 \\
\hline HR & 0.07 & 0.00 & 0.11 & 0.06 & 0.05 & 0.00 & 0.00 & 0.04 \\
\hline $\begin{array}{l}\text { Strategy \& corporate } \\
\text { development }\end{array}$ & 0.05 & 0.10 & 0.25 & 0.22 & 0.09 & 0.05 & 0.09 & 0.10 \\
\hline General management & 0.05 & 0.06 & 0.11 & 0.08 & 0.00 & 0.00 & 0.00 & 0.05 \\
\hline \multicolumn{9}{|l|}{ Employment history } \\
\hline $\begin{array}{l}\text { Tenure with firm } \\
\text { (years) }\end{array}$ & 15.40 & 13.96 & 10.00 & 8.88 & 8.83 & 7.95 & 11.50 & 11.71 \\
\hline $\begin{array}{l}\text { Experience in other } \\
\text { firms (in relation to } \\
\text { years of service) }\end{array}$ & 0.46 & 0.24 & 0.55 & 0.46 & 0.53 & 0.54 & 0.35 & 0.43 \\
\hline $\begin{array}{l}\text { Years of experience in } \\
\text { other industries (in } \\
\text { relation to years of } \\
\text { service) }\end{array}$ & 0.28 & 0.17 & 0.41 & 0.39 & 0.29 & 0.40 & 0.29 & 0.29 \\
\hline
\end{tabular}

Note: $\mathrm{M}=$ male; $\mathrm{F}=$ female 
Table II-1-8. Solutions for high levels of business digitalization: Contingency perspective

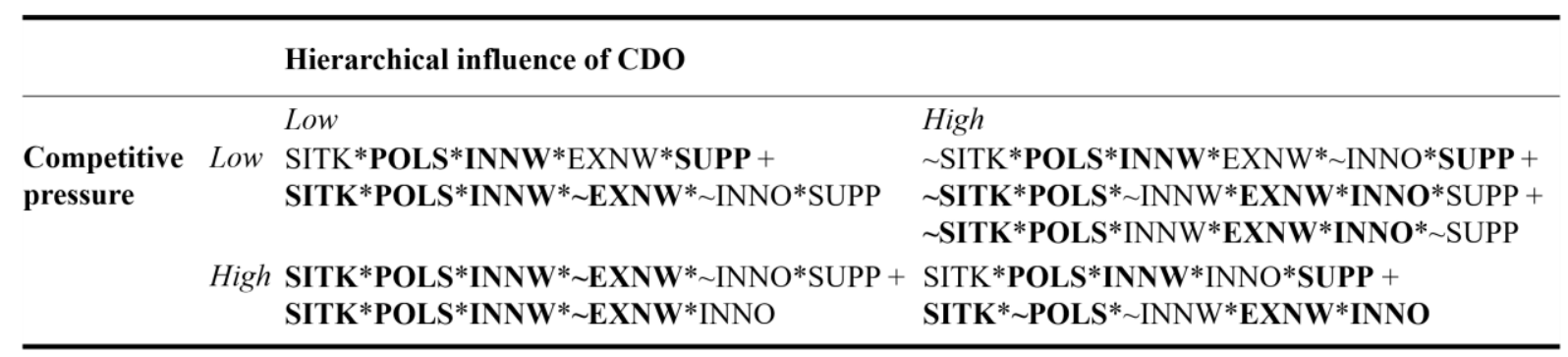

Note: SITK = strategic IT knowledge; POLS = political skills; INNW = internal network; EXNW = external network; $\mathrm{INNO}=$ innovative role behavior; SUPP = supportive role behavior;

$\sim=$ logical NOT; + = logical OR; * = logical AND;

Bold font indicates core conditions.

Solution 1. The first type of CDO combines strong political skills with a large and diverse internal network and strong engagement in supportive role behavior as causal core conditions. In three different situational contexts these characteristics can be supplemented either by profound strategic IT knowledge and a valuable (i.e., large and diverse) external network (solution 1a), or by a valuable external network, low strategic IT knowledge, and a lack of innovative role behavior (solution 1b), or by high levels of strategic IT knowledge and strong innovative behavior (solution 1c). Considering demographics and professional background, CDOs of this type are on average the oldest and are more likely than most other types to be educated (i.e., vocational training or university degree) in business administration or economics.

The apparent fit between this CDO's personal resources and exerted innovation-related role behavior is likely to explain his/her effectiveness. Instead of initiating digital transformation, this digital leader focuses on an "enabling" role and is well equipped to do so. Solution 1 depicts CDOs who contribute to digital transformation by helping individual innovators and project teams overcome internal barriers, advocating their ideas to other decision makers across the firm, and securing resources for developing and implementing digitalization initiatives. Their political skills and their large and diverse internal network provide them with profound knowledge about social dynamics and distribution of power within the firm (Hambrick \& Mason, 1984). Solution 1 types may thus act as a "process promoter" of digital transformation - that is, an experienced manager who is able to communicate new ideas, technologies, and procedures across intra-organizational boundaries (Rost et al., 2007). In doing so, this CDO can play an important role in overcoming administrative and organizational hurdles that hinder the implementation of digitalization initiatives (Milovich, 2015).

With regard to the context, Table 8 shows that this CDO can be effective across a number of different situations. On the one hand, when equipped with strategic IT knowledge and a valuable external network, he/she can foster business digitalization even when the competitive pressure for digitalization and his/her hierarchical influence in the firm is low (Solution 1a). In this situation, digital transformation is likely to be a secondary priority on a company's strategic agenda. Low pressure from the environment might lead firms to evaluate their current state of business digitalization as satisfying; this may reduce the sense of urgency regarding the need 
to invest in digital technologies (Andersen et al., 2016). Moreover, this type of CDO does not have the hierarchical position and authority to drive business digitalization in a proactive manner (Matt et al., 2015). Hence, to propel digital transformation he/she must primarily rely on his/her organizational knowledge and informal social influence. At the same time, CDOs depicted in Solution 1a must also build on their own profound knowledge on digital opportunities and on insights acquired from external contacts to insert new ideas from outside the firm in order to create positivity and excitement across the organization regarding the adoption of digital technologies (Karahanna, Straub, \& Chervany, 1999).

On the other hand, other subtypes of this CDO profile can be successful in contexts of low competitive pressure and high hierarchical influence (Solution $1 \mathrm{~b}$ ) as well as high pressure and high influence (Solution 1c). In the former context, the causal core conditions are complemented by the presence of a large and diverse external network as well as the absence of strategic IT knowledge and lack of innovative role behavior. In the latter context, strategic IT knowledge and innovative role behavior represent the peripheral conditions. We argue that those differences might be explained by the argument, that in a low-pressure context (Solution 1b) CDOs might rather profit from the ability to encourage creativity and fresh perspectives in the organization (Haffke et al., 2016; Hargadon \& Sutton, 1997; Singh \& Hess, 2017; Tumbas et al., 2017) whereas in high-pressure contexts firms might need CDOs that take initiative and lead by action (Deschamps, 2008; Makri \& Scandura, 2010; Yadav et al., 2007). As the differences between low- and high-pressure environments become even more visible in Solutions 3 and 4, we discuss our theoretical arguments on this issue in more depth there.

Solution 2. This type of CDO possesses both strong political skills and quite profound strategic IT knowledge. Another core feature of the Solution 2 type is that he/she has developed a large and diverse network, but only within the corporate boundaries. This CDO group is characterized by the youngest average age of all identified configurations and an overrepresentation of managers with background in production and operations. Compared to the other identified profiles, this CDO has a long tenure with the given firm and spent the least relative amount of time working for other employers or in different industries.

Due to these attributes this CDO type is likely to be a "local", i.e., a person who is very loyal to the firm and has accepted, internalized, and cultivated its norms, rules, and worldviews (Gouldner, 1957). Thanks to his/her profound expertise and a valuable internal network, this CDO possesses the personal resources to act as a trusted expert, arbitrating between technical and economic departments and domains (Armstrong \& Sambamurthy, 1999). He/she thus is well equipped to educate staff on the functionality and applications of novel information technologies, reduce reservations resulting from managers' and employees' lack of expertise in the field of business digitalization, and facilitate the adoption and diffusion of digitalization initiatives across the firm. Our results indicate that this type of CDO is effective in companies where the CDO position has only low influence on the firm's strategic decision-making. Solution 2 managers thus are rather likely to act as supporters and educators (Milovich, 2015) than "champions" (Howell \& Boies, 2004). This insight on the CDOs is in line with the findings from early studies on the CIOs which indicated that firms may need technological leaders "who can conciliate and defuse and explain instead of confront" (Feeny et al., 1992, p. 445). 
Solution 2 types can be effective both in situations when the competitive pressure is high or low. However, differences do exist: In a low-pressure context, the core characteristics mentioned above must be paired with weak innovative role behavior and strong supportive role behavior. In a high-pressure context, on the contrary, a successful "local" CDO is likely to demonstrate strong innovative role behavior. In such situations that are frequently associated with high level of uncertainty and stress, a more active and direct involvement of a CDO who enjoys the reputation of a trustworthy expert might help in providing the necessary impetus to overcome organizational inertia (Gilbert, 2005), rather than a more supportive and enabling leadership approach (Yukl, 2012).

Solution 3. These CDOs possess strong political skills, a valuable external network, and demonstrate strong innovative role behavior. The peripheral conditions of this configuration include weak strategic IT knowledge and either a combination of an underdeveloped internal network and strong supportive role behavior or a combination of a valuable internal network and weak supportive role behavior. The large and diverse external network of Solution 3 types is likely to result from their specific professional biography: on average, these CDOs have spent about $55 \%$ of their career in other companies than their current employer and $41 \%$ of their career in other industries.

The access to diverse external knowledge sources via their network allows these CDOs to combine non-redundant ideas and thus create innovative solutions. Political skills may help in disseminating these external ideas within the company and thus educating and persuading internal stakeholders and adopters of digital innovations (Smaltz et al., 2006). Thus, we argue that these CDOs are likely to benefit business digitalization by acting as gatekeepers (Tushman \& Scanlan, 1981) and knowledge brokers (Hargadon \& Sutton, 1997) - introducing new ideas from outside sources, challenging established perspectives and mental frames, and redefining the firm's vision and its underlying business logic in the light of digital business opportunities (Haffke et al., 2016; Singh \& Hess, 2017; Tumbas et al., 2017).

The absence of strategic IT knowledge at first seems surprising. However, data also indicate that the professional competences of Solution 3 CDOs are all but low, they merely lie in other fields: CDOs with this profile are the most well-educated group when it comes to the percentage of university degrees, and they are most likely to possess degrees in business administration or economics and functional experience in corporate finance, marketing, or strategy departments. The challenges of digitalization are often related to economic and business facets, rather than purely technological aspects (Fitzgerald et al., 2014). Hence, a deep understanding of marketrelated and financial issues might help Solution 3 managers evaluate and select most promising, that is, economically feasible innovative solutions from outside sources and find more convincing arguments to achieve buy-in for these solutions within the organization.

Furthermore, our analysis shows that CDOs of this profile are only effective in a context characterized by low competitive pressure and high hierarchical influence. In this situation, the main hurdles in the CDO's task to foster business digitalization might be the limited awareness of digital technologies and business opportunities across the firm, a low sense of urgency to initiate change as well as low experience of other organizational members with digitalization 
initiatives (Singh \& Hess, 2017; Tumbas et al., 2017). A Solution 3 type CDO is likely to be effective in overcoming these hurdles when he/she promotes anticipatory change, actively develops and advocates creative ideas, and experiments with digital innovations (Matt et al., 2015). High levels of hierarchical influence, control, and power may be necessary in order to ensure the legitimacy of these efforts in the organization.

Solution 4. This CDO is characterized by strong strategic IT knowledge, weak political skills, a large and diverse external network, and strong engagement in innovative role behavior as causal core conditions. In comparison to the previous three configurations, this group of CDOs includes a much higher percentage of graduates from the fields of engineering and science as well as the largest share of PhDs. Concerning their functional background, an over-proportional number of this CDO type worked in technology-oriented functions of R\&D and IT.

This type of CDO can benefit business digitalization by being the key innovation player and demonstrating direct and active involvement in digitalization initiatives (Chun \& Mooney, 2009; Haffke et al., 2016). As they are often apparent "bits and bytes" persons, Solution 4 CDOs draw on profound expertise on digital technologies and their business applications, which should help them in developing innovative solutions of high usefulness, overcoming technical problems and obstacles in the development process, and exerting influence over others thanks to their high expert reputation (Smaltz et al., 2006). A broad range of external contacts exposes them to diverse sources of information and ideas, which also act as a fuel for their innovative performance (Hargadon \& Sutton, 1997).

Most strikingly, our results indicate a lack of political skills for this type of CDO which stands in sharp contrast to all other types of effective digital leaders. Hence, the Solution 4 managers cannot rely on elaborated interpersonal skills when it comes to understanding and convincing other people. In line with this blatant weakness, they have rather underdeveloped internal networks and thus, are "lone fighters" within their organization. Still, the data indicate that this CDO seems to compensate for that shortcoming by the sheer quality of his/her functional expertise. Acting as the firm's solitary digitalization engine, Solution 4 executives benefit their firms mostly by designing concrete and valuable problem solutions, rather than by their interactions and support of others.

In light of this profile, it comes probably at no surprise that CDOs of this type are effective when they are equipped with sufficient hierarchical power to make a direct impact and operate in an organization that is under considerable environmental pressure. In contrast to the CDO depicted by Solution 3 who has the tools and skills to encourage anticipatory change and is effective under low level of pressure, the Solution $4 \mathrm{CDO}$ is able to spearhead change and act as a role model to others by taking the initiative in generating innovation (Gerstner et al., 2013; Makri \& Scandura, 2010; Yadav et al., 2007). In a situation of pressure, this hands-on innovator might overcome organizational inertia and resistance to the adoption of new technologies (Gilbert, 2005) by demonstrating task-oriented rather than relations-oriented leadership behaviors (Yukl, 2012).

Contrary to the first four solutions the last three profiles describe CDOs who failed to foster business digitization in their firms. 
Solution 5. This solution depicts a top manager who misses out on most of the skills, networks, and behaviors discussed above. Most prominently, CDOs of this type lack a large and diverse internal network, largely engage neither in innovative role behavior nor in supportive role behavior, and are not provided with hierarchical influence by their organization. Regarding their demographics and their professional background, Solution 5 type CDOs mostly have a technology background, were educated in the tech field (engineering or science), spent most of their career in IT \& infrastructure departments and possess only little experience in business functions such as finance, marketing, and strategy/corporate development.

Solution 5 seems to describe a phenomenon that both research literature and practice-oriented publications often highlight: many organizations perceive business digitalization as a mere extension of the IT function and thus promote IT specialists to the CDO role or simply create a joint CIO/CDO role (Fitzgerald et al., 2014; Hess et al., 2016; Matt et al., 2015). In line with this, 13 of the 21 CDOs that have the characteristics of Solution 5 simultaneously hold the CIO position. Though in general, appointing proficient managers to lead a new function can be effective, such an approach is questionable, when the new function requires quite different skill sets than the old one (Campbell, Kunisch, \& Müller-Stewens, 2012; Kunisch, Müller-Stewens, \& Campbell, 2014; Menz, 2012). Whereas the existing legacy of the IT function is focused on system reliability and cost containment (Chun \& Mooney, 2009; Haffke et al., 2017), business digitalization is a more strategic task that involves creating new competitive advantages, new products and services (Fitzgerald et al., 2014; Hess et al., 2016). Thus, the CDO's duties demand for different and in general more complex personal resources and leadership approaches so that executives who were successful IT managers might still fail (Haffke et al., 2016; Milovich, 2015; Singh \& Hess, 2016).

Solution 6. This type of CDO combines low levels of innovative role behavior, an underdeveloped internal network, and weak political skills with a large and diverse external network and strong supportive role behavior. In terms of education and professional biography, there are noteworthy similarities with Solution 3 as most of the Solution 6 executives also possess degrees in business administration or dual degrees, and they have spent a large share of their career in other companies than their current employer and in other industries.

While Solution 3 demonstrates that leadership experience in different organizational or industrial contexts as well as access to diverse knowledge sources in a large external network may benefit a CDO, there are important differences between Solution 3 and Solution 6 that help understand the failure of the latter. On the one hand, while a top manager's external experience and network can provide him/her with broader insights and a less-entrenched perspective on the firm's issues, this comes at the cost of less insider knowledge, support, and legitimacy (Helfat \& Bailey, 2005; Helfat \& Martin, 2015). Solution 6 CDOs most likely cannot compensate those shortcomings as they possess neither political skills, nor a strong internal network, nor hierarchical power. On the other hand, in contrast to Solution 3, CDOs of this type focus on supporting innovators in the firm rather than spearheading digital innovation themselves. However, such supporting role behavior is unlikely to bear fruit: due to the lack of hierarchical influence, political skills and social connections, Solution 6 CDOs may not be able to help employees with valuable ideas to overcome administrative and organizational hurdles 
(Rost et al., 2007). The more active approach taken by Solution 3 CDOs is likely to better complement the CDOs skills and personal resources, namely the external experience and external network.

Solution 7. Finally, the last profile depicts a CDO with low levels of political skills and an underdeveloped internal network. On the upside, CDOs in this group possess profound strategic IT knowledge and engage strongly in supportive role behavior, most of them also in innovative role behavior. Comparing skills, networks, behaviors, but also demographics and professional background, Solution 7 appears like a mirror image of Solution 4: both CDO types have a strong professional background in IT or R\&D, possess profound expertise on how to use IT for strategic benefit, actively engage in role behaviors aimed to lead digital transformation, but lack social skills and social support within the firm. The difference is that both types operate in different environmental contexts. For Solution 4, competitive pressure is high so that people in the organization might look out for "champions" and "great men" that spearhead change, demonstrate task-focus, and get the job done (Howell \& Boies, 2004; Makri \& Scandura, 2010; Yadav et al., 2007). Still, task-oriented leaders are often prone to overlook the achievements and contributions of others, are perceived as "bulldozers" who do not care about others' needs, and harm organizational climate in the long term (Khurana, 2002). When they on top of that lack social skills and isolate themselves from peers and subordinates, negative consequences are almost inevitable (Kellerman, 2004; Lubit, 2004). In line with this, research has shown that even if a manager acts in accordance with the legitimate goals, tasks and strategies of the firm and is able to obtain impressive results, subordinates and other managers may still perceive such behavior as "tyranny" if they feel ignored, belittled, or humiliated (Einarsen, Aasland, \& Skogstad, 2007). In the low-pressure context in which Solution 7 CDOs operate, the costs arising from the lack of political skills and internal networks will thus most likely outmatch the benefits that stem from the quality of their functional expertise.

\section{Theoretical contributions}

In this paper, we examined how the skills, networks, and role behaviors of CDOs interact across different contexts in predicting firm-level business digitalization. In summary, our research makes several contributions to previous top management literature. First, we are able to uncover four equifinal configurations that explain how new top management roles, i.e., CDOs succeed or fail in promoting transformative change and creating economic value for the organizations. Past academic research but also practice-oriented publications on this topic largely focused on describing the expectations and challenges that CDOs face and strived to derive catalogues of skills, experiences, traits, and tasks that a digital leader should fulfill. In line with the notion of the CDO as "transformer in chief", practice-oriented works often painted the picture of the CDO as an omnipotent and omnicompetent managerial "super-hero" (Péladeau et al., 2019; Rickards et al., 2015). On the contrary, scholars advocated the view that CDOs might take a more focused and differentiated role (Haffke et al., 2016; Singh \& Hess, 2017; Tumbas et al., 2017). Our results clearly demonstrate that striving to be a "jack-of-all-trades" when it comes to digital leadership is likely to be both unrealistic and ineffective. Instead, we provide a more comprehensive and multi-faceted viewpoint on the role of the CDO by demonstrating that at least four different types of effective CDOs exist. 
Second, our study contributes to the research on functional TMT members in general. Whereas many firms seem to stumble when it comes to structuring their TMT and assigning functional TMT positions (Campbell et al., 2012; Kunisch et al., 2014), studies that examine the antecedents that contribute to the effectiveness and failure of functional top managers are still scarce (Garms and Engelen, 2019; Menz, 2012). Mostly, previous works focused on the mere presence of a certain top management role and examined the circumstances under which the existence of that particular position in the firm benefits organizational performance. In contrast, we argue that not the mere presence of a CDO but the specific internal and external resources that he/she can deploy in conjunction with the specific kinds of role behavior that he/she exhibits are likely to benefit business digitalization. By drawing on the assumptions of the configurational theory, we were able to explore four "causal recipes" (Ragin, 2008) for the determinants of CDOs' effectiveness. These "causal recipes" depict distinct types of functional managers that each benefit organizational performance by a unique contribution that is based on their respective combination of skills, networks, and role behaviors. By outlining the complex interplay of these variables, we were thus able to identify archetypes of successful functional top managers and shed light on the causal mechanism that determine $\mathrm{CxOs}$ effectiveness in their managerial role.

Third, our study also advances the contingency perspective on functional TMT members by providing insights on the contextual factors that affect the impact of CDOs on organizational digital transformation. By including competitive pressure for digitalization and hierarchical influence of CDO as context variables, we were able to discern between four distinct situational contexts and explore their role in determining which combinations of managers' skills, networks, and role behaviors are effective. In doing so, on the one hand, we specified the argument raised by the upper echelon theory that the impact of top managers is conditional on these managers' internal influence opportunities and authority (Hambrick \& Mason, 1984). In particular, we demonstrated that whereas Solution 3 and Solution 4 CDOs that aim to be epicenters of innovation and digital change in the firm need high levels of power in order to be effective, Solution 1 and Solution 2 types that contribute to business digitalization rather by enabling and educating others can also be effective in positions of lower hierarchical influence.

On the other hand, our results indicate that the level of competitive pressure also renders certain types of managers ineffective. For instance, both the Solution 3 and the Solution 4 CDOs exhibit innovative role behavior to lead digital transformation. However, the former successfully propels business digitalization in absence of external pressure whereas the latter is only effective in situations where the competitive pressure is high. Also, our analysis reveals that CDOs with profound functional expertise, but underdeveloped social skills can succeed in fostering organizational change in high-stakes situations (Solution 4), but when pressure and sense of urgency are low, those CDOs are likely to fail (Solution 7). In sum, our findings enrich theoretical insights on the roles of top managers by conceptualizing and exploring different sets of situational variables upon which the performance of functional executives is likely to be contingent.

Finally, from the more general theoretical perspective, our paper contributes to the current debate in organization and management literature on various ways of theorizing. Similar to 
other research streams, previous top management studies have been dominated by correlational "net-effects thinking" (Ragin, 2008), that is, the inclination to "perceive the social world mainly in terms of linear relationships that take a correlational form of "the more of X, the more of $Y$.", (Delbrige \& Fiss, 2013, p. 328). In our study, we answer the call made, for instance, by Fiss (2011) and Delbridge and Fiss (2013) to acknowledge more complex notions of causality, such as equifinality and causal asymmetry. In particular, contrary to the "correlational theorizing", our study shows that for managers there are different ways to succeed and different ways to fail. Moreover, our results demonstrate that whereas a specific independent variable (e.g. welldeveloped intra-organization network) contributes to managerial effectiveness in some configurations, its low value in other configurations does not predict low performance. Last but not least, in illuminating those rich-in-content configurations we also concur with another important call made by Delbridge and Fiss (2013, p. 329) when they advocate typologies as "a particularly attractive form of theorizing", at least in top management studies.

\section{Practical implications}

Our findings provide several implications for both CDOs and firms that pursue business digitalization. For CDOs, the configurations unveiled in this study might serve as blueprints for analyzing and evaluating the own position inside the firm, the own skill base, network of contacts, and role activities in fostering digitalization initiatives. Based on this self-evaluation, appropriate adjustments in the form of plans for skill and network development may be derived.

For firms, our results provide implications for two important practical questions: 1) which candidates to select to fill the CDO position; and 2) how to define and design the executive role of the CDO. Concerning candidate selection, an intriguing insight of our research refers to when and how to make use of externally hired CDOs (that is, CDOs with significant external experience). According to the "2019 Chief Digital Officer Study" by the consultancy Strategy\&, almost half of the surveyed companies (48.8\%) appointed an external hire to their CDO position (Péladeau et al., 2019). Though our study demonstrates that externally experienced CDOs can be effective and successfully introduce fresh perspectives into the firm (Solution 3), our results also indicate that in order for that to work out, a) the firm must be in a low-pressure situation where it can handle business digitalization as anticipatory change and $b$ ) the CDO needs profound social skills and must get personally involved in digital transformation initiatives. More generally, the identified configurations may serve as blueprints for the personal profiles of potential candidates to be hired or promoted for a CDO position.

Concerning the design of the CDO's executive role, our results provide empirical evidence (see Solution 5) for the notion that the mere promotion of IT specialists or the extension of the CIO position will most likely not result in digital transformation achievements (Fitzgerald et al., 2014; Haffke et al., 2016; Singh \& Hess, 2016). While our results indicate that CDOs with background in IT may well be effective in their new position, organizations should make themselves aware that the CDO position has to deal with a complex and strategic task that goes beyond the IT function that is primarily focused on "keeping the lights on" (Chun \& Mooney, 2009; Haffke et al., 2017). Furthermore, we argue that it is crucial that firms equip their CDOs with adequate hierarchical power. Though Solutions 1 and 2 demonstrate that CDOs can also 
be effective in low-influence positions, our analysis demonstrates that often, lack of hierarchical influence is an important cause for CDOs failure. Hence, we appraise the current trend that CDOs increasingly attain a seat at the managerial board (from $40.0 \%$ in 2016 to $53.5 \%$ in 2018 (Péladeau et al., 2019)) and advise firms that did not already to endow their CDO with adequate authority and decision-making competences.

\section{Limitations and further research}

Our work has several limitations which provide promising avenues for further research. First, as our study is specifically focused at the CDOs, it has to be considered that this position constitutes a quite novel executive role that has still to prove the legitimacy of its rank in the csuite (Gerth \& Peppard, 2016). Hence, our research context, despite its high level of topicality and practical relevance, might reflect a quite special case. Future research should thus conduct configurational studies on other, more established top management roles like CEO, COO, CTO, $\mathrm{CSO}$, or $\mathrm{CIO}$ and compare eventual differences in the configurations of skills, networks, and role behaviors that lead to valuable organizational outcomes.

Second, our research conceptually focused on the impact of a single functional executive. However, the current TMT literature argues that to fulfill the full range of complex tasks associated with top management responsibilities, division of labor and coordination between several top management team members is necessary (Menz, 2012). Future research should thus examine how the combination of skills, networks, and behaviors of several top-level managers, for instance the "triad" of CEO, CIO and CDO, might benefit organizational outcomes and especially business digitalization.

Third, the results of a configurational analysis and the derived theoretical propositions are generally sensitive to the variables included or, respectively, excluded from the analysis (Ordanini et al., 2014). Though we carefully selected the included variables based on a comprehensive review of top management literature, important variables might have been left beyond the scope of our study. Hence, future research could compare different configurational models and thus further test the validity of our findings.

Final limitations concern our methodology. Our data collection was cross-sectional and the procedure relied on self-report. Though we took several appropriate measures to account for potential biases stemming from our approach, we suggest that future research should draw on longitudinal data and consult multiple data sources. In summary, as business digitalization increasingly becomes a key area of top management responsibility, we hope that our study will spur additional research on this interesting and promising issue. 


\subsection{References}

Andersen, E., Demir, R., Mähring, M., Sannes, R., Wennberg, K., \& Woerner, S.L. (2016). Organizing for digitalization: A cross-country study of CIO attention to digital technology. In Proceedings Workshop “Organizing for Digital Innovation”, Amsterdam, March 11-12. Albert, R., \& Barabási, A.L. (2002). Statistical mechanics of complex networks. Reviews of Modern Physics, 74, 47-99.

Alexiev, A.S., Jansen, J.J., Van den Bosch, F.A., \& Volberda, H.W. (2010). Top management team advice seeking and exploratory innovation. Journal of Management Studies, 47, 13431364.

Angwin, D., Paroutis, S., \& Mitson, S. (2009). Connecting up strategy: Are senior strategy directors a missing link?. California Management Review, 51, 74-94.

Armstrong, J.S., \& Overton, T.S. (1977). Estimating nonresponse bias in mail surveys. Journal of Marketing Research, 14, 396-402.

Armstrong, C.P., \& Sambamurthy, V. (1999). Information technology assimilation in firms: The influence of senior leadership and IT infrastructures. Information Systems Research, 10, 304-327.

Arthur, W.B. (2009). The nature of technology: What it is and how it evolves. New York: Free Press.

Bagozzi, R.P., \& Yi, Y. (1988). On the evaluation of structural equation models. Journal of the Academy of Marketing Science, 16, 74-94.

Bharadwaj, A., El Sawy, O.A., Pavlou, P.A., \& Venkatraman, N. (2013). Digital business strategy. MIS Quarterly, 37, 471-482.

Blau, P.M. (1977). Inequality and heterogeneity. New York: Free Press.

Bromiley, P. \& Rau, D. (2016). Social, behavioral, and cognitive influences on upper echelons during strategy process: A literature review. Journal of Management, 42, 174-202.

Brown, M.G. \& Svenson, R.A. (1988). Measuring R\&D productivity. Research-Technology Management, 31, 11-15.

Busenbark, J.R., Krause, R., Boivie, S., \& Graffin, S.D. (2016). Toward a configurational perspective on the CEO. Journal of Management, 42, 234-268.

Campbell, A., Kunisch, S., \& Müller-Stewens, G. (2012). Are CEOs getting the best from corporate functions?. MIT Sloan Management Review, 53, 12-14.

Cao, Q., Maruping, L.M., \& Takeuchi, R. (2006). Disentangling the effects of CEO turnover and succession on organizational capabilities. Organization Science, 17, 563-576.

Cao, Q., Simsek, Z., \& Jansen, J.J. (2015). CEO social capital and entrepreneurial orientation of the firm. Journal of Management, 41, 1957-1981.

Carpenter, M.A., Geletkanycz, M.A., \& Sanders, W.G. (2004). Upper echelons research revisited. Journal of Management, 30, 749-778.

Chun, M., \& Mooney, J. (2009). CIO roles and responsibilities: Twenty-five years of evolution and change. Information \& Management, 46, 323-334.

Collins, C.J., \& Clark, K.D. (2003). Strategic human resource practices, top management team social networks, and firm performance. Academy of Management Journal, 46, 740-751.

Cross, R., Borgatti, S.P., \& Parker, A. (2001). Beyond answers: Dimensions of the advice network. Social Networks, 23, 215-235. 
Delbridge, R., \& Fiss, P.C. (2013). Editors' comments: Styles of theorizing and the social organization of knowledge. Academy of Management Review, 38, 325-331.

Deschamps, J.P. (2008). Innovation leaders: How senior executives stimulate, steer and sustain innovation. Chichester: Wiley.

Einarsen, S., Aasland, M.S. \& Skogstad, A. (2007). Destructive leadership behaviour: A definition and a conceptual model. The Leadership Quarterly, 18, 207-216.

Feeny, D.F., Edwards, B.R., \& Simpson, K.M. (1992). Understanding the CEO/CIO relationship. MIS Quarterly, 16, 435-448.

Ferris, G.R., Treadway, D.C., Kolodinsky, R.W., Hochwarter, W.A., Kacmar, C.J., Douglas, C., \& Frink, D.D. (2005). Development and validation of the political skill inventory. Journal of Management, 31, 126-152.

Fiss, P.C. (2011). Building better causal theories: A fuzzy set approach to typologies in organization research. Academy of Management Journal, 54, 393-420.

Fitzgerald, M., Kruschwitz, N., Bonnet, D., \& Welch, M. (2014). Embracing digital technology. MIT Sloan Management Review, 55, 1-12.

Fornell, C., \& Larcker, D.F. (1981). Evaluating structural equation models with unobservable variables and measurement error. Journal of Marketing Research, 18, 39-50.

Gargiulo, M., \& Benassi, M. (2000). Trapped in your own net? Network cohesion, structural holes, and the adaptation of social capital. Organization Science, 11, 183-196.

Gawer, A., \& Cusumano, M.A. (2014). Industry platforms and ecosystem innovation. Journal of Product Innovation Management, 31, 417-433.

Geletkanycz, M.A., \& Hambrick, D.C. (1997). The external ties of top executives. Administrative Science Quarterly, 42, 654-681.

George, G., Haas, M.R., \& Pentland, A. (2014). Big data and management. Academy of Management Journal, 27, 121-126.

Gerstner, W.C., König, A., Enders, A., \& Hambrick, D.C. (2013). CEO narcissism, audience engagement, and organizational adoption of technological discontinuities. Administrative Science Quarterly, 58, 257-291.

Gerth, A.B., \& Peppard, J. (2016). The dynamics of CIO derailment: How CIOs come undone and how to avoid it. Business Horizons, 59, 61-70.

Gilbert, C.G. (2005). Unbundling the structure of inertia: Resource versus routine rigidity. Academy of Management Journal, 48, 741-763.

Gottschalk, P. (1999). The role of the CIO in Norwegian organizations. International Journal of Information Management, 19, 389-399.

Gouldner, A.W. (1957). Cosmopolitans and locals: Toward an analysis of latent social roles. Administrative Science Quarterly, 2, 281-306.

Garms, F.P., \& Engelen, A. (2019). Innovation and R\&D in the upper echelons: The association between the CTO's power depth and breadth and the TMT's commitment to innovation. Journal of Product Innovation Management, 36, 87-106.

Greckhamer, T., Furnari, S., Fiss, P.C., \& Aguilera, R.V. (2018). Studying configurations with qualitative comparative analysis: Best practices in strategy and organization research. Strategic Organization, 16, 482-495. 
Greckhamer, T., Misangyi, V.F., \& Fiss, P.C. (2013). The two QCAs: From a small-N to a large-N set theoretic approach. In P.C. Fiss, B. Cambré, \& A. Marx (Eds.), Configu-rational theory and methods in organizational research (pp. 49-75). Bingley: Emerald.

Greve, H.R., \& Mitsuhashi, H. (2007). Power and glory: Concentrated power in top management teams. Organization Studies, 28, 1197-1221.

Grigoriou, K., \& Rothaermel, F.T. (2014). Structural microfoundations of innovation: The role of relational stars. Journal of Management, 40, 586-615.

Grover, V., Jeong, S.R., Kettinger, W.J., \& Lee, C.C. (1993). The Chief Information Officer: A study of managerial roles. Journal of Management Information Systems, 10, 107-130.

Haffke, I., Kalgovas, B., \& Benlian, A. (2016). The role of the CIO and the CDO in an organization's digital transformation. In Proceedings of the 37th International Conference on Information Systems (ICIS), Dublin, December 11-14.

Haffke, I., Kalgovas, B., \& Benlian, A. (2017). Options for transforming the IT function using bimodal IT. MIS Quarterly Executive, 16, 101-120.

Hambrick, D.C. (2007). Upper echelons theory: An update. Academy of Management Review, $32,334-343$.

Hambrick, D.C., \& Cannella, A.A. (2004). CEOs who have COOs: Contingency analysis of an unexplored structural form. Strategic Management Journal, 25, 959-979.

Hambrick, D.C., \& Mason, P.A. (1984). Upper echelons: The organization as a reflection of its top managers. Academy of Management Review, 9, 193-206.

Hargadon, A., \& Sutton, R.I. (1997). Technology brokering and innovation in a product development firm. Administrative Science Quarterly, 42, 716-749.

Helfat, C.E., \& Bailey, E.E. (2005). External succession and disruptive change: Heirs-apparent, forced turnover and firm performance. Strategic Organization, 3, 47-83.

Helfat, C.E., \& Martin, J.A. (2015). Dynamic managerial capabilities: Review and assessment of managerial impact on strategic change. Journal of Management, 41, 1281-1312.

Heyden, M.L., Van Doorn, S., Reimer, M., Van Den Bosch, F.A., \& Volberda, H.W. (2013). Perceived environmental dynamism, relative competitive performance, and top management team heterogeneity: Examining correlates of upper echelons' advice-seeking. Organization Studies, 34, 1327-1356.

Hoffman, R.C., \& Hegarty, W.H. (1993). Top management influence on innovations: Effects of executive characteristics and social culture. Journal of Management, 19, 549-574.

Howell, J.M., \& Boies, K. (2004). Champions of technological innovation: The influence of contextual knowledge, role orientation, idea generation, and idea promotion on champion emergence. The Leadership Quarterly, 15, 123-143.

Iansiti, M., \& Lakhani, K.R. (2014). Digital ubiquity: How connections, sensors, and data are revolutionizing business. Harvard Business Review, 92, 90-99.

Johnson, A.M., \& Lederer, A.L. (2005). The effect of communication frequency and channel richness on the convergence between chief executive and chief information officers. Journal of Management Information Systems, 22, 227-252.

Karahanna, E., \& Preston, D.S. (2013). The effect of social capital of the relationship between the CIO and top management team on firm performance. Journal of Management Information Systems, 30, 15-56. 
Karahanna, E., Straub, D.W., \& Chervany, N.L. (1999). Information technology adoption across time: A cross-sectional comparison of pre-adoption and post-adoption beliefs. MIS Quarterly, 23, 183-213.

Kearns, G.S., \& Sabherwal, R. (2007). Antecedents and consequences of information systems planning integration. IEEE Transactions on Engineering Management, 54, 628-643.

Kellerman, B. (2004). Bad leadership: What it is, how it happens, why it matters. Boston: Harvard Business School Press.

Ketchen, D.J., Thomas, J.B., \& Snow, C.C. (1993). Organizational configurations and performance. Academy of Management Journal, 36, 1278-1313.

Khurana, R. (2002). The curse of the superstar CEO. Harvard Business Review, 80, 60-67.

Knight, E., \& Paroutis, S. (2017). Becoming salient: The TMT leader's role in shaping the interpretive context of paradoxical tensions. Organization Studies, 38, 403-432.

Kotha, S., \& Vadlamani, B.L. (1995). Assessing generic strategies: An empirical investigation of two competing typologies in discrete manufacturing industries. Strategic Management Journal, 16, 75-83.

Kunisch, S., Müller-Stewens, G., \& Campbell, A. (2014). Why corporate functions stumble. Harvard Business Review, 92, 110-117.

Lenox, M., \& King, A. (2004). Prospects for developing absorptive capacity through internal information provision. Strategic Management Journal, 25, 331-345.

Lewellyn, K.B., \& Fainshmidt, S. (2017). Effectiveness of CEO power bundles and discretion context: Unpacking the 'fuzziness' of the CEO duality puzzle. Organization Studies, 38, $1603-1624$.

Li, Q., Maggitti, P.G., Smith, K.G., Tesluk, P.E., \& Katila, R. (2013). Top management attention to innovation: The role of search selection and intensity in new product introductions. Academy of Management Journal, 56, 893-916.

Lubit, R. (2004). The tyranny of toxic managers: Applying emotional intelligence to deal with difficult personalities. Ivey Business Journal, 68, 1-7.

Makri, M., \& Scandura, T.A. (2010). Exploring the effects of creative CEO leadership on innovation in high-technology firms. The Leadership Quarterly, 21, 75-88.

Marcel, J.J. (2009). Why top management team characteristics matter when employing a chief operating officer: A strategic contingency perspective. Strategic Management Journal, 30, $647-658$.

Matt, C., Hess, T., \& Benlian, A. (2015). Digital transformation strategies. Business \& Information Systems Engineering, 57, 339-343.

McDonald, M.P., \& Rowsell-Jones, A. (2012). The digital edge: Exploiting information \& technology for business advantage. Stamford: Gartner.

Medcof, J.W. (2008). The organizational influence of the Chief Technology Officer. $R \& D$ Management, 38, 406-420.

Menz, M. (2012). Functional top management team members: A review, synthesis, and research agenda. Journal of Management, 38, 45-80.

Menz, M., \& Scheef, C. (2014). Chief Strategy Officers: Contingency analysis of their presence in top management teams. Strategic Management Journal, 35, 461-471. 
Meuer, J. (2014). Archetypes of inter-firm relations in the implementation of management innovation: A set-theoretic study in China's biopharmaceutical industry. Organization Studies, 35, 121-145.

Meyer, A.D., Tsui, A.S., \& Hinings, C.R. (1993). Configurational approaches to organizational analysis. Academy of Management Journal, 36, 1175-1195.

Milovich, M. (2015). Moving technology leaders up the influence curve. MIS Quarterly Executive, 14, 39-49.

Misangyi, V.F., \& Acharya, A.G. (2014). Substituting or complements? A configurational examination of corporate governance mechanisms. Academy of Management Journal, 57, 1681-1705.

Misangyi, V.F., Greckhamer, T., Furnari, S., Fiss, P.C., Crilly, D., \& Aguilera, R. (2017). Embracing causal complexity: The emergence of a neo-configurational perspective. Journal of Management, 43, 255-282.

Mumford, M.D., Scott, G.M., Gaddis, B., \& Strange, J.M. (2002). Leading creative people: Orchestrating expertise and relationships. The Leadership Quarterly, 13, 705-750.

Nahapiet, J., \& Ghoshal, S. (1998). Social capital, intellectual capital, and the organizational advantage. Academy of Management Review, 23, 242-266.

Nambisan, S., Lyytinen, K., Majchrzak, A., \& Song, M. (2017). Digital innovation management: Reinventing innovation management research in a digital world. MIS Quarterly, 41, 223-238.

Péladeau, P., Acker, O., \& Müller, K. (2019). The 2019 Chief Digital Officer (CDO) study: Global findings. Retrieved from: https://www.strategyand.pwc.com/media/file/2019-CDOStudy_Global-findings.pdf

Peppard, J. (2010). Unlocking the performance of the Chief Information Officer (CIO). California Management Review, 52, 73-99.

Podsakoff, P.M., MacKenzie, S.B., Lee, J.-Y., \& Podsakoff, N.P. (2003). Common method biases in behavioral research. Journal of Applied Psychology, 88, 879-903.

Ordanini, A., Parasuraman, A., \& Rubera, G. (2014). When the recipe is more important than the ingredients: A qualitative comparative analysis (QCA) of service innovation configurations. Journal of Service Research, 17, 134-149.

Ragin, C.C. (2008). Redesigning social inquiry. Chicago: University of Chicago Press.

Ragin, C.C., \& Davey, S. (2016). Fuzzy-set qualitative comparative analysis 3.0. Irvine: Department of Sociology, University of California.

Ragin, C.C., \& Fiss, P.C. (2008). Net effects analysis vs. configurational analysis. In C.C. Ragin (Ed.), Redesigning Social Inquiry (pp. 190-212). Chicago: University of Chicago Press.

Rickards, T., Smaje, K., \& Sohoni, V. (2015). 'Transformer in chief': The new Chief Digital Officer. Retrieved from: https://www.mckinsey.com/business-functions/organization/ourinsights/transformer-in-chief-the-new-chief-digital-officer

Rost, K., Hölzle, K., \& Gemünden, H.G. (2007). Promotors or champions? Pros and cons of role specialisation. Schmalenbach Business Review, 59, 340-363.

Saldanha, T., \& Krishnan, M. (2011). Leveraging IT for business innovation: Does the role of the CIO matter? In Proceedings of the 32th International Conference on Information Systems (ICIS), Shanghai, December 4-7. 
Sambamurthy, V., Bharadwaj, A., \& Grover, V. (2003). Shaping agility through digital options: Reconceptualizing the role of information technology in contemporary firms. MIS Quarterly, 27, 237-263.

Sealey, D. (2015). Does Starbucks show that organizations need a Chief Digital Officer?. Retrieved from: https://econsultancy.com/blog/66470-does-starbucks-show-thatorganisations-need-a-chief-digital-officer/

Schilke, O., \& Goerzen, A. (2010). Alliance management capability: An investigation of the construct and its measurement. Journal of Management, 36, 1192-1219.

Scott, S.G., \& Bruce, R.A. (1994). Determinants of innovative behavior: A path model of individual innovation in the workplace. Academy of Management Journal, 37, 580-607.

Singh, A., \& Hess, T. (2017). How Chief Digital Officers promote the digital transformation of their companies. MIS Quarterly Executive, 16, 1-17.

Smaltz, D.H., Sambamurthy, V., \& Agarwal, R. (2006). The antecedents of CIO role effectiveness in organizations. IEEE Transactions on Engineering Management, 53, 207222.

Spreitzer, G.M. (1995). Psychological empowerment in the workplace. Academy of Management Journal, 38, 1442-1465.

Stephen, A.T., \& Toubia, O. (2009). Explaining the power-law degree distribution in a social commerce network. Social Networks, 31, 262-270.

Teerlink, M., Sigmon, P.W., Gow, B., \& Banerjee, K. (2014). The new hero of big data and analytics. Somers: IBM Corporation.

Tichy, N.M., Tushman, M.L., and Fombrun, C. (1979). Social network analysis for organizations. Academy of Management Review, 4, 507-519.

Tumbas, S., Berente, N., \& vom Brocke, J. (2017). Three types of Chief Digital Officers and the reasons organizations adopt the role. MIS Quarterly Executive, 16, 121-134.

Tushman, M.L., \& Scanlan, T.J. (1981). Boundary spanning individuals: Their role in information transfer and their antecedents. Academy of Management Journal, 24, 289-305.

Wagemann, C., \& Schneider, C.Q. (2010). Standards of good practice in qualitative comparative analysis (QCA) and fuzzy-sets. Comparative Sociology, 9, 397-418.

Watts, S., \& Henderson, J.C. (2006). Innovative IT climates: CIO perspectives. Journal of Strategic Information Systems, 15, 125-151.

Weill, P., \& Woerner, S.L. (2015). Thriving in an increasingly digital ecosystem. MIT Sloan Management Review, 56, 27-34.

Yadav, M.S., Prabhu, J.C., \& Chandy, R.K. (2007). Managing the future: CEO attention and innovation outcomes. Journal of Marketing, 71, 84-101.

Yoo, Y., Boland, R.J., Lyytinen, K., \& Majchrzak, A. (2012). Organizing for innovation in the digitized world. Organization Science, 23, 1398-1408.

Yukl, G. (2012). Effective leadership behavior: What we know and what questions need more attention. Academy of Management Perspectives, 26, 66-85. 
2. Publication 2: Toward a Taxonomy of Innovation Leadership on the C-Level - An Exploratory Study on the Leadership Behaviors of Senior Executives

\subsection{Note on Submitted Paper}

The following paper titled "Toward a Taxonomy of Innovation Leadership on the C-LevelAn Exploratory Study on the Leadership Behaviors of Senior Executives" was authored by me as single author. I submitted the paper to a leading international academic journal (VHB: A; ABS: 4) where it is currently under review.

An earlier version of the paper has been accepted for presentation at the 80th Annual Meeting of the Academy of Management in Vancouver, Canada (date of presentation: August $11^{\text {th }}, 2020$ ) after a double-blind peer-review process. The conference editors selected the paper among the best $10 \%$ of accepted submissions. Thus, an abridged 6-page version of the paper was published in the Academy of Management Best Paper Proceedings.

Publication details:

Reck, F. (2020). Toward a taxonomy of innovation leadership on the c-level. Academy of Management Best Paper Proceedings, 19523-1-19523-6.

https://doi.org/10.5465/AMBPP.2020.32 


\title{
2.2. Academic Paper
}

\begin{abstract}
There is broad evidence for the impact of senior executives on organizational innovation. Still, research lacks insight what top managers "actually do", i.e., by which behaviors they promote innovation in the firm. Drawing on strategic leadership theory and configuration theory, this paper develops a taxonomy of innovation leadership on the c-level. I first review research literature to subsume four different leadership behaviors that cover the major ways of how top managers get involved in organizational innovation. Second, I employ cluster analysis on survey data from 411 senior executives in German manufacturing firms to classify different innovation leadership "styles", i.e., how top managers combine those four innovation leadership behaviors. Third, I conduct discriminant analysis to explore if variables discussed in strategic leadership theory such as demographics, professional background, personality, and job characteristics predict in which innovation leadership behaviors top managers engage. As a result, eight different types of top managers and innovation leadership styles are identified: (1) Lightweight; (2) Inventor; (3) Hands-on Innovator; (4) Entrepreneur; (5) Headcoach; (6) Gardener; (7) Evangelist; (8) Superhero. Furthermore, discriminant analysis demonstrates that for each of these eight types a distinct profile of observable experiences, personality traits, and job characteristic exists.
\end{abstract}

Keywords: Innovation Leadership; Top Management; Organizational Innovation; Configuration Theory; Cluster Analysis; Discriminant Analysis

\section{PRACTITIONER POINTS}

- There are eight types of top managers regarding their innovation leadership "style", i.e., the behaviors in which they engage to foster innovation in the firm.

- The innovation leadership behavior of a top manager most distinctly depends on personality and job characteristics.

- There is no "one-size-fits-all"-approach to innovation leadership and it is unlikely that a single manager possesses the skills and resources to simultaneously exert the full spectrum of behaviors necessary to initiate and enable innovation in the firm.

- Effective innovation leadership on the c-level should thus be perceived as teamwork and will most likely require the active involvement of different top managers in the firm instead of "great men".

\section{INTRODUCTION}

Management research provides broad evidence for the significant impact of top-level executives on organizational innovation (e.g. Damanpour \& Schneider, 2009; Green, 1995; Hoffman \& Hegarty, 1993; Talke et al., 2011). However, despite the assumed importance of top managers for firms' innovation outcomes, academic research provides surprisingly little insight on "innovation leadership" on the c-level, i.e., by which behaviors top managers "stimulate, steer, and sustain innovation in their organization" (Deschamps, 2008: xiii). Most research simply used demographic proxies in order to represent top managers' motivation and 
ability to get involved in organizational innovation (Damanpour \& Schneider, 2009; Gerstner et al., 2013; Hoffman \& Hegarty, 1993). Hence, the majority of works just inferred top managers' innovation leadership behaviors but did not conceptualize and examine the nature and impact of those behaviors (Elenkov et al., 2005; Makri \& Scandura, 2010).

The small body of research that actually discusses c-level innovation leadership suffers from several limitations. First, most studies tend to focus exclusively on a narrow set of innovation leadership behaviors, either direct "technical" influence of $\mathrm{CxOs}$ on innovation outcomes (e.g. Li et al., 2013; Yadav et al., 2007) or indirect "social” influence (e.g. Jung et al., 2008; Tsui et al., 2006), either top managers involvement on the project (e.g. Gomes et al., 2001; Green, 1995) or on the firm level (e.g. Papadakis \& Bourantas, 1998; Slater et al., 2014). Consequently, those works do not adequately address the notion that " $[\mathrm{t}]$ here are a number of ways by which strategic leaders can influence organizational innovation processes" (Elenkov et al., 2005: 669).

Second, no research exists that discusses how strategic leaders configure different types of leadership behaviors to instigate innovation. Most studies treat innovation leadership as a continuous variable on a one-dimensional scale. This is in sharp contrast to case-based observations in top management literature that point at the existence of different managerial "styles" (Finkelstein et al., 2009; Mintzberg, 2009) and provide various anecdotes on how managers may benefit innovation by combining different leadership behaviors in different ways (Deschamps, 2008; Hansen \& Birkinshaw, 2007; Hunter \& Cushenbery, 2011).

Third, there is little discussion of the antecedents of innovation leadership in current literature. Generally, the vast majority of studies uses top managers' innovation leadership as independent variable affecting firm-level innovation outcomes rather than as a dependent or mediator variable (e.g. Elenkov et al., 2005; Green, 1995; Makri \& Scandura, 2010; Yadav et al., 2007). In their literature review on top management involvement in NPD, for instance, Felekoglu and Moultrie therefore remark that "[v]ery few studies provide information on the reasons why/why not top management gets involved in NPD projects" (2014: 73). Hence, they suggest that research should try to understand the reasons why top management gets involved in organizational innovation as well as to understand the factors driving this involvement.

In this paper, I aim to provide insight into these research gaps by developing a taxonomy of the innovation leadership styles of top managers. The specific research goals behind this approach are the following: (1) to develop a comprehensive model of top managers' behaviors that constitute innovation leadership at the c-level; (2) to empirically identify varieties in how top managers configure different behaviors (innovation leadership styles) and classify top managers into different types; (3) to explore the antecedents of different configurations of innovation leadership behaviors by empirically identifying profiles of personal and positional characteristics for each identified type of top manager.

The empirical focus of my study thereby is on functional top managers (CxOs) - executives responsible for one or more functional areas such as finance, operations, or marketing (Menz, 2012). I choose this focus for several reasons. First, while a large majority of past studies focuses on the role of the Chief Executive Officer (CEO) in organizational innovation (Finkelstein et al., 2009), functional top managers have an important impact on organizational 
outcomes but are largely ignored in research literature (Guadalupe et al., 2014). Second, the focus on functional top managers allows for comparing the innovative contribution of different members of the top management team (TMT) and is thus likely to provide a more faceted overview on top managers' innovation behaviors than a study among CEOs would (Hambrick, 2007). Third, whereas CEOs might be freer in choosing the contents of their managerial work (Hambrick \& Cannella, 2004), the task context of various $\mathrm{CxO}$ positions provides a set of potential influence variables on top managers' leadership behavior that is worth to be examined (Menz, 2012).

\section{THEORETICAL BACKGROUND}

\section{Top Managers, Strategic Leadership, and Organizational Innovation}

Research literature consistently treats top management as one of the most important influence factors on organizational innovation (e.g. Damanpour \& Schneider, 2009; Felekoglu \& Moultrie, 2014; Slater et al., 2014). In this paper, I follow Crossan and Apaydin in defining the term "organizational innovation" as the "production or adoption, assimilation, and exploitation of a value-added novelty in economic and social spheres; renewal and enlargement of products, services, and markets; development of new methods of production; and establishment of new management systems" (2010: 1155). The term thus broadly describes innovation capabilities and outcomes in the firm context and infers a relative as opposed to an absolute view on the novelty dimension of innovation (i.e., a novel solution or practice is considered an innovation if it is "new to the firm" instead of "new to the world").

Most works draw on strategic leadership theory as referential frame (Cannella \& Monroe, 1997; Finkelstein et al., 2009; Makri \& Scandura, 2010). Strategic leadership theory advocates a perspective of "the organization as a reflection of its top managers" (Hambrick \& Mason, 1984: 193). Top managers possess a unique position in the firm that allows them to allocate critical resources to innovation initiatives and programs (e.g. Barker \& Mueller, 2002; Garms \& Engelen, 2019; Makri et al., 2006). Due to their hierarchical power, top managers thus considerably affect organizational innovation by their attention and efforts, either positively (e.g. Elenkov et al., 2005; Papadakis \& Bourantas, 1998; Yadav et al., 2007) or negatively (e.g. Khurana, 2002; Tripsas \& Gavetti, 2000).

According to strategic leadership theory, top managers can influence organizational innovation in a number of different ways and by a number of different behaviors. Makri and Scandura (2010), for instance, differentiated between operational leadership (i.e., monitoring, scouting, evaluating, and venturing opportunities in the firm's environment) and creative leadership (i.e., stimulating creative staff, providing mentorship, and promoting individual initiative). Elenkov et al. discussed four different behaviors by which strategic leaders may promote firm-level innovation outcomes: "[1] seeing environmental trends that affect the organization's future and providing more effective communication to the rest of the organization [...] [2] the creation of an exciting vision of the future about successfully conducted innovation activity [...] [3] the selection, promotion, and ongoing support of change champions [...] [4] to create an organizational culture in which productive work is done, productive workers are rewarded, and 
productive relationships are built and enhanced" (2005: 669). Hunter and Cushenbery (2011) distinguish between direct and indirect influences of leaders on innovation and creativity. Thereby, they use celebrity CEOs such as Larry Page or Steve Jobs as examples to illustrate a range of different leadership behaviors such as "creative input and idea suggestion", "vision and strategy", "resource allocation", "establishing a climate for creativity".

While thus there is somewhat informed insight on a number of different innovation-related behaviors that top managers may exert, those single behaviors will most likely be insufficient for capturing the concept of c-level innovation leadership comprehensively. Following current perspectives on the issue, strategic leadership should be perceived as the full range of actions and behaviors in which a top manager might engage to solve organizational problems and thus influence organizational outcomes (such as innovation) (Antonakis \& House, 2014; Li \& Patel, 2019). As such organizational problems tend to be highly complex, strategic leaders usually must combine and engage in a number of different problem-oriented behaviors. Mintzberg (2009) and Finkelstein et al. (2009) therefore highlight the importance of "managerial styles" respectively "leadership patterns" for understanding strategic leadership. Such styles of leadership represent combinations of different influence tactics, different strategic or organizational issues emphasized, and different activities in which a top manager engages when tackling an organizational issue.

In line with such notions, several works in the fields of innovation management suggest that innovation leadership is a multi-dimensional concept and different behaviors need to be combined to promote innovation in the firm (e.g. Deschamps, 2008; Elenkov et al., 2005; Hunter \& Cushenbery, 2011; Mumford \& Licuanan, 2004; Tsui et al., 2006). Also, especially practice-oriented works provide various anecdotes on how managers may benefit innovation by combining different leadership behaviors in different ways. For instance, Google's Larry Page or Facebook's Mark Zuckerberg have been described as epicenters of innovation in their firm. They are described as using their technical expertise and their business acumen to directly get involved in idea generation and product development, even after their company had grown from start-up to corporate (Hunter \& Cushenbery, 2011; Yadav et al., 2007). In contrast, former CEOs A. G. Lafley (P\&G), Steve Bennett (Intuit), and Jack Welch (GE) were mainly praised for their ability to set up adequate organizational structures, define innovation strategies and processes, and mentor innovative employees. On the flipside, they engaged less in operational tasks such as the implementation of new projects and practices (Hansen \& Birkinshaw, 2007; Lakshman, 2005).

Concerning c-level innovation leadership, Deschamps (2008: xv) thus draws the following conclusion: "there is not a 'one-size-fits-all' approach to innovation leadership! There are probably several types of innovation leaders". Those types of innovation leaders will differ from each other with regard to the leadership behaviors in which they engage and which they combine to foster innovation in their firm. In other words, those types of innovation leaders will feature different "styles" of innovation leadership. The goal of this paper is to systematically identify which combinations of innovation leadership behaviors prevail among top managers. As a result, a taxonomy of c-level innovation leadership will be developed that serves to describe those different innovation leadership styles based on large scale empirical evidence. 


\section{Toward a Taxonomy of C-level Innovation Leadership}

In order to explore the innovation leadership styles of top managers and develop a taxonomy of innovation leadership on the c-level, I employ a classification approach. Classification approaches are rooted in configuration theory. Configuration theory proposes that phenomena in the field of management are characterized by bundles of attributes rather than by individual attributes in isolation (e.g. Doty \& Glick, 1994; Fiss, 2011). One key assumption of is that for most organizational or managerial settings, attributes related to a particular phenomenon are usually interdependent and tend to fall into coherent patterns, so called "configurations" (Dess et al., 1993). Thereby, the number of different configurations that can be observed empirically will be limited. The "classification approach" aims to identify those patterns and develop taxonomies, i.e., "sets of different configurations that collectively exhaust a large fraction of the target population of organizations [or other units of analysis such as individual top managers] under consideration" (Miller \& Friesen, 1984: 12). Taxonomies structure complex phenomena into a finite set of easy-to-remember profiles (Doty \& Glick, 1994). Based on such profiles, more comprehensive management theories can be developed that go beyond the scope of the isolated effects of single attributes (Fiss, 2011).

The classification approach employed in this paper comprises two steps. The first step serves to discern different types of top managers with regard to their style of innovation leadership, i.e., to identify the configurations of innovation leadership behaviors that are the most empirically relevant. To this end, I draw on previous literature to develop a conceptual model that captures the major domains of innovation leadership on the c-level. Those conceptual domains of innovation leadership then determine the input variables for cluster analysis. In the second step, I aim to explore if different combinations of demographics, experiences, personality traits, and job characteristics predict the likelihood for top managers to engage in a certain innovation leadership style. Drawing on the literature referencing to strategic leadership theory, I select a set of core constructs that have been assumed to influence the way in which top managers engage in organizational innovation and employ discriminant analysis. Discriminant analysis "takes into account all of the independent variables and their interrelationships to produce a function that maximally distinguishes among the groups" (Ehrhart \& Klein, 2001: 168). The emphasis of this second step of my research approach is thus on the combinations of personal and positional characteristics that are related to each innovation leadership style rather than hypothesizing isolated effects.

\section{CONCEPTUAL MODEL}

\section{Procedure for Selecting Constructs}

Following the two-step approach of taxonomy development, the conceptual model comprises two sets of variables. The first set aims to capture major types of innovation leadership behaviors. The variables in this set will serve as the criteria for classifying top managers and their innovation leadership styles. The second set of variables comprises personal and job characteristics. In contrast to the first set, the second set of variables is not used to group top managers based on their style of innovation leadership. Instead, those variables are used to 
explore how demographics, professional background, personality, and job context affect the probability of a certain top manager to engage in a certain innovation leadership style.

Previous literature provides several recommendations on how to determine input variables for classifying empirical observations and identifying consistent groups in taxonomy development (Dess et al., 1993). In general, it is suggested to choose variables "in a way that fosters rich description of a sample's characteristics" (Ketchen \& Shook, 1996: 444). To this end, three criteria are agreed upon by scholars: (1) exhaustive coverage of conceptual domains related to the investigated phenomenon; (2) limited conceptual overlap between the selected variables; (3) parsimonious number of variables included to allow for meaningful interpretation (Gruber et al., 2010; Homburg et al., 2008). With those criteria in mind, I review literature on top managers and innovation leadership and select the core constructs discussed or examined in these works (based on repeated emphasis the literature and their expected causal relevance). In the following, I describe the constructs employed in more detail.

\section{Innovation Leadership Behaviors}

To identify relevant innovation leadership behaviors at the c-level, I reviewed academic literature on strategic leadership and top management involvement in organizational innovation. In general, there are two major streams of top management research that conceptualize and operationalize top managers' innovation leadership behaviors. On the one hand, studies in the fields of strategic management and organizational studies draw on the concept of transformational leadership as well as Bass and Avolio's (1992) Multifactor Leadership Questionnaire (MLQ) to represent top managers' behaviors linked to organizational innovation (Elenkov et al., 2005; Jung et al., 2008; Ling et al., 2008). However, this approach has been criticized as "the MLQ does not capture the behaviors of a CEO [and in a broader sense those of other top managers] which are most associated with the dimensions of the innovation value chain" (Makri \& Scandura, 2010: 77). Hence, it is argued that while "these traditional conceptualizations can reflect the CEO's relationship with followers, the concept of strategic leadership in the context of high-technology firms calls for constructs reflective of the CEO's overall effectiveness in spearheading invention, innovation and commercialization" (Makri \& Scandura, 2010: 75).

On the other hand, studies from the innovation and new product development (NPD) background employed the construct "top management involvement" to conceptualize and measure leadership behaviors by which top managers actively influence innovation outcomes (e.g. Gomes et al., 2001; Green, 1995; Hegarty \& Hoffman, 1990; Kleinschmidt et al., 2007; Rodrìguez et al., 2008; Unger et al., 2012). However, Felekoglu et al. (2014) remark in their comprehensive review of this stream of literature that there is a lack of consistency with regard to the behaviors that constitute top management involvement in organizational innovation. Moreover, studies in this stream focus more on "the process-related roles of senior management" and less on "involvement where top management spends time and is in contact with other people" (Felekoglu et al., 2014: 173).

In all, it can be stated that literature might mention, discuss, and examine a range of different leadership behaviors by which top managers may contribute to organizational innovation. 
However, it is also evident that prevailing perspectives on c-level innovation leadership are inconclusive in several ways. First, the concepts employed are unidimensional by representing either direct "technical" influence of $\mathrm{CxOs}$ on innovation outcomes or indirect "social" influence, either influence on the project or on the firm level (Felekoglu et al., 2014). Second, frequently employed concepts such as "transformational leadership" or "top management involvement" have originally been developed to capture issues such as the general relationship between organizational leaders and followers or general success factors for NPD initiatives, but not for measuring top managers' engagement in organizational innovation. Hence, those concepts do not pinpoint how top managers take influence in the innovation process (Makri \& Scandura, 2010). Third, while research mentioned, discussed, and examined a range of leadership behaviors by which top managers may contribute to organizational innovation, few attempts have been made to structure those behaviors into a framework that captures the different facets of c-level innovation leadership comprehensively.

Due to these limitations in previous research, I could not rely on using existing concepts in order to select a set of variables that fulfill the requirements of exhaustive coverage, limited conceptual overlap, and parsimoniousness. Instead, I had to establish a scheme for grouping innovation leadership behaviors into mutually exclusive and collectively exhaustive categories. This scheme structures the concept of c-level innovation leadership based on two criteria: (1) immediacy of a top managers' involvement in organizational innovation; (2) level of organization on which a top manager contributes to organizational innovation. Concerning the former, I follow Hunter and Cushenbery who distinguished between top managers' direct influences "such as resource allocation or explicit creative idea generation" and indirect influences "such as the establishment of an environment that permits novel thinking" (2011: 253). Concerning the latter, I adopt the conceptions of Felekoglu and Moultrie (2014), Deschamps (2008), and Gomes et al. (2001) who discern top managers' contributions on the project and the firm level.

With regard to the direct vs. indirect influence taking of top managers on organizational innovation, some works perceive innovation leadership as a top-down activity whereas others view innovation leadership as the efforts of a top manager to support bottom-up innovation. Both behaviors lead to quite different contributions of top managers in the context of organizational innovation (Deschamps, 2008; Hunter \& Cushenbery, 2011). By engaging in the former, the top manager takes the role of an epicenter of innovation in the firm (Yadav et al., 2007). Doing so, CxOs direct their attention to the technical/operational/“hard" aspects of organizational innovation (Felekoglu \& Moultrie, 2014; Makri \& Scandura, 2010) by actively taking part in innovation initiatives, implementing new ideas, and providing a strategic roadmap for the future development of the firm (e.g. Damanpour \& Schneider, 2009; Li et al., 2013). In contrast, the latter behavior assigns an indirect role to top managers and perceives them more as enablers of innovation (Hunter \& Cushenbery, 2011; Mumford et al., 2002). Here, rather than taking direct influence, top managers attend to the social/"soft" aspects of organizational innovation. They thereby play “an important role in leveraging the firm's internal resources and capabilities, especially human and social capital, and in creating a corporate environment that fosters invention and creates new knowledge content" (Makri \& Scandura, 2010: 78). 
Concerning the level of organization, top managers can influence organizational innovation by leadership actions either on the project or the firm level. In order to innovate effectively, firms need to be able to excel at the development and commercialization of new products, services, processes, or business models (project/operative level) but also require adequate plans, structures, and cultural values for aligning individual innovation initiatives (firm/strategic level) (Cooper, 1999). As a consequence, some leadership behaviors discussed in the literature address the project level (e.g. Enns et al., 2003; Gomes et al., 2001; Green, 1995) whereas others address the overall firm level (e.g. Hegarty \& Hoffman, 1990; Makri \& Scandura, 2010; Papadakis \& Bourantas, 1998). On the project level, top managers can benefit the firm by using their expertise, legitimacy, and organizational knowledge to support the implementation of a new idea (Yadav et al., 2007). In contrast, on the firm level, top managers' contribution lies in ensuring a firm's capacity for innovation and aligning the innovation portfolio to overall business strategy (Slater et al., 2014). The former perspective thus views top managers' contribution more as a hands-on operational activity with a tangible innovative task (Green, 1995) whereas the latter assumes a more intangible task frame and denotes the strategic development of a firm's innovative capability (Pisano, 2015).

Using those two criteria to structure innovation leadership on the c-level, a $2 \times 2$ matrix for categorizing different leadership behaviors can be derived (see Figure 1). The four fields of the matrix depict four different bundles of behaviors: (1) involvement in idea creation and innovation projects (direct contribution at the project level); (2) sponsoring innovators and innovation projects (indirect contribution at the project level); (3) formulation and implementation of an innovation strategy (direct contribution at the firm level); (4) establishing a climate for innovation (indirect contribution at the firm level).

The first group of behaviors involvement in idea creation and innovation projects describes when top managers contribute to organizational innovation by being "the idea generators and not simply the shepherds of novel thinking" (Hunter \& Cushenbery, 2011: 256). Behaviors that fall into this category include: active search for new ideas and useful solutions to business problems ( $\mathrm{Li}$ et al., 2013), engagement in the development of concepts and prototypes (Damanpour \& Schneider, 2009), and championing the implementation of the developed solutions (Howell \& Higgins, 1990).

The second behavior sponsoring innovators and innovation projects depicts top managers that indirectly influence organizational innovation by providing guidance, support, and mentorship (Hunter \& Cushenbery, 2011). Among others, top managers can stimulate and enable the innovative efforts of others through giving advice and feedback (Watts \& Henderson, 2006), establishing communication links between innovators and key decision-makers (Makri \& Scandura, 2010), or securing and allocating resources and manpower (Gottschalk, 1999).

Formulation and implementation of an innovation strategy as the third group of innovation leadership behaviors comprises among others if a top manager develops and articulates a vision of the technological and market-related development path of the firm (Lynn \& Reilly, 2002), develops a goal and metric system for capturing the firm's progress (Christensen et al., 2008), 
or strengthens the firm's innovative capability by resource planning and skill development (e.g. by closing skill gaps through attracting talent) (Pisano, 2015).

Fourth, establishing a climate for innovation describes when a top manager deals with creating an organizational climate that facilitates innovation, creativity, and exploration (Makri \& Scandura, 2010). Among others, a top manager that exerts behaviors of this type will try to provoke new ways of thinking by challenging staff (Milovich, 2015), free up space in work schedules to allow for employees' engagement in creative projects (Mumford et al., 2002), or encourage a learning culture in which mistakes are seen as opportunities (Watts \& Henderson, 2006).

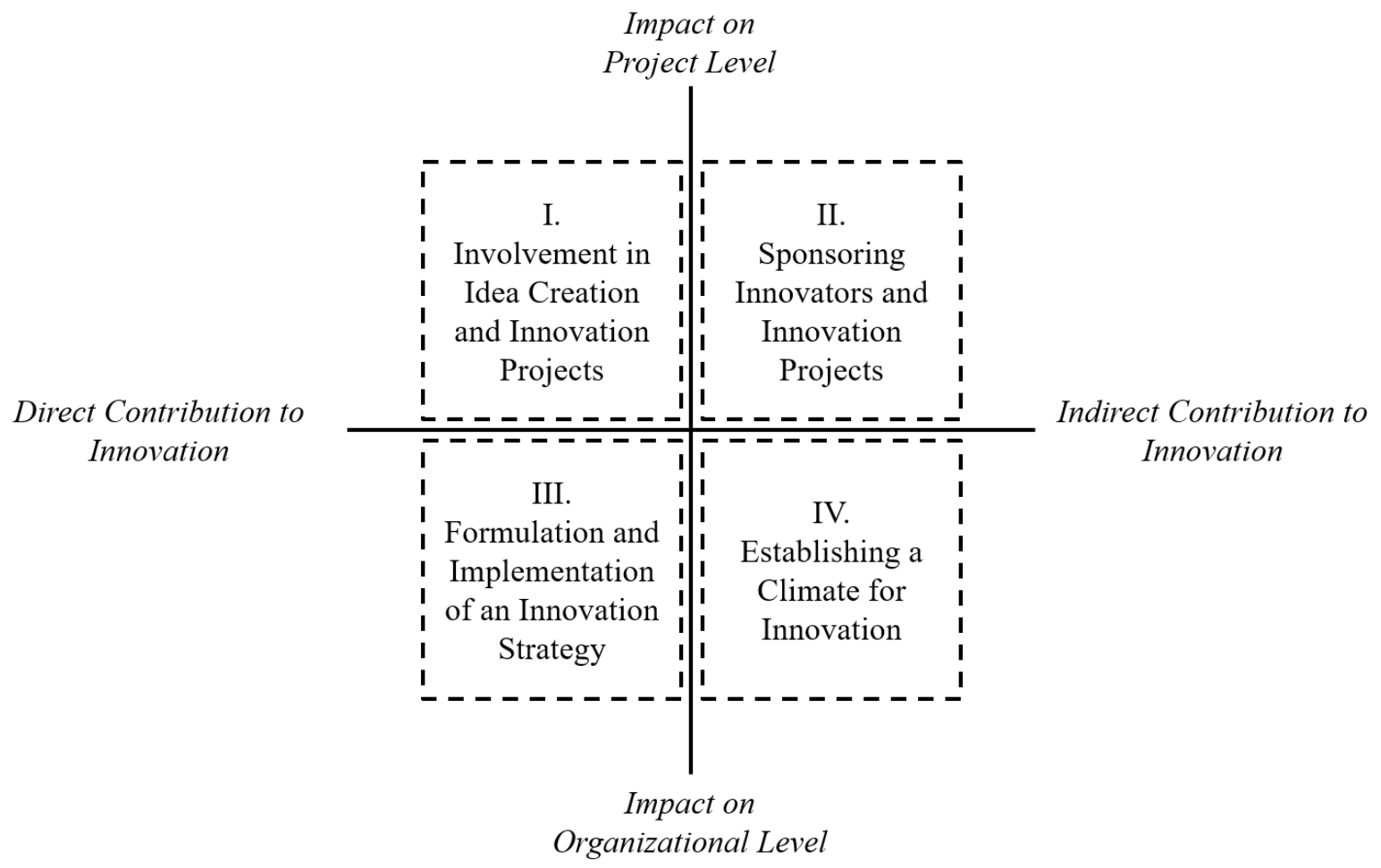

Figure II-2-1. Innovation leadership behaviors at the c-level (own illustration)

Those four behavioral domains match well with previous works that explicitly discuss and differentiate between the multiple ways in which top managers may influence innovation in the firm (Deschamps, 2008; Elenkov et al., 2005; Gomes et al., 2001; Hunter \& Cushenbery, 2011). They arguably span the range of functions top managers may fulfill in the context of organizational innovation quite exhaustively. Furthermore, the behaviors are conceptually delineated from each other and together allow for specifying, comparing, and differentiating the innovation-related actions of top managers. Hence, I use this four-dimensional framework as basis for the classification approach and employ the four types of innovation leadership behaviors as clustering variables. 


\section{Determinants of Top Managers' Innovation Leadership Behavior}

Next, I describe the variables that are used to explore the antecedent conditions that predict which innovation leadership style a top manager takes. From its origin on, strategic leadership theory has attributed differences in top managers' behaviors to personal characteristics (Cannella \& Monroe, 1997; Finkelstein et al., 2009; Hambrick, 2007; Hambrick \& Mason, 1984). For instance, Finkelstein et al. argue that in performing their work task and tackling organizational problems, top managers "inject a great deal of themselves - their experiences, preferences, and personalities, for instance - into figuring out what to do" (2009: 44). Personal "executive orientation" which comprises both observable experiences and underlying psychological characteristics (Bromiley \& Rau, 2016; Carpenter et al., 2004; Finkelstein et al., 2009) will thus most likely influence the innovation leadership behaviors in which a top manager engages. As both classes of personal characteristics cover different but equally relevant aspects representing the top manager as an individual person (Finkelstein et al., 2009), the conceptual model of this work will include both observable (demographics and professional background) and psychological variables (personality).

While strategic leadership theory assumes that personal characteristics play a major role in determining top managers' leadership behavior, research also acknowledges that managerial styles are shaped by external expectations and the necessities of the managerial job. As Mintzberg (2009: 130) puts it, "context matters: people don't usually find themselves in managerial jobs by chance, to shape them as they wish. [...] Rather, what you do as a manager is mostly determined by what you face as a manager.". Top managers are generally directed "by their environment in stimulus-response exchanges" (Tengblad, 2006: 1456). Therefore, job contents (e.g. Grover et al., 1993; Paolillo, 1987), job demands (e.g. Hambrick et al., 2005a; Wu et al., 2014), and incentivized outcomes (e.g. Alessandri \& Pattit, 2014; Makri et al., 2006) most likely will impact how top managers interpret their job and, more specifically, how they engage in innovation-related behaviors. Hence, I include job characteristics along with personal characteristics in my research model.

Observable Experiences: Observable characteristics such as demographics, education, or functional background have for long been prominent in top management studies in the context of innovation (e.g. Barker \& Mueller, 2002; Damanpour \& Schneider, 2009; Hoffman \& Hegarty, 1993). Those factors are widely assumed to translate into different problem-solving and cognition styles as well as to reflect differences in personal interests (Hambrick \& Mason, 1984). In my conceptual model, I include four variables that cover the three factors that are widely agreed upon to reflect a top manager's personal experiences: age, education, functional background (Finkelstein et al., 2009).

The first observable characteristics included in my conceptual model is age. On the one hand, research suggests that older top managers are less likely to spearhead innovation initiatives as they might be socialized to the current status quo (Barker \& Mueller, 2002; Li \& Tan, 2013). On the other hand, seniority can lead to better insight into complex business problems as well as respect from colleagues and employees so that older managers are often very inclined to serve as mentors in the innovation process (Damanpour \& Schneider, 2009). 
Concerning education, research has differentiated between the level and type of education. Higher levels of education are seen to be linked to better information processing abilities, higher flexibility of thinking, and a more positive attitude towards novel ideas which all may have an impact on the "style" of innovation leadership (Damanpour \& Schneider, 2009; Garms \& Engelen, 2019). In contrast, the type of education is likely to reflect certain worldviews, approaches to problem solving, but also tendencies in interacting with other people (Enns et al., 2003; Tyler \& Steensma, 1998). Managers with a technical degree (i.e., a degree in science or engineering) have thereby been assumed to promote innovation rather directly by contributing their expertise and establishing technological issues on the firm's strategic agenda (Barker \& Mueller, 2002; Islam \& Zein, 2019). However, other works have argued that "technicians" may miss out compared to managers holding business, economic, or legal degrees when it comes to the administrative, social, and political issues of organizational innovation (Finkelstein et al., 2009; Garms \& Engelen, 2019).

Finally, concerning functional background, the career path of top managers, in particular the diversity of organizational functions in which they worked, may have an effect on CxOs' leadership behaviors. Diversity of experience may lead to a more "generalist" perspective on innovation issues and may predispose the top manager to focus more on the "bigger picture" aiming to align innovation at the firm level (Barker \& Mueller, 2002; Hoffman \& Hegarty, 1993). In contrast, limited functional background diversity leads to a more "specialist" perspective that might result in top managers focusing their innovative engagement more on developing solutions to specific function-related issues (Garms \& Engelen, 2019).

Psychological factors: Psychological characteristics, on the other hand, reflect top managers' personality. Those factors provide the cognitive basis from which executives filter and interpret information and develop strategies on how to deal with organizational problems such as innovation (e.g. Berson et al., 2008; Gerstner et al., 2013; Papadakis \& Bourantas, 1998). Previous research on top managers' role in organizational innovation mainly examined the effect of individual personality variables such as over-confidence (Galasso \& Simcoe, 2011), narcissism (Gerstner et al., 2013), need for cognition (Wu et al., 2014), or locus of control (Boone et al., 2000). However, those variables only cover individual traits instead of providing a comprehensive reflection of the different domains of personality.

In order to meet the criteria for construct selection mentioned above, I thus use the Big Five traits to cover top managers' personality: extraversion (which expresses sociability and excitement-seeking), openness (which expresses imagination and curiosity), conscientiousness (which expresses responsibility and persistency), agreeableness (which expresses peopleorientation and kindness), and neuroticism (which expresses insecurity and suspicion) (Li \& Tan, 2013). These five characteristics are widely seen to be able to cover the full range of an individual's personality traits and are widely accepted as a measure of psychological profile of people across different occupational contexts (Judge \& Bono, 2000). The Big Five traits have been shown to affect leadership (Judge et al., 2002) and innovative behavior (Reilly et al., 2002). Moreover, Elenkov et al. (2005) found significant relationships between firms' innovative performance and top managers' Big Five traits (positive effect: extraversion, openness to experience, agreeableness; negative effect: neuroticism). The Big Five traits can 
thus be considered as a both exhaustive and parsimonious reflection of the underlying psychological factors that may affect top managers' innovation leadership behavior.

Job Characteristics. Concerning the managerial position, previous research has identified three factors that might influence top managers' leadership behavior and engagement in innovation: job autonomy, job demands, and job content. Job autonomy describes the degree to which a top manager is free in making relevant decisions and choosing on which issues he/she spends his/her work time (Meyer et al., 2010). Autonomy has been linked to increased levels of individuals' engagement in innovation (e.g. Beugelsdijk, 2008), how broadly managers define their leadership role (e.g. Parker \& Axtell, 2001), and how much they engage in activities beyond the prescribed requirements of their functional task (e.g. Gellatly \& Irving, 2001). Also, research found that autonomy is an important contingent factor on if and how personality affects engagement in organizational innovation (e.g. Wu et al., 2014).

Second, job demand, i.e., "the degree to which a given executive experiences his or her job as difficult or challenging" (Hambrick et al., 2005a: 473), is likely to determine a top manager's innovation leadership behavior. While the opinion is widely held that "high levels of job demand may squeeze out novelty and fresh thinking" (Hambrick et al., 2005b: 504), other studies show that job demand also may serve as an activating stimulus that may induce engagement in innovation (Ohly \& Fritz, 2010) and provokes leaders to think of more sophisticated ways of delegating and coordinating innovative efforts (Unsworth \& Parker, 2003). In line with previous research on c-level executives that largely focused on quantitative job demands (e.g. workload) instead of qualitative work demands (e.g. conflicting obligations) (Hambrick et al., 2005a; $\mathrm{Ng}$ et al., 2008), I use time pressure as an indicator for job demand in the context of this study. Time pressure thereby describes the extent to which the job tasks of a manager occupy respectively exceed the time available (Wu et al., 2014).

Third and finally, job content may determine the innovation leadership behaviors of a top manager. The job content describes the scope of tasks and responsibilities assigned (Mintzberg, 2009). It thus reflects the expectations of peers and principals with regard to what top managers should accomplish in their position (Guadalupe et al., 2014). Research has shown that individuals' innovative efforts depend on the degree to which innovation is expected in the job (Scott \& Bruce, 1994). Similarly, top managers have been found to adjust their engagement in innovation based on the goals and incentives that the firm assigns to their position (Makri et al., 2006). In the context of this study, job content can be represented by the degree of supply vs. demand orientation that is expected of a $\mathrm{CxO}^{\prime}$ s functional department. Supply-oriented functions usually have to work cost-oriented and provide specialist support to other departments (Tumbas et al., 2017). Demand-oriented functions will be expected to follow more valueoriented goals and target the market (Priem et al., 2012). As orientation of their functional department will thus entail different expectations on top managers (Guadalupe et al., 2014), it can be expected that the degree of supply/demand orientation will have an influence on top managers' innovation leadership style. 


\section{METHODOLOGY}

\section{Data Collection Procedure}

I collected the empirical data in a quantitative survey with a random sample of 3,828 c-level functional executives from German, Austrian, and Swiss manufacturing firms. The top managers in the sample held positions of CIO, CTO, COO, CMO, CFO, and CHRO. They were sent an invitation e-mail with a link to the online questionnaire. After the first half of the data collection period (i.e., after 30 days), I sent a reminder to all who had not completed the questionnaire yet. 411 completed and usable questionnaires were received in total. Hence, the effective response rate was $10.74 \%$. To test for non-response bias, all research variables were compared between the earlier and the latter half of the sample (Armstrong \& Overton, 1977). The $t$-test yielded no significant differences, except that in the latter half, more respondents held technical degrees ( $72 \%$ versus $63 \%$ in the earlier half, $t=2.102, p=.036)$. The mean age of the respondents was 45.67 years, they had an average tenure of 8.68 years in their position. Of the 411 respondents, 38 were female. The sample encompassed 80 CIOs, 83 CTOs, 67 COOs, 80 CMOs, 70 CFOs, and 31 CHROs. Concerning firm size, 297 of the CxOs in the final sample came from firms with less than 499 employees $(72.26 \%), 114$ from firms with more than 500 employees $(27.74 \%)$. The industry sectors that were most present in the sample were machinery (45.50\%), automotive $(24.82 \%)$, and electric equipment $(17.03 \%)$.

\section{Measurement Procedure}

Most research variables were measured via multiple items that were rated on a seven-point Likert scale. The measurement scale for involvement in idea creation and innovation projects used Scott and Bruce's (1994) items for measuring individuals' innovative behavior that captures idea generation, idea promotion, and idea realization (seven items). For the other three leadership behaviors, I was not able to draw on existing scales. Hence, I conducted an in-depth literature review scanning academic articles for descriptions of top managers' innovation leadership behaviors. Furthermore, I reviewed top manager interviews focused on organizationnal innovation in business magazines such as Forbes, Financial Times, or McKinsey Quarterly. Based on the gathered information I developed a list of measurement items that I discussed with nine academic colleagues and 14 senior managers from manufacturing industry. Based on their feedback, I revised and removed items so that I arrived at three six-item scales measuring the three different innovation leadership behaviors. For the variable sponsoring innovators and innovation projects, the scale was based on behaviors described by Watts and Henderson (2006) (two items), Gottschalk (1999) (two items), and Gomes et al. (2001) (two item). Formulation and implementation of an innovation strategy draws on items based on the descriptions of Deschamps (2008). The measurement scale for establishing a climate for innovation adapts two items from Makri and Scandura's (2010) scale for creative leadership as well as descriptions by Tsui et al. (2006) (two items) and Watts and Henderson (2006) (two items).

For the job variables, autonomy was measured based on three items by $\mathrm{Wu}$ et al. (2014), time pressure based on three items by Wu et al. (2014), and supply vs. demand orientation on a twosided scale ( 1 = full supply orientation; 7 = full demand orientation) with four items based on Priem et al. (2012) and Tumbas et al. (2017). For the personality variables, the Big Five dimen- 
sions were measured by three items each from Li and Tan (2013) for openness, conscientiousness, and extraversion, and each three items from McRae and Costa (1992) for agreeableness and Hofstee et al. (1992) for neuroticism. Age was measured based on self-report, educational level by a five staged scale ( $1=$ "no or lower secondary education" to $5=$ "PhD"), technical education by a question if the educational degree was obtained in the fields of engineering, IT or science, and functional background diversity by calculating the Blau's (1977) index on the distribution of the manager's career in eight functional areas (IT, R\&D, M\&S, Operations \& Logistics, Strategy, Finance, HR, General Management). Table 1 depicts construct means, standard deviations, and correlations; Tables 2, 3, 4, and 5 summarize the items used. The questionnaire was pretested by a sample of 22 senior managers from manufacturing firms in Germany.

Cronbach's alpha, composite reliability, average variance extracted ( $A V E)$, and factor loadings all met the required thresholds (Bagozzi \& Yi, 1988). I employed confirmatory factor analysis in AMOS to evaluate the fit of the measurement model. The analysis indicates good fit between model and data $\left(\chi^{2} / d f=1.17, R M S E A=0.03, C F I=0.98, N N F I=0.98, A G F I=0.86 ; S R M S R\right.$ $=0.04)$. Concerning discriminant validity, all constructs fulfilled the Fornell and Larckner (1981). Finally, in order to test for common-method bias I conducted Harman's one-factor test (Podsakoff et al., 2003). The unrotated factor solution resulted in 12 factors that explained $63.1 \%$ of the variance (the largest variance explained by one factor was $13.9 \%$ ). Therefore, common-method bias is unlikely to be a problem in this study. 
Table II-2-1. Means, standard deviations, and correlations

\begin{tabular}{|c|c|c|c|c|c|c|c|c|c|c|c|c|c|c|c|c|c|c|}
\hline & Variable & Mean & S. D. & 1 & 2 & 3 & 4 & 5 & 6 & 7 & 8 & 9 & 10 & 11 & 12 & 13 & 14 & 15 \\
\hline 1. & $\begin{array}{l}\text { Involvement in Idea Creation and } \\
\text { Innovation Projects }\end{array}$ & 3.99 & 1.45 & & & & & & & & & & & & & & & \\
\hline 2. & $\begin{array}{l}\text { Sponsoring Innovators and } \\
\text { Innovation Projects }\end{array}$ & 3.98 & 1.32 & -.02 & & & & & & & & & & & & & & \\
\hline 3. & $\begin{array}{l}\text { Formulation and Implementation } \\
\text { of an Innovation Strategy }\end{array}$ & 4.32 & 1.49 & .07 & $.34 * * *$ & & & & & & & & & & & & & \\
\hline 4. & $\begin{array}{l}\text { Establishing a Climate for } \\
\text { Innovation }\end{array}$ & 3.69 & 1.30 & $-.27 * * *$ & $.26 * * *$ & $.32 * * *$ & & & & & & & & & & & & \\
\hline 5. & Age & 45.67 & 8.42 & -.05 & $.16^{* *}$ & .05 & .00 & & & & & & & & & & & \\
\hline 6. & Educational Level & 3.87 & 0.53 & $.22 * * *$ & .05 & $.24 * * *$ & .00 & .04 & & & & & & & & & & \\
\hline 7. & Technical Education & 0.68 & 0.47 & $.27^{* * *}$ & $.11^{*}$ & .05 & .07 & .01 & $.11 *$ & & & & & & & & & \\
\hline 8. & Functional Background Diversity & 0.25 & 0.24 & .09 & $.19^{* * *}$ & $.41^{* * *}$ & .06 & $.12 *$ & $.15^{* *}$ & -.02 & & & & & & & & \\
\hline 9. & Extraversion & 4.35 & 1.34 & $.13^{* *}$ & $.17 * *$ & $.42 * * *$ & $.17 * * *$ & .04 & $.17 * *$ & .00 & $.24 * * *$ & & & & & & & \\
\hline 10. & Openness to Experience & 4.28 & 1.32 & $.27^{* * *}$ & -.06 & .08 & .05 & $-.13 * *$ & $.10^{*}$ & $.15^{* *}$ & -.07 & $.21 * * *$ & & & & & & \\
\hline 11. & Conscientiousness & 4.70 & 1.12 & $.13^{*}$ & $.16^{* *}$ & $.11 *$ & $-.23 * * *$ & $.14^{* *}$ & .01 & -.00 & .08 & -.09 & $-.21 * * *$ & & & & & \\
\hline 12. & Agreeableness & 4.33 & 1.08 & $-.31 * * *$ & $.30 * * *$ & -.04 & $.14^{* *}$ & .05 & $-.15^{* *}$ & -.06 & -.03 & -.00 & $-.16^{* *}$ & -.09 & & & & \\
\hline 13. & Neuroticism & 4.03 & 1.07 & $-.17 * *$ & $-.25^{* * *}$ & $-.33^{* * *}$ & .08 & .05 & -.07 & -.01 & $-.20 * * *$ & $-.16^{* *}$ & $-.12 *$ & $-.15^{* *}$ & -.04 & & & \\
\hline 14. & Autonomy & 4.40 & 1.13 & .01 & -.02 & .09 & $.10^{*}$ & -.03 & .05 & .07 & -.05 & .08 & $.28 * * *$ & -.07 & $-.14^{* *}$ & -.09 & & \\
\hline 15. & Time Pressure & 4.46 & 1.16 & .02 & $-.12 *$ & $-.11 * *$ & .06 & .07 & -.09 & $-.12 *$ & -.00 & $-.17^{* * *}$ & $-.23 * * *$ & .08 & -.03 & $.11^{*}$ & $-.16^{* *}$ & \\
\hline 16. & Supply vs. Demand Orientation & 4.01 & 1.33 & $.20 * * *$ & $-.13^{* *}$ & $19^{* * *}$ & $.18^{* * * *}$ & $-.12 *$ & $.12 *$ & .09 & $.17 * * *$ & $.29 * * *$ & $.32 * * *$ & $-.24 * * *$ & -.07 & -.06 & $.25^{* * *}$ & .05 \\
\hline
\end{tabular}

Notes: $* \mathrm{p}<.05 \quad * * \mathrm{p}<.01 \quad * * * \mathrm{p}<.001$ 
Table II-2-2. Construct specifications and item loadings

\begin{tabular}{|c|c|c|c|c|}
\hline & Item & Load & Mean & S.D. \\
\hline Involvement in & I identify potentials for improvement and generate new ideas. & .794 & 4.06 & 1.68 \\
\hline Idea Creation & I develop new solutions for current business problems. & .774 & 4.08 & 1.67 \\
\hline $\begin{array}{l}\text { and Innovation } \\
\text { Projects }\end{array}$ & $\begin{array}{l}\text { I actively search for new and useful information, technologies, and procedures that may be useful for developing and } \\
\text { improving solutions to business problems. }\end{array}$ & .782 & 3.96 & 1.74 \\
\hline$(\alpha=.92$ & I mobilize support for my ideas. & .825 & 4.02 & 1.80 \\
\hline $\mathrm{CR}=.92$ & I secure resources for the implementation of my ideas. & .802 & 3.88 & 1.75 \\
\hline \multirow[t]{2}{*}{$\mathrm{AVE}=.63)$} & I look for ways of applying new ideas in our business. & .791 & 4.00 & 1.81 \\
\hline & I evaluate the usefulness of my ideas and improve them based on user feedback. & .800 & 3.94 & 1.83 \\
\hline $\begin{array}{l}\text { Sponsoring } \\
\text { Innovators and }\end{array}$ & $\begin{array}{l}\text { I give advice to innovators based on my functional expertise and inform them on current developments and politics in the } \\
\text { firm. }\end{array}$ & .739 & 4.10 & 1.61 \\
\hline $\begin{array}{l}\text { Innovation } \\
\text { Projects }\end{array}$ & $\begin{array}{l}\text { I help in composing project teams for the development of new concepts and solutions and for the implementation of } \\
\text { novel ideas. }\end{array}$ & .737 & 4.04 & 1.65 \\
\hline$(\alpha=.87$ & I evaluate the quality and usefulness of project resources and help to gather further ones if necessary. & .745 & 3.99 & 1.62 \\
\hline \multirow[t]{3}{*}{$\begin{array}{l}\mathrm{CR}=.87 \\
\mathrm{AVE}=.54)\end{array}$} & $\begin{array}{l}\text { I help innovators in putting their ideas in the broader organizational context and thus realizing and improving the value } \\
\text { potential from said ideas. }\end{array}$ & .694 & 3.91 & 1.66 \\
\hline & $\begin{array}{l}\text { I monitor the progress of projects, evaluate the quality of work results, set schedules and provide suggestions for } \\
\text { improvements. }\end{array}$ & .712 & 3.98 & 1.78 \\
\hline & $\begin{array}{l}\text { I support innovators in communicating and implementing their ideas, establish contact between innovators and decision } \\
\text { makers and try to persuade important stakeholders }\end{array}$ & .774 & 3.88 & 1.77 \\
\hline
\end{tabular}

Notes: $\alpha=$ Cronbach's $\alpha$ CR = Composite Reliability; AVE = Average Variance Extracted 
Table II-2-3. Construct specifications and item loadings (continued)

\begin{tabular}{|c|c|c|c|c|}
\hline & Item & Load & Mean & S.D. \\
\hline $\begin{array}{l}\text { Formulation and } \\
\text { Implementation }\end{array}$ & $\begin{array}{l}\text { I formulate and communicate a clear vision of the technological, market-related, and organizational path of development } \\
\text { of our organization. }\end{array}$ & .798 & 4.36 & 1.70 \\
\hline $\begin{array}{l}\text { of an Innovation } \\
\text { Strategy }\end{array}$ & $\begin{array}{l}\text { I get an overview on our firm and ist environment (e.g. technology, market, politics), analyze current developments and } \\
\text { deduce possible consequences for my department. }\end{array}$ & .801 & 4.29 & 1.75 \\
\hline $\begin{array}{l}(\alpha=.91 \\
\mathrm{CR}=.91\end{array}$ & $\begin{array}{l}\text { I formulate an innovation strategy for my department, define short-term and long-term goals and develop plans for its } \\
\text { implementation }\end{array}$ & .788 & 4.48 & 1.68 \\
\hline \multirow[t]{3}{*}{$\mathrm{AVE}=.63)$} & $\begin{array}{l}\text { I review different innovation initiatives, evaluate them concerning their alignment to the overall innovation strategy, and } \\
\text { coordinate resources between the individual initiatives. }\end{array}$ & .793 & 4.22 & 1.85 \\
\hline & $\begin{array}{l}\text { I evaluate different courses of actions concerning the innovation strategy, e.g. the initiation of internal R\&D projects, the } \\
\text { acquisition of technologies and companies, or the cooperation with customers, suppliers, and competitors. }\end{array}$ & .821 & 4.41 & 1.91 \\
\hline & $\begin{array}{l}\text { I work on increasing the innovative capability of my department, e.g. by establishing innovation processes, creating } \\
\text { adequate organizational structures/systems, and acquiring know-how. }\end{array}$ & .775 & 4.20 & 1.84 \\
\hline Establishing a & I involve my staff in challenging innovation initiatives and allow for autonomy and self management. & .708 & 3.51 & 1.70 \\
\hline Climate for & I challenge my staff, provoke their ways of thinking, and encourage them in taking new perspectives. & .721 & 3.74 & 1.61 \\
\hline $\begin{array}{l}\text { Innovation } \\
(\alpha=.88\end{array}$ & $\begin{array}{l}\text { I encourage experiments and creativity and actively promote a mindset that recognizes mistakes as opportunities for } \\
\text { learning a well as a central element in the process of innovation. }\end{array}$ & .762 & 3.83 & 1.67 \\
\hline \multirow[t]{3}{*}{$\begin{array}{l}\mathrm{CR}=.88 \\
\mathrm{AVE}=.54)\end{array}$} & $\begin{array}{l}\text { I carefully listen to my employees, try to be responsive to their needs, and offer help when problems arise in the } \\
\text { professional, but also the private context. }\end{array}$ & .705 & 3.65 & 1.68 \\
\hline & I try to act as a role model, believe in values, and aim to inspire employees with my passion and enthusiasm. & .747 & 3.78 & 1.70 \\
\hline & $\begin{array}{l}\text { I put emphasis on developing my employees' skills, on stimulating processes of learning, and creating sensitivity and } \\
\text { attention for important business problems. }\end{array}$ & .768 & 3.65 & 1.55 \\
\hline
\end{tabular}

Notes: $\alpha=$ Cronbach's $\alpha$ CR = Composite Reliability; AVE = Average Variance Extracted 
Table II-2-4. Construct specifications and item loadings (continued)

\begin{tabular}{|c|c|c|c|c|}
\hline & Item & Load & Mean & S.D. \\
\hline $\begin{array}{l}\text { Extraversion } \\
(\alpha=.84 \\
\mathrm{CR}=.84 \\
\mathrm{AVE}=.63)\end{array}$ & $\begin{array}{l}\text { I enjoy the company of others. } \\
\text { I seem to instinctively know how to influence people. } \\
\text { I am able to quickly understand and correctly evaluate political or social situations. }\end{array}$ & $\begin{array}{l}.822 \\
.761 \\
.802\end{array}$ & $\begin{array}{l}4.39 \\
4.41 \\
4.25\end{array}$ & $\begin{array}{l}1.49 \\
1.56 \\
1.57\end{array}$ \\
\hline $\begin{array}{l}\text { Openness to } \\
\text { Experience } \\
(\alpha=.88 \\
\mathrm{CR}=.88 \\
\mathrm{AVE}=.71)\end{array}$ & $\begin{array}{l}\text { I like tasks that require me to think thoroughly. } \\
\text { I love to challenge existing norms and standards. } \\
\text { I like tasks in which it necessary to come up with new approaches and solutions. }\end{array}$ & $\begin{array}{l}.833 \\
.848 \\
.841\end{array}$ & $\begin{array}{l}4.15 \\
4.29 \\
4.40\end{array}$ & $\begin{array}{l}1.51 \\
1.41 \\
1.49\end{array}$ \\
\hline $\begin{array}{l}\text { Conscientiousness } \\
(\alpha=.85 \\
\mathrm{CR}=.85 \\
\mathrm{AVE}=.66)\end{array}$ & $\begin{array}{l}\text { When I tackle a problem, I put emphasis on each detail. } \\
\text { I always follow a strict timetable when I work on a task. } \\
\text { I do not stop puzzling over a problem until I find the perfect solution. }\end{array}$ & $\begin{array}{l}.826 \\
.790 \\
.819\end{array}$ & $\begin{array}{l}4.75 \\
4.80 \\
4.54\end{array}$ & $\begin{array}{l}1.29 \\
1.31 \\
1.22\end{array}$ \\
\hline $\begin{array}{l}\text { Agreeableness } \\
(\alpha=.79 \\
\mathrm{CR}=.80 \\
\mathrm{AVE}=.57)\end{array}$ & $\begin{array}{l}\text { Helping others is very important for me. } \\
\text { I always try to treat others with benevolence. } \\
\text { Achieving my own goals stands above everything else.* }\end{array}$ & $\begin{array}{l}.794 \\
.777 \\
.684\end{array}$ & $\begin{array}{l}4.33 \\
4.46 \\
4.21\end{array}$ & $\begin{array}{l}1.28 \\
1.27 \\
1.30\end{array}$ \\
\hline $\begin{array}{l}\text { Neuroticism } \\
(\alpha=.79 \\
\mathrm{CR}=.80 \\
\mathrm{AVE}=.57)\end{array}$ & $\begin{array}{l}\text { I consider myself to be quite emotional. } \\
\text { I am often impatient with others and myself. } \\
\text { I often get worried about the future. }\end{array}$ & $\begin{array}{l}.696 \\
.783 \\
.792\end{array}$ & $\begin{array}{l}4.21 \\
4.05 \\
3.82\end{array}$ & $\begin{array}{l}1.26 \\
1.24 \\
1.29\end{array}$ \\
\hline
\end{tabular}

Notes: $\alpha=$ Cronbach's $\alpha$; $\mathrm{CR}=$ Composite Reliability; AVE = Average Variance Extracted

*Item is reverse coded 
Table II-2-5. Construct specifications and item loadings (continued)

\begin{tabular}{|c|c|c|c|c|}
\hline & Item & Load & Mean & S.D. \\
\hline Autonomy & I am largely autonomous when it comes to making decisions. & .819 & 4.41 & 1.32 \\
\hline$(\alpha=.84$, & For the most part, I decide by myself how I spend my working hours. & .761 & 4.53 & 1.31 \\
\hline $\begin{array}{l}\mathrm{CR}=.84 \\
\mathrm{AVE}=.63)\end{array}$ & I act on my own authority when it comes to choosing adequate methods and tools for fulfilling my professional duties. & .809 & 4.27 & 1.29 \\
\hline Time Pressure & I often doubt that I will able to complete the demanded workload in time. & .787 & 4.43 & 1.22 \\
\hline$(\alpha=.85$, & I work under considerable time pressure. & .824 & 4.30 & 1.38 \\
\hline $\begin{array}{l}\mathrm{CR}=.85 \\
\mathrm{AVE}=.65)\end{array}$ & I frequently lack the time to do my job properly. & .806 & 4.65 & 1.36 \\
\hline $\begin{array}{l}\text { Supply vs. } \\
\text { Demand }\end{array}$ & $\begin{array}{l}\text { Top management expects my department to fulfill internal demands most effectively and efficiently./Top managements } \\
\text { expects my department to work customer-oriented and exploit new sales potentials. }\end{array}$ & .875 & 4.01 & 1.50 \\
\hline Orientation & Top management thinks of my department as a cost center./Top management thinks of my department as a profit center. & .850 & 4.01 & 1.50 \\
\hline $\begin{array}{l}(\alpha=.91 \\
\mathrm{CR}=.91\end{array}$ & $\begin{array}{l}\text { Top management expects stability, continuous improvement, and risk minimization from my department./ Top } \\
\text { management expects forward-thinking, entrepreneurship, and risk taking from my department. }\end{array}$ & .855 & 4.15 & 1.55 \\
\hline $\mathrm{AVE}=.72)$ & $\begin{array}{l}\text { Top management does not expect an innovative contribution from my department./Top management considers innovation } \\
\text { as a core task of my department. }\end{array}$ & .805 & 3.88 & 1.43 \\
\hline
\end{tabular}

Notes: $\alpha=$ Cronbach's $\alpha$; $\mathrm{CR}=$ Composite Reliability; AVE = Average Variance Extracted

*Item is reverse coded 


\section{Analysis Procedure}

In order to unveil the innovation leadership styles of top managers, I employed cluster analysis in SAS 9.4. To determine the appropriate number of clusters, I applied the hierarchical clustering algorithm developed by Ward (1963) in combination with the cubic clustering criterion (Sarle, 1983) and the pseudo- $t^{2}$ index (Duda \& Hart, 1973). As Ward's algorithm can be sensitive to scaling, all four clustering variables were standardized based on their range (Milligan \& Hirtle, 2003). Furthermore, outliers might disturb the algorithm when more than $90 \%$ of all observations are included in the analysis (Punj \& Stewart, 1983). Based on the criteria proposed by Homburg et al. (2008), I thus excluded $15 \%$ of the observations from further steps of analysis. The hierarchical clustering procedure yielded strong support for a solution with eight clusters. In order to test if this number was robust, I reran Ward's (1963) algorithm on 20 randomly selected subsamples (each with $2 / 3$ of the research cases). The number of clusters remained constant.

To assign research cases to the most appropriate cluster, I used k-means clustering (Gruber et al., 2010). Finally, to assess the stability of the cluster assignment, I applied the cross-validation procedure by McIntyre and Blashfield (1980). Thereby, the sample was split in random halves and the k-means clustering procedure was computed for each half. After this, each case in the second half was assigned to the cluster with the nearest cluster centroid from the first half (based on the lowest squared Euclidean distance). As a result, all cases in the second half had two cluster assignments which were used to compare assignment consistency with Rand's (1971) index. The Rand (1971) index calculated in this procedure as .84 which is an acceptable value that indicates adequate levels of consistency (Gruber et al., 2010; Homburg et al., 2008).

To determine the factors that predict the membership of research cases in the identified clusters, I applied linear discriminant analysis. Discriminant analysis is useful for classifying objects by a set of independent predictor variables into a number of exclusive categories (Ruvio et al., 2010). Thus, discriminant analysis complements the structure-exploring procedure of cluster analysis (Lachenbruch, 1975). In comparison to logistic regression which may be used to a similar end, discriminant analysis has an advantage when the number of groups to be explained is larger than two. When there are three or more groups, the procedure of discriminant analysis uses more information from the empirical data and is thus able to produce more efficient and robust estimations than logistic regression (Hastie et al., 2009). Moreover, discriminant analysis estimates group membership based on the overall combination of input variables rather than by bivariate correlations (Ehrhart \& Klein, 2001). Therefore, discriminant analysis is an adequate statistical method with regard to the configurational approach of this study.

For conducting the discriminant analysis, I used the Statistical Package for the Social Sciences (SPSS) discriminant analysis procedure. The discriminant functions were estimated in a stepwise procedure in which the predictor variables were successively added according to the Wilks' lambda criterion (Miceli \& Near, 1984). The predictive quality of the discriminant functions was evaluated by classification accuracy. Classification accuracy denotes the share of research cases that were classified into the right groups based on the estimated discriminant functions (Ramanujam et al., 1986). Additional to the discriminant analysis, I ran a one-way 
ANOVA that compared mean values of all predictor variables between the eight cluster groups to support the interpretation of the obtained results.

\section{RESULTS}

\section{Cluster Analysis}

In the cluster analysis, eight categories of managers were identified. Table 6 shows the number of cases in each group and the cluster means for all four innovation leadership behaviors. To validate whether the identified clusters allow for meaningful interpretations, I tested if the identified clusters differ significantly with regard to the four grouping variables. Following the suggestions by Homburg et al. (2008), I compared the means of the clusters based on two different multiple comparison post-hoc criteria: (1) Waller and Duncan's (1969) multiple range test; and (2) Tukey's (1949) honestly significant differences test (both at $p<.05$ ). I used the results to assign the clusters to brackets for each of the grouping variables and translated the brackets into verbal labels (see Table 7). Cluster means for a given variable that have the same label do not differ at $p<.05$. Additionally, I examined the distribution of the identified clusters across the six managerial positions in the sample (see Table 8). 
Table II-2-6. Statistical cluster description

\begin{tabular}{|c|c|c|c|c|c|c|c|c|}
\hline \multirow[b]{2}{*}{ Variable } & \multicolumn{8}{|c|}{ Cluster } \\
\hline & $\begin{array}{c}1 \\
(n=77)\end{array}$ & $\begin{array}{c}2 \\
(n=47)\end{array}$ & $\begin{array}{c}3 \\
(n=30)\end{array}$ & $\begin{array}{c}4 \\
(n=64)\end{array}$ & $\begin{array}{c}5 \\
(n=63)\end{array}$ & $\begin{array}{c}6 \\
(n=49)\end{array}$ & $\begin{array}{c}7 \\
(n=58)\end{array}$ & $\begin{array}{c}8 \\
(n=23)\end{array}$ \\
\hline $\begin{array}{l}\text { Involvement in Idea } \\
\text { Creation and Innovation } \\
\text { Projects }\end{array}$ & $2.85^{\mathrm{d}}$ & $5.22^{\mathrm{b}}$ & $5.67^{\mathrm{a}}$ & $5.84^{\mathrm{a}}$ & $3.14^{\mathrm{c}}$ & $2.75^{\mathrm{d}}$ & $3.03^{\mathrm{c}, \mathrm{d}}$ & $5.39^{\mathrm{b}}$ \\
\hline $\begin{array}{l}\text { Sponsoring Innovators } \\
\text { and Innovation Projects }\end{array}$ & $2.74^{\mathrm{f}}$ & $3.09^{\mathrm{e}}$ & $4.83^{\mathrm{c}}$ & $3.53^{\mathrm{d}}$ & $5.60^{\mathrm{a}}$ & $5.26^{\mathrm{b}}$ & $3.07^{\mathrm{e}}$ & $5.29^{\mathrm{b}}$ \\
\hline $\begin{array}{l}\text { Formulation and } \\
\text { Implementation of an } \\
\text { Innovation Strategy }\end{array}$ & $2.72^{\mathrm{d}}$ & $2.61^{\mathrm{d}}$ & $2.76^{\mathrm{d}}$ & $5.89^{\mathrm{a}}$ & $5.63^{\mathrm{a}}$ & $4.21^{\mathrm{c}}$ & $5.10^{\mathrm{b}}$ & $5.62^{\mathrm{a}}$ \\
\hline $\begin{array}{l}\text { Establishing a Climate for } \\
\text { Innovation }\end{array}$ & $2.87^{\mathrm{d}, \mathrm{e}}$ & $2.78^{\mathrm{e}}$ & $3.01^{\mathrm{d}, \mathrm{e}}$ & $3.05^{\mathrm{d}, \mathrm{e}}$ & $3.20^{\mathrm{d}}$ & $5.77^{\mathrm{a}}$ & $4.80^{\mathrm{c}}$ & $5.13^{b}$ \\
\hline
\end{tabular}

Notes: Reported values are mean values. In each row, clusters with the same superscript are not significantly different $(\mathrm{p}<0.05)$ on the basis of Waller and Duncan's (1969) multiple range test. The highest bracket is labeled with superscript "a", the next highest bracket with superscript "b", etc. 
Table II-2-7. Verbal cluster description

\begin{tabular}{|c|c|c|c|c|c|c|c|c|}
\hline \multirow[b]{2}{*}{ Variable } & \multicolumn{8}{|c|}{ Cluster } \\
\hline & $\begin{array}{c}1 \\
\text { Lightweight }\end{array}$ & $\begin{array}{c}2 \\
\text { Inventor }\end{array}$ & $\begin{array}{c}3 \\
\text { Hands-on } \\
\text { Innovator } \\
\end{array}$ & $\begin{array}{c}4 \\
\text { Entre- } \\
\text { preneur }\end{array}$ & $\begin{array}{c}5 \\
\text { Headcoach }\end{array}$ & $\begin{array}{c}6 \\
\text { Gardener }\end{array}$ & $\begin{array}{c}7 \\
\text { Evangelist }\end{array}$ & $\begin{array}{c}8 \\
\text { Superhero }\end{array}$ \\
\hline $\begin{array}{l}\text { Involvement in Idea Creation } \\
\text { and Innovation Projects }\end{array}$ & Very Low & High & Very High & Very High & Low & Very Low & $\begin{array}{l}\text { Very Low, } \\
\text { Low }\end{array}$ & High \\
\hline $\begin{array}{l}\text { Sponsoring Innovators and } \\
\text { Innovation Projects }\end{array}$ & Very Low & Low & $\begin{array}{l}\text { Moderately } \\
\text { High }\end{array}$ & $\begin{array}{l}\text { Moderately } \\
\text { Low }\end{array}$ & Very High & High & Low & High \\
\hline $\begin{array}{l}\text { Formulation and Implementation } \\
\text { of an Innovation Strategy }\end{array}$ & Very Low & Very Low & Very Low & Very High & Very High & Low & High & Very High \\
\hline $\begin{array}{l}\text { Establishing a Climate for } \\
\text { Innovation }\end{array}$ & $\begin{array}{l}\text { Very Low, } \\
\text { Low }\end{array}$ & Very Low & $\begin{array}{l}\text { Very Low, } \\
\text { Low }\end{array}$ & $\begin{array}{l}\text { Very Low, } \\
\text { Low }\end{array}$ & Low & Very High & Medium & High \\
\hline
\end{tabular}


Table II-2-8. Cluster membership for managerial positions

\begin{tabular}{|c|c|c|c|c|c|c|c|c|c|}
\hline \multirow[b]{2}{*}{ Managerial Position } & \multirow[b]{2}{*}{$\mathrm{N}$ of Cases } & \multicolumn{8}{|c|}{ Cluster } \\
\hline & & $\begin{array}{c}1 \\
\text { Lightweight }\end{array}$ & $\begin{array}{c}2 \\
\text { Inventor }\end{array}$ & $\begin{array}{c}3 \\
\text { Hands-on } \\
\text { Innovator } \\
\end{array}$ & $\begin{array}{c}4 \\
\text { Entre- } \\
\text { preneur } \\
\end{array}$ & $\begin{array}{c}5 \\
\text { Headcoach }\end{array}$ & $\begin{array}{c}6 \\
\text { Gardener }\end{array}$ & $\begin{array}{c}7 \\
\text { Evangelist }\end{array}$ & $\begin{array}{c}8 \\
\text { Superhero }\end{array}$ \\
\hline $\mathrm{CIO}$ & 80 & $\begin{array}{c}17 \\
(21.3 \%)\end{array}$ & $\begin{array}{c}11 \\
(13.8 \%)\end{array}$ & $\begin{array}{c}11 \\
(13.8 \%)\end{array}$ & $\begin{array}{c}11 \\
(13.8 \%)\end{array}$ & $\begin{array}{c}8 \\
(10.0 \%)\end{array}$ & $\begin{array}{c}12 \\
(15.0 \%)\end{array}$ & $\begin{array}{c}3 \\
(3.8 \%)\end{array}$ & $\begin{array}{c}7 \\
(8.8 \%)\end{array}$ \\
\hline CTO & 83 & $\begin{array}{c}6 \\
(7.2 \%)\end{array}$ & $\begin{array}{c}16 \\
(19.3 \%)\end{array}$ & $\begin{array}{c}9 \\
(10.8 \%)\end{array}$ & $\begin{array}{c}19 \\
(22.9 \%)\end{array}$ & $\begin{array}{c}5 \\
(6.0 \%)\end{array}$ & $\begin{array}{c}15 \\
(18.1 \%)\end{array}$ & $\begin{array}{c}8 \\
(9.6 \%)\end{array}$ & $\begin{array}{c}5 \\
(6.0 \%)\end{array}$ \\
\hline $\mathrm{COO}$ & 67 & $\begin{array}{c}11 \\
(16.4 \%)\end{array}$ & $\begin{array}{c}15 \\
(22.4 \%)\end{array}$ & $\begin{array}{c}7 \\
(10.5 \%)\end{array}$ & $\begin{array}{c}5 \\
(7.5 \%)\end{array}$ & $\begin{array}{c}14 \\
(20.9 \%)\end{array}$ & $\begin{array}{c}5 \\
(7.5 \%)\end{array}$ & $\begin{array}{c}9 \\
(13.4 \%)\end{array}$ & $\begin{array}{c}1 \\
(1.5 \%)\end{array}$ \\
\hline $\mathrm{CMO}$ & 80 & $\begin{array}{c}13 \\
(16.3 \%)\end{array}$ & $\begin{array}{c}4 \\
(5.0 \%)\end{array}$ & $\begin{array}{c}2 \\
(2.5 \%)\end{array}$ & $\begin{array}{c}21 \\
(26.3 \%)\end{array}$ & $\begin{array}{c}9 \\
(11.3 \%)\end{array}$ & $\begin{array}{c}9 \\
(11.3 \%)\end{array}$ & $\begin{array}{c}17 \\
(21.3 \%)\end{array}$ & $\begin{array}{c}5 \\
(6.3 \%)\end{array}$ \\
\hline CFO & 70 & $\begin{array}{c}21 \\
(30.0 \%)\end{array}$ & $\begin{array}{c}1 \\
(1.4 \%)\end{array}$ & $\begin{array}{c}1 \\
(1.4 \%)\end{array}$ & $\begin{array}{c}8 \\
(11.4 \%)\end{array}$ & $\begin{array}{c}21 \\
(30.0 \%)\end{array}$ & $\begin{array}{c}1 \\
(1.4 \%)\end{array}$ & $\begin{array}{c}13 \\
(18.6 \%)\end{array}$ & $\begin{array}{c}4 \\
(5.7 \%)\end{array}$ \\
\hline CHRO & 31 & $\begin{array}{c}9 \\
(29.0 \%)\end{array}$ & $\begin{array}{c}0 \\
(0.0 \%)\end{array}$ & $\begin{array}{c}0 \\
(0.0 \%)\end{array}$ & $\begin{array}{c}0 \\
(0.0 \%)\end{array}$ & $\begin{array}{c}6 \\
(19.4 \%)\end{array}$ & $\begin{array}{c}7 \\
(22.6 \%)\end{array}$ & $\begin{array}{c}8 \\
(25.8 \%)\end{array}$ & $\begin{array}{c}1 \\
(3.2 \%)\end{array}$ \\
\hline
\end{tabular}

Notes: $\mathrm{CIO}=$ Chief Information Officer; $\mathrm{CTO}=$ Chief Technology Officer; $\mathrm{COO}=$ Chief Operation Officer; $\mathrm{CMO}=$ Chief Marketing Officer; $\mathrm{CFO}=\mathrm{Chief}$ Financial Officer; $\mathrm{CHRO}=\mathrm{Chief}$ Human Resources Officer 


\section{Discriminant Analysis}

Table 9 presents the results for the discriminant analysis. Of the seven discriminant functions obtained, six were significant at $p<.001$, the remaining one was significant at $p<.05$. The classification analysis indicated good levels of accuracy (see Table 10). 67.4\% of the research cases could be correctly classified which means that the predictive power of the estimated set of discriminant functions is high. The relative predictive power of the individual discriminant variables is usually assessed based on the discriminant function coefficient and the $F$-value derived from ANOVA (see Table 11). It reflects the unique contribution of each independent variable to the successful classification of the research cases (Tsui et al., 2006; Ruvio et al., 2010). While the $F$-values indicate that each of the twelve variables used significantly accounts for differences between the eight groups, personality traits and job characteristics seem to have the largest impact on the innovation leadership style. In particular, openness and agreeableness are strong discriminators. Time pressure, supply vs. demand orientation, extraversion, and conscientiousness also have a rather strong impact on innovation leadership behavior. 
II. Publications in Focus Area I: Top Management and Leadership

Table II-2-9. Discriminant analysis results

\begin{tabular}{|c|c|c|c|c|c|c|c|}
\hline & \multicolumn{7}{|c|}{ Functions } \\
\hline & 1 & 2 & 3 & 4 & 5 & 6 & 7 \\
\hline \multicolumn{8}{|l|}{$\begin{array}{l}\text { Canonical Discriminant Functions } \\
\text { Evaluated at Group Means (Centroids) }\end{array}$} \\
\hline 1. Lightweight & -0.522 & -1.701 & 0.056 & -0.189 & -0.391 & -0.070 & -0.111 \\
\hline 2. Inventor & 0.919 & 0.159 & -0.092 & -1.415 & 0.464 & 0.045 & 0.034 \\
\hline 3. Hands-on Innovator & 0.657 & 0.007 & -0.289 & 0.787 & 0,896 & -0.108 & -0.436 \\
\hline 4. Entrepreneur & -0.067 & 0.757 & 1.502 & 0.153 & -0.099 & 0.177 & -0.016 \\
\hline 5. Headcoach & -1.630 & 1.435 & -0.737 & -0.113 & -0.215 & -0.031 & -0.050 \\
\hline 6. Gardener & -0.986 & -0.810 & -0.131 & 0.495 & 0.596 & 0.082 & 0.322 \\
\hline 7. Evangelist & 1.765 & 0.170 & -0.696 & 0.417 & -0.398 & 0.302 & 0.072 \\
\hline 8. Superhero & 1.310 & 0.618 & 0.253 & 0.276 & -0.209 & -1.062 & 0.186 \\
\hline \multicolumn{8}{|l|}{$\begin{array}{l}\text { Rotated Standardized Discriminant } \\
\text { Function Coefficients }\end{array}$} \\
\hline Age & -.193 & .055 & .025 & .051 & .150 & -.187 & .161 \\
\hline Eductional Level & .037 & .175 & .195 & .195 & .026 & .251 & -.341 \\
\hline Technical Education & .080 & .278 & .202 & -.022 & .588 & -.041 & .612 \\
\hline Functional Background Diversity & -.301 & .397 & -.003 & .073 & -.274 & .126 & .371 \\
\hline Extraversion & .009 & .506 & -.067 & .261 & .032 & .324 & .140 \\
\hline Openness to Experience & .471 & .267 & -.111 & -.086 & .495 & -.217 & -.289 \\
\hline Conscientiousness & -.412 & .345 & .288 & -.276 & .191 & .147 & -.275 \\
\hline Agreeableness & -.480 & -.064 & -.524 & .530 & .322 & -.113 & -.094 \\
\hline Neuroticism & .240 & -.363 & -.270 & -.110 & .185 & .710 & .195 \\
\hline Autonomy & .195 & .074 & -.355 & -.131 & -.410 & -.317 & .432 \\
\hline Time Pressure & .026 & -.397 & .561 & .328 & .162 & -.263 & .196 \\
\hline Supply vs. Demand Orientation & .388 & -.099 & .299 & .493 & -.171 & .097 & -.193 \\
\hline Eigenvalue & 1.263 & 1.074 & 0.527 & 0.351 & 0.191 & 0.086 & 0.032 \\
\hline Cumulated Variance Explained & 35.8 & 66.3 & 81.3 & 91.2 & 96.7 & 99.1 & 100.0 \\
\hline Wilks Lambda & 0.077 & 0.175 & 0.363 & 0.554 & 0.749 & 0.892 & 0.969 \\
\hline$\chi^{2 / d f}$ & $12.19 * * *$ & $10.56 * * *$ & $8.11 * * *$ & $6.56^{* * *}$ & $4.82 * * *$ & $3.26 * * *$ & $2.13 *$ \\
\hline Box $M$ & \multicolumn{7}{|c|}{$811,047 * * *$} \\
\hline
\end{tabular}

Notes: $* * * \mathrm{p}<.001 ; * * \mathrm{p}<.01 ; * \mathrm{p}<.05$ 
II. Publications in Focus Area I: Top Management and Leadership

Table II-2-10. Results of classification analysis

\begin{tabular}{|c|c|c|c|c|c|c|c|c|c|}
\hline \multirow{2}{*}{ Actual Group } & \multirow{2}{*}{$\begin{array}{c}\mathrm{N} \text { of } \\
\text { Cases }\end{array}$} & \multicolumn{8}{|c|}{ Predicted Group Membership } \\
\hline & & 1 & 2 & 3 & 4 & 5 & 6 & 7 & 8 \\
\hline 1. Lightweight & 77 & $\begin{array}{c}52 \\
(67.5 \%)\end{array}$ & $\begin{array}{c}3 \\
(3.9 \%)\end{array}$ & $\begin{array}{c}2 \\
(2.6 \%)\end{array}$ & $\begin{array}{c}2 \\
(2.6 \%)\end{array}$ & $\begin{array}{c}2 \\
(2.6 \%)\end{array}$ & $\begin{array}{c}12 \\
(15.6 \%)\end{array}$ & $\begin{array}{c}3 \\
(3.9 \%)\end{array}$ & $\begin{array}{c}1 \\
(1.3 \%)\end{array}$ \\
\hline 2. Inventor & 47 & $\begin{array}{c}5 \\
(10.6 \%)\end{array}$ & $\begin{array}{c}32 \\
(68.1 \%)\end{array}$ & $\begin{array}{c}1 \\
(2.1 \%)\end{array}$ & $\begin{array}{c}3 \\
(6.4 \%)\end{array}$ & $\begin{array}{c}0 \\
(0.0 \%)\end{array}$ & $\begin{array}{c}0 \\
(0.0 \%)\end{array}$ & $\begin{array}{c}3 \\
(6.4 \%)\end{array}$ & $\begin{array}{c}3 \\
(6.4 \%)\end{array}$ \\
\hline 3. Hands-on Innovator & 30 & $\begin{array}{c}1 \\
(3.3 \%)\end{array}$ & $\begin{array}{c}4 \\
(13.3 \%)\end{array}$ & $\begin{array}{c}16 \\
(53.3 \%)\end{array}$ & $\begin{array}{c}1 \\
(3.3 \%)\end{array}$ & $\begin{array}{c}1 \\
(3.3 \%)\end{array}$ & $\begin{array}{c}3 \\
(10.0 \%)\end{array}$ & $\begin{array}{c}3 \\
(10.0 \%)\end{array}$ & $\begin{array}{c}1 \\
(3.3 \%)\end{array}$ \\
\hline 4. Entrepreneur & 64 & $\begin{array}{c}2 \\
(3.1 \%)\end{array}$ & $\begin{array}{c}3 \\
(4.7 \%)\end{array}$ & $\begin{array}{c}1 \\
(1.6 \%)\end{array}$ & $\begin{array}{c}46 \\
(71.9 \%)\end{array}$ & $\begin{array}{c}2 \\
(3.1 \%)\end{array}$ & $\begin{array}{c}3 \\
(4.7 \%)\end{array}$ & $\begin{array}{c}2 \\
(3.1 \%)\end{array}$ & $\begin{array}{c}5 \\
(7.8 \%)\end{array}$ \\
\hline 5. Headcoach & 63 & $\begin{array}{c}2 \\
(3.2 \%)\end{array}$ & $\begin{array}{c}1 \\
(1.6 \%)\end{array}$ & $\begin{array}{c}3 \\
(4.8 \%)\end{array}$ & $\begin{array}{c}3 \\
(4.8 \%)\end{array}$ & $\begin{array}{c}51 \\
(81.0 \%)\end{array}$ & $\begin{array}{c}1 \\
(1.6 \%)\end{array}$ & $\begin{array}{c}1 \\
(1.6 \%)\end{array}$ & $\begin{array}{c}1 \\
(1.6 \%)\end{array}$ \\
\hline 6. Gardener & 49 & $\begin{array}{c}7 \\
(14.3 \%)\end{array}$ & $\begin{array}{c}0 \\
(0.0 \%)\end{array}$ & $\begin{array}{c}5 \\
(10.2 \%)\end{array}$ & $\begin{array}{c}1 \\
(2.0 \%)\end{array}$ & $\begin{array}{c}3 \\
(6.1 \%)\end{array}$ & $\begin{array}{c}30 \\
(61.2 \%)\end{array}$ & $\begin{array}{c}1 \\
(2.0 \%)\end{array}$ & $\begin{array}{c}2 \\
(4.1 \%)\end{array}$ \\
\hline 7. Evangelist & 58 & $\begin{array}{c}1 \\
(1.7 \%)\end{array}$ & $\begin{array}{c}3 \\
(5.2 \%)\end{array}$ & $\begin{array}{c}6 \\
(10.3 \%)\end{array}$ & $\begin{array}{c}3 \\
(5.2 \%)\end{array}$ & $\begin{array}{c}0 \\
(0.0 \%)\end{array}$ & $\begin{array}{c}2 \\
(3.4 \%)\end{array}$ & $\begin{array}{c}38 \\
(65.5 \%)\end{array}$ & $\begin{array}{c}5 \\
(8.6 \%)\end{array}$ \\
\hline 8. Superhero & 23 & $\begin{array}{c}0 \\
(0.0 \%)\end{array}$ & $\begin{array}{c}0 \\
(0.0 \%)\end{array}$ & $\begin{array}{c}3 \\
(13.0 \%)\end{array}$ & $\begin{array}{c}3 \\
(13.0 \%)\end{array}$ & $\begin{array}{c}1 \\
(4.3 \%)\end{array}$ & $\begin{array}{c}0 \\
(0.0 \%)\end{array}$ & $\begin{array}{c}4 \\
(17.4 \%)\end{array}$ & $\begin{array}{c}12 \\
(52.2 \%)\end{array}$ \\
\hline
\end{tabular}

Percentage of "grouped" cases correctly classified: $67.4 \%$ 
II. Publications in Focus Area I: Top Management and Leadership

Table II-2-11. Covariate cluster means, standard deviations, and results of one-way ANOVA

\begin{tabular}{|c|c|c|c|c|c|c|c|c|c|}
\hline \multirow[b]{2}{*}{ Variable } & \multicolumn{8}{|c|}{ Cluster } & \multirow[b]{2}{*}{$\mathbf{F}$} \\
\hline & 1 & 2 & 3 & 4 & 5 & 6 & 7 & 8 & \\
\hline \multicolumn{10}{|l|}{ Demography } \\
\hline Age & $\begin{array}{l}45.13 \\
(7.59)\end{array}$ & $\begin{array}{l}44.34 \\
(6.95)\end{array}$ & $\begin{array}{l}44.83 \\
(7.63)\end{array}$ & $\begin{array}{l}46.44 \\
(9.18)\end{array}$ & $\begin{array}{l}48.57 \\
(7.47)\end{array}$ & $\begin{array}{c}48.35 \\
(10.00)\end{array}$ & $\begin{array}{l}42.02 \\
(8.27)\end{array}$ & $\begin{array}{l}44.65 \\
(8.21)\end{array}$ & $3.90 * * *$ \\
\hline \multicolumn{10}{|l|}{ Professional Background } \\
\hline Education Level & $\begin{array}{c}3.62 \\
(0.51)\end{array}$ & $\begin{array}{c}3.81 \\
(0.58)\end{array}$ & $\begin{array}{c}3.97 \\
(0.67)\end{array}$ & $\begin{array}{c}4.16 \\
(0.51)\end{array}$ & $\begin{array}{c}3.90 \\
(0.47)\end{array}$ & $\begin{array}{c}3.71 \\
(0.46)\end{array}$ & $\begin{array}{c}3.97 \\
(0.42)\end{array}$ & $\begin{array}{c}3.87 \\
(0.55)\end{array}$ & $6.70^{* * *}$ \\
\hline Technical Education & $\begin{array}{c}.36 \\
(.48)\end{array}$ & $\begin{array}{c}.91 \\
(.31)\end{array}$ & $\begin{array}{c}.80 \\
(.41)\end{array}$ & $\begin{array}{c}.81 \\
(.41)\end{array}$ & $\begin{array}{c}.62 \\
(.49)\end{array}$ & $\begin{array}{c}.76 \\
(.43)\end{array}$ & $\begin{array}{c}.66 \\
(.48)\end{array}$ & $\begin{array}{c}.83 \\
(.39)\end{array}$ & $9.02 * * *$ \\
\hline Functional Background Diversity & $\begin{array}{c}.15 \\
(.22)\end{array}$ & $\begin{array}{c}.12 \\
(.20)\end{array}$ & $\begin{array}{l}.15 \\
(.20)\end{array}$ & $\begin{array}{c}.38 \\
(.21)\end{array}$ & $\begin{array}{c}.42 \\
(.20)\end{array}$ & $\begin{array}{c}.23 \\
(.24)\end{array}$ & $\begin{array}{c}.24 \\
(.22)\end{array}$ & $\begin{array}{c}.26 \\
(.25)\end{array}$ & $15.10 * * *$ \\
\hline \multicolumn{10}{|l|}{ Personality } \\
\hline Extraversion & $\begin{array}{c}3.21 \\
(1.05)\end{array}$ & $\begin{array}{c}3.87 \\
(1.24)\end{array}$ & $\begin{array}{c}4.68 \\
(1.32)\end{array}$ & $\begin{array}{c}4.80 \\
(1.33)\end{array}$ & $\begin{array}{c}5.00 \\
(0.81)\end{array}$ & $\begin{array}{c}4.02 \\
(1.08)\end{array}$ & $\begin{array}{c}5.06 \\
(1.30)\end{array}$ & $\begin{array}{c}4.59 \\
(1.22)\end{array}$ & $20.15 * * *$ \\
\hline Openness to Experience & $\begin{array}{c}3.26 \\
(1.10)\end{array}$ & $\begin{array}{c}5.08 \\
(0.99)\end{array}$ & $\begin{array}{c}5.26 \\
(0.92)\end{array}$ & $\begin{array}{c}4.18 \\
(1.17)\end{array}$ & $\begin{array}{c}3.88 \\
(1.13)\end{array}$ & $\begin{array}{c}3.52 \\
(1.03)\end{array}$ & $\begin{array}{c}5.24 \\
(0.95)\end{array}$ & $\begin{array}{c}5.45 \\
(1.00)\end{array}$ & $33.57 * * *$ \\
\hline Conscientiousness & $\begin{array}{c}4.61 \\
(1.06)\end{array}$ & $\begin{array}{c}4.91 \\
(0.98)\end{array}$ & $\begin{array}{c}4.23 \\
(1.21)\end{array}$ & $\begin{array}{c}5.35 \\
(0.73)\end{array}$ & $\begin{array}{c}5.39 \\
(0.90)\end{array}$ & $\begin{array}{c}4.68 \\
(0.87)\end{array}$ & $\begin{array}{c}3.60 \\
(1.07)\end{array}$ & $\begin{array}{c}4.19 \\
(0.83)\end{array}$ & $21.96 * * *$ \\
\hline Agreeableness & $\begin{array}{c}4.48 \\
(0.92)\end{array}$ & $\begin{array}{c}3.43 \\
(0.88)\end{array}$ & $\begin{array}{c}4.96 \\
(0.79)\end{array}$ & $\begin{array}{c}3.59 \\
(0.82)\end{array}$ & $\begin{array}{c}5.00 \\
(0.84)\end{array}$ & $\begin{array}{c}5.21 \\
(0.88)\end{array}$ & $\begin{array}{c}4.08 \\
(1.07)\end{array}$ & $\begin{array}{c}3.91 \\
(0.73)\end{array}$ & $29.02 * * *$ \\
\hline Neuroticism & $\begin{array}{c}4.48 \\
(0.97)\end{array}$ & $\begin{array}{c}4.40 \\
(0.93)\end{array}$ & $\begin{array}{c}4.07 \\
(0.96)\end{array}$ & $\begin{array}{c}3.56 \\
(0.98)\end{array}$ & $\begin{array}{c}3.28 \\
(1.09)\end{array}$ & $\begin{array}{c}4.41 \\
(0.84)\end{array}$ & $\begin{array}{c}4.43 \\
(0.77)\end{array}$ & $\begin{array}{c}3.17 \\
(0.99)\end{array}$ & $16.78 * * *$ \\
\hline \multicolumn{10}{|l|}{ Job Characteristics } \\
\hline Autonomy & $\begin{array}{c}4.10 \\
(1.14)\end{array}$ & $\begin{array}{c}4.70 \\
(1.03)\end{array}$ & $\begin{array}{c}4.16 \\
(0.95)\end{array}$ & $\begin{array}{c}4.07 \\
(1.11)\end{array}$ & $\begin{array}{c}4.40 \\
(1.01)\end{array}$ & $\begin{array}{c}3.80 \\
(1.25)\end{array}$ & $\begin{array}{c}5.17 \\
(0.73)\end{array}$ & $\begin{array}{c}5.38 \\
(0.79)\end{array}$ & $12.49 * * *$ \\
\hline Time Pressure & $\begin{array}{c}5.14 \\
(0.89)\end{array}$ & $\begin{array}{c}3.88 \\
(1.03)\end{array}$ & $\begin{array}{c}4.48 \\
(0.90)\end{array}$ & $\begin{array}{c}5.04 \\
(0.98)\end{array}$ & $\begin{array}{c}3.50 \\
(1.06)\end{array}$ & $\begin{array}{c}5.02 \\
(1.10)\end{array}$ & $\begin{array}{c}3.91 \\
(0.96)\end{array}$ & $\begin{array}{c}4.57 \\
(0.74)\end{array}$ & $24.61 * * *$ \\
\hline Supply vs. Demand Orientation & $\begin{array}{c}3.50 \\
(1.36)\end{array}$ & $\begin{array}{c}3.38 \\
(1.05)\end{array}$ & $\begin{array}{c}4.62 \\
(1.28)\end{array}$ & $\begin{array}{c}4.54 \\
(1.19)\end{array}$ & $\begin{array}{c}3.22 \\
(1.04)\end{array}$ & $\begin{array}{c}3.59 \\
(1.05)\end{array}$ & $\begin{array}{c}5.13 \\
(0.93)\end{array}$ & $\begin{array}{c}4.98 \\
(0.83)\end{array}$ & $23.63 * * *$ \\
\hline
\end{tabular}

Notes: $* * * \mathrm{p}<0.001$

Codes for clusters: 1 = Lightweight; 2 = Inventor; 3 = Hands-on Innovator; $4=$ Entrepreneur; $5=$ Headcoach; $6=$ Gardener;

$7=$ Evangelist; $8=$ Superhero 


\section{DISCUSSION}

\section{Interpretation of the Identified Clusters}

Overall, eight clusters were identified in the empirical data analysis. In interpreting these clusters, I assigned labels to highlight the empirically distinct combinations of innovation leadership behaviors that were identified to facilitate the discussion of the cluster profile (Gruber et al., 2010; Homburg et al., 2008).

Cluster 1: Lightweight. The first identified cluster describes a top manager who does not engage in any of the four behaviors examined. This cluster is the largest one and contains 77 of the 411 observations in the sample. "Lightweights" are quite conscientious and agreeable heads of largely supply-oriented departments with a non-technical education (correspondingly, the lightweight is overrepresented in the positions of CFO and CHRO). They operate under time pressure and lack openness. This cluster thus might represent a prototype custodian who does well in "keeping the lights on" but lacks the motivation and the time to engage in innovative efforts and is also not expected to do so (e.g. Carter et al., 2011; Hart \& Quinn, 1993). Hence, the lightweight reflects the notion that many top managers simply do not get involved into organizational innovation but merely serve as administrators of the firm (Yadav et al., 2007).

Cluster 2: Inventor. The "inventor" is characterized by high levels of direct involvement in innovation at the project level, but low levels in all the other three behaviors. This role is assumed by managers who are highly open and conscientious, lack agreeableness and extraversion, possess a technical degree but limited functional diversity, and experience autonomy and time slack. Almost exclusively, "inventors" work in the positions of CIO, CTO, and $\mathrm{COO}$ with a strong supply-focus of their department. Together, all this draws an archetypical picture of a technology-focused "geek" (Glen, 2003). While there are several works that praise the benefits of top managers as "inventors" (e.g. Hunter \& Cushenbery, 2011; Islam \& Zein, 2019), those works perceive direct involvement of top managers in innovation projects as a valuable add-on to their rather strategic tasks. Islam and Zein (2019: 2) for instance argue that "inventor experience may endow them [i.e., top managers] with valuable innovationrelated insights that translate into a superior ability to evaluate, select, and execute innovationintensive investment projects". In contrast, the "inventor" type identified here engages in innovation exclusively by direct involvement on the project level. The existence of this type indicates that especially in technology-oriented business functions, a significant share of top managers will primarily contribute to organizational innovation by taking part in development efforts (such as improving product and process technologies (Carter et al., 2011)).

Cluster 3: Hands-on Innovator. The "hands-on innovator" resembles the "inventor", but instead of solely engaging in the development of own ideas, this type of manager also supports others in their innovative efforts. Moreover, there are clear differences between the two roles with regard to job characteristics and personality traits. The "hands-on innovator" heads a demand-oriented department. Hence, though "hands-on innovators" works in the same managerial positions as "inventors", the definition of these positions in the firm seem to be different. Concerning personality, "hands-on innovators" are highly open, but also quite extroverted and agreeable which might explain their tendency to encourage, support, and 
mentor other innovators in the firm. In sum, the "hands-on innovator" group represents a top manager that accounts for high levels of senior management involvement and support on the project level (e.g. Felekoglu \& Moultrie, 2014; Green, 1995; Gomes et al., 2001).

Cluster 4: Entrepreneur. This type of manager gets involved directly in organizational innovation, both on the operational and the strategic level. CTOs and CMOs are overrepresented in this cluster. This type of manager combines high levels of education in science or engineering with diverse functional experience. He/she normally heads a demand-oriented function and works under time pressure. Extraversion and especially conscientiousness are highly developed, he/she has medium levels of openness, low agreeableness, and low neuroticism. The managerial style depicted by this combination of behaviors matches well with previous descriptions of top managers as "entrepreneurs". The "entrepreneur" role was first conceptualized by Mintzberg who argued that one of the major tasks of a strategic leader is to act "as initiator and designer of much of the controlled change in his organization" (1971: 105). This includes direct involvement in high impact innovation projects, but more importantly the identification of technological and environmental trends as well as aligning the firm's strategy to those trends (Finkelstein et al., 2009). Combining those two behaviors, "entrepreneurs" can help integrate technological and business aspects of organizational innovation (Maidique, 1980). A top manager of this type thus acts "as an organizational change agent [...] to influence the future strategic direction and opportunities of the firm" (Grover et al., 1993: 112).

Cluster 5: Headcoach. This profile combines innovation strategy formulation and sponsoring of innovators. Those managers gained experience in a variety of different organizational functions, their position allows them to work autonomously under low time pressure, and they combine extraversion, conscientiousness, and agreeableness as main personality traits. The administrative functions of CFO and CHRO but also COO are overrepresented. The behavior reflected by this cluster arguably coincides with Deschamps (2008) description of the "coach" role of innovation leaders. According to this description, innovation leaders must "develop a strategy and process to win" but also "attend to the development of individuals" and "stimulate and motivate the team" (Deschamps, 2008: 200). Thus, like a headcoach, this type of manager is not entering the "playground" in the innovation game him-/herself but provides "players" (i.e., employees and middle managers) with a strategic direction and engages closely with them to help in their innovative efforts. Such a combination of strategic thinking and people-focus is also reflected in the managerial style described by former CEOs A. G. Lafley (P\&G) and Jack Welch (GE). For instance, Lafley argues that in order to be an effective innovation leader, a top manager needs to be both a "visionary strategist" who sets the roadmap for the firm's future development and "a hardheaded humanist" who encourages and mentors employees to bring forth innovations in line with this roadmap (Lafley \& Charan, 2008: vii).

Cluster 6: Gardener. The "gardener" is the mirror image of the "entrepreneur". Instead of initiating organizational innovation, this type of manager fully focuses on an enabling style of innovation leadership. On average, "gardeners" are the oldest group in the sample, they work under time pressure, and lead a supply-oriented department. Concerning personality, they combine agreeableness and conscientiousness. Bill Campbell, the late former Chairman of the software developer Intuit, gives a description of innovation leadership that strongly resembles 
the "gardener": "You have to go out and recruit the best person you can who knows how to create an innovation culture. He or she doesn't need to be personally the most innovative person, but he or she needs to know how to foster innovation." (Mendoca \& Sneader, 2007: 72). Scholars that explain organizational innovation by promotor theory (i.e., by the cooperation of different specialized persons that each provide a specific contribution in the innovation process (Rost et al., 2007)) also seem to coincide with the "gardener" profile. These works highlight that top managers might benefit innovation most by employing their organizational knowledge and hierarchical power to remove barriers in the firm and provide the framework conditions for subordinate experts to develop innovative solutions (Gemünden et al., 2007).

Cluster 7: Evangelist. This type strongly engages in innovation strategy formulation and moderately in climate shaping. He/she is educated in business and likely assumes the roles of $\mathrm{CMO}, \mathrm{CFO}$, or CHRO. His/her position is demand-oriented, grants job autonomy and low time pressure. Extraversion and openness are the defining personality traits. The innovation leadership style and profile of this type bear some commonalities with the picture by transformational/visionary conceptualizations of leadership. Those works argue that top managers' main contribution to organizational innovation lies in their efforts on the firm level, by providing strategic direction in the form of a compelling vision, and by finding ways to motivate, inspire, and stimulate innovative efforts by employees (e.g. Jung et al., 2008; Ling et al., 2008). Literature on top management in the information systems context draws on case study evidence to highlight a similar innovation leadership style, the "evangelist". In such an "evangelist" role, top managers challenge and reformulate the firm's strategic mission, promote new business opportunities, and lay out roadmaps for organizational change (Chun \& Mooney, 2009; Peppard, 2010). Extending transformational/visionary leadership perspectives, descriptions of the "evangelist" stress the importance of top managers that integrate strategic and cultural aspects of leadership at the firm level. For instance, Haffke et al. (2016) gives examples of top managers that majorly led innovation by introducing a "fresh spirit" to the firm as a whole. In specific, those managers mainly worked on putting innovation on their firms' strategic agenda, sensitizing peers and subordinates about the importance of innovation, and inducing cultural change.

Cluster 8: Superhero. Finally, the "superhero" cluster describes a leader that exerts all four behaviors to a high degree. The "superhero" profile is evenly distributed across functional positions, except COO. High demand-orientation and high autonomy are typical. On average, "superheroes" have the highest levels of openness and the lowest levels of neuroticism. This type of manager is the rarest in the sample with only 23 observations. As the "superheroes" cater for all major aspects of stimulating organizational innovation, this cluster evokes the image of the "great man" that has been a foundational paradigm of early innovation research. According to the "great man" perspective, innovation is fostered by extraordinary individuals who lead innovation from the top by single-handedly identifying opportunities, developing ideas, and assembling followers (Achilladelis et al., 1971; Chakrabarti, 1974; Schön, 1963; Schumpeter, 1934). Until today, the ideal of an omni-competent top manager who promotes innovation is still quite common in management practice (e.g. see various depictions of top managers as "transformers-in-chief" or "heroes of innovation" (e.g. Rickards et al., 2015; 
Teerlink et al., 2014)). In more recent academic research, such views are meanwhile labeled as "managerial mystique" (Finkelstein et al., 2009). Though it is thus unlikely top managers in the "superhero" cluster will single-handedly bring forth innovation, they still seem to enact their innovation role in accordance with generalist ideals that resemble the "great man", acting both as innovator and supporter, both as operational and strategic leader.

\section{Theoretical Implications on C-Level Innovation Leadership}

The findings of my analysis provide several important implications for research on the role of top managers in organizational innovation. In the narrower sense, as the first contribution, this paper advances research on top management and innovation by identifying and specifying a taxonomy of eight different innovation leadership styles. In contrast to most previous research which often relies on managerial anecdotes or a limited range of case studies, this work draws on a large data sample and a rigorous classification procedure. Due to this procedure, the developed taxonomy should adequately cover the most empirically relevant innovation leadership styles on the c-level.

The eight identified types of top managers in my taxonomy bear resemblance to previous academic and practice-oriented perspectives on c-level innovation leaders but also provide new insights and amendments. For some of the types, there is a rather broad literature (both anecdotal and scientific) that provides descriptions of top managers' leadership behavior that exhibit many similarities to the empirically derived profiles in this paper (specifically, "lightweight", "entrepreneur", and "evangelist"). For other types, however, previous evidence is largely restricted to anecdotes and best practice narratives ("headcoach", "gardener", and "superhero") and/or only implicitly related to the leadership styles identified here ("hands-on innovator" and "gardener"). Still for other types, the identified clusters might somewhat match previous perspectives of top managers' role in organizational innovation but differ from those perspectives in important aspects ("inventor"). In sum, my work thus advances previous research by providing a more complete and better specified picture of how top managers influence and get involved in organizational innovation.

More generally, as the second contribution, the results of this paper suggest that a theory of clevel innovation leadership must account for multiplicity of managerial styles. Such a perspective may help consolidate different perspectives on top managers' role in organizational innovation. Previous studies and anecdotes usually illustrated one single way of how top managers are supposed to act in order to foster organizational innovation. As demonstrated above, the types of top managers identified in my research approach partially match with those perspectives. While my results thus indicate that existing depictions of top managers' contribution to organizational innovation bear some valid insight, they also imply that none of those depictions is able to provide a comprehensive reflection of c-level innovation leadership by itself. Instead of a "one-size-fits-all" approach to innovation leadership, my findings thus clearly demonstrate that different top managers may contribute to organizational innovation in a number of different ways. Future research on top managers and innovation leadership thus should not ask "To which degree is a top manager involved in organizational innovation?" but rather "In which way(s) does a top manager contribute to organizational innovation?". 
As the third contribution, this paper endorses the importance of specialization as a major aspect of c-level innovation leadership. My findings indicate that apart from the "lightweight" (who does not engage in any innovation leadership behavior) and the "superhero" (who engages in all four behaviors), a large majority (75.7\%) of the managers in the sample take roles in which they focus on one or maximum two different leadership behaviors. Hence, c-level innovation leadership is not adequately reflected by "great man" or "superstar" perspectives that still prevail in both academic and practice-oriented works (e.g. Howell \& Higgins, 1990; Khurana, 2002; Yadav et al., 2007). The results of this work are more in line with perspectives that perceive innovation and innovation leadership as teamwork between a number of actors that bring in different skills and fulfill different tasks (e.g. Gemünden et al., 2007; Rost et al., 2007). Looking ahead, the findings of this work might open up a range of questions on how to group and coordinate different types of leaders in the organizational structure of the c-suite. Further research on these questions could inform both the literature on TMT composition and processes (e.g. Buyl et al., 2011; Talke et al., 2011) but also the literature on functional managers and their division of managerial work (e.g. Guadalupe et al., 2014).

\section{Theoretical Implications on the Determinants of Innovation Leadership Behavior}

In line with strategic leadership theory, most top management research assumes that observable experiences, psychological factors, and job characteristics considerably influence how top managers interpret their role as organizational and - more specifically - innovation leaders (Bromiley \& Rau, 2016; Carpenter et al., 2004; Finkelstein et al., 2009; Hambrick, 2007). Besides identifying different types of innovation leadership styles, the taxonomical approach in this paper thus also aimed to explore if and how such innovation leadership styles are related to a top manager's person and position. Indeed, discriminant analysis found that there were typical and unique profiles of personal and job characteristics that allowed for predicting a top manager's innovation leadership style with good accuracy. By this result, this study addresses one of the major critiques on strategic leadership theory - that research most often simply assumed personality traits and experiences to translate into top managers' tendency to engage in certain behaviors without actually studying those behaviors (e.g. Cannella \& Monroe, 1997; Carpenter et al., 2004; Elenkov et al., 2005).

General Implications. Taking a more detailed look on the results of the discrimination analysis, it is evident that the relative predictive power of the personality variables and the job characteristics is considerably higher compared to the demographic and professional background variables. This finding has two implications. On the one hand, instead of being solely determined by personal predisposition, the innovation leadership behavior of top managers is thus rather determined by both "who a top manager is" and "what he/she faces as a manager" (Mintzberg, 2009). This implication is in line with the notion that the "only way to think of any given [general managerial] job is the person-in-the-job" (Kaplan, 1983: 29). When aiming to explain in which way a top manager gets involved in organizational innovation, research should thus account for the interaction between person and job context.

On the other hand, this finding adds insight to the discussion of whether to employ observable characteristics or psychological factors as predictor variables in strategic leadership theory 
(Finkelstein et al., 2009). My research results demonstrate that demographics and professional background indeed add significant predictive power to the discriminant function but play a rather small role in comparison to personality variables. This does not mean that the use of observable experiences in top management research is unjustified. Executive background variables without a doubt have advantages when it comes to data access and - as also this study indicates - indeed affect top managers' cognitions and behaviors. Still, based on the results of my study, it is reasonable to state that at least concerning their involvement in organizational innovation, personality traits are more proximate and stronger predictors. I thus suggest that future top management research in the fields of strategy and innovation should increasingly include psychological variables in their theoretical models and research designs, despite the methodological and data access challenges.

With regard to the specific effects of demographics, professional background, personality, and job characteristics, my findings also help advance strategic leadership theory. Here, it is important to note again that in line with the assumptions of configuration theory my research procedure aimed at explaining the antecedents of different innovation leadership behaviors "through overall patterns of multiple variables rather than through selected variables and their bivariate relationships" (Homburg et al., 2008: 134). Hence, it is ineligible to interpret isolated effects of single variables. Rather, the conjunction of antecedent variables must be considered (Dess et al., 1993; Meyer et al., 1993). Still, for all three groups of predictor variables employed in my analysis, some overall patterns can be identified that might inform our understanding of what determines innovation leadership behavior on the c-level. In the following, I will discuss those patterns.

Personality. I will first take a closer look at the effects of personality as this group of variables was found to possess the highest relative predictive power in discriminant analysis. Starting with the personality profile of the "lightweight", the results indicate that low levels of extraversion and openness and medium to high levels of conscientiousness, agreeableness, and neuroticism are typical for organizational leaders who do not care much about getting involved in innovation. In all, this result matches well with previous studies on the link between personality and individual innovative behavior, that predominantly found positive effects of openness and extraversion as well as negative effects of conscientiousness, agreeableness, and neuroticism (Baer \& Oldham, 2006; Marcati et al., 2008; Wang et al., 2012).

For the other types of innovation leaders, the findings are more nuanced. Still, several general patterns are evident. First, innovation leadership styles in which the support of innovators and bottom-up innovation efforts plays a defining role (i.e., "hands-on innovator", "headcoach", "gardener") coincide with high levels of agreeableness. This finding is in line with previous studies on upper echelons' personality which argue that top managers scoring high on agreeableness tend to favor decentralization and interpret their managerial roles mostly as mentors to subordinates (O'Reilly et al., 2014; Peterson et al., 2003).

Second, innovation leadership styles that include high levels of direct involvement either on project or organizational level require a combination of either extraversion and openness ("hands-on innovator", "evangelist", "superhero"), extraversion and conscientiousness 
(“entrepreneur", "headcoach"), or openness and conscientiousness (“inventor"). Previous research has argued that all three personality traits might motivate organizational leaders to get personally involved in organizational innovation: extraversion by a preference for proactivity and craving for admiration by peers and subordinates (Zhao \& Seibert, 2006), openness by general interest in novelty and creative work (Baer \& Oldham, 2006), and conscientiousness by caring for the firm's success and goal accomplishment (Wang et al., 2012). While empirical studies testing those assumptions produced quite mixed results (George \& Zhou, 2001; Judge et al., 2002; Marcati et al., 2008), the results of my work indicate that it might be the combination of two of those motives that will explain if and in which way organizational leaders engage directly in innovative tasks. Future research (especially qualitative) might help to better understand how such a combination of personality traits and related personal preferences shape top managers' innovation leadership styles.

Third, concerning neuroticism, "entrepreneur", "headcoach", and "superhero" score rather low while "inventor", "hands-on innovator", and "evangelist" score rather high. It is evident that all three profiles with rather low neuroticism depict managers whose leadership style includes dealing with issues of innovation strategy. This finding can be linked to Zhao and Seibert (2006) who argue based on a comparison between entrepreneurs and administrative managers that selfesteem and frustration tolerance (which are associated with low neuroticism) predispose individuals to engage in highly-complex tasks requiring a holistic take on innovation and organizational development. With regard to the "inventor" type, research has demonstrated that top managers with high neuroticism tend to care less for social aspects of leadership (O'Reilly et al., 2014). Also, Feist (1993) and Patterson (2002) found that neuroticism is associated with individuals that easily get taken up in scientific or engineering tasks and tend to "tinker" on technological artefacts. Finally, with regard to the "Evangelist" and the "Gardener", my findings might be explained by previous works that argue that high levels of neuroticism are likely found in individuals who are no actual "doers" themselves but instead prefer to get taken up in ideation and creativity (Feist, 1999) or attend to the functioning of social collectives and take a supportive role in organizations (Zhao \& Seibert, 2006). Still, also here further research is needed to better explain and solidify the empirically observed relations.

Job Characteristics. With regard to job characteristics, a substantial part of previous research assumed high levels of job autonomy and low levels of time pressure to be conducive for the engagement of employees and managers in organizational innovation (e.g. Baer \& Oldham, 2006; Beugelsdijk, 2008; Parker \& Axtell, 2001; Wu et al., 2014). Indeed, our results partially match those patterns, as especially top managers who do not get involved in organizational innovation ("lightweights") have to deal with low job autonomy and high time pressure whereas "inventors", "hands-on innovators", "headcoaches", "evangelists", and "superheroes" experience medium to high autonomy and low to medium time pressure in their jobs.

However, my findings also provide counterexamples to the rule that innovative engagement of top managers requires job autonomy and low levels of time pressure: both "entrepreneurs" and "gardeners" on average work under time pressure and are not allowed or able to define their job autonomously. There are two potential explanations for this counterintuitive finding. On the one hand, there may be interaction or compensation effects between job autonomy, time 
pressure, and the personal characteristics of those top managers so that detrimental direct effects of the job context can be overcome (Baer \& Oldham, 2006; Wu et al., 2014; Xie \& Johns, 1995). On the other hand, rather than impeding involvement in organizational innovation, time pressure and low autonomy may actually stimulate a certain style of innovation leadership. Zhou and Shalley (2003), Gardner (1990), and Baer and Oldham (2006), for instance, outline that high levels of time pressure may activate individuals engagement and foster exploratory behaviors, experimentation, and risk taking - behaviors that match well with the "entrepreneur" profile.

Concerning job content, my results uncover a quite clear divide between the roles taken by top managers heading supply-oriented and demand-oriented functions. If top managers in charge of supply-oriented functions actually contribute to organizational innovation (most "lightweights" work in rather supply-oriented functions), they seem to do so by getting involved directly in solution development ("inventor") or taking supporting roles ("headcoach", "gardener"). This finding is well in line with descriptions in previous research (Guadalupe et al., 2014; Priem et al., 2012; Tumbas et al., 2017) that assume that the most valuable contribution of supply-oriented functions to organizational innovation may lie in the provision of expert knowledge and advice. In contrast, top managers in charge of demand-oriented functions tend to assume an innovation leadership style that includes involvement in innovation strategy formulation. As demand-oriented functions are expected to focus on customers and value creation (Priem et al., 2012; Tumbas et al., 2017), the tendency of top managers heading such functions to take leadership styles such as "entrepreneur", "evangelist", or "superhero" seems plausible.

Observable Characteristics: Finally, the results of discriminant analysis demonstrate that also observable characteristics help predict the likelihood of a top manager assuming a certain innovation leadership style. Concerning age, "headcoaches" and "gardeners" are on average the oldest groups, "evangelists" are the youngest. This matches well with previous works suggesting that younger top managers might be more eager to induce change in the firm and aligning it towards future challenges (Barker \& Mueller, 2002; Li \& Tan, 2013) whereas older top managers may be more inclined to advise and/or support others (Damanpour \& Schneider, 2009). Concerning education, top managers with degrees in engineering and science and rather high levels of education tend to get directly involved in innovative projects ("inventors", "hands-on innovators", “entrepreneurs", "superheroes"). However, as also "headcoaches", "gardeners", and "evangelists" are quite likely to possess higher-level degrees in technologyrelated fields, only the "lightweight" type really stands out with a rather low probability of a technology degree and the lowest levels of education on average. This finding supports previous notions that lower degrees of education and non-technical degrees are characteristics of top managers that refuse to get involved in organizational innovation (Barker \& Mueller, 2002; Damanpour \& Schneider, 2009; Garms \& Engelen, 2019). Finally, concerning background diversity, "entrepreneur" and "headcoach" score highest whereas "lightweight", "inventor", and "hands-on innovator" have the lowest diversity of functional experience. Also here, the findings are well aligned with strategic leadership research. This literature links high levels of functional background diversity to "generalist" approaches of innovation leadership that entail 
engagement on the organizational level. In contrast, low levels of functional background diversity relate to "specialist" approaches of innovation leadership that entail engagement on the project level (Barker \& Mueller, 2002; Garms \& Engelen, 2019; Hoffman \& Hegarty, 1993).

\section{Practical Implications}

This work provides several implications for management practice. For top managers, the developed conceptual framework might serve as a tool for self-assessment. Based on the four behaviors described, c-level executives can evaluate their innovation leadership style and develop a comprehensive understanding of their contribution to their firms' innovation outcomes. Also, they may spot own deficiencies which they can try to eliminate by themselves or to compensate by coordinating their activities with other members of the c-suite and complementing each other's strength and weaknesses. For firms, this work provides evidence for the notion that there are "probably several different types of innovation leaders and it may be interesting to characterize them, if only for senior management to know how to attract, develop, and deploy them" (Deschamps, 2008, p. xv). The profiles identified can serve as input for leadership development programs but also as a tool for candidate selection for top management positions. Moreover, the results of this work imply that top managers tend to specialize in their innovation leadership style and engage only in a limited range of innovationrelated behaviors. As it is unlikely that a single manager possesses the skills and resources to simultaneously exert the full spectrum of behaviors necessary to initiate and enable innovation in the firm, effective innovation leadership on the c-level will thus require teamwork and a distribution of roles and contributions between a firm's top managers. Firms can use this insight for decisions on the design of the TMT and the staffing of c-suite positions.

\section{Limitations}

This work has several limitations which provide promising avenues for further research. Concerning theoretical limitations, this study sought to identify different types of top managers with regard to their innovation leadership behavior, but did not link these types to innovation performance, neither theoretically nor empirically. Further works should examine which types of top managers actually foster firms' innovation performance or explore under which circumstances which innovation leadership style performs well. Further, in my exploratory study I could only provide first rudimentary explanations for the empirically observed combinations of innovation leadership behavior and top managers' demographics, professional background, personality, and job characteristics. Further research should build on this exploratory work to explicate and test the causal mechanisms behind my empirical observations. In doing so, scholars could overcome the shortcoming in strategic leadership theory that causal relations between top managers' characteristics and their actual behaviors are rather assumed than observed (Carpenter et al., 2004).

Concerning methodological limitations, the empirical study is located in the context of the German, Austrian, and Swiss manufacturing sector. In this technology-oriented industry, there may be specific requirements to top managers which may influence the innovation leadership behaviors that are taken. Also, in other industries such as consumer goods, the demographics of the top managers may differ significantly when it comes to education, professional 
background, and background which also might produce different results concerning top managers' innovation leadership behaviors. Moreover, I focused on functional top managers. The identified leadership profiles should thus be tested for CEOs, but also for divisional top managers that operate on the same hierarchical level as the CxOs (Guadalupe et al., 2014). Finally, there are several limitations concerning my empirical research design. Data collection was cross-sectional and the procedure relied on self-report measures. Though I took several appropriate measures to account for potential biases stemming from my approach, I suggest that future research should draw on longitudinal data and consult multiple data sources. 


\subsection{References}

Achilladelis, B., Jervis, P., \& Robertson, A. B. 1971. A Study of Success and Failure in Industrial Innovation. Sussex, UK: University of Sussex Press.

Alessandri, T. M., \& Pattit, J. M. 2014. Drivers of R\&D Investment: The Interaction of Behavioral Theory and Managerial Incentives. Journal of Business Research, 67(2): 151158.

Antonakis, J., \& House, R. J. 2014. Instrumental Leadership: Measurement and Extension of Transformational-Transactional Leadership Theory. The Leadership Quarterly, 25(4): $746-771$.

Armstrong, J. S., \& Overton, T. S. 1977. Estimating Nonresponse Bias in Mail Surveys. Journal of Marketing Research, 14(3): 396-402.

Baer, M., \& Oldham, G. R. 2006. The Curvilinear Relation Between Experienced Creative Time Pressure and Creativity: Moderating Effects of Openness to Experience and Support for Creativity. Journal of Applied Psychology, 91(4): 963-970.

Bagozzi, R. P., \& Yi, Y. 1988. On the Evaluation of Structural Equation Models. Journal of the Academy of Marketing Science, 16(1): 74-94.

Barker, V. L., \& Mueller, G. C. 2002. CEO Characteristics and Firm R\&D Spending. Management Science, 48(6): 782-801.

Bass, B. M., \& Avolio, B. J. 1992. Multifactor Leadership Questionnaire - Short Form. Binghamton, NY: Center for Leadership Studies.

Berson, Y., Oreg, S., \& Dvir, T. 2008. CEO Values, Organizational Culture and Firm Outcomes. Journal of Organizational Behavior, 29(5): 615-633.

Beugelsdijk, S. 2008. Strategic Human Resource Practices and Product Innovation. Organization Studies, 29(6): 821-847.

Blau, P. M. 1977. Inequality and Heterogeneity. New York: Free Press.

Boone, C., De Brabander, B., \& Hellemans, J. 2000. Research Note: CEO Locus of Control and Small Firm Performance. Organization Studies, 21(3): 641-646.

Bromiley, P., \& Rau, D. 2016. Social, Behavioral, and Cognitive Influences on Upper Echelons during Strategy Process: A Literature Review. Journal of Management, 42(1): 174-202.

Buyl, T., Boone, C., Hendriks, W., \& Matthyssens, P. 2011. Top Management Functional Diversity and Firm Performance. Journal of Management Studies, 48(1): 151-177.

Cannella, A. A., \& Monroe, M. J. 1997. Contrasting Perspectives on Strategic Leaders: Toward a More Realistic View of Top Managers. Journal of Management, 23(3): 213-237.

Carpenter, M. A., Geletkanycz, M. A., \& Sanders, W. G. 2004. Upper Echelons Research Revisited. Journal of Management, 30(6): 749-778.

Carter, M., Grover, V., \& Thatcher, J. B. 2011. The Emerging CIO Role of Business Technology Strategist. MIS Quarterly Executive, 10(1): 19-29.

Chakrabarti, A. K. 1974. Role of Champion in Product Innovation. California Management Review, 17(2), 58-62.

Christensen, C. M., Kaufman, S. P., \& Shih, W. C. 2008. Innovation Killers: How Financial Tools Destroy Your Capacity to Do New Things. Harvard Business Review, 86(1): 98-105. Chun, M., \& Mooney, J. 2009. CIO Roles and Responsibilities: Twenty-five Years of Evolution and Change. Information \& Management, 46(6): 323-334. 
Cooper, R. G. 1999. The Invisible Success Factors in Product Innovation. Journal of Product Innovation Management, 16(2): 115-133.

Crossan, M. M., \& Apaydin, M. 2010. A Multi-dimensional Framework of Organizational Innovation: A Systematic Review of the Literature. Journal of Management Studies, 47(6): $1154-1191$.

Damanpour, F., \& Schneider, M. 2009. Characteristics of Innovation and Innovation Adoption in Public Organizations. Journal of Public Administration Research, 19(3): 495-522.

Deschamps, J. P. 2008. Innovation Leaders: How Senior Executives Stimulate, Steer and Sustain Innovation. Chichester, UK: Wiley.

Dess, G. G., Newport, S., \& Rasheed, A. M. 1993. Configuration Research in Strategic Management: Key Issues and Suggestions. Journal of Management, 19(4): 775-795.

Doty, D. H., \& Glick, W. H. 1994. Typologies as a Unique Form of Theory Building: Toward Improved Understanding and Modeling. Academy of Management Review, 19(2): 230-251.

Duda, R. O., \& Hart, P. E. 1973. Pattern Classification and Scene Analysis. New York: John Wiley.

Ehrhart, M. G., \& Klein, K. J. 2001. Predicting Followers' Preferences for Charismatic Leadership: The Influence of Follower Values and Personality. The Leadership Quarterly, 12(2): 153-179.

Elenkov, D. S., \& Manev, I. M. 2005. Top Management Leadership and Influence on Innovation: An International Multi-cluster Comparative Study. Journal of Management, 31(3): 381-402.

Enns, H. G., Huff, S. L., \& Higgins, C. A. 2003. CIO Lateral Influence Behaviors: Gaining Peers' Commitment to Strategic Information Systems. MIS Quarterly, 27(1): 155-176.

Feist, G. J. 1993. A Structural Model of Scientific Eminence. Psychological Science, 4(6): 366371.

Feist, G. J. 1999. The Influence of Personality on Artistic and Scientific Creativity, in: Sternberg, R. J. (ed.). Handbook of Creativity. New York: Cambridge University Press: 273-296.

Felekoglu, B., \& Moultrie, J. 2014. Top Management Involvement in New Product Development: A Review and Synthesis. Journal of Product Innovation Management, 31(1): 159-175.

Finkelstein, S., Cannella, S. F. B., Hambrick, D. C., \& Cannella, A. A. 2009. Strategic Leadership: Theory and Research on Executives, Top Management Teams, and Boards. New York: Oxford University Press.

Fiss, P. C. 2011. Building Better Causal Theories: A Fuzzy Set Approach to Typologies in Organization Research. Academy of Management Journal, 54(2): 393-420.

Fornell, C., \& Larckner, D. F. 1981. Evaluating Structural Equation Models with Unobservable Variables and Measurement Error. Journal of Marketing Research, 18(1): 39-50.

Galasso, A., \& Simcoe, T. S. 2011. CEO Overconfidence and Innovation. Management Science, 57(8): 1469-1484.

Garms, F. P., \& Engelen, A. 2019. Innovation and R\&D in the Upper Echelons: The Association between the CTO's Power Depth and Breadth and the TMT's Commitment to Innovation. Journal of Product Innovation Management, 36(1): 87-106. 
Gellatly, I. R., \& Irving, P. G. 2001. Personality, Autonomy, and Contextual Performance of Managers. Human Performance, 14(3): 231-245.

Gemünden, H. G., Salomo, S., \& Hölzle, K. 2007. Role Models for Radical Innovations in Times of Open Innovation. Creativity and Innovation Management, 16(4): 408-421.

George, J. M., \& Zhou, J. 2001. When Openness to Experience and Conscientiousness Are Related to Creative Behavior: An Interactional Approach. Journal of Applied Psychology, 86(3), 513-524.

Gerstner, W. C., König, A., Enders, A., \& Hambrick, D. C. 2013. CEO Narcissism, Audience Engagement, and Organizational Adoption of Technological Discontinuities. Administrative Science Quarterly, 58(2): 257-291.

Glen, P. 2003. Leading Geeks: How to Manage and Lead the People Who Deliver Technology. San Francisco: Wiley.

Gomes, J., Weerd-Nederhof, P., Pearson, A., \& Fissher, O. 2001. Senior Management Support in New Product Development Process. Creativity and Innovation Management, 10(4): 234 242.

Gottschalk, P. 1999. The Role of the CIO in Norwegian Organisations. International Journal of Information Management, 19(5): 389-399.

Green, S. G. 1995. Top Management Support of R\&D Projects: A Strategic Leadership Perspective. IEEE Transactions on Engineering Management, 42(3): 223-232.

Grover, V., Jeong, S.R., Kettinger, W.J., \& Lee, C.C. 1993. The Chief Information Officer: A Study of Managerial Roles. Journal of Management Information Systems, 10(2): 107-130.

Gruber, M., Heinemann, F., Brettel, M., \& Hungeling, S. 2010. Configurations of Resources and Capabilities and their Performance Implications: An Exploratory Study on Technology Ventures. Strategic Management Journal, 31(12): 1337-1356.

Guadalupe, M., Li, H., \& Wulf, J. 2014. Who Lives in the C-suite? Organizational Structure and the Division of Labor in Top Management. Management Science, 60(4): 824-844.

Haffke, I., Kalgovas, B., \& Benlian, A. 2016. The Role of the CIO and the CDO in an Organization's Digital Transformation. Proceedings of the 37th International Conference on Information Systems (ICIS), Dublin, December 11-14.

Hambrick, D. C. 2007. Upper Echelons Theory: An Update. Academy of Management Review, 32(2): 334-343.

Hambrick, D. C., \& Cannella, A. A. 2004. CEOs Who Have COOs: Contingency Analysis of an Unexplored Structural Form. Strategic Management Journal, 25(10): 959-979.

Hambrick, D. C., Finkelstein, S., \& Mooney, A. C. 2005a. Executive Job Demands: New Insights for Explaining Strategic Decisions and Leader Behaviors. Academy of Management Review, 30(3): 472-491.

Hambrick, D. C., Finkelstein, S., \& Mooney, A. C. 2005b. Executives Sometimes Lose It, Just Like the Rest of Us. Academy of Management Review, 30(3): 503-508.

Hambrick, D. C., \& Mason, P. A. 1984. Upper Echelons: The Organization as a Reflection of its Top Managers. Academy of Management Review, 9(2): 193-206.

Hansen, M. T., \& Birkinshaw, J. 2007. The Innovation Value Chain. Harvard Business Review, 85(6): 121-130.

Hart, S. L., \& Quinn, R. E. 1993. Roles Executives Play: CEOs, Behavioral Complexity, and Firm Performance. Human Relations, 46(5): 543-574 
Hastie, T. Tibshirani, R., \& Friedman, J. 2009. The Elements of Statistical Learning. New York: Springer.

Hegarty, W. H., \& Hoffman, R. C. 1990. Product/Market Innovations: A Study of Top Management Involvement among Four Cultures. Journal of Product Innovation Management, 7(3): 186-199.

Hoffman, R. C., \& Hegarty, W. H. 1993. Top Management Influence on Innovations: Effects of Executive Characteristics and Social Culture. Journal of Management, 19(3): 549-574.

Hofstee, W. K., De Raad, B., \& Goldberg, L. R. 1992. Integration of the Big Five and Circumplex Approaches to Trait Structure. Journal of Personality and Social Psychology, 63(1): 146-163.

Homburg, C., Jensen, O., \& Krohmer, H. 2008. Configurations of Marketing and Sales: A Taxonomy. Journal of Marketing, 72(3): 133-154.

Howell, J. M., \& Higgins, C. A. 1990. Champions of Technological Innovation. Administrative Science Quarterly, 35(2): 317-341.

Hunter, S. T., \& Cushenbery, L. 2011. Leading for Innovation: Direct and Indirect Influences. Advances in Developing Human Resources, 13(3): 248-265.

Islam, E., \& Zein, J. 2019. Inventor CEOs. Journal of Financial Economics. Forthcoming.

Judge, T. A., \& Bono, J. E. 2000. Five-factor Model of Personality and Transformational Leadership. Journal of Applied Psychology, 85(5), 751-765.

Judge, T. A., Bono, J. E., Ilies, R., \& Gerhardt, M. W. 2002. Personality and Leadership: A Qualitative and Quantitative Review. Journal of Applied Psychology, 87(4): 765-780.

Jung, D. D., Wu, A., \& Chow, C. W. 2008. Towards Understanding the Direct and Indirect Effects of CEOs' Transformational Leadership on Firm Innovation. The Leadership Quarterly, 19(5): 582-594.

Kaplan, R. E. 1983. Creativity in the Everyday Business of Managing. Leadership in Action, 3(2): $1-6$.

Ketchen, D. J., \& Shook, C. L. 1996. The Application of Cluster Analysis in Strategic Management Research: An Analysis and Critique. Strategic Management Journal, 17(6): 441-458.

Khurana, R. 2002. The Curse of the Superstar CEO. Harvard Business Review, 80(9): 60-67.

Kleinschmidt, E. J., De Brentani, U., \& Salomo, S. 2007. Performance of Global New Product Development Programs: A Resource-based View. Journal of Product Innovation Management, 24(5): 419-441.

Lachenbruch, P. 1975. Discriminant Analysis. New York: Hafner Press.

Lafley, A. G., \& Charan, R. 2008. Game-changer: How Every Leader Can Drive Everyday Innovation. London: Profile Books.

Lakshman, C. 2005. Top Executive Knowledge Leadership: Managing Knowledge to Lead Change at General Electric. Journal of Change Management, 5(4): 429-446.

Li, M., \& Patel, P. C. 2019. Jack of All, Master of All? CEO Generalist Experience and Firm Performance. The Leadership Quarterly, 30(3): 320-334.

Li, Q., Maggitti, P. G., Smith, K. G., Tesluk, P. E., \& Katila, R. 2013. Top Management Attention to Innovation: The Role of Search Selection and Intensity in New Product Introductions. Academy of Management Journal, 56(3): 893-916. 
Li, Y., \& Tan, C. H. 2013. Matching Business Strategy and CIO Characteristics: The Impact on Organizational Performance. Journal of Business Research, 66(2): 248-259.

Ling, Y. A. N., Simsek, Z., Lubatkin, M. H., \& Veiga, J. F. 2008. Transformational Leadership's Role in Promoting Corporate Entrepreneurship: Examining the CEO-TMT Interface. Academy of Management Journal, 51(3): 557-576.

Lynn, G. S., \& Reilly, R. R. 2002. Blockbuster: Five Keys to Developing Great New Products. New York: Harper Business.

Maidique, M. A. 1980. Entrepreneurs, Champions, and Technological Innovation. MIT Sloan Management Review, 21(2): 59-76.

Makri, M., Lane, P. J., \& Gomez-Mejia, L. R. 2006. CEO Incentives, Innovation, and Performance in Technology-intensive Firms: A Reconciliation of Outcome and Behaviorbased Incentive Schemes. Strategic Management Journal, 27(11): 1057-1080.

Makri, M., \& Scandura, T. A. 2010. Exploring the Effects of Creative CEO Leadership on Innovation in High-Technology Firms. The Leadership Quarterly, 21(1): 75-88.

Marcati, A., Guido, G., \& Peluso, A. M. 2008. The Role of SME Entrepreneurs' Innovativeness and Personality in the Adoption of Innovations. Research Policy, 37(9): 1579-1590.

McCrae, R. R., \& Costa, P. T. 1992. Discriminant Validity of NEO-PIR Facet Scales. Educational and Psychological Measurement, 52(1): 229-237.

Mclntyre, R. M., \& Blashfield, R. K. 1980. A Nearest-centroid Technique for Evaluating the Minimum-Variance Clustering Procedure. Multivariate Behavioral Research, 15(2): 225238.

Mendoca, L., \& Sneader, K. 2007. Coaching Innovation: An Interview with Intuit's Bill Campbell. McKinsey Quarterly, 1: 66-75.

Menz, M. 2012. Functional Top Management Team Members: A Review, Synthesis, and Research Agenda. Journal of Management, 38(1), 45-80.

Meyer, A. D., Tsui, A. S., \& Hinings, C. R. 1993. Configurational Approaches to Organizational Analysis. Academy of Management Journal, 36(6): 1175-1195.

Meyer, R. D., Dalal, R. S., \& Hermida, R. 2010. A Review and Synthesis of Situational Strength in the Organizational Sciences. Journal of Management, 36(1): 121-140.

Miceli, M. P., \& Near, J. P. 1984. The Relationships among Beliefs, Organizational Position, and Whistle-blowing Status: A Discriminant Analysis. Academy of Management Journal, 27(4): 687-705.

Miller, D. \& Friesen, P. H. 1984. Organizations: A Quantum View. Englewood Cliffs: Prentice-Hall.

Milligan, G. W., \& Hirtle, S. C. 2003. Clustering and Classification Methods, in: Schinka, J. A., Velicer, W. F., \& Weiner, I. B. (eds.). Handbook of Psychology: Research Methods in Psychology. New York: John Wiley: 165-186.

Milovich, M. 2015. Moving Technology Leaders up the Influence Curve. MIS Quarterly Executive, 14(1): 39-49.

Mintzberg, H. 1971. Managerial Work: Analysis from Observation. Management Science, 18(2): 97-110.

Mintzberg, H. 2009. Managing. San Francisco: Berrett-Koehler.

Mumford, M. D., \& Licuanan, B. 2004. Leading for Innovation: Conclusions, Issues, and Directions. The Leadership Quarterly, 15(1): 163-171. 
Mumford, M. D., Scott, G. M., Gaddis, B., \& Strange, J. M. 2002. Leading Creative People: Orchestrating Expertise and Relationships. The Leadership Quarterly, 13(6): 705-750.

Ng, K. Y., Ang, S., \& Chan, K. Y. 2008. Personality and Leader Effectiveness: A Moderated Mediation Model of Leadership Self-efficacy, Job Demands, and Job Autonomy. Journal of Applied Psychology, 93(4), 733-743.

O'Reilly, C. A., Caldwell, D. F., Chatman, J. A., \& Doerr, B. 2014. The Promise and Problems of Organizational Culture: CEO Personality, Culture, and Firm Performance. Group \& Organization Management, 39(6), 595-625.

Ohly, S., \& Fritz, C. 2010. Work Characteristics, Challenge Appraisal, Creativity, and Proactive Behavior: A Multi-level Study. Journal of Organizational Behavior, 31(4): 543-565.

Papadakis, V., \& Bourantas, D. 1998. The Chief Executive Officer as Corporate Champion of Technological Innovation: An Empirical Investigation. Technology Analysis \& Strategic Management, 10(1): 89-110.

Paolillo, J. G. P. 1987. Role Profiles for Managers in Different Functional Areas. Group and Organization Studies, 12(1): 109-118.

Parker, S. K., \& Axtell, C. M. 2001. Seeing Another Viewpoint: Antecedents and Outcomes of Employee Perspective Taking. Academy of Management Journal, 44(6): 1085-1100.

Patterson, F. 2002. Great Minds Don't Think Alike? Person-level Predictors of Innovation at Work. International Review of Industrial and Organizational Psychology, 17(1): 115-144.

Peppard, J. 2010. Unlocking the Performance of the Chief Information Officer (CIO). California Management Review, 52(4): 73-99.

Peterson, R. S., Smith, D. B., Matorana, P. V., \& Owens, P. D. 2003. The Impact of Chief Executive Officer Personality on Top Management Team Dynamics: One Mechanism by Which Leadership Affects Performance. Journal of Applied Psychology, 88(5): 795-808.

Pisano, G.P. 2015. You Need an Innovation Strategy. Harvard Business Review, 93(6): 44-54. Podsakoff, P. M., MacKenzie, S. B., Lee, J.-Y., \& Podsakoff, N. P. 2003. Common Method Biases in Behavioral Research. Journal of Applied Psychology, 88(5): 879-903.

Priem, R. L., Li, S., \& Carr, J. C. 2012. Insights and New Directions from Demand-side Approaches to Technology Innovation, Entrepreneurship, and Strategic Management Research. Journal of Management, 38(1): 346-374.

Punj, G., \& Stewart, D. W. 1983. Cluster Analysis in Marketing Research: Review and Suggestions for Application. Journal of Marketing Research, 20(5): 134-148.

Ramanujam, V., Venkatraman, N., \& Camillus, J. C. 1986. Multi-objective Assessment of Effectiveness of Strategic Planning: A Discriminant Analysis Approach. Academy of $\boldsymbol{m}$ Management Journal, 29(2): 347-372.

Rand, W. M. 1971. Objective Criteria for the Evaluation of Clustering Methods. Journal of the American Statistical Association, 66(336): 846-850.

Reilly, R. R., Lynn, G. S., \& Aronson, Z. H. 2002. The Role of Personality in New Product Development Team Performance. Journal of Engineering and Technology Management, 19(1): 39-58.

Rickards, T., Smaje, K., \& Sohoni, V. 2015. 'Transformer in Chief': The New Chief Digital Officer. Retrieved from: https://www.mckinsey.com/business-functions/organization/ourinsights/transformer-in-chief-the-new-chief-digital-officer 
Rodríguez, N. G., Pérez, M. J. S., \& Gutiérrez, J. A. T. 2008. Can A Good Organizational Climate Compensate for A Lack of Top Management Commitment to New Product Development? Journal of Business Research, 61(2): 118-131.

Rost, K., Hölzle, K., \& Gemünden, H. G. 2007. Promotors or Champions? Pros and Cons of Role Specialisation. Schmalenbach Business Review, 59(4): 340-363.

Ruvio, A., Rosenblatt, Z., \& Hertz-Lazarowitz, R. 2010. Entrepreneurial Leadership Vision in Nonprofit vs. For-profit Organizations. The Leadership Quarterly, 21(1): 144-158.

Sarle, W. S. 1983. Cubic Clustering Criterion. Cary, NC: SAS Institute.

Schön, D. A. 1963. Champions for Radical New Invention. Harvard Business Review, 41(2), 77-86.

Schumpeter, J. A. 1934. The Theory of Economic Development. London: Transaction Publishers.

Scott, S. G., \& Bruce, R. A. 1994. Determinants of Innovative Behavior. Academy of Management Journal, 37(3): 580-607.

Slater, S. F., Mohr, J. J., \& Sengupta, S. 2014. Radical Product Innovation Capability: Literature Review, Synthesis, and Illustrative Research Propositions. Journal of Product Innovation Management, 31(3): 552-566.

Talke, K., Salomo, S., \& Kock, A. 2011. Top Management Team Diversity and Strategic Innovation Orientation: The Relationship and Consequences for Innovativeness and Performance. Journal of Product Innovation Management, 28(6): 819-832.

Teerlink, M., Sigmon, P. W., Gow, B., \& Banerjee, K. 2014. The New Hero of Big Data and Analytics. Somers, NY: IBM Corporation.

Tengblad, S. 2006. Is There a 'New Managerial Work'? A Comparison with Henry Mintzberg's Classic Study 30 Years Later. Journal of Management Studies, 43(7): 1437-1461.

Tripsas, M., \& Gavetti, G. 2000. Capabilities, Cognition, and Inertia: Evidence from Digital Imaging. Strategic Management Journal, 21(10-11): 1147-1161.

Tsui, A. S., Zhang, Z. X., Wang, H., Xin, K. R., \& Wu, J. B. 2006. Unpacking the Relationship Between CEO Leadership Behavior and Organizational Culture. The Leadership Quarterly, 17(2): 113-137.

Tukey, J. 1949. Comparing Individual Means in the Analysis of Variance. Biometrics, 5(2): 9114.

Tumbas, S., Berente, N., \& vom Brocke, J. 2017. Three Types of Chief Digital Officers and the Reasons Organizations Adopt the Role. MIS Quarterly Executive, 16(2): 121-134.

Tyler, B. B., \& Steensma, H. K. 1998. The Effects of Executives' Experiences and Perceptions on Their Assessment of Potential Technological Alliances. Strategic Management Journal, 19(10): 939-965.

Unger, B. N., Kock, A., Gemünden, H. G., \& Jonas, D. 2012. Enforcing Strategic Fit of Project Portfolios by Project Termination: An Empirical Study on Senior Management Involvement. International Journal of Project Management, 30(6): 675-685.

Unsworth, K. L., \& Parker, S. K. 2003. Proactivity and Innovation: Promoting a New Workforce for the New Workplace, in: Holman, D., Wall, T. D., Clegg, C. W., Sparrow, P., \& Howard, A. (eds.). The New Workplace: A Guide to the Human Impact of Modern Working Practices. Chichester, UK: Wiley: 175-196. 
Waller, R. A., \& Duncan, D. B. 1969. A Bayes Rule for the Symmetric Multiple Comparisons Problem. Journal of the American Statistical Association, 64(12): 1484-1503.

Wang, H., Begley, T., Hui, C., \& Lee, C. 2012. Are the Effects of Conscientiousness on Contextual and Innovative Performance Context Specific? Organizational Culture as a Moderator. International Journal of Human Resource Management, 23(1): 174-189.

Ward, J. H. 1963. Hierarchical Grouping to Optimize an Objective Function. Journal of the American Statistical Association, 58(301): 236-244.

Watts, S., \& Henderson, J. C. 2006. Innovative IT Climates: CIO Perspectives. Journal of Strategic Information Systems, 15(2): 125-151.

Wu, C. H., Parker, S. K., \& De Jong, J. P. 2014. Need for Cognition as an Antecedent of Individual Innovation Behavior. Journal of Management, 40(6): 1511-1534.

Yadav, M. S., Prabhu, J. C., \& Chandy, R. K. 2007. Managing the Future: CEO Attention and Innovation Outcomes. Journal of Marketing, 71(4): 84-101.

Zhao, H., \& Seibert, S. E. 2006. The Big Five Personality Dimensions and Entrepreneurial Status: A Meta-analytical Review. Journal of Applied Psychology, 91(2): 259-271. 
III. Publications in Focus Area II: Networks and External Partners

\section{Publications in Focus Area II: Networks and External Partners}




\section{Publication 3: Innovation Networks in the German Energy Industry - An Empirical} Analysis of Inter-organizational Knowledge Transfer

\subsection{Note on Submitted Paper}

The following paper on "Innovation Networks in the German Energy Industry - An Empirical Analysis of Inter-organizational Knowledge Transfer" was co-authored by my colleague Dr. Michael Kolloch and myself. The paper was submitted to the international academic journal International Journal of Energy Sector Management (VHB: B) and was accepted for publication after a double-blind peer-review process. It was also part of the doctoral dissertation of Dr. Kolloch.

Publication details:

Kolloch, M., \& Reck, F. (2017). Innovation networks in the German energy industry - An empirical analysis of interorganizational knowledge transfer. International Journal of Energy Sector Management, 11(2), 268-294. https://doi.org/10.1108/IJESM-02-2016-0003 


\title{
1.2. Academic Paper
}

\begin{abstract}
Purpose - This paper aims to focus on how different types of knowledge are exchanged within innovation networks in the German energy industry. External factors such as market pressure through liberalization, de-carbonization and decentralization challenge established actors in the industry. Answers to these challenges cannot be found by single actors but require networks to gather and concentrate innovation activities. This implies a need for knowledge transfer among energy providers. The authors aim at exploring knowledge exchange relations in-depth by treating them as multidimensional flows which can comprise technological, market, managerial or regulatory knowledge. In detail, the authors examine patterns of knowledge exchange on network-, dyad- and firm-level. Furthermore, first empiric results are provided on how two of these patterns, namely, a firm's propensity to form multiplex instead of uniplex ties as well as the composition of externally acquired knowledge concerning the four types, influence organizational innovativeness.
\end{abstract}

Design/methodology/approach - The authors address their research questions by conducting an in-depth investigation of the largest network of municipal utilities in Germany. The analysis is based on quantitative data collected via standardized online questionnaires drawing on sociometric methods to reconstruct knowledge exchange networks as well as traditional approaches from socio-empiric research to evaluate firm innovativeness.

Findings - The findings indicate that while technological, market, managerial and regulatory knowledge represent different types of knowledge with different exchange patterns, these transfers are interdependent. In particular, the analysis reveals non-hierarchical relations of complementarity. The authors furthermore provide evidence for the existence of ideal profiles for attaining different types of innovation. One central tendency across all of these profiles is that outperformers acquire regulatory knowledge to a significantly lesser degree than other firms and focus more on the other types instead.

Research limitations/implications - This paper solely focusses on the largest network of municipal utilities whereby it is questionable how representative it is for the whole industry. Additionally, due to the cross-sectional design, the paper cannot fully rule out issues of endogeneity in the quantitative analysis.

Practical implications - This paper delivers valuable insights for managers in the energy sector who seek to either enter and manage inter-organizational networks or apply external knowledge to foster innovation. In particular, the authors reveal benchmark profiles for external knowledge acquisition which may serve as templates for strategic collaboration and innovation management.

Originality/value - To the authors' knowledge, this paper presents the first innovation-related network analysis in the energy industry. Rather than operationalizing knowledge transfer as a simplex flow relation, the authors examine different types of knowledge, their patterns of exchange and their distinct effects on process, product and administrative innovations. 
III. Publications in Focus Area II: Networks and External Partners

Keywords Knowledge transfer, Innovation, Knowledge management, Online surveys, Network analysis, Innovation networks, German energy industry, Municipal utilities 


\section{Introduction}

Presently, probably no other industry faces such severe changes and upheavals as the energy industry (Bhattacharyya, 2007). Especially in Germany, a pioneering country concerning renewable energy (RE) strategies and implementation (Dusonchet and Telaretti, 2010), energy companies struggle to find adequate ways of dealing with issues of disruptive change. These challenges exacerbate the need for innovation and organizational renewal to remain or become competitive. A growing body of research has therefore begun to investigate how firms in the energy sector might navigate the waters of such disruptive change. Thus far, this research has concentrated on revealing success factors for handling changes in the resource base (Pätäri, 2010), delineating business models for REs (Richter, 2012) or examining companies' forecasting capabilities in relation to economic change and the progress of RE technologies (Kehrel and Sick, 2014). Against this background, organizational innovativeness which is defined as the propensity of a firm to innovate or develop new products, production processes or forms of organization (Ettlie et al., 1984) represents an essential capability in energy industry presently.

In particular, inter-organizational networks as a means to grant access to knowledge may represent a key foundation of such innovative performance. Thus far, a broad body of literature has dealt with knowledge management in different fields of practice such as power generation (Carroll et al., 2002) and power transmission (Klashner and Sabet, 2007). According to this stream of research, innovative firms are likely to be those which are more proficient in effectively coordinating knowledge development and application (Grant,1996). This notion explicitly includes access to external knowledge as a way to foster innovativeness (Chesbrough, 2006). Firms acquire knowledge from other organizations, and thus, knowledge exchange via inter-organizational networks may serve as a key antecedent of organizational innovation output (Easterby-Smith et al., 2008). In the context of utilities in Germany, which form an industry structure comprising more than 1,000 distinctly heterogeneous energy providers (Nikogosian and Veith, 2012; Müller et al., 2008), it might be particularly important for small and medium utilities to open up their innovative activity and draw on networks of collaboration (Lee et al., 2010). In recent years, several such networks like THÜGA, Trianel and STEAG have emerged which serve as hybrid forms of organization that facilitate knowledge exchange between network members and help affiliated organizations to respond to emerging trends in the energy market.

Despite the apparently growing relevance of such inter-organizational networks in the energy sector, research largely neglected this topic (notwithstanding some honorable exceptions such as Jacobsson and Bergek, 2004). Accordingly, academic investigations largely fail to provide substantiated findings which allow managers and policy makers to design networks or capture value from them. As channeling knowledge flows between member organizations represents a cornerstone of value creation, examining the actual knowledge flows in such networks is a potentially gainful starting point for research. Hence, this study investigates how and to what extent knowledge is exchanged in the largest network of German utilities. Our conceptualization of knowledge thereby follows pioneering studies which use knowledge as a multidimensional construct and distinguish between different types of knowledge flows such 
as technological, market or managerial knowledge (Alberti and Pizzurno, 2015; Moos et al., 2015; Sammarra and Biggiero, 2008). Drawing on network analytic methods, we aim to explore patterns of knowledge exchange and unveil initial insight in how such patterns may influence the innovativeness of network members. In combining a multidimensional operationalization of knowledge and a network analytic approach, this work thereby departs from traditional network studies which treat knowledge exchange as simplex flow relations displayed through licensing or employee mobility (Cassiman and Veugelers, 2006) and thus capture the complexity of the phenomenon only to a limited extent (Simpson, 2015).

The following paragraphs intend to build on research on multidimensional knowledge flows and advance it in several ways. First and foremost, this paper seeks to provide a more finelygrained examination of the multidimensional nature of knowledge exchange by refusing to restrict its analysis to the network level (e.g. Sammarra and Biggiero, 2008), instead choosing to include the dyad and firm levels in its investigations. We thereby explore further issues of knowledge transfer and provide initial answers for both theory and practice. At the dyad level, the following text aims to explore the nature of knowledge exchange relations and thus determine the specific characteristics of knowledge flows in inter-organizational networks. In particular, the questions of which types of knowledge are more likely to be exchanged in conjunction with each other and to what extent combinations of more than one type of knowledge are present within single exchange relations are addressed in this work. At the firm level, different companies will have different knowledge requirements and capacities. As such, they may acquire different knowledge types to varying extents, and it is therefore likely that distinct profiles will be observable. We attempt to provide initial indications regarding how different knowledge profiles and firms' propensity to acquire knowledge via multiplex vs. uniplex ties impact organizational innovativeness. In doing so, this study takes a first step in explaining how firms can profit from considering knowledge exchange as a multidimensional construct and how they can develop strategies to address this issue.

In order to tackle these research goals, we conducted a survey within the context of a corporate network in the energy industry comprising 92 members. This article thereby aims to answer the following research questions:

RQ1: In which patterns at the network and dyad level are different types of knowledge exchanged and how do these patterns differ or interrelate across knowledge types?

$R Q 2$ : Which effects do different knowledge exchange profiles and firms' propensity to acquire knowledge via multiplex vs. uniplex ties have on organizational innovativeness?

\section{Inter-organizational networks among municipal utilities}

In Germany, probably no other industry has undergone such severe changes as the energy sector. In recent years, this sector has been faced with manifold external challenges. These have included the planned closure of Germany's nuclear power plants, the transition in energy production which that entails, the liberalization of the power supply market and the decentralization of power generation (e.g. Federal Ministry of Economics and Technology, 2010). Since most of the challenges mentioned above are not compatible with the traditional 
way of doing business, a need for innovation has arisen. The generation as well as the distribution of electricity has become more and more decentralized. This development has been fostered by the liberalization of the Energy Industry Act, which occurred in two steps in 1998 and 2005 , as well as by growing de-carbonization and the individualized generation of RE. Therefore, customers increasingly shift back to municipal utilities because of the locallyproduced electricity.

In general, besides new market entries that provide green energy, municipal utilities can be regarded as the winners in the German energy transition in terms of market shares and sales. Nonetheless, small and local utilities often suffer from an essential mismatch in contrast to big players: economies of scale. In order to counteract these circumstances, the majority of municipal utilities have entered into particular types of alliances and collaborative networks to bundle their purchasing or research activities. As a consequence, the market structure of the (German) energy market is considerably influenced by many of these networks, which gain the market losses of the former Big Four (E.ON, RWE, Vattenfall and EnBW). The most popular ones are THÜGA, Trianel and STEAG.

This work draws on Provan et al. (2007, p. 482) who define inter-organizational networks as

[...] a group of three or more organizations connected in ways that facilitate achievement of a common goal. That is, the networks we discuss are often formally established and governed and goal directed rather than occurring serendipitously.

These have two basic functions: the establishment of resource flows (the pipe function) as well as the alignment and coordination of actions (the bond function) (Borgatti and Halgin, 2011). As these functions allow for different benefits, firms deliberately participate in clusters, form associations or engage in other network-like forms of organization (e.g. Ozer and Zhang, 2015). One key purpose of such network organizations is to mobilize and distribute knowledge among partners (Dhanaraj and Parkhe, 2006). As knowledge exchange is always a social process (Brown and Duguid, 2001), networks of inter-organizational relations have to fulfill the aforementioned bond and pipe functions in order to provide a structural, relational and cognitive infrastructure (Inkpen and Tsang, 2005; van Wijk et al., 2008), which is to secure the benefits and reduce the costs of inter-organizational knowledge transfer.

\section{Knowledge exchange in networks, knowledge types and innovation}

Single elements of knowledge contain tentative conclusions based on facts, theories or methods and eventually represent the building blocks of innovations (Fleming and Sorenson, 2004). These elements are not isolated, but connected to other pieces of knowledge (Yayavaram and Ahuja, 2008). Innovation stems from operations founded on these knowledge structures, which are subsumed under the term "recombination" (Schumpeter, 1983). These recombinations allow firms to explore possible configurations of knowledge elements with the goal of identifying superior solutions to existing problems (Fleming and Sorenson, 2004). According to the knowledge-based view of the firm (Grant, 1996), the availability of knowledge elements as key assets in the innovation process thus strongly determines a firm's innovative output (von Krogh et al., 2012; Nonaka, 1994). 
There is no doubt that knowledge is a key concept central to strategy and to fostering innovation in the energy industry (Edwards, 2008). As far as knowledge and innovations are concerned, the energy industry is mainly characterized by a broad technological knowledge base. Hence, the energy industry heavily depends on capabilities which reside in the generation and distribution of electric power, in addition to research in that field. While former innovations were mainly driven by technology, recent and future innovations are primarily market (customer-oriented) driven. In addition, increasing European competition plus higher transmission and regulatory costs are exacerbating firms' needs to foster managerial and business model innovations in order to improve their performance and/or organizational efficiency. When faced with these opportunities and challenges, it is reasonable to assume that multi-content knowledge transfer for innovative as well as organizational performance is of the utmost importance.

Three distinctive knowledge types in the form of technological, market and managerial knowledge have been outlined in the relevant literature (Sammarra and Biggiero, 2008). Technological knowledge mainly refers to organizations' know-how and their concomitant ability to respond to technological changes (across the whole value-chain, encompassing generation facilities, transmission infrastructure and even the development of end-user products). Secondly, market knowledge equates to an organization's capability to organize and structure the market for the purpose of gaining relevant information (Li and Calantone, 1998). Relevant information includes, for example, know-how and insights into customer needs, customers' respective willingness to pay as well as competitive knowledge. Thirdly, managerial knowledge is defined as know-how and competencies related to the optimization of organizational structures and orientation. Thus, process efficiencies, resource management and organizational structuring can be subsumed under this heading (e.g. Hult et al., 2007).

Additionally, due to the considerable importance of politics, regulation and legislation, regulatory knowledge constitutes another relevant type of knowledge, especially in the case of the energy industry (Kolloch and Golker, 2016). Regulation itself not only carries risks or hurdles for firms operating within the energy industry, but also offers chances. The role of governmental intervention as the starting point of whole cycles of innovation has frequently been discussed in the literature (Ashford et al., 1985). Regulatory knowledge refers to information on how regulations and directives externally induce, foster or hinder innovation. Due to its importance, this has been added to the three types of knowledge outlined by Sammarra and Biggiero (2008) in the further course of the analysis that follows.

\section{Multidimensionality of knowledge exchange on the network level}

Based on the assumption that business tasks are complex and require different types of knowledge, Alberti and Pizzurno (2015) argue against the predominant focus on technological knowledge exchange in inter-firm networks. The contacts achieved via networks would thus serve the exchange of other types of knowledge, too. Based on a quantitative case study, Sammarra and Biggiero (2008) made some initiatory propositions concerning the multidimensional nature of knowledge exchange at the network level. Firstly, while knowledge exchange is multidimensional, technological knowledge focusing on product or process 
improvements seems to represent the prime interest of firms. The need to integrate these technologies into complex business systems will then induce the further exchange of other dimensions of knowledge, such as market or managerial knowledge. Secondly, the predominance of different types of knowledge and their overall distribution will depend on characteristics specific to the industrial context and the member firms of the network. This raises the question of the intensity with which the four identified types of knowledge are exchanged in the energy industry and if the assumption of technological knowledge as an inductor also holds true in this context.

\section{Multidimensionality of knowledge exchange on the relation level}

Breaking down network-wide knowledge exchange into single events of transfer, these incidents happen in dyadic relationships between two firms (Easterby-Smith et al., 2008). These companies form a distinct transfer relation defined by the knowledge flows in each of the four dimensions (van Wijk et al., 2008). Therefore, while the network-level perspective yields an insight into the complexity of the macro-structures of knowledge exchange, only an analysis on the dyad level can capture the complexity of actual exchange processes (Burt and Schott, 1985). Assuming the existence of patterns of interdependency and complementarity between different types of knowledge (Sammara and Biggiero, 2008), there should be a non-random propensity of types of knowledge to be transferred in conjunction with each other, so that the likelihood of certain combinations of two or three types of knowledge being transferred together may differ (Simpson, 2015). These differences will provide hints regarding the interdependence of different knowledge types in the energy industry and thus be of interest to academics and practitioners in that sector.

From another perspective, the general likelihood of ties involving the exchange of more than one type of knowledge is linked to the concept of multiplexity in network theory (Rank et al., 2010). A relation is referred to as multiplex if a pair of actors is linked by more than one relationship. On the opposite side, ties involving only one type of knowledge tend to be specific or simply called uniplex (Simpson, 2015). The uniplex vs. multiplex question is highly important in further understanding and developing theories on knowledge exchange. It is particularly important to know which of the two general types of ties is more beneficial for companies engaged in inter-organizational networks. On the one hand, multiplex ties may provide a rich relational infrastructure based on mutual understanding and trust, thereby allowing for a more effective exchange (Ibarra, 1992) while keeping transaction costs low (Fliaster and Spiess, 2008). On the other hand, analogous to single vs. multiple sourcing issues (Burke et al., 2007), uniplex ties may help to explore specialization benefits based on partners' unique knowledge bases as well as overcome the capacity constraints of single relationships transferring multiple types of knowledge. This important issue will be explored in the analysis of the relational level presented below.

\section{Multidimensionality of knowledge exchange on the firm level}

Inter-organizational networks represent an important antecedent for innovation as a knowledgebased outcome, because the scope of knowledge that single firms can create, process and use is limited, and useful knowledge is imperfectly dispersed among organizations (Kogut, 2000). 
Firms' application of external knowledge to learning and innovation (Laursen and Salter, 2006) thus possesses the potential for benefits of discovery, fostering the value of their own products, services, processes or business models. This phenomenon, named "Open Innovation" by Henry Chesbrough (2006), highlights inter-organizational knowledge transfer as a key mechanism in achieving innovative performance (Dahlander \& Gann, 2010). According to this theory, innovative firms should be more capable to access to external knowledge via their respective network (e.g. Leiponen and Helfat, 2010).

While previous works highlighted the breadth and depth of accessible knowledge (Laursen and Salter, 2006), its diversity (Dell'Era and Verganti, 2010), or the sources of knowledge (Fabrizio, 2009) as determinants of a focal firm's capacity for innovation, the actual content of the incoming knowledge may likewise play an essential role. It is likely that firms will differ in the extent to which they acquire technological, market, managerial and regulatory knowledge (Sammarra and Biggiero, 2008). For instance, if a firm's knowledge inflow in the technological dimension is higher than in the other three dimensions, the firm will place a greater emphasis on this particular type of knowledge and will deploy more of its capacities for knowledge acquisition in this area. In doing so, the company determines the configuration of knowledge inputs in the context of its innovative activities (Moos et al., 2015). Depending on the specifics of an industry's technological, competitive, customer and market structure, a configurational congruence (Meyer et al., 1993) may occur between certain knowledge input profiles and the different innovative tasks at hand. This article thus aims to explore which different profiles of external knowledge acquisition are prevalent in the energy industry and which profiles are superior concerning firm innovativeness.

\section{Research design}

The present paper is based on data collected from the biggest and most economically successful network of municipal utilities within the German energy industry. Its respective members are local players that operate all over the country. According to official statistics (annual closure of the network holding), the network consists of 92 members with approximately $€ 22$ billion of accumulated revenues and accounting for more than 18,000 employees. The 92 member firms are comprised as follows: 11 large utilities ( $>500$ employees), 38 medium-sized utilities (between 500 and 80 employees), 35 small utilities ( $<80$ employees) and 8 organizations established by a central network coordination unit which provide services and advice concerning specific topics (e.g. assurance, metering and renewables).

Social network analysis (SNA) was chosen as an appropriate tool to address the research questions raised. The quantitative SNA provides an overall picture of the whole network's multiple content knowledge flows and allows for the calculation of indices at firm, dyad and network levels (Sammarra and Biggiero, 2008). In doing so, it becomes possible to measure inter-organizational knowledge transfer with regard to the respective type of knowledge which is exchanged through collaborative relations. We sent a questionnaire to individuals in all member organizations within the network. The underlying sampling strategy was aimed at contacting managers who are responsible for innovation management within their respective firms. In total, 247 potential sources within all 92 member organizations were contacted via e- 
mail and telephone calls. 102 of these contacts responded, representing 61 companies. Of these, 6 responses had to be excluded due to missing data or unidentifiable respondent affiliation. This resulted in a sum total of 96 usable questionnaires. For most firms represented in the sample (35), one key individual responded, while in 26 cases between two and seven sources participated. In cases involving more than one respondent, we took the average of their ratings as a measurement value for the respective firm ${ }^{1}$. Having obtained data for 61 firms out of 92 , the study has a response rate of $66.3 \%$ on an organizational and $38.9 \%(96 / 247)$ on a personal level. Non-respondent bias was accounted for by comparing the size and geographic location of respondents and non-respondents. There were no significant differences in both dimensions (size: $t=1.49, p>.14$; geographic location: $t=1.34, p>.18$ ).

We administered the data collection via an online questionnaire using the survey tool $O N A$ Surveys. The applied quantitative questionnaire contains two main elements. The first one elicits ties between organizations by asking respondents to indicate from which of the other network members they have received innovation-related knowledge. Following this, respondents rated organizational innovation on a Likert-scale.

\section{Reconstruction of knowledge transfer networks}

Our research questions are directed towards revealing innovation-related knowledge transfer. With this in mind, respondents were asked to indicate exchange(s) of this sort in the following way:

From the list below, please select the firms from which your company received information relevant for innovation activity within the last three years. The receipt of this knowledge may stem from formal exchange(s) during joint $R \& D$ projects, discussions in innovation circles, or informal exchange(s) on the personal level, amongst others. Feel free to include as many firms as you consider to be relevant sources of knowledge.

In addition, it was assumed that the transfer in one or both directions is not a dichotomous variable but rather has different intensities. Therefore, we obtain data on the intensity flows of technological, regulatory, managerial and market knowledge between each pair of participants (see Table 1 for the items).

\footnotetext{
${ }^{1}$ We are aware that an approach utilizing multiple key informants also entails some issues. Firstly, different functional backgrounds may yield different perspectives which could result in systematic bias. Therefore, a oneway variance analysis was conducted among three groups of respondents: c-level management (42 respondents), specialized innovation managers (18), functional senior managers responsible for innovation (36). The study variables did not differ significantly among all three groups $(p>.20)$. Secondly, there is a potential issue regarding agreement among informants. We followed the approach taken by Schilke and Goerzen (2010) to assess inter-rater reliability by calculating the percentage of item ratings in which a pair of respondents differs by one point or less on the 7-point Likert-scale (76.0 percent of ratings). The results indicate sufficient levels of agreement among sources.
} 
Table III-1-1. Questionnaire items for knowledge exchange dimensions

\begin{tabular}{|c|c|c|c|c|}
\hline & Technological knowledge & Market knowledge & Managerial knowledge & Regulatory knowledge \\
\hline Item & $\begin{array}{l}\text { Please indicate to which } \\
\text { extent you receive } \\
\text { information and knowledge } \\
\text { for the development of } \\
\text { technologies, products and } \\
\text { processes from this firm. } \\
\text { This includes purely } \\
\text { scientific findings as well as } \\
\text { prototypes and solutions } \\
\text { ready for application. }\end{array}$ & $\begin{array}{l}\text { Please indicate to which } \\
\text { extent you receive } \\
\text { information and knowledge } \\
\text { about customers, their } \\
\text { characteristics and } \\
\text { preferences as well as your } \\
\text { market environment from } \\
\text { this firm. }\end{array}$ & $\begin{array}{l}\text { Please indicate to which } \\
\text { extent you receive } \\
\text { information and knowledge } \\
\text { for the efficient and effective } \\
\text { coordination of your } \\
\text { companies resources and } \\
\text { processes from this firm. } \\
\text { This includes both methods } \\
\text { of operational management } \\
\text { (e.g. quality management) } \\
\text { and more abstract procedures } \\
\text { (e.g. decision making, } \\
\text { strategy formulation). }\end{array}$ & $\begin{array}{l}\text { Please indicate to which } \\
\text { extent you receive } \\
\text { information and knowledge } \\
\text { about political developments, } \\
\text { legal issues, jursidiction, } \\
\text { legislation and industrial } \\
\text { standards from this firm. }\end{array}$ \\
\hline
\end{tabular}

Notes: all four items were rated on a 7-point Likert-Scale ( $1=$ "no exchange", $7=$ "very intensive exchange")

Based on the collected data, we constructed four network matrices, one for each type of knowledge transferred (see Figures A1-A4). The networks constructed are weighted. This makes sense when one considers that there are highly intensive relations as well as those lacking in intensity. Furthermore, there exist relationships which are asymmetrical in nature, as knowledge transfer in one direction does not necessarily presuppose the same transfer in the other direction ${ }^{2}$.

\section{Multiplexity}

In common with previous works, we measured the degree of a tie's multiplexity according to how many different types of relations exist between a pair of actors. This approach thereby follows that of previous works in evaluating multiplex relations (e.g. Ibarra, 1992).

\footnotetext{
${ }^{2}$ Before treating the dimensions of knowledge exchange as distinct variables in the course of analysis, some issues of measurement must be acknowledged. The instance that respondents rate knowledge transfer in each of the four dimensions simultaneously for each observed tie, the choice to assign low amounts of knowledge exchange to a particular type instead of no exchange may be an inevitable side effect of the network-analytic methodology. Therefore, using the original values as a basis carries the risk of overestimating the multiplexity of ties and the density of the individual networks as well as the possibility of distorting the observed distribution of knowledge flows. One way to circumvent this issue is to adjust the data by eliminating low intensity values (Borgatti et al., 2013). Assuming that a relatively high exchange intensity with a certain partner will be salient to the respondent (and thus presumably valid), while low levels for one or more types of knowledge in comparison to the highest value for the tie may be a byproduct due to the measurement method, new matrices for each knowledge type were constructed by eliminating values which were more than 1 Likert-point lower than the maximum value for exchange intensity in the tie. This rather restrictive operationalization thus potentially underestimates the multiplexity of knowledge exchanges and the density of the networks for all four types. In order to ensure the validity of the results presented here, a triangulation of measures was conducted by running each analysis with both network data sets; the original one which may tend to overestimate the presence of ties, as well as the modified one which leans toward underestimation (Borgatti et al., 2013). All results reported in this paper draw on the original data. The analyses, including the modified tie operationalization, display similar results. These may be obtained upon request from the authors.
} 


\section{Knowledge exchange volume}

The volume of exchanged knowledge is determined by two factors: the number of ties concerning the particular knowledge type and the intensity of those ties. In order to derive a single index for further analysis, we first standardized both scales by $z$-transformation to ensure comparability. Second, we averaged both scores in order to derive the volume of acquired knowledge for each firm in the network. As such, we use a formative principal component approach to derive an index comprising both elements (Diamantopoulos and Winkelhofer, 2001).

\section{Knowledge transfer profiles}

For each firm, we derived a knowledge transfer profile which provides an overview of which types of knowledge are comparably more and which are comparably less acquired by a focal firm. In doing so, we modified Gilsing et al.'s (2008) approach to calculate revealed technological advantages (RTA) which display the distribution of a firm's patents across a range of patent classes. Instead of patent classes, we had different volumes of knowledge exchanged distributed across four knowledge types which we compared by subtracting the mean of all four volumes from the value of the particular knowledge type's exchange volume. Using this approach, we derived profiles which indicate the relative focus a firm puts on technological, market, managerial or regulatory knowledge.

\section{Organizational innovativeness}

As our research goal demands an analysis of organizational innovativeness within the given network, the second part of the questionnaire consists of questions about the respondent firms' innovativeness. The latent constructs utilized are based on earlier studies yielding high reliability and construct validity scores: three items for product/service innovation (Yli-Renko et al., 2001), three items for process innovation (Frishammar et al., 2012), three items for administrative innovation (Whittington et al., 1999). These constructs were measured on a $7-$ point Likert scale and respondents were explicitly asked to rate own innovation outcomes compared to competitors in the energy industry.

\section{Results}

\section{Description of multidimensional knowledge transfer}

In order to address the first research question, it is necessary to begin by providing a descriptive overview of different dimensions of knowledge transfer within the network. To evaluate the extent of knowledge transfer within the network, we utilized density as an indicator wellestablished in previous research (e.g. Rank et al., 2005). Network density is calculated as follows:

$$
D=\frac{\sum \sum x_{i j}}{n *(n-1)-M V}
$$


Within this formula, $x_{i j}$ displays the presence or absence of an exchange relation between firms $i$ and $j$, attaining values of 1 or 0 . Further, $\mathrm{n}$ represents the number of firms within the network (92), and $M V$ the number of missing values (because of non-response). In comparison to other (similar) studies as Rank et al. (2005) (bio-technology) or Sammarra and Biggiero (2008) (aerospace), a relatively high density of $10 \%$ with respect to under $5 \%$ in similar studies can be observed (see Table 2).

Table III-1-2. Descriptive data on networks

\begin{tabular}{llllll}
\hline & Overall & $\begin{array}{l}\text { Techn. } \\
\text { knowledge }\end{array}$ & $\begin{array}{l}\text { Market } \\
\text { knowledge }\end{array}$ & $\begin{array}{l}\text { Managerial } \\
\text { knowledge }\end{array}$ & $\begin{array}{l}\text { Regulatory } \\
\text { knowledge }\end{array}$ \\
\hline $\begin{array}{l}\text { No. of responding } \\
\text { firms }\end{array}$ & 61 & 61 & 61 & 61 & 61 \\
$\begin{array}{l}\text { No. of firms in the } \\
\text { network }\end{array}$ & 92 & 92 & 92 & 92 & 92 \\
$\begin{array}{l}\text { Observed ties } \\
\text { Density }\end{array}$ & 557 & 417 & 382 & 349 & 352 \\
& $10,0 \%$ & $7,5 \%$ & $6,9 \%$ & $6,3 \%$ & $6,3 \%$ \\
Symmetry & $22,1 \%$ & $20,5 \%$ & $18,9 \%$ & $18,6 \%$ & $19,3 \%$ \\
\hline
\end{tabular}

Among the four types of knowledge, technological knowledge is the predominant one exchanged in the network. One the one hand, density is highest in the network of technological knowledge exchange. This is followed by market knowledge and regulatory knowledge. As the traditional measure of density does only incorporate the number of ties and not their intensity, we additionally compared the average values for the indicator of knowledge volume presented in chapter 3. As Figure 1 outlines the volume of technological knowledge exchanged is highest, followed by regulatory knowledge which is ranked before market knowledge here because of a higher average intensity of exchange. We tested if these differences are statistically significant by conducting Snijders and Borgatti's (1999) bootstrap-paired sample t-test for network densities as well as a bootstrapped $t$-test on related samples for the knowledge volume indicator (see Table 3 for results). The overall results indicate that technological knowledge exchange is significantly higher than each other type. Additionally, the market knowledge network is denser than the managerial knowledge network and knowledge volume for market and regulatory knowledge is higher than for managerial knowledge. 
III. Publications in Focus Area II: Networks and External Partners

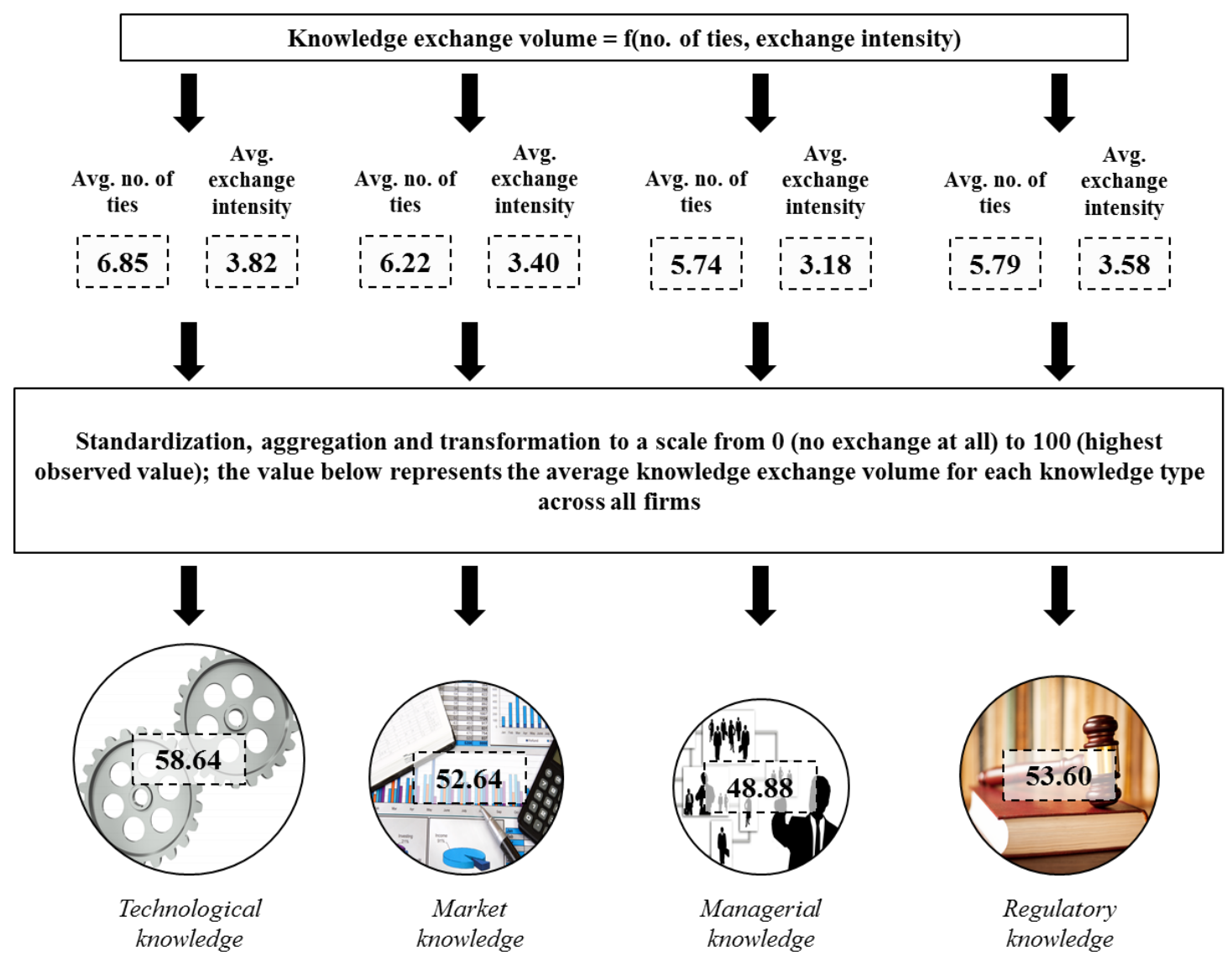

Figure III-1-1. Knowledge exchange volume in all four dimensions (own illustration)

Table III-1-3. Significance test for density and exchange volume differences

\begin{tabular}{lcccccc}
\hline & $\begin{array}{l}\text { Density } \\
\text { difference }\end{array}$ & $t$ & $p$ & $\begin{array}{l}\text { Volume } \\
\text { difference }\end{array}$ & \multicolumn{2}{l}{$p$} \\
\hline $\begin{array}{l}\text { Technological knowledge \& } \\
\text { market knowledge }\end{array}$ & $0.64 \%$ & $1.948^{+}$ & .055 & 6.00 & $3.857^{* * *}$ & .000 \\
$\begin{array}{l}\text { Technological knowledge \& } \\
\text { managerial knowledge }\end{array}$ & $1.24 \%$ & $2.979^{* *}$ & .004 & 9.76 & $5.417^{* * *}$ & .000 \\
$\begin{array}{l}\text { Technological knowledge \& } \\
\text { regulatory knowledge }\end{array}$ & $1.19 \%$ & $2.678^{* *}$ & .009 & 5.04 & $3.237^{* *}$ & .002 \\
$\begin{array}{l}\text { Market knowledge \& } \\
\text { managerial knowledge }\end{array}$ & $0.61 \%$ & $1.642^{+}$ & .098 & 3.75 & $1.867^{+}$ & .067 \\
$\begin{array}{l}\text { Market knowledge \& } \\
\text { regulatory knowledge }\end{array}$ & $0.55 \%$ & 1.536 & .125 & -0.96 & -0.478 & .635 \\
$\begin{array}{l}\text { Managerial knowledge \& } \\
\text { regulatory knowledge }\end{array}$ & $0.06 \%$ & 0.162 & .861 & -4.72 & $-2.484^{*}$ & .016 \\
\hline
\end{tabular}

Notes: ${ }^{+} \mathrm{p}<.10 * \mathrm{p}<.05 * * \mathrm{p}<.01 \quad * * * \mathrm{p}<.001$

Bootstrapping with 20,000 permutations 
Taken alone, the fact that technological knowledge is the most frequently shared form of knowledge among network partners does not, however, provide sufficient evidence to support Sammarra and Biggiero's (2008) line of reasoning. They postulate that collaboration to facilitate the transfer of technological knowledge is a starting point and an inductor of opportunities which provide for the exchange of the other knowledge types. If this statement were to hold true, there would be only very few cases in which market, managerial or regulatory knowledge would be exchanged in a tie devoid of an equal or higher extent of technological knowledge. To test for this, we follow Cross et al. (2001) who tested whether different types of advice offered between senior managers form a Guttman scale. On a Guttman scale, variables can be arranged in an order so that, if a variable is present, so too are the variables of lower rank (Guttman, 1944). If the exchanges of different types of knowledge were to form a Guttman scale, this would substantiate the indication that the exchange of more market, managerial and regulatory knowledge types is based on the single exchange of technological knowledge.

We proceeded as proposed by Guttman (1944). First, we created a matrix with 4 columns and 455 rows (each column contained the dichotomized values for the respective tie in the respective dimension). Within this, we arranged the columns according to the number of entries (that is to say, in the order: technological-market-regulatory-managerial knowledge) and inserted two column matrices for each pair of knowledge types. We then counted Guttman errors in the data (instances where a higher order condition is present but a lower order condition is absent $)^{3}$. Given the Guttman errors, it is possible to calculate the quality indicators coefficient of reproducibility $(=1-(E / X)$, where $E$ is the number of Guttman errors and $X$ the number of possible errors) and coefficient of scalability $(=1-(E / Y)$, where $Y$ is the number of errors expected by chance). This procedure of analysis itself is, however, only able to handle binary data. Consequently, if one wishes to include exchange intensity in the analysis, one must compare the coefficients across different levels of dichotomization (Cross et al., 2001). The results of this procedure are presented in Table 4.

\footnotetext{
${ }^{3} \mathrm{We}$ also tested all other possible permutations of the variables. All results were inferior to the ones presented above.
} 
Table III-1-4. Guttman scale analysis results

\begin{tabular}{|c|c|c|c|c|c|c|c|c|c|c|}
\hline & \multicolumn{2}{|c|}{ Baseline } & \multicolumn{2}{|c|}{$\begin{array}{l}\text { Dichotomization } \\
\geqq 3\end{array}$} & \multicolumn{2}{|c|}{$\begin{array}{l}\text { Dichotomization } \\
\geqq 4\end{array}$} & \multicolumn{2}{|c|}{$\begin{array}{l}\text { Dichotomization } \\
\geqq 5\end{array}$} & \multicolumn{2}{|c|}{$\begin{array}{l}\text { Dichotomization } \\
\geqq 6\end{array}$} \\
\hline & $C R$ & CS & $C R$ & CS & $C R$ & CS & $C R$ & $C S$ & $C R$ & $C S$ \\
\hline TK-MktK-RK-MgtK & .663 & .479 & .708 & .414 & .756 & .529 & .693 & .528 & .602 & .443 \\
\hline TK-MktK & .829 & .610 & .843 & .533 & .879 & .590 & .886 & .717 & .859 & .697 \\
\hline TK-MgtK & .826 & .587 & .884 & .637 & .922 & .754 & .886 & .718 & .833 & .641 \\
\hline TK-RK & .816 & .564 & .829 & .476 & .868 & .566 & .887 & .723 & .824 & .619 \\
\hline MktK-MgtK & .782 & .457 & .809 & .342 & .847 & .549 & .772 & .459 & .700 & .365 \\
\hline MktK-RK & .801 & .507 & .784 & .272 & .789 & .351 & .730 & .364 & .596 & .413 \\
\hline RK-MgtK & .770 & .404 & .824 & .375 & .861 & .598 & .746 & .402 & .759 & .488 \\
\hline
\end{tabular}

Notes: $\quad$ CR - coefficient of reproducibility; CS - coefficient of scalability; TK - technological knowledge;

MktK - market knowledge; MgtK - managerial knowledge; RK - regulatory knowledge

Bold numbers are above the thresholds of .90 for CR (Guttman, 1944) and .60 for CS (Menzel, 1953)

Based on the results of the Guttman scale analysis, no type of knowledge exchange may reasonably be considered as a lower order condition in relation to the other types of exchange. Though predominantly technological knowledge is exchanged, there are too many instances involving the transfer of market, managerial or regulatory knowledge without partners also communicating on technological issues. Based on the data, this leads to the conclusion that the variables do not form a Guttman Scale, as well as the rejection of the notion of a hierarchical ordering among different types of knowledge exchange relations. Thus, the findings do not provide evidence for Sammarra and Biggiero's (2008) propositions.

By taking a closer look on the level of individual exchange ties, it becomes clear that knowledge exchange between partners in the network represents a multidimensional construct. Hence, a large share of ties is multiplex (see Table 5). 93.0\% of knowledge transfer relations in the original respectively $83.7 \%$ in the adjusted data involve at least 2 types of knowledge, $80.4 \% / 58.7 \%$ of ties involve at least 3 types and $58.0 \% / 32.7 \%$ include each technological, market, managerial and regulatory knowledge. In order to further test the assumption that knowledge exchange is largely multiplex, we analyzed the correlations between the four knowledge exchange networks by applying the quadratic assignment procedure (QAP) in UCINET 6 as proposed by Borgatti et al. (2013). This technique correlates two network matrices by reshaping them into one-column vectors, calculating Pearson's $r$ and constructing a $p$-value based on a permutation test. Tables 6 and 7 show that the matrices are highly correlated and display similar correlations to those of studies which examine different types of knowledge flows on the individual level (Cross et al., 2001). This further strengthens the notion of a high likelihood of tie multiplexity, as ties of each kind are likely to emerge together rather than in a scattered fashion. Although there are ties which are specialized on the exchange of 
one type of knowledge, these rather represent special cases. As a further result, the correlations among technological and market as well as managerial and regulatory knowledge are particularly high, indicating that these knowledge dimensions are more likely to be exchanged in conjunction ${ }^{4}$.

Table III-1-5. Analysis of knowledge exchange multiplexity

\begin{tabular}{lcccc}
\hline & \multicolumn{2}{c}{ Adjusted data } & \multicolumn{2}{c}{ Original data } \\
& $\#$ & $\%$ & $\#$ & $\%$ \\
\hline Single (Tech) & 34 & 7.47 & 19 & 4.18 \\
Single (Market) & 17 & 3.74 & 3 & 0.66 \\
Single (Mgmt) & 7 & 1.54 & 6 & 1.32 \\
Single (Reg) & 16 & 3.52 & 4 & 0.88 \\
& & & & \\
Double (Tech, Market) & 45 & 9.89 & 28 & 6.15 \\
Double (Tech, Mgmt) & 19 & 4.18 & 12 & 2.64 \\
Double (Tech, Reg) & 23 & 5.05 & 6 & 1.32 \\
Double (Market, Mgmt) & 5 & 1.10 & 2 & 0.44 \\
Double (Market, Reg) & 4 & 0.88 & 1 & 0.22 \\
Double (Mgmt, Reg) & 18 & 3.96 & 8 & 1.76 \\
& & & & \\
Triple (Tech, Market, Mgmt) & 41 & 9.01 & 32 & 7.03 \\
Triple (Tech, Market, Reg) & 41 & 9.01 & 40 & 8.79 \\
Triple (Tech, Mgmt, Reg) & 24 & 5.27 & 17 & 3.74 \\
Triple (Market, Mgmt, Reg) & 12 & 2.64 & & 2.86 \\
& & & & 58.02 \\
Quadruple & 149 & 32.74 & & \\
Missing Values & & & & \\
\hline
\end{tabular}

\footnotetext{
${ }^{4}$ See Table A1 for the results of a Steiger's Z-test in order to compare correlated correlation coefficients (Meng et al., 1992).
} 
III. Publications in Focus Area II: Networks and External Partners

Table III-1-6. Correlations between knowledge exchange networks (original data)

\begin{tabular}{lcccc}
\hline & $\begin{array}{c}\text { Technological } \\
\text { knowledge }\end{array}$ & $\begin{array}{c}\text { Market } \\
\text { knowledge }\end{array}$ & $\begin{array}{l}\text { Managerial } \\
\text { knowledge }\end{array}$ & $\begin{array}{l}\text { Regulatory } \\
\text { knowledge }\end{array}$ \\
\hline $\begin{array}{l}\text { Technological } \\
\text { knowledge }\end{array}$ & 1.00 & & & \\
$\begin{array}{l}\text { Market } \\
\text { knowledge }\end{array}$ & .87 & 1.00 & & \\
$\begin{array}{l}\text { Managerial } \\
\text { knowledge }\end{array}$ & .83 & .81 & 1.00 & \\
$\begin{array}{l}\text { Regulatory } \\
\text { knowledge }\end{array}$ & .83 & .80 & .84 & 1.00 \\
\hline
\end{tabular}

Notes: Pearson correlations are significant at $\mathrm{p}<.001$ (QAP with 20,000 permutations)

Original data as described in footnote 3 , thus the results are likely to overestimate correlations

Table III-1-7. Correlations between knowledge exchange networks (adjusted data)

\begin{tabular}{lcccc}
\hline & $\begin{array}{c}\text { Technological } \\
\text { knowledge }\end{array}$ & $\begin{array}{c}\text { Market } \\
\text { knowledge }\end{array}$ & $\begin{array}{l}\text { Managerial } \\
\text { knowledge }\end{array}$ & $\begin{array}{l}\text { Regulatory } \\
\text { knowledge }\end{array}$ \\
\hline $\begin{array}{l}\text { Technological } \\
\text { knowledge }\end{array}$ & 1.00 & & & \\
$\begin{array}{l}\text { Market } \\
\text { knowledge }\end{array}$ & .72 & 1.00 & & \\
$\begin{array}{l}\text { Managerial } \\
\text { knowledge }\end{array}$ & .66 & .62 & 1.00 & 1.00 \\
$\begin{array}{l}\text { Regulatory } \\
\text { knowledge }\end{array}$ & .63 & .53 & .64 & \\
\hline
\end{tabular}

Notes: Pearson correlations are significant at $\mathrm{p}<.001$ (QAP with 20,000 permutations) Adjusted data as described in footnote 3, only intensity values within a range of 1 from the maximum of the dyad's most intense exchange were included, thus the results are likely to underestimate correlations 


\section{Effects of knowledge types and tie multiplexity on innovative performance}

Thus far, we explored and described the nature of different types of knowledge exchange as well as the dispersion and antecedents of multiplex ties. Nevertheless, it is highly important both from perspectives of economics and business administration whether inter-firm differences also account for performance differences in this context. On the one hand, if external knowledge is a multifaceted resource which is needed to meet organizational tasks, the resource-based view of the firm would imply that certain combinations of this resource yield superior outcomes, e.g. different forms of innovation (Galunic and Rodan, 1998). Recent approaches organizational research argue that it is possible to identify ideal configurations of organizational resources, and that companies which deviate less form these ideal profiles will be more successful (Pullen et al., 2012). In the context of this study, the relative focus that a firm puts on the four types of knowledge is likely to have an influence on the particular firm's performance in generating process, product and administrative innovations. On the other hand, it is unclear as to whether either a uniplex supply with knowledge from specialized sources or rich relations involving several types of knowledge exchange are preferable. As such, we test the influence of deviations from ideal profiles as well as that of tie multiplexity on organizational innovativeness.

In order to obtain the measure profile deviation, we first identified suitable ideal profiles. There are several approaches in the literature which all derive the ideal profile from the bestperforming companies in a sample, under the premise that the share of selected successful companies should not exceed the "top third limit" (Olson et al., 2005). For the purposes of this study, we chose three different ideal profiles and compared the results of the further analysis in this connection. For Profiles I and II we used percentiles as thresholds for inclusion in the top performer group. Profile I is calculated from the means of the profiles of the top $25 \%$ innovators in each category; namely, the process, product and administrative dimensions. Profile II is calculated from the top $10 \%$ in the respective categories. As Vorhies and Morgan (2005) propose using only the single best performing company as a benchmark, Profile III applies this approach. The profile deviation for each company was then calculated by the Euclidean distance from the ideal prolife across all four dimensions of external knowledge acquisition using the following formula:

$$
E D_{s i}=\sqrt{\sum_{j=1}^{4}\left(X_{s j}-X_{i j}\right)^{2}}
$$

where $X_{s j}$ is the score of the firm $s$ on the $j$ th knowledge type, $X_{i j}$ is the score of the ideal profile type ( $i \in\{I ; I I ; I I I\})$ for the $j$ th knowledge type. The multiplexity of a firm's knowledge exchange relations was calculated as the average value of tie multiplexity across all the firm's ties. Hence, a firm with larger value would tend to acquire knowledge rather from multidimensional relations while a firm with lower values would possess relations that are each specialized on only few types of knowledge. We tested the effects via ordinary least squares (OLS) regression including the geographic position of a firm (using the average geographic distance from a firm 
to the other network members) as well as firm size (using the log of the number of employees) as control variables. The results are presented in Table 8.

The results reveal the following. Firstly, there are ideal profiles of the composition of externally acquired knowledge for distinct types of innovations. The more firms deviate from the particular ideal profile, the less likely they will outperform other firms in terms of process, product and administrative innovations. Secondly, the strength of this relation differs across innovation types. Especially in the case of product innovation, an ideal profile may be more clearly pronounced and there will be fewer other ways to achieve high performance than in the case of process innovation, for example. Thirdly, multiplexity does not benefit firms' innovation outcome. As $\beta$-coefficients are negative specialized channels may be more advantageous. However, the coefficients fail to meet significance criteria. Finally, as an additional result concerning the control variables, geographic closeness to the other network members benefits both process and administrative innovativeness, but not product innovativeness.

Due to the apparent existence of ideal configurations concerning the four types of knowledge exchange, it now seems prudent to take a closer look to the nature of these ideal configurations. Table 9 shows the profile characteristics by provide the results of a $t$-test which compares the profiles of the top $25 \%$ performers for each innovation type with the average profile of the bottom $25 \%$ of firms. For process innovation, innovative firms put a lower emphasis on regulatory knowledge. For product innovation, successful firms acquire a larger proportion of market knowledge at the cost of regulatory knowledge. For administrative innovation, meanwhile, managerial knowledge seems to be of particular importance and again lowperforming firms focus clearly more on regulatory knowledge.

Figure 2 displays the composition of Profiles I, II and III. As shown in the previous section, knowledge exchange volume is unequally distributed across the four types of knowledge within the network. Hence, we compared all three profiles to a baseline profile which depicts the average relative level of knowledge exchange in all four dimensions. In all, top performers put a far lower emphasis on the acquisition of regulatory knowledge from external sources. In the case of process innovation, these free capacities are almost evenly distributed across technological, market and managerial knowledge. The data concerning product innovation is clearly indicative of a higher emphasis on market knowledge and slightly higher relative amounts of technological and managerial knowledge. Finally, for administrative innovation, free capacities are largely deployed across technological and market knowledge. Taken together with the $t$-test above, this means that successful firms do not exchange managerial knowledge to a particularly high degree, but unsuccessful ones fail to acquire the necessary amount of external managerial expertise. 
III. Publications in Focus Area II: Networks and External Partners

Table III-1-8. OLS regression result for different types of innovation

\begin{tabular}{|c|c|c|c|c|c|c|c|c|c|}
\hline & & \multicolumn{4}{|c|}{ Models with Profile I } & \multicolumn{2}{|c|}{$\begin{array}{l}\text { Models with } \\
\text { Profile II }\end{array}$} & \multicolumn{2}{|c|}{$\begin{array}{l}\text { Models with } \\
\text { Profile III }\end{array}$} \\
\hline & & $1 \mathrm{a}$ & $1 b$ & $1 \mathrm{c}$ & $1 d$ & $2 \mathrm{a}$ & $2 b$ & $3 a$ & $3 b$ \\
\hline \multirow{6}{*}{$\begin{array}{l}\text { Process } \\
\text { innovation }\end{array}$} & Multiplexity & & -.08 & & -.13 & & -.13 & & -.13 \\
\hline & $\begin{array}{l}\text { Profile } \\
\text { deviation }\end{array}$ & & & $-.25^{+}$ & $-.27^{+}$ & $-.25^{+}$ & $-.27^{+}$ & $-.25^{+}$ & $-.27^{+}$ \\
\hline & Firm size & .16 & .20 & .13 & .14 & .13 & .15 & .13 & .15 \\
\hline & $\begin{array}{l}\text { Geographic } \\
\text { position }\end{array}$ & $-.28 *$ & $-.26^{+}$ & $-.28^{+}$ & $-.27^{+}$ & $-.28^{+}$ & $-.27^{+}$ & $-.28^{+}$ & $-.27^{+}$ \\
\hline & R-square & .12 & .14 & .19 & .20 & .18 & .20 & .18 & .20 \\
\hline & F-value & $3.28 *$ & 2.19 & $3.26^{*}$ & $2.63 *$ & $3.23 *$ & $2.61 *$ & $3.23 *$ & $2.61 *$ \\
\hline \multirow{6}{*}{$\begin{array}{l}\text { Product } \\
\text { innovation }\end{array}$} & Multiplexity & & -.22 & & $-.27 *$ & & $-.29 *$ & & -.17 \\
\hline & $\begin{array}{l}\text { Profile } \\
\text { deviation }\end{array}$ & & & $-.47 * * *$ & $-.50 * * *$ & $-.44 * *$ & $-.48 * * *$ & $-.59 * * *$ & $-.57 * * *$ \\
\hline & Firm size & .06 & .12 & -.02 & .02 & -.03 & .01 & .02 & .05 \\
\hline & $\begin{array}{l}\text { Geographic } \\
\text { position }\end{array}$ & .11 & .14 & .09 & .11 & .08 & .10 & .08 & .10 \\
\hline & R-square & .01 & .06 & .23 & .30 & .19 & .27 & .36 & .38 \\
\hline & F-value & 0.31 & 0.94 & $4.25^{* *}$ & $4.44 * *$ & $3.43^{*}$ & $3.92 * *$ & $7.93 * * *$ & $6.53 * * *$ \\
\hline \multirow{6}{*}{$\begin{array}{l}\text { Administrative } \\
\text { innovation }\end{array}$} & Multiplexity & & -.22 & & $-.25^{+}$ & & $-.28^{+}$ & & -.19 \\
\hline & $\begin{array}{l}\text { Profile } \\
\text { deviation }\end{array}$ & & & $-.32 *$ & $-.35 *$ & -.21 & $-.28^{+}$ & $-.44 * *$ & $-.43 * *$ \\
\hline & Firm size & -.01 & -.03 & -.07 & -.03 & -.06 & -.03 & -.06 & -.02 \\
\hline & $\begin{array}{l}\text { Geographic } \\
\text { position }\end{array}$ & $-.25^{+}$ & $-.27^{+}$ & $-.30^{*}$ & $-.28 *$ & $-.31^{*}$ & $-.29 *$ & $-.31 *$ & $-.29 *$ \\
\hline & R-square & .06 & .13 & .19 & .28 & .13 & .20 & .28 & .31 \\
\hline & F-value & 1.55 & 2.19 & $3.26^{*}$ & $3.46^{*}$ & 2.10 & $2.62 *$ & $5.43 * *$ & $4.70^{* *}$ \\
\hline
\end{tabular}

Notes: ${ }^{+} \mathrm{p}<.10 * \mathrm{p}<.05 * * \mathrm{p}<.01 * * * \mathrm{p}<.001$ 
Table III-1-9. $t$-test for profile differences between high and low performers

\begin{tabular}{|c|c|c|c|c|c|c|c|c|}
\hline & & \multirow[t]{2}{*}{$t$} & \multirow[t]{2}{*}{ df } & \multirow[t]{2}{*}{$\begin{array}{c}\text { Sig. } \\
\text { (2-tailed) }\end{array}$} & \multirow[t]{2}{*}{$\begin{array}{c}\text { Mean } \\
\text { difference }\end{array}$} & \multirow[t]{2}{*}{$\begin{array}{l}\text { Std. error } \\
\text { difference }\end{array}$} & \multicolumn{2}{|c|}{$\begin{array}{l}95 \% \text { confidence } \\
\text { intervall of the } \\
\text { difference }\end{array}$} \\
\hline & & & & & & & Lower & Upper \\
\hline \multirow{4}{*}{$\begin{array}{l}\text { Process } \\
\text { innovation }\end{array}$} & $\begin{array}{l}\text { Technological } \\
\text { knowledge }^{\text {a }}\end{array}$ & .989 & 17.209 & .336 & .09541 & .09646 & -.10791 & .29873 \\
\hline & $\begin{array}{l}\text { Market } \\
\text { knowledge }\end{array}$ & .392 & 22 & .699 & .03761 & .09585 & -.16117 & .23640 \\
\hline & $\begin{array}{l}\text { Managerial } \\
\text { knowledge }\end{array}$ & 1.279 & 12.195 & .225 & .17417 & .13615 & -.12195 & .47028 \\
\hline & $\begin{array}{l}\text { Regulatory } \\
\text { knowledge }\end{array}$ & $-2.461^{*}$ & 22 & .022 & -.30719 & .12483 & -.56608 & -.04830 \\
\hline \multirow{4}{*}{$\begin{array}{l}\text { Product } \\
\text { innovation }\end{array}$} & $\begin{array}{l}\text { Technological } \\
\text { knowledge }\end{array}$ & 1.262 & 22 & .220 & .15399 & .12201 & -.09904 & .40703 \\
\hline & $\begin{array}{l}\text { Market } \\
\text { knowledge }\end{array}$ & $2.204^{*}$ & 22 & .038 & .35103 & .15925 & .02077 & .68128 \\
\hline & $\begin{array}{l}\text { Managerial } \\
\text { knowledge }\end{array}$ & -.053 & 22 & .958 & -.00722 & .13659 & -.29049 & .27606 \\
\hline & $\begin{array}{l}\text { Regulatory } \\
\text { knowledge }\end{array}$ & $-3.469 * *$ & 22 & .002 & -.49780 & .14350 & -.79540 & -.20020 \\
\hline \multirow{4}{*}{$\begin{array}{l}\text { Administrative } \\
\text { innovation }\end{array}$} & $\begin{array}{l}\text { Technological } \\
\text { knowledge }\end{array}$ & 1.507 & 17 & .150 & .21864 & .14510 & -.08747 & .52477 \\
\hline & $\begin{array}{l}\text { Market } \\
\text { knowledge }\end{array}$ & -.221 & 17 & .828 & .03566 & .16151 & -.37642 & .30509 \\
\hline & $\begin{array}{l}\text { Managerial } \\
\text { knowledge }\end{array}$ & $2.009^{+}$ & 7.366 & .082 & .23090 & .11494 & -.03819 & .49998 \\
\hline & $\begin{array}{l}\text { Regulatory } \\
\text { knowledge }\end{array}$ & $-2.174^{*}$ & 17 & .044 & -.40093 & .18441 & -.78999 & -.01187 \\
\hline
\end{tabular}

Notes: $\quad{ }^{+} \mathrm{p}<.10 * \mathrm{p}<.05 * * \mathrm{p}<.01 * * * \mathrm{p}<.001$

$\mathrm{df}-$ degrees of freedom; Sig. - significance; Std. error - standard error

a as for technological knowledge (process innovation) and managerial knowledge (process and administrative innovation) Levene's Test for equality of variances indicates a violation of the assumption of homogeneous variance among groups, we correct for this by not using the pooled estimate for the error term for the t-statistic, and also making adjustments to the degrees of freedom using the Welch-Satterthwaite method 
III. Publications in Focus Area II: Networks and External Partners

\begin{tabular}{|c|c|c|c|c|c|c|c|c|}
\hline & & Profile I & Profile II & Profile III & $\begin{array}{l}\text { Average } \\
\text { profile }\end{array}$ & $\begin{array}{c}\text { Compared } \\
\text { level }\end{array}$ & $\begin{array}{l}\text { Technological } \\
\text { knowledge }\end{array}$ & $\begin{array}{l}\text { - Top } 25 \% \text { of } \\
\text { firms }\end{array}$ \\
\hline \multirow{4}{*}{$\begin{array}{l}\text { Process } \\
\text { innovation }\end{array}$} & $\begin{array}{l}\text { Technological } \\
\text { knowledge }\end{array}$ & 0.24 & 0.24 & 0.24 & 0.22 & $\begin{array}{l}\text { Moderately } \\
\text { high }\end{array}$ & & $\begin{array}{c}\text {-Average } \\
\text { profile }\end{array}$ \\
\hline & $\begin{array}{l}\text { Market } \\
\text { knowledge }\end{array}$ & 0.01 & 0.02 & 0.02 & -0.04 & $\begin{array}{l}\text { Moderately } \\
\text { high }\end{array}$ & & $\begin{array}{l}\text { ket } \\
\text { edge }\end{array}$ \\
\hline & $\begin{array}{l}\text { Managerial } \\
\text { knowledge }\end{array}$ & -0.12 & -0.14 & -0.14 & -0.17 & $\begin{array}{l}\text { Moderately } \\
\text { high }\end{array}$ & & \\
\hline & $\begin{array}{l}\text { Regulatory } \\
\text { knowledge }\end{array}$ & -0.13 & -0.12 & -0.12 & -0.01 & Low & & \\
\hline \multirow{5}{*}{$\begin{array}{l}\text { Product } \\
\text { innovation }\end{array}$} & & & & & & & $\begin{array}{l}\text { Technological } \\
\text { knowledge }\end{array}$ & \\
\hline & $\begin{array}{l}\text { Technological } \\
\text { knowledge }\end{array}$ & 0.25 & 0.21 & 0.37 & 0.22 & High & & \\
\hline & $\begin{array}{l}\text { Market } \\
\text { knowledge }\end{array}$ & 0.14 & 0.15 & 0.30 & -0.04 & Very high & & \\
\hline & $\begin{array}{l}\text { Managerial } \\
\text { knowledge }\end{array}$ & -0.15 & -0.21 & -0.06 & -0.17 & $\begin{array}{l}\text { Moderately } \\
\text { high }\end{array}$ & & \\
\hline & $\begin{array}{l}\text { Regulatory } \\
\text { knowledge }\end{array}$ & -0.23 & -0.15 & -0.60 & -0.01 & Very low & $\begin{array}{l}\text { Managerial } \\
\text { knowledge }\end{array}$ & \\
\hline \multirow{4}{*}{$\begin{array}{l}\text { Adminis- } \\
\text { trative } \\
\text { innovation }\end{array}$} & $\begin{array}{l}\text { Technological } \\
\text { knowledge }\end{array}$ & 0.34 & 0.30 & 0.37 & 0.22 & High & $\begin{array}{l}\text { Technological } \\
\text { knowledge }\end{array}$ & \\
\hline & $\begin{array}{l}\text { Market } \\
\text { knowledge }\end{array}$ & 0.03 & 0.11 & 0.30 & -0.04 & High & \multirow{3}{*}{$\begin{array}{l}\text { Managerial } \\
\text { knowledge }\end{array}$} & \\
\hline & $\begin{array}{l}\text { Managerial } \\
\text { knowledge }\end{array}$ & -0.17 & -0.17 & -0.06 & -0.17 & $\begin{array}{c}\text { Moderately } \\
\text { High }\end{array}$ & & \\
\hline & $\begin{array}{l}\text { Regulatory } \\
\text { knowledge }\end{array}$ & -0.19 & -0.25 & -0.60 & -0.01 & Very low & & \\
\hline
\end{tabular}

Figure III-1-2. Profiles of high performing firms (own illustration)

\section{Discussion}

Our results indicate several interesting findings for the energy industry as a whole, as well as for practitioners dealing with innovation management in addition to inter-organizational relations and academic research. First of all, the paper reveals the multidimensional nature of knowledge transfer and exchange. Building on prior research by Sammarra and Biggiero (2008), Moos et al. (2015) and Alberti and Pizzurno (2015), we advance this stream of research by exploring how technological, market, managerial and regulatory knowledge are exchanged within the largest network of German utility providers. In detail, our data indicates that among all kinds that technological knowledge is predominantly exchanged in contrast to managerial knowledge, which is exchanged the least. This notwithstanding, we have not found evidence to suggest a hierarchy among the different dimensions of knowledge exchange. Indeed, a Guttman scale analysis yields low values of fitness. Moreover, it can be stated that knowledge exchange relations are far more likely multiplex than uniplex. Thereby, the pairwise comparison of the correlations among the four knowledge exchange networks indicates that the combinations of technological and market as well as managerial and regulatory knowledge occur in significantly higher correlations than others.

Together, these findings advance academic knowledge on the multidimensionality of knowledge exchange. Hence, while the knowledge exchange dimensions form distinct networks, clear interdependencies exist. In a similar fashion to different types of advice 
exchanged via interpersonal relations between managers (Cross et al., 2001), relations which are specific to a single type of knowledge seem to be the exception rather than the rule. These findings indicate non-hierarchical complementarity among knowledge types. On the one hand, different knowledge resources can be pooled to conjointly address business challenges (Helfat, 1997). For instance, among two of the most likely pairwise combinations of knowledge, technological and market knowledge largely refer to primary business activities like e.g. operations and sales while regulatory and managerial knowledge address supporting activities such as procurement (Porter, 1985). Moreover, when firms aim at integrating new technologies into existing business ventures, they strive to acquire complementary elements of market, managerial and regulatory knowledge in order to address customers-, administration-, or regulation-related issues. These occur due to the systemic nature of innovations, which explains the high correlations of technological knowledge exchange with the other three dimensions. Therefore, in searching for external knowledge on business issues of this sort, firms may perceive complementary benefits which result from different types of knowledge resources and acquire them accordingly. On the other hand, our analysis rejects notions of hierarchy among the four types of knowledge. While technological knowledge is predominantly exchanged in the network, there are a considerable number of exchange relations involving market, managerial and regulatory knowledge with only little intensity or no technological knowledge exchange at all. Thus, even in the energy industry, a sector which is dominated by engineering and which involves a high salience of technology in the context of innovation, technological knowledge exchange does not serve as a basis for the acquisition of other types of knowledge in the same tie. Instead, firms seem to acquire market, managerial and regulatory knowledge as original input for developing solutions to specific business needs rather than a mere supplement for technological knowledge. This line of reasoning would further support the proposition that firms purposefully choose knowledge sources based on such needs, as well as on the respective partners' competences. However, as we cannot draw a final conclusion based on our data, we recommend further research to address this issue.

Secondly, we reveal how the different the types of knowledge and their exchange via specialized or multiplex ties impact innovative performance of firms. For three types of innovations (process, product and administrative), we derived ideal profiles and provided evidence that deviation from these profiles negatively influences innovation output. The common denominator amongst these profiles is that the share of regulatory knowledge is comparably low. For all three types of innovation, firms do not substantially rely on this type of knowledge and instead use their capacities to rather acquire technological, market and managerial knowledge. This does not demonstrate that regulatory knowledge is unnecessary; rather, it indicates that an overreliance on current rules and competitive norms is detrimental to innovation. In fact, regulatory knowledge exchange is often a reactive approach, since, with the exception of lobbying, it is not possible for actors to predict or even influence the outcomes of regulation in the industry. While regulation only sets the frame for competitive action, it does not generate value in itself. Thus, a rather pro-active approach focusing on better technological solutions, customer-driven topics and efficient ways of organizational management will be more advantageous. 
For managers and practitioners, our findings provide valuable implications and insights. First and foremost, we demonstrated that, when pursuing innovation, it is not only about the extent or source of acquired knowledge but rather about the composition of the content. In order to succeed, firms should analyze what kinds of knowledge they acquire and how applicable it is to the innovation tasks at hand. We accordingly provide empirically-based ideal profiles which may serve as templates for innovation managers directing their efforts towards a specific innovative undertaking.

Furthermore, our insights may be useful for policy-makers and network managers trying to orchestrate and design inter-organizational network as well as coordinate and mobilize knowledge flows. While technology knowledge seems to be the naturally predominant type transferred, the other knowledge dimensions also hold important benefits for firms. Although it is impossible to predict exactly how and when knowledge flows finally induce innovation, it is crucial to establish flows and relations in advance. Therefore, network management should aim at explicitly providing exchange infrastructure for all four types of knowledge. While some socialization techniques, such as technology forums, are quite common, intra-network information and socialization processes of this sort should also be directed towards topics relating to market, managerial and regulatory issues.

\section{Concluding remarks}

We are convinced that our selection and simultaneous limitation on the four distinctive knowledge types enabled us to contribute to and advance previous work on sector-specific and innovation network studies alike. Thereby, we have been able to clarify the multidimensional nature of knowledge exchange and imply that further research should investigate the nature and effect of the different knowledge types. Moreover, we shed light on issues on network, dyad and firm level which need to be understood in order to foster organizational innovation in the energy sector. These findings thus address innovation management executives at the firm level by outlining characteristics of innovation-inducing network constellations. It also speaks to network managers and policy-makers aiming to design effective firm networks by presenting patterns of knowledge exchange within an association of German energy providers.

However, there are several limitations which should be acknowledged. Firstly, despite choosing the biggest collaboration network in the German energy industry, this remains but a section of the whole branch. It seems reasonable to assume that knowledge transfer in order to foster innovation is not only limited to network partners. Hence, our findings and arguments are restricted to network-internal knowledge transfer and thus not fully generalizable. Secondly, we primarily gathered empirical data focused on inter-organizational knowledge transfer. Therefore, we were able to evaluate the extent to which the sample organizations were willing to receive knowledge from network partners. Unfortunately, this method is not a perfect means to gain insights into the way in which this knowledge is then integrated and processed within the firm in order to create innovation. Finally, like all cross-sectional work, our study is not free of endogeneity issues. For instance, the possibility that the composition of externally acquired knowledge may be a consequence rather than an antecedent of firm innovation cannot be discounted. Innovation strategies aiming at following others rather than pioneering and thus 
prescribing low innovation rates may account for different knowledge needs and preferences. On the basis of the data presented here, however, it is impossible to offer a definitive standpoint on this issue. We suggest further research to include the strategic orientation of firms' innovation management in investigations as well as to examine the different types of knowledge exchange in a longitudinal design. Such efforts would strengthen the empirical basis of the results outlined here and further serve to advance theoretical thinking on multidimensional knowledge transfer.

\section{Appendices}

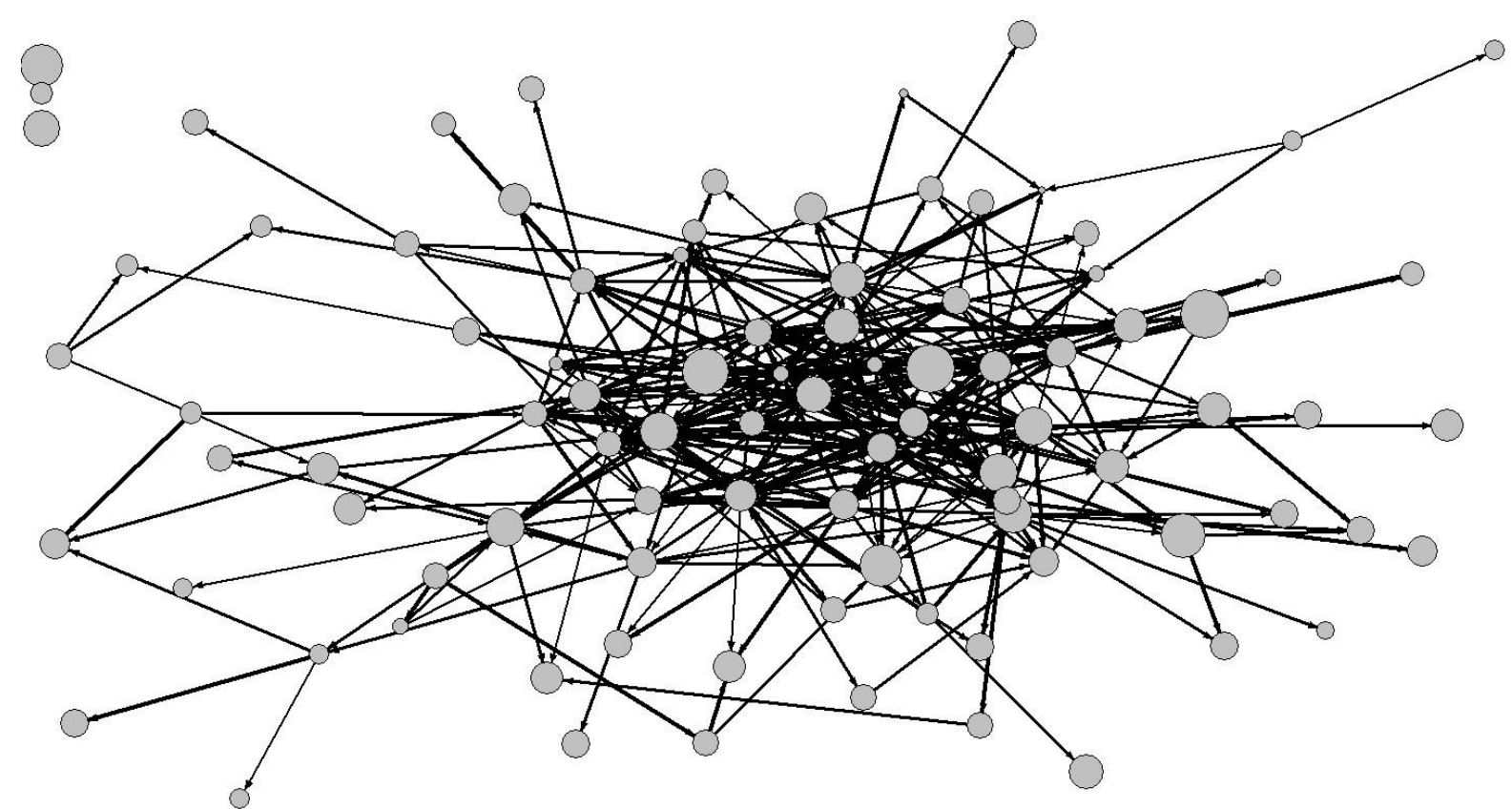

Figure III-1-A1. Network of technological knowledge transfer (own illustration) 
III. Publications in Focus Area II: Networks and External Partners

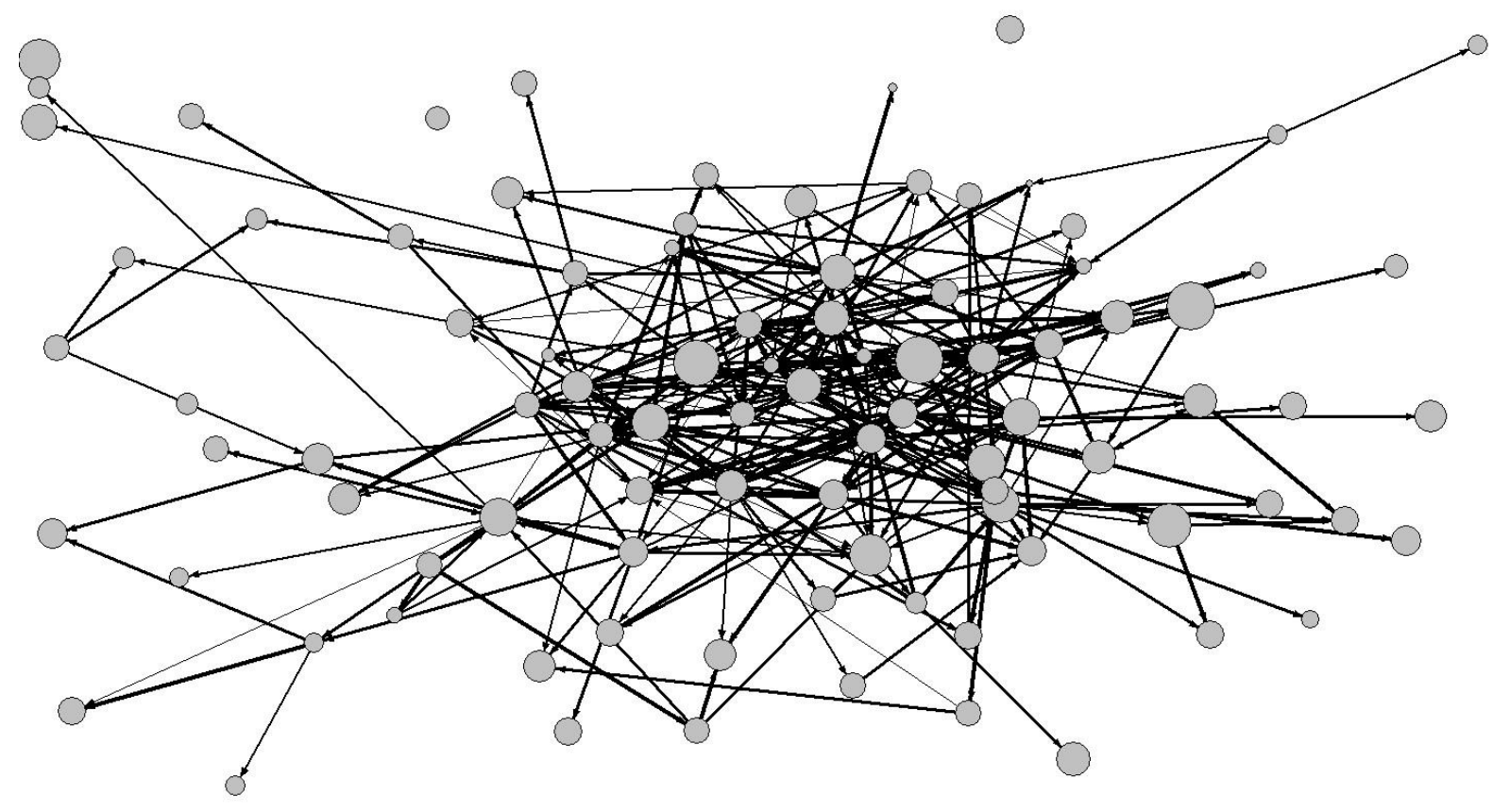

Figure III-1-A2. Network of market knowledge transfer (own illustration)

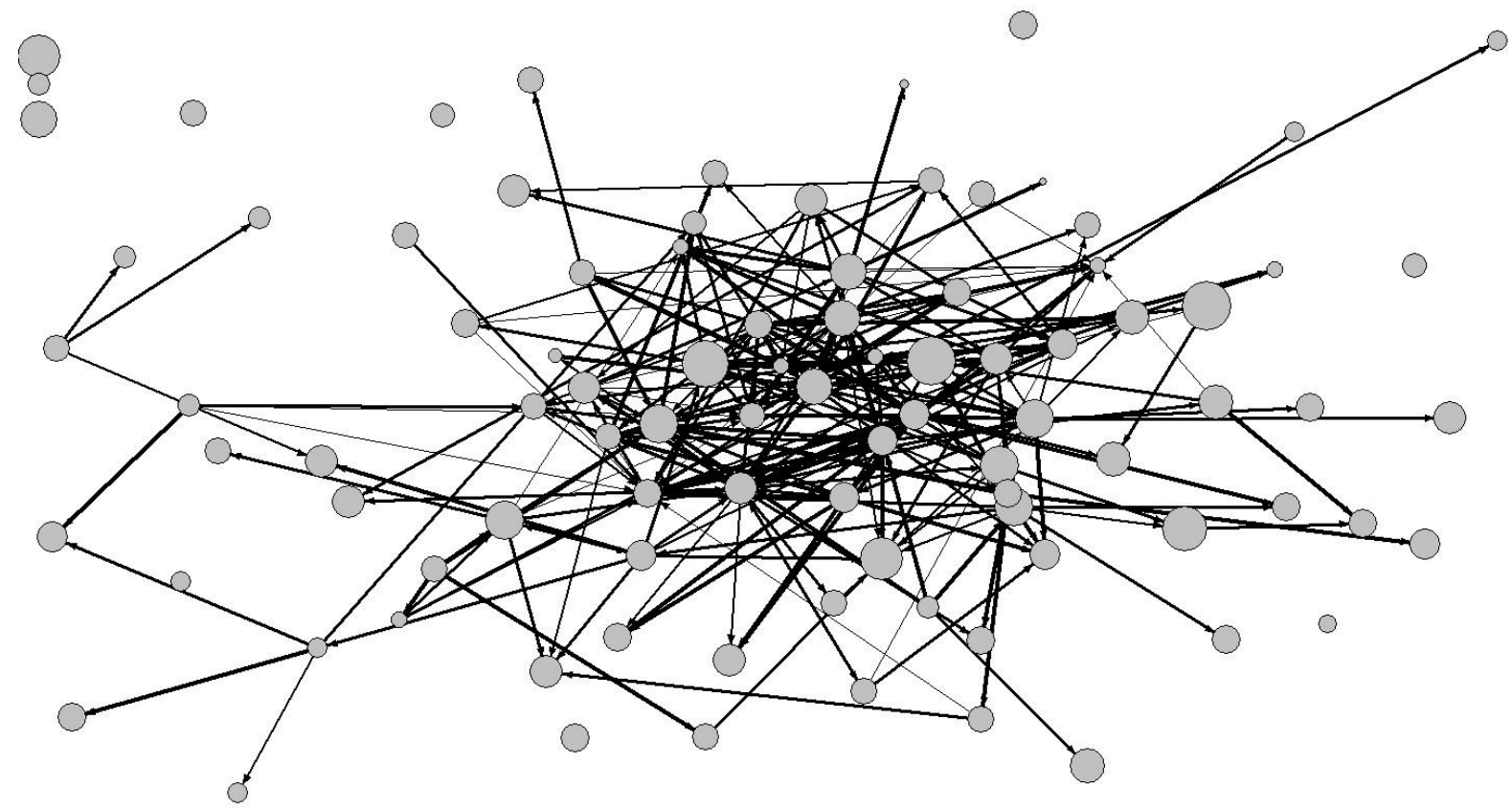

Figure III-1-A3. Network of managerial knowledge transfer (own illustration) 
III. Publications in Focus Area II: Networks and External Partners

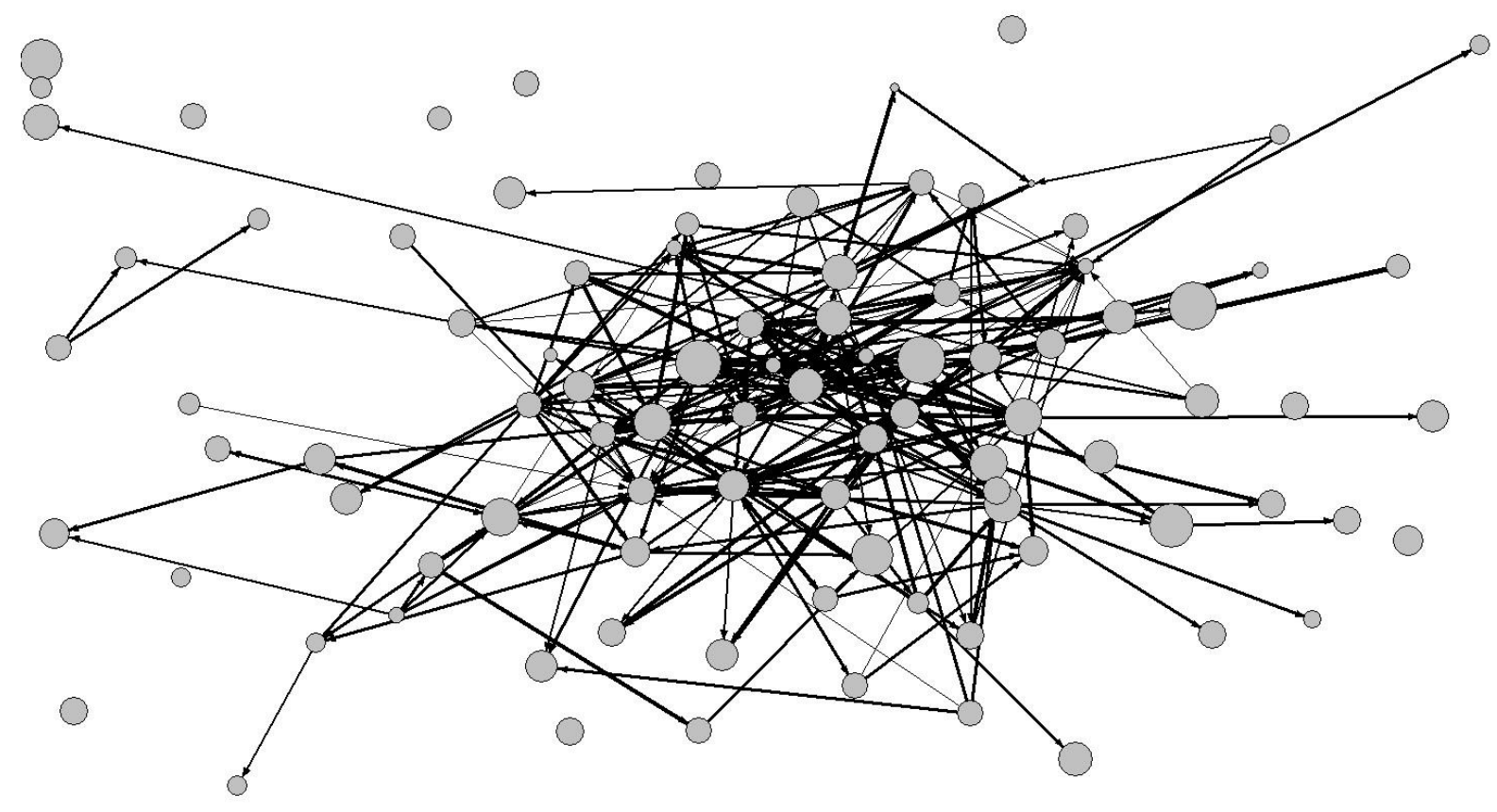

Figure III-1-A4. Network of regulatory knowledge transfer (own illustration) 
Table III-1-A1. Significance test for correlation differences among the four knowledge exchange networks

\begin{tabular}{|c|c|c|c|c|}
\hline & \multicolumn{2}{|c|}{ Original data } & \multicolumn{2}{|c|}{ Adjusted data } \\
\hline & $Z$ & $p$ & $Z$ & $p$ \\
\hline TK-MktK \& TK-MgK & $10.532 * * *$ & .000 & $7.732 * * *$ & .000 \\
\hline TK-MktK \& TK-RegK & $10.355^{* * *}$ & .000 & $10.407 * * *$ & .000 \\
\hline TK-MgK \& TK-RegK & 0.000 & 1.000 & $3.658 * * *$ & .000 \\
\hline MktK-TK \& MktK-MgK & $15.841 * * *$ & .000 & $13.054 * * *$ & .000 \\
\hline MktK-TK \& MktK-RegK & $18.183^{* * *}$ & .000 & $22.538 * * *$ & .000 \\
\hline MktK-MgK \& Mkt-RegK & $2.382 *$ & .017 & $10.043 * * *$ & .000 \\
\hline MgK-TK \& MgK-MktK & $5.437 * * *$ & .000 & $5.406^{* * *}$ & .000 \\
\hline MgK-TK \& MgK-RegK & $-2.565^{*}$ & .010 & $2.428^{*}$ & .015 \\
\hline MgK-MktK \& MgK-RegK & $-6.997 * * *$ & .000 & $2.132 *$ & .033 \\
\hline RegK-TK \& RegK-MktK & $8.041^{* * *}$ & .000 & $12.589^{* * *}$ & .000 \\
\hline RegK-TK \& RegK-MgK & $-2,565^{*}$ & .010 & -1.231 & .218 \\
\hline RegK-MktK \& RegK-MgK & $-9.365^{* * *}$ & .000 & $-12.133 * * *$ & .000 \\
\hline
\end{tabular}

Notes: $\quad{ }^{+} \mathrm{p}<.10 * \mathrm{p}<.05 * * \mathrm{p}<.01 * * * \mathrm{p}<.001$

Steiger's $Z$-Test

TK - technological knowledge; MktK - market knowledge; MgtK - managerial knowledge;

$\mathrm{RK}$ - regulatory knowledge 


\subsection{References}

Alberti, F.G. and Pizzurno, E. (2015), "Knowledge exchanges in innovation networks. Evidences from an Italian aerospace cluster”, Competitiveness review, Vol. 25 No. 3, pp. $258-287$.

Ashford N., Ayers C. and Stone, R.F. (1985), "Using Regulation to Change the Market for Innovation", Harvard environmental law review, Vol. 9 No. 2, pp. 419-466.

Bhattacharyya, S.C. (2007), "Energy sector management issues: an overview", International Journal of energy sector management, Vol. 1 No. 1, pp. 13-33.

Borgatti, S.P., Everett, M.G. and Johnson, J.C. (2013), Analyzing social networks, Sage, Los Angeles.

Borgatti, S.P. and Halgin, D.S. (2011), “On Network Theory”, Organization science, Vol. 22 No. 5, pp. 1168-1181.

Brass, D.J., Galaskiewicz, J., Greve, H.R. and Tsai, W. (2004), “Taking stock of networks and organizations: A multilevel perspective", Academy of management journal, Vol. 47 No. 6, pp. $795-817$.

Brown, J.S. and Duguid, P. (2001), "Knowledge and Organization. A Social-Practice Perspective", Organization science, Vol. 12 No. 2, pp. 198-213.

Burke, G.J., Carrillo, J.E. and Vakharia, A.J. (2007), "Single versus multiple supplier sourcing strategies", European journal of operational research, Vol. 182 No.1, pp. 95-112.

Burt, R.S. and Schøtt, T. (1985), "Relational contents in multiple networks", Social science research, Vol. 14, pp. 287-308.

Carroll, J.S., Rudolph, J.W. and Hatakenaka, S. (2002), "Learning from experience in highhazard organizations", Research in organizational behavior, Vol. 24, pp. 87-137.

Cassiman, B. and Veugelers, R. (2006), "In search of complementarity in innovation strategy: Internal R\&D and external knowledge acquisition”, Management science, Vol. 52 No. 1, pp. $68-82$.

Chesbrough, H.W. (2006), Open innovation: The new imperative for creating and profiting from technology, Harvard business press, Boston.

Cross, R., Borgatti, S.P., \& Parker, A. (2001), "Beyond answers: dimensions of the advice network", Social networks, Vol. 23 No. 3, pp. 215-235.

Dahlander, L. and Gann, D.M. (2010), "How open is innovation?", Research policy, Vol. 39 No. 6, pp. 699-709.

Dell'Era, C. and Verganti, R. (2010), "Collaborative strategies in design-intensive industries: knowledge diversity and innovation”, Long range planning, Vol. 43 No. 1, pp. 123-141.

Dhanaraj, C. and Parkhe, A. (2006), "Orchestrating innovation networks", Academy of management review, Vol. 31 No. 3, pp. 659-669.

Diamantopoulos, A. and Winklhofer, H.M. (2001), „Index construction with formative indicators: An alternative to scale development”, Journal of marketing research, Vol 38 No. 2, pp. 269-277.

Dusonchet, L. and Telaretti, E. (2010), "Economic analysis of different supporting policies for the production of electrical energy by solar photovoltaics in western European Union countries", Energy policy, Vol. 38 No. 7, pp. 3297-3308. 
Easterby-Smith, M., Lyles, M.A. and Tsang, E.W.K. (2008), "Inter-organizational knowledge transfer. Current themes and future prospects", Journal of management studies, Vol. 45 No. 4, pp. 677-690.

Edwards, J.S. (2008), "Knowledge management in the energy sector. Review and future directions", International journal of energy sector management, Vol. 2 No. 2, pp. 197217.

Ettlie, J.E., Bridges, W.P. and O'Keefe, R.D. (1984). “Organization strategy and structural differences for radical versus incremental innovation", Management science, Vol. 30 No. 6, pp. 682-95.

Fabrizio, K.R. (2009), “Absorptive capacity and the search for innovation”, Research policy, Vol. 38 No. 2, pp. 255-267.

Federal Ministry of Economics and Technology (2010), “The federal government's energy concept of 2010 and the transformation of the energy system of 2011”, Federal Ministry of Economics and Technology, Berlin.

Fleming, L. and Sorenson, O. (2004), "Science as a map in technological search", Strategic management journal, Vol. 25 No. 89, pp. 909-928.

Fliaster, A. and Spiess, J. (2008), "Knowledge mobilization through social ties: The cost benefit analysis", Schmalenbach business review, Vol. 60 No. 1, pp. 99-117.

Federal Ministry of Economics and Technology (2010), “The federal governemnt's energy concept of 2010 and the transformation of the energy system of 2011".

Frishammar, J., Kurkkio, M., Abrahamsson, L. and Lichtenthaler, U. (2012), “Antecedents and consequences of firms' process innovation capability: a literature review and a conceptual framework", IEEE transactions on engineering management, Vol. 59 No. 4, pp. 519 529.

Galunic, D.C. and Rodan, S. (1998), "Resource recombinations in the firm: Knowledge structures and the potential for Schumpeterian innovation", Strategic management journal, Vol. 19 No. 12, pp. 1193-1201.

Gilsing, V., Nooteboom, B., Vanhaverbeke, W., Duysters, G. and Van den Oord, A. 2008. "Network embeddedness and the exploration of novel technologies: Technological distance, betweenness centrality and density", Research policy, Vol. 37 No. 10, pp. 17171731 .

Grant, R.M. (1996), “Toward a knowledge-based theory of the firm”, Strategic management journal, Vol. 17 No. S2, pp. 109-122.

Guttman, L. (1944) "A basis for scaling qualitative data", American sociological review, Vol. 9 No. 2, pp. 139-150.

Helfat, C.E. (1997), "Know-how and asset complementarity and dynamic capability accumulation: The case of R\&D”, Strategic management journal, Vol. 18 No. 5, pp. 339360 .

Hult, G.T.M., Ketchen, D.J. and Arrfelt, M. (2007), "Strategic supply chain management: Improving performance through a culture of competitiveness and knowledge development", Strategic management journal, Vol. 28 No. 10, pp. 1035-1052.

Ibarra, H. (1992), "Homophily and differential returns: Sex differences in network structure and access in an advertising firm" Administrative science quarterly, Vol. 37 No. 3, pp. $422-447$. 
Inkpen, A.C., and Tsang, E.W.K. (2005), "Social capital, networks, and knowledge transfer", Academy of management review, Vol. 30 No. 1, pp. 146-165.

Jacobsson, S. and Bergek, A. (2004), "Transforming the energy sector: the evolution of technological systems in renewable energy technology", Industrial and corporate change, Vol. 13 No. 5, pp. 815-849.

Kehrel, U. and Sick, N. (2014), "Economic and technological forecasting competencies of German energy companies”, International journal of energy sector management, Vol. 8 No. 4, pp. 588-610.

Klashner, R. and Sabet, S. (2007), “A DSS Design Model for complex problems. Lessons from mission critical infrastructure”, Decision support systems, Vol. 43 No. 3, pp. 990-1013.

Kogut, B. (2000), "The network as knowledge. Generative rules and the emergence of structure", Strategic management journal, Vol. 21 No. 3, pp. 405-425.

Kolloch, M., and Golker, O. (2016). "Staatliche Regulierung und Digitalisierung als Antezedenzien für Innovationen in der Energiewirtschaft am Beispiel von REMIT", Zeitschrift für Energiewirtschaft, Vol. 40 No. 1, pp. 41-54.

Laursen, K. and Salter, A. (2006), “Open for innovation: the role of openness in explaining innovation performance among UK manufacturing firms", Strategic management journal, Vol. 27 No. 2, pp. 131-150.

Lee, S., Park, G., Yoon, B., and Park, J. (2010), “Open innovation in SMEs - An intermediated network model”, Research policy, Vol. 39 No. 2, pp. 290-300.

Leiponen, A. and Helfat, C.E. (2010), "Innovation objectives, knowledge sources, and the benefits of breadth", Strategic management journal, Vol. 31 No. 2, pp. 224-236.

Li, T. and Calantone, R.J. (1998), "The impact of market knowledge competence on new product advantage. Conceptualization and empirical examination", Journal of marketing, Vol. 62 No. 4, p. 13-29.

Meng, X.L., Rosenthal, R. and Rubin, D.B. (1992), "Comparing correlated correlation coefficients", Psychological bulletin, Vol. 111 No. 1, pp. 172-175.

Menzel, H. (1953), "A new coefficient for scalogram analysis" Public opinion quarterly, Vol. 17 No. 2, pp. 268-280.

Meyer, A.D., Tsui, A.S. and Hinings, C.R. (1993), "Configurational approaches to organizational analysis", Academy of management journal, Vol. 36 No. 6, pp. 1175-1195.

Moos, B., Wagner, T.-H., Beimborn, D. and Weitzel, T. (2015), "The contagious power of innovativeness: How different corporate partners contribute to a firm's knowledge", International journal of innovation management, Vol. 19 No. 4, pp. 1-38.

Müller, R., Steinert, M. and Teufel, S. (2008), "Successful diversification strategies of electricity companies. An explorative empirical study on the success of different diversification strategies of German electricity companies in the wake of the European market liberalization", Energy policy, Vol. 36 No. 1, pp. 398-412.

Nikogosian, V. and Veith, T. (2012), "The impact of ownership on price-setting in retail-energy markets-The German case", Energy policy, Vol. 41, pp. 161-172.

Nonaka, I. (1994), “A dynamic theory of organizational knowledge creation”, Organization science, Vol. 5 No. 1, pp. 14-37. 
Olson, E.M., Slater, S.F. and Hult, G.T.M. (2005), "The performance implications of fit among business strategy, marketing organization structure and strategic behavior", Journal of marketing, Vol. 69 No. 3, pp. 49-65.

Ozer, M. and Zhang, W. (2015), "The effects of geographic and network ties on exploitative and exploratory product innovation", Strategic management journal, Vol. 36 No. 7, pp. $1105-1114$.

Pätäri, S. (2010), "Industry and company level factors influencing the development of the forest energy business - Insights from a Delphi Study", Technological forecasting and social change, Vol. 77 No. 1, pp. 94-109.

Porter. M.E. (1985), Competitive advantage: Creating and sustaining superior performance, Simon and Schuster, New York.

Provan, K.G., Fish, A., and Sydow, J. (2007). "Interorganizational networks at the network level: a review of the empirical literature on whole networks", Journal of management, Vol. 33 No. 3, pp. 479-516.

Pullen, A.J., Weerd-Nederhof, P.C., Groen, A.J. and Fisscher, O.A. (2012) "Open innovation in practice: goal complementarity and closed NPD networks to explain differences in innovation performance for SMEs in the medical devices sector", Journal of product innovation management, Vol. 29 No. 6, pp. 917-934.

Rank, C., Rank, O.N. and Wald, A. (2005), "Netzwerke - Netzwerke in der Biotechnologie Eine empirische Analyse des inter- organisationalen informations- und Wissenstransfers", Zeitschrift für betriebswirtschaftliche Forschung, Vol. 57 No. 11, pp. $617-634$.

Rank, O.N., Robins, G.L. and Pattison, P.E. (2010), "Structural logic of intraorganizational networks", Organization science, Vol. 21 No. 3, pp. 745-764.

Richter, M. (2012), “Utilities' business models for renewable energy: a review”, Renewable and sustainable energy reviews, Vol. 16 No. 5, pp. 2483-2493.

Sammarra, A. and Biggiero, L. (2008), "Heterogeneity and specificity of inter-firm knowledge flows in innovation networks", Journal of management studies, Vol. 45 No. 4, pp. 800 829.

Schilke, O. and Goerzen, A. (2010), "Alliance management capability: an investigation of the construct and its measurement", Journal of management, Vol. 36 No. 5, pp. 1192-1219.

Schumpeter, J.A. (1983), The theory of economic development: An inquiry into profits, capital, credit, interest, and the business cycle, Social science classics series, Transaction Books, New Brunswick, NJ.

Simpson, C.R. (2015), "Multiplexity and strategic alliances: The relational embeddedness of coalitions in social movement organisational fields", Social networks, Vol. 42, pp. 4259.

Snijders, T.A.B. and Borgatti, S.P. (1999), "Non-parametric standard errors and tests for network statistics”, Connections, Vol. 22, pp. 139-157.

van Wijk, R., Jansen, J.J.P. and Lyles, M.A. (2008), "Inter- and intra-organizational knowledge transfer. A meta-analytic review and assessment of its antecedents and consequences", Journal of management studies, Vol. 45 No. 4, pp. 830-853. 
Von Krogh, G., Nonaka, I. and Rechsteiner, L. (2012), "Leadership in organizational knowledge creation: a review and framework", Journal of management studies, Vol. 49 No. 1, pp. 240-277.

Vorhies, D.W. and Morgan, N.A. (2005), "Benchmarking marketing capabilities for sustainable competitive advantage", Journal of marketing, Vol. 69 No. 1, pp. 80-94.

Whittington, R., Pettigrew, A., Peck, S., Fenton, E. and Conyon, M. (1999), "Change and complementarities in the new competitive landscape: a European panel study, 19921996", Organization science, Vol. 10 No. 5, pp. 583-600.

Yayavaram, S. and Ahuja, G. (2008), "Decomposability in knowledge structures and its impact on the usefulness of inventions and knowledge-base malleability", Administrative science quarterly, Vol. 53 No. 2, pp. 333-362.

Yli-Renko, H., Autio, E. and Sapienza, H.J. (2001), "Social capital, knowledge acquisition, and knowledge exploitation in young technology-based firms", Strategic management journal, Vol. 22 No. 6-7, pp. 587-613.

Zott, C. and Amit, R. (2010), "Business model design: an activity system perspective", Long range planning, Vol. 43 No. 2, pp. 216-226.

\section{Further reading}

Brass, D.J., Galaskiewicz, J., Greve, H.R. and Tsai, W. (2004), "Taking stock of networks and organizations: a multilevel perspective", Academy of management journal, Vol. 47 No. 6, pp.795-817. 
2. Publication 4: Management of Knowledge Networks in Industry Clusters and Product Innovation Performance - Development and Test of a Mediation Model

\subsection{Note on Submitted Paper}

The following paper on "Management of Knowledge Networks in Industry Clusters and Product Innovation Performance - Development and Test of a Mediation Model” was coauthored by my PhD supervisor Prof. Dr. Alexander Fliaster, my colleague Dr. Michael Kolloch, and myself. As corresponding author, I submitted the paper to a leading international academic journal (VHB: A; ABS: 4) where it is currently under review. Earlier versions of the paper were accepted for presentation at the Fachtagung "Der Stand der Netzwerkforschung", Deutsche Gesellschaft für Netzwerkforschung in Darmstadt, Germany (date of presentation: December $5^{\text {th }}, 2016$ ) as well as at the 77th Annual Meeting of the Academy of Management in Atlanta, USA (date of presentation: August $8^{\text {th }}, 2017$ ) after double-blind peer-review processes. 


\title{
2.2. Academic Paper
}

\begin{abstract}
Though knowledge exchange in industry clusters is widely perceived as an important driver of innovation performance, little is known about how firms manage to develop and maintain an innovation-enhancing network of knowledge exchange relationships within a cluster environment. To close this research gap, this paper establishes a conceptual bridge between two research streams - social network theory and the resource- respectively capability-based view - and develops a mediation model that depicts the causal sequence from firm-level network management capabilities via intra-cluster knowledge network characteristics to product innovation performance. The model is tested empirically based on data collected from a quantitative survey of 74 companies from the largest cluster network in the German energy industry. The results demonstrate that distinct structural and compositional network properties increase cluster firms' product innovation performance and that for developing each type of network properties discussed, firms require different bundles of internal network management capabilities.
\end{abstract}

Keywords: inter-organizational networks; industry clusters; knowledge transfer; product innovation; organizational capabilities; network management 


\section{INTRODUCTION}

Industry clusters, i.e., groups of independent firms from the same industry that share a geographic locality (Brown and Hendry, 1998; Harrison et al., 1996), have been found to foster the firm-level innovation performance (Bell, 2005; Owen-Smith and Powell, 2004; Ozer and Zhang, 2015). Industry clusters provide an infrastructure for social interaction and knowledge transfer so that cluster members are likely to have better access to information (e.g. Pouder and St. John, 1996), are provided with more opportunities for learning and cooperative problemsolving (e.g. Inkpen and Tsang, 2005), and consequently enhance their capability for knowledge creation and innovation (e.g. Arikan, 2009). Still, research also found that firms differ in their ability to benefit from cluster membership so that for some companies being part in an industry cluster might have little or no effect on innovation performance (Boschma, 2005; McCann and Folta, 2011; Pouder and St. John, 1996).

One way to explain differences in innovation performance between cluster members is by applying social network theory (Inkpen and Tsang, 2005; Sammarra and Biggiero, 2008). Network research assumes that a firm's access to knowledge resources and learning opportunities is fundamentally determined by the structure of that firm's ego-network, i.e., the pattern of its direct knowledge transfer ties to other firms (Ahuja, 2000a; Baum et al., 2000; McEvily and Zaheer, 1999). In line with this notion, a number of studies found that cluster firms' innovation performance depends on the number, content, and strength of inter-firm knowledge transfer ties (e.g. Boschma and Ter Wal, 2007; McCann and Folta, 2011; OwenSmith and Powell, 2004; Singh, 2005; Zhang and Li, 2010; Zaheer and Bell, 2005). While these works offer several important insights to explain the network characteristics that foster firmlevel innovation in industry clusters, they also suffer from an important limitation as they assume firms' ego-networks to be exogenous (Stuart and Sorenson, 2007). Studies in the light of social network theory mostly neglect the question why some firms achieve to build a beneficial ego-network of knowledge sources in the cluster and others do not (Phelps et al., 2012; Rowley and Baum, 2008; Salancik, 1995). Hence, the extensive literature from the network perspective only provides a partial explanation for the differences between cluster members when it comes to innovative performance.

In contrast to the network-theoretic literature, studies that examine inter-organizational networks from a capability perspective accentuate firms' internal resources and capabilities as crucial factors that shape innovation performance (Hagedoorn et al., 2006; Vesalainen and Hakala, 2014; Walter et al., 2006). According to this growing stream of research, firms are able to intentionally evolve and cultivate their ego-networks of inter-organizational relations (Capaldo, 2007; Dhanaraj and Parkhe, 2006; Lorenzoni and Lipparini, 1999). In order to do so, they need adequate means of network management, i.e., processes and routines to strategically organize the initiation, development, and maintenance of business interactions, co-operations, alliances, or similar relationships with external partners (Mitrega et al., 2012; Sarkar et al., 2009). Thus, outcome differences between firms that operate in inter-organizational networks are likely to result from variance in capability across those firms (Ireland et al., 2002). Supporting this notion, studies in this stream have found significant effects of network 
management capabilities on firms' innovation performance (e.g. Leischnig et al., 2014; Mu and Di Benedetto, 2012; Ritter and Gemünden, 2003; Rothaermel and Deeds, 2006).

Both streams of literature thus put forth fundamentally different but potentially complementary explanations for why firms in inter-organizational networks in general and industry clusters in specific succeed or fail when it comes to product innovation. Whereas the capability-theoretic stream offers a firm-internal managerial perspective, the network-theoretic stream advocates a firm-external perspective focusing on the characteristics of firms' ego-networks and the accessible knowledge resources (Faems et al., 2012). However, even though both streams seem to complement each other, research is only beginning to examine how knowledge network properties and firm-level network management might interact to affect innovation performance (Degener et al., 2018; Sarkar et al., 2009; Schreiner et al., 2009). Surprisingly, the explanation that some firms might possess a specific bundle of network management capabilities and hence are more able to obtain an ego-network with favorable characteristics that grant access to valuable knowledge resources for product innovation has been largely neglected up to this point.

In this paper, we therefore build a conceptual bridge between literature on the basis of network theory that explains the effects of firms' ego-networks and literature on the basis of the resource-based view that explains the effects of firm-level network management capabilities on innovation performance. Rather than treat internal management routines and external knowledge networks as separate realms of enquiry, we seek to understand how the network properties that may impact the performance of firms in industry clusters are shaped by the firmlevel network management capabilities. To this end, we propose a mediation model that depicts the causal sequence from network management over ego-network characteristics to product innovation performance.

In doing so, we first discern three key properties of a firm's knowledge network that are likely to impact innovation outcomes in the context of industry clusters. These are network size (e.g. Ahuja, 2000a; Owen-Smith and Powell, 2004; Rothaermel and Deeds, 2006), knowledge complementarity (e.g. Fang, 2011; Pullen et al., 2012; Sampson, 2007), and tie strength (e.g. McEvily and Marcus, 2005; Rowley et al., 2000 Tiwana, 2008). Second, we draw on previous work on the development of inter-organizational relationships and argue that in order to obtain and maintain the three beneficial knowledge network properties firms need to overcome different constraints. Third, we theorize that overcoming each of these constraints requires different sets of network management routines operating on different levels of analysis portfolio management and relationship management (Wang and Rajagopalan, 2015). We empirically test the resulting mediation model based on data collected from a quantitative survey of 74 member firms from the largest cluster network of German municipal energy providers. Finally, we discuss the results of our study, identify its limitations, and address the main implications of our work from both research and managerial perspectives.

In summary, this paper advances the literature on industry clusters, inter-organizational networks, and product innovation in a number of ways: 1) by examining the extent to which different properties of intra-cluster knowledge networks contribute to firms' product innovation 
performance; 2) by illuminating if and in what way the development of different knowledge network properties demands different types of network management capabilities; and 3) by shedding light on how network-level properties and firm-level network management capabilities interact in predicting product innovation performance. In particular, we demonstrate that firms in industry clusters do indeed exert an influence on the properties of their knowledge networks. Furthermore, we specify the causal mechanisms behind the effects of firm-level network management capabilities, and unveil the distinct effects of the management routines that focus on knowledge transfer relationships at the dyadic level and the ones that address the overall portfolio of a focal firm's knowledge sources.

\section{THEORETICAL BACKGROUND}

\section{Industry Clusters, Knowledge Networks, and Product Innovation}

The term "industry cluster" describes "a group of firms from the same or related industries located geographically near to each other" (Bell, 2005, p. 288). An industry cluster usually consists of a number of firms producing similar products or services, as well as supporting organizations and specialized intermediaries which provide member firms with services in a specific technological or business area, and some public or private institutions that facilitate collaboration and assume the task of coordinating interaction between cluster members (Alberti and Pizzurno, 2015; Inkpen and Pien, 2006; Zhang and Li, 2010). Clusters represent a form of network organization, i.e., a loosely-coupled system of autonomous firms that at least to some degree share a common goal, interact, and cooperate (Dai et al., 2018). This form of organization entails potential benefits of agglomeration and flexibility so that cluster membership may result in considerable competitive advantage (Porter, 1998). Most noticeably, research has pointed out the capacity of clusters to foster member firms' innovativeness as a major reason for the economic and strategic importance of industry clusters (Delgado et al., 2014).

Firm-level product innovation is defined as "the extent to which a focal firm can successfully develop and introduce new products to the market" (Ozer and Zhang, 2015, p. 1106). Product innovation is a knowledge-intensive activity (Bierly et al., 2009). As the knowledge required for new product development is often complex and spans multiple domains of expertise, external knowledge becomes an increasingly important driver for fostering product innovation at the firm level (Zhang and Li, 2010). By acquiring knowledge from external sources, firms can overcome fundamental limitations in the scope of information they are able to create, handle, and use on their own (Baum et al., 2000; Dyer and Nobeoka, 2000). Thereby, opportunities for synthesizing and recombining previously isolated perspectives into novel ideas, design concepts, and product functionalities and applications are created (Hargadon and Sutton, 1997).

Industry clusters benefit innovation by providing a social infrastructure for mobilizing knowledge flows between firms (Arikan, 2009; Dhanaraj and Parkhe, 2006). Previous studies reveal that inter-firm knowledge transfer is afflicted with considerable barriers such as lack of motivation, lack of trust, and lack of absorptive capacity (Easterby-Smith et al., 2008; Szulanski, 1996; van Wijk et al., 2008). In the context of an industry cluster, firms are more 
likely to overcome transfer barriers because they experience a sense of identification with other cluster members, engage in the same industry events, and develop shared concepts, tools, language, and norms of business conduct (Bell and Zaheer, 2007; Ozer and Zhang, 2015). Hence, within industry clusters, knowledge flows between member firms are generally more likely to occur and hence, comparably dense knowledge networks tend to emerge (Alberti and Pizzurno, 2015; Boschma, 2005; Sammarra and Biggiero, 2008).

However, research has also shown that not all the firms in the cluster have equal access to knowledge flows (Giuliani, 2007). Rather, knowledge transfer ties are unevenly distributed so that there is variance in the number of knowledge sources firms use to access, the quality of the knowledge that is accessible to them, and the intensity of their engagement with their knowledge sources (Alberti and Pizzurno, 2015; Sammarra and Biggiero, 2008; Tödtling et al., 2013). In other words, cluster firms differ with regard to the characteristics of their intra-cluster ego-networks (Boschma and Ter Wal, 2007; Giuliani, 2007; Morrison, 2008). Hence, in industry clusters some firms will occupy more central roles and cultivate ego-networks that allow them to acquire valuable knowledge resources while other cluster members will fail to do so.

\section{Knowledge Network Characteristics and Product Innovation Performance}

According to social network theory, the composition of the ego-network, i.e., the content and arrangement of a firms' network ties (Wassmer, 2010), influences the quantity and quality of the external knowledge that a firm can acquire (Borgatti and Halgin, 2011; Borgatti and Foster, 2003; Gulati et al., 2011; Zaheer, et al., 2010). We argue that in the context of an industry cluster as well, specific ego-network characteristics are likely to determine the knowledge resources available to firms in the product innovation process and thus be an important factor when it comes to explaining differences in product innovation between cluster firms.

The literature discusses three major types of ego-network features that influence firms' knowledge access: structural, compositional, and relational characteristics (Wassmer, 2010). Research from the first perspective argues that the structure of a firm's ego-network, as expressed by the numbers of direct and indirect ties, has a significant effect on firm-level innovative outcomes. Empirical studies provided evidence on this positive effect in various industrial settings (e.g. Ahuja, 2000a; McCann and Folta, 2011; McEvily and Zaheer, 1999; Owen-Smith and Powell, 2004; Shan et al., 1994). The larger a firm's network, the greater its reach of knowledge resources, that is, the volume of available external knowledge (Gulati et al., 2011; Koka and Prescott, 2002; Rothaermel and Deeds, 2006). Through such knowledge reach, the likelihood of receiving new insights and ideas that provide solutions to technological or market-related problems increases (Baker et al., 2016). Hence, opportunities for learning, knowledge creation, and eventually product innovation emerge more frequently. Furthermore, a large network is helpful for timely access to information (Ahuja, 2000a). The more external relationships the firm possesses, the more likely it is to become aware of new developments in technology, regulatory, and market environment early (Owen-Smith and Powell, 2004).

A second line of research focuses on the composition of firms' ego-networks. Within this research stream, knowledge complementarity, that is, the degree to which the knowledge bases 
of the focal firm and its partners differ and add to each other, has received substantial scholarly attention (e.g. Fang, 2011; Pullen et al., 2012; Sarkar et al., 2001). The concept of complementarity takes into account that the value of another firm's knowledge resources is not fully objective but rather depends on the expertise gaps on the side of the focal firm (Gulati et al., 2011). The development of new products generally requires a broad set of expertise and skills so that it is often impossible, or at least very costly, for firms to develop all these skills internally (Mitchell and Singh, 1996). Hence, if a firm can acquire complementary expertise via its network, it becomes able to concentrate its efforts on strengthening its own core expertise while simultaneously compensating for knowledge deficits with the help of network partners (Ahuja, 2000b) so that the firm's innovation performance is likely to increase (Pullen et al., 2012).

Finally, the relational perspective focuses on the quality and strength of dyadic relationships between a firm and its partners to explain beneficial effects of networks on product innovation performance (Michelfelder and Kratzer, 2013; Rowley et al., 2000; Tiwana, 2008). Research on inter-organizational networks demonstrates, for instance, that strong dyadic ties increase the effectiveness of knowledge transfer (Tiwana, 2008) and, as a consequence, the rate and magnitude of organizational knowledge creation and innovation (Capaldo, 2007; Sampson, 2007). Strong ties bring with them higher levels of trust and relation-specific collaboration norms (Dyer and Singh, 1998; Kale et al., 2000), social cohesion (Tiwana, 2008), and mutual understanding (Nahapiet and Ghoshal, 1998), which yield positive effects on inter-firm learning as well as an increased depth and scope of knowledge transferred (Michelfelder and Kratzer, 2013). Particularly when knowledge is tacit and complex, strong ties lead to higher levels of receptivity so that the focal firm's ability to profit from the transferred knowledge and implement it in new product concepts increases (McEvily and Marcus, 2005).

\section{Firm-level Network Management as an Enabler of Knowledge Network Development}

Whereas research literature provides much insight into what a knowledge network that is conducive to innovation should look like, much less is known on if and by which means firms can improve the innovation-related features of their ego-networks (Borgatti and Foster, 2003; Phelps et al., 2012). Although firms might, to a certain degree, shape their portfolio of knowledge sources, their scope of action is fundamentally restrained. Challenges associated with network development and maintenance limit the number of relationship opportunities that a firm can create and realize (Hoffmann, 2007; Madhavan et al., 2008; Ozcan and Eisenhardt, 2009; Rowley and Baum, 2008). Accordingly, though firms can influence the structural setup, composition, and purpose of their relations to other companies, the possibility of such "network action" is fundamentally constrained (Gulati and Srivastava, 2014).

Successfully developing an innovation-fostering ego-network, thus likely requires firm to actively try to overcome constraints of inter-firm networking by recognizing, extending, and navigating the own available scope of action (Doreian, 2008; Hoffmann, 2007). Hence, an advantage of some firms over others when it comes to strategically "picking” (Makadok, 2001) valuable network resources "stems not merely from opportunity structures embedded in networks but also from the distribution of ability and motivation among firms" (Madhavan et 
al., 2008, p. 457). Up to now, most research originating from the "structuralist heritage" of network theory (Borgatti and Foster, 2003, p. 1000) did not elaborate on such abilities and motivations at the firm level. Still, research on organizational capabilities brought up its own stream of literature that focuses on the processes of managing firms' relationships with other companies as well as the impact of those management processes on innovative performance (Anand and Khanna, 2000; Lorenzoni and Lipparini, 1999; Vesalainen and Hakala, 2014).

Network-related capabilities have been discussed across several research domains and disciplines. Consequently, terminology and taxonomies vary even though oftentimes the discussed concepts are similar in meaning. For instance, strategic management research tends to focus on strategic alliances as unit of analysis and thus predominantly discusses "alliance capabilities" or "alliance management capabilities" (e.g. Degener et al., 2018; Heimeriks and Duysters, 2007; Sarkar et al., 2009; Schilke and Goerzen, 2010; Schreiner et al., 2009). On the other hand, research from the background of industrial marketing tends to take a broader perspective by discussing business relationships and uses the terms "network capabilities", "networking capabilities", and "network management" (e.g. Mitrega et al., 2012; Vesalainen and Hakala, 2014). Other works thematize "relational capabilities" (Capaldo, 2007; Lorenzo and Lipparini, 1999), "network competence" (Ritter and Gemünden, 2003), and "cooperative capabilities" (Blomqvist and Levy, 2006).

In this study, we deploy the term "network management" defining it as identifiable and specific routines and processes with the aim to purposefully initiate, maintain, and utilize relationships with external partners (Mitrega et al., 2012; Mu and Di Benedetto, 2012; Walter et al., 2006). We intentionally take a broad perspective on the type of relationship and include insights from both alliance capability literature and the literature on network capabilities. Thereby, we follow the assumption that irrespectively of the specific network and relationship type, similar generic tasks of planning, coordinating, communicating, and monitoring are necessary in order to effectively develop inter-organizational ties and realize corresponding benefits (Walter et al., 2006). Furthermore, our definition implies a process perspective on network management, which conceptualizes and operationalizes organizational capabilities by means of a bundle of underlying constituent routines and processes (Degener et al., 2018; Mitrega et al., 2012; Sarkar et al. 2009; Schilke and Goerzen, 2010). Taking this perspective circumvents the tautology problem frequently inherent to research on organizational capabilities by separating the notion of capability from its effects and allows for identifying an observable set of routines and processes that can be tested empirically (Eisenhardt and Martin, 2000; Nelson and Winter, 1982; Zollo and Winter, 2002).

With regard to managing a network of inter-firm ties past research has distinguished between two different levels of analysis: 1) processes and routines that determine a firm's ability to manage individual relationships to external partners; and 2) processes and routines that determine a firm's ability to develop and coordinate a whole portfolio of inter-organizational relationships (Wang and Rajagopalan, 2015). These two distinct bundles of activities can be seen as constituent elements of the organizational capability that is network management (Schreiner et al., 2009). Both types of network management are expected to support and 
complement each other by addressing two different but likewise important issues (Kale and Singh, 2009; Parise and Casher, 2003).

The first type, relationship management, comprises the skills to handle or manage individual relationships with other firms (Dyer and Singh, 1998). This component consists of coordination, communication, and bonding processes that operate at the dyadic level (Schreiner et al., 2009; Kale et al., 2000). First, the focal firm must develop and execute appropriate coordination mechanisms for single relationships (Heimeriks and Duysters, 2007; Walter et al., 2006). Thereby, partners can discuss and decide on cross-company processes and standards, synchronize activities, and manage dyadic conflicts in an integrative manner (Kale et al., 2000). Second, well-elaborated communication routines, such as discussions on the form and content of the relation or the installation of feedback mechanisms, contribute to a deeper understanding of the given relationship and the partner (Kale and Singh, 2007). Finally, there should be routines that foster strong personal relationships between members of both organizations (Schreiner et al., 2009). As every inter-organizational relation ultimately happens at an interpersonal level, the socialization of key individuals is an important factor (Ritter and Gemünden, 2003).

In contrast, portfolio management describes the skills that comprise a firm's capability to manage its overall portfolio of relationships with other firms (Hoffmann, 2007). Past research indicates that portfolio management consists of three types of processes: planning/designing, organizing/coordinating, and monitoring/controlling. First, firms need to develop and pursue a networking strategy that is aligned with the needs of their overall business strategy (Parise and Casher, 2003). This allows for proactiveness in searching for and initiating new ties as well as decision-making considering the ties' fit to a firm's existing ego-network and strategic needs (Edvardsson et al., 2008; Mitrega et al, 2012). Second, coordination and organization are necessary to minimize conflicts and foster synergies among diverse partners (Schilke and Goerzen, 2010; Walter et al., 2006). Firms need to cultivate an internal system of aligned responsibilities and synchronized actions across all relationships to master these tasks (Sarkar et al., 2009; Schilke and Goerzen, 2010). Finally, companies must keep informed about partners, monitor their resources and strategies, and assess potential complementarities and conflicts, as well as environmental changes (Schilke and Goerzen, 2010).

\section{HYPOTHESIS DEVELOPMENT}

Summarizing past research, we assume that specific characteristics of firms' ego-networks in industrial clusters entail specific knowledge benefits. In particular, these key characteristics are network size (structural dimension), knowledge complementarity (compositional dimension), and tie strength (relational dimension). However, developing such knowledge network characteristics is afflicted with specific constraints that firms need to overcome. Firms with highly developed network management capabilities should be more able to overcome those constraints and achieve to obtain an ego-network with beneficial, that is, innovation-friendly characteristics. Moreover, we argue that as different network characteristics are associated with different types of constraints, portfolio and relationship management processes should have different effects on these different characteristics. 
In the following, we discuss and specify these effects by theorizing how either portfolio management or relationship management, or both, may help in developing and maintaining each of the three ego-network characteristics. Furthermore, we integrate these explanations into a multi-path mediation model that includes the direct effects of network management on egonetwork configuration as well as its indirect effects on firms' product innovation performance (Figure 1).

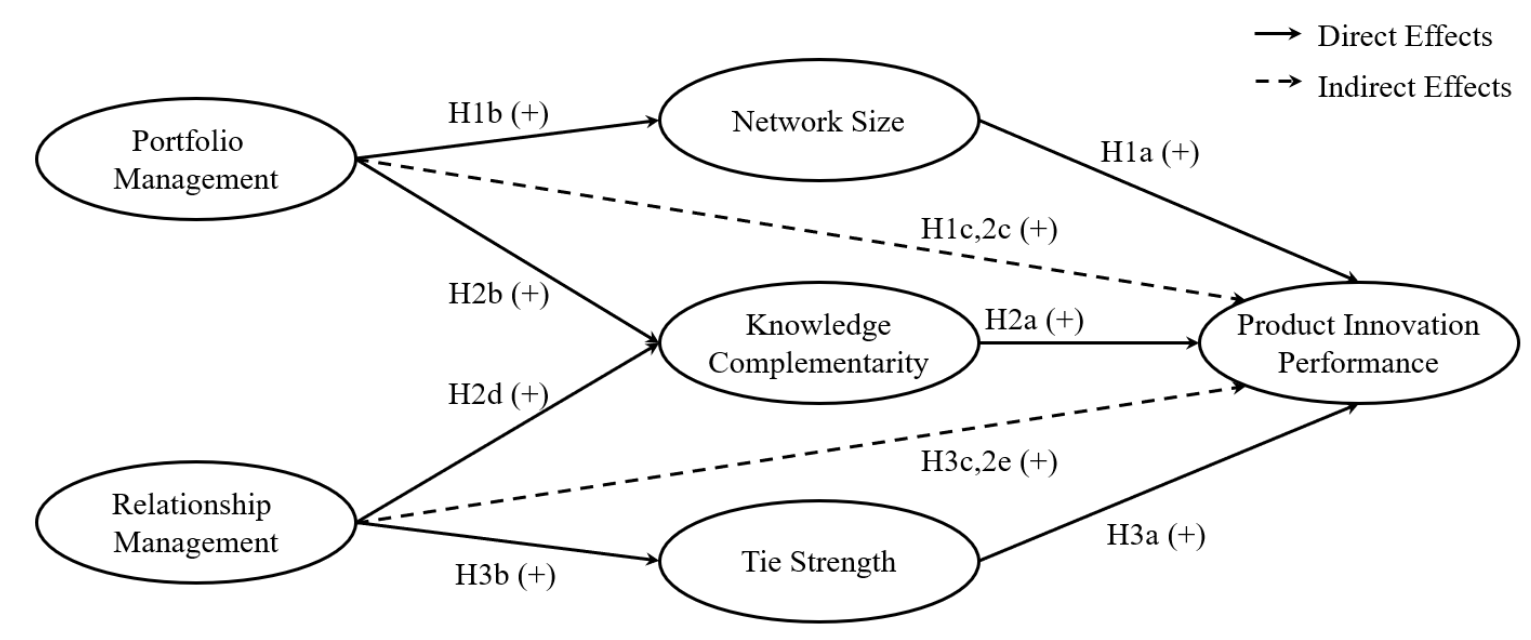

Notes: Control variables and their paths are not shown for the sake of clarity.

Figure III-2-1. Hypothesized model (own illustration)

\section{Network Management and Network Size}

A high number of ties to other cluster members is likely to increase the volume of innovationrelated knowledge resources available to a firm, the timeliness of access to these resources, and consequently product innovation performance. A large ego-network, however, may be difficult and costly to develop and maintain. We argue that the primary constraint associated with the development and maintenance of an extensive ego-network lies in the complexity and costs that increase with a growing portfolio of network ties (Duysters and Lokshin, 2011; Mariotti and Delbridge, 2012; Parise and Casher, 2003).

First, in order to extend or adjust their networks, firms need to identify potential new partners and evaluate the costs and benefits associated with the respective relationships as validly as possible (Gulati et al., 2011). However, in many cases, firms do not have an easy access to the required information or lack the means to distinguish relevant from irrelevant information (Ramos et al., 2012) and generally possess only limited cognitive ability to process this information (Duysters and Lokshin, 2011). Consequently, most firms build an inaccurate perception of the firms, knowledge resources, and relationships in their external environment (Abrahamsen et al., 2012). Interesting partner opportunities can thus be overlooked or misevaluated (Powell et al., 1996). In contrast, if a firm is able to obtain and process relevant network-related information, the likelihood of identifying a larger number of relevant partner opportunities increases. Network experiments, for instance by van Liere et al. (2008), support 
this notion by demonstrating that firms with a more profound level of information on their environment are significantly more likely to build a large and diverse network than firms lacking such information.

Moreover, the larger the ego-network, the more likely are conflicts and negative interdependencies to occur. The more ties a firm establishes, the more likely some partner firms will have contradicting interests, perceive each other as rivals, and engage in mutual adversities (Zajac and Olsen, 1993). Such conflicts and rivalries may stem from a variety of circumstances, such as competing in the same market segments, demands for exclusivity, and fears of knowledge spillover (Parise and Casher, 2003). As a result of such negative interdependencies, focal firms may need to quit several relationships but also may miss out on creating new partner opportunities because of being too caught up in attending to existing network ties (Kale and Singh, 2009). Altogether, with a growing number of ties maintenance costs for the ego-network are likely to grow, e.g. due to a need for an effective conflict management (Duysters and Lokshin, 2011; Elfring and Hulsink, 2007).

We argue that portfolio management processes at the firm level are likely to be helpful when dealing with such constraints of complexity. First, organizational routines for planning, coordinating, and monitoring the overall portfolio of knowledge sources help firms to proactively acquire information about the network environment as well as increase their capacity to process this information while avoiding information overload (Fund et al., 2008). Hence, firms engaging in portfolio management will most likely have more timely and reliable information about potential new knowledge sources and partnering opportunities than firms that do not (Sarkar et al., 2009). Second, portfolio management routines also will allow firms to better match novel knowledge sources with existing ones due to better information basis in the process of partner selection (Sarkar et al., 2001). Hence, a good fit is more likely to occur so that negative interdependencies and conflicts can be prevented in the first place. Third, firms with strong portfolio coordination capability will regularly monitor their ego-network for potential conflicts (Degener et al., 2018). Hence, these firms are more likely to anticipate emerging tensions in advance and engage in coordination activities to constructively handle differing objectives and conflicts (Hoffmann, 2007; Ireland et al., 2002). In all, the more complex the knowledge network becomes due to growing network size, the more managerial attention is required for portfolio issues (Duysters and Lokshin, 2011). Therefore, firms with more sophisticated routines and processes for portfolio management are likely to be able to develop and maintain a large size knowledge network. Summarizing the considerations made above, we thus arrive at the following set of hypotheses:

\section{Hypothesis 1a: Network size will have a positive effect on product innovation performance.}

Hypothesis 1b: Portfolio management will have a positive effect on network size.

Hypothesis 1c: Network size will mediate the positive effect of portfolio management on product innovation performance. 


\section{Network Management and Knowledge Complementarity}

In contrast to network size, developing an ego-network with a high level of knowledge complementarity entails challenges of limited availability and competition. On the one hand, firms must be quite selective when it comes to choosing knowledge sources, which includes a thorough analysis of potential partners' knowledge resources in comparison to their own knowledge base (Baum et al., 2010). On the other hand, resulting from this need for selectivity, the set of potential knowledge sources will presumably shrink to a limited number of firms (Lovas and Sorenson, 2008). In other words, partners with complementary expertise are scarce (Sarkar et al., 2009). In order to access those firms' crucial resources, a company needs to convince them to share their knowledge (Gulati et al., 1994). Thereby, it is important to gain the attention of the decision makers in potential partner firms, to present oneself as an attractive partner, and to persuade the opposite party of the possible win-win situation (Ahuja, 2000b). Still, especially if the potential partner firm has an excellent reputation for its expertise, many firms are likely to struggle to spark interest from this attractive partner and be considered as a collaboration candidate (Edvardsson et al., 2008; Jensen and Roy, 2008). Therefore, opportunities for relationships with firms that possess complementary expertise are often contested and the market for partners is highly competitive (Sarkar et al., 2001).

We argue that portfolio management can be instrumental in overcoming the availability constraint associated with the development of high complementarity ego-networks. First, a clear portfolio strategy, thorough coordination across different business relationships, and monitoring of the results and progression of business relationships are likely to lead to a more resource-driven approach when it comes to selecting potential partners and assembling the overall partner portfolio (Hoffmann, 2007). Hence, firms with sophisticated portfolio management are likely to be able to better evaluate potential new partners and their fit to the own internal resource base (Wassmer and Dussauge, 2012). Second, firms engaging in portfolio management are likely to act more proactively when it comes to developing new ties to potential knowledge sources (Sarkar et al., 2009). Especially when the number of adequate partnering opportunities is low, those firms may enjoy first-mover advantages in that they are able to initiate relations to the most preferable partners instead of the leftovers (Sarkar et al., 2001). Third, firms with effective management processes at the portfolio level should be more likely to possess a holistic overview of the portfolio and a clearer picture of the value added by each network tie (Parise and Casher, 2003). Consequently, those firms should be more likely to terminate relationships in which knowledge complementarity is low (Mitrega et al., 2012; Zaefarian et al., 2017). Thus, portfolio management is likely to lead to a higher level of knowledge complementarity in the partner network. In summary, we state the following set of hypotheses:

Hypothesis 2a: Knowledge complementarity will have a positive effect on product innovation performance.

Hypothesis 2b: Portfolio management will have a positive effect on knowledge complementarity. 
Hypothesis 2c: Knowledge complementarity will mediate the positive effect of portfolio management on product innovation performance.

Furthermore, we argue that portfolio management is not enough to ensure high levels of knowledge complementarity and suggest that relationship management processes also play an important role in achieving this objective. Because the range of options in finding partners with complementary knowledge is limited, firms cannot not rely on playing a "numbers game" as might be possible in the case of network size. Hence, attracting and establishing close relationships with those few partners is essential for ensuring knowledge complementarity within the network (Ahuja, 2000b). Thereby, Park and Ungson (2001) and Schreiner et al. (2009) argue that there are two major reasons for losing a key partner: 1) lack of cooperative motivation; and 2) insufficient management of shared action, interdependencies, and conflicts. Concerning the former, firms engaging in relationship management should be more likely to perceive the goals, needs, and values of another firm and find ways to correspond to those needs as well as to reconcile partners' needs with the own motivations and goals (Kale and Singh, 2009; Mitrega et al., 2012). Concerning the latter, firms with well-elaborated relationship management should be more able to recognize and interpret information and social stimuli in the particular relation so that potential conflicts or governance challenges will be detected early (Walter et al. 2006). On the other hand, relationship management should enable firms to better communicate those issues with the partner, so that appropriate solutions can be developed jointly (Kale et al., 2000). In all, we thus suggest that for ensuring knowledge complementarity, a firm needs effective relationship management routines to deploy relationships with particularly important knowledge sources. Consequently, we formulate the following hypotheses:

\section{Hypothesis 2d: Relationship management will have a positive effect on knowledge complementarity.}

Hypothesis 2e: Knowledge complementarity will mediate the positive effect of relationship management on product innovation performance.

\section{Network Management and Tie Strength}

The main constraint in building an ego-network with a high level of tie strength is related to the costs and difficulties that arise from developing and maintaining such strong partnerships. On the one hand, inter-firm relationships are fragile in nature. For strong ties to emerge, firms must promote increasing levels of social interaction over a longer period of time so that high levels of mutual trust as well as shared norms and procedures can be formed (Mariotti and Delbridge, 2012). During that time, various incidents and conflicts between partners can happen that may cause instant failure of the relationship (Majchrzak et al., 2015; Park and Ungson, 2001). On the other hand, strong ties entail high costs for both establishment and maintenance (Fliaster and Spiess, 2008). Firms willing to cultivate strong ties must expend effort and pay managerial attention to ensuring that their partners are motivated to contribute to the relationship and reciprocate the efforts made (Gulati et al., 2011). Particularly in situations when, for instance, the partners display an entitlement mentality (Jensen and Roy, 2008) or are quite different in their organizational mindset (Reagans and McEvily, 2003), the costs associated with a strong 
relationship can be extensive. Such relationships may thus act as a drain on organizational resources so that a firm's capacity for strong ties is ultimately constrained (Steier and Greenwood, 2000).

Effective relationship management is likely to have a positive influence on the development of an ego-network with a high level of tie strength. Routines for communication, coordination, and bonding between two partners should help overcome the constraints associated with developing and maintaining intense knowledge exchange relations. On the one hand, relationship management should allow firms to pass more smoothly through the process of strong tie development (Schreiner et al., 2009). When a firm dedicates organizational resources to attending the challenges that may arise during the relationship life cycle, engages in intense communication with partner firms, and strives to install formal and informal mechanisms for governing inter-firm relationships, it may anticipate and overcome critical incidents at a much higher probability. On the other hand, relationship management may help keeping the costs of maintaining inter-organizational relationships in check. The more a firm engages in coordination, communication, and bonding activities with external partners the more it is likely to develop effective rules, norms, and codes of conduct but also mutual trust, benevolence, and understanding (Kale and Singh, 2009). Such relational capital can lead to increased efficiency in joint operations, reduced need for coordination, minimized conflict in goal alignment, and lower need for safeguarding against partner opportunism (Dyer and Singh, 1998). Consequently, firms with sophisticated relationship management are likely to be able to maintain strong ties at lower costs so that an ego-network of high tie strength can be sustained more easily. Hence, we suggest the following hypotheses:

Hypothesis 3a: Tie strength will have a positive effect on product innovation performance.

Hypothesis 3b: Relationship management will have a positive effect on tie strength.

Hypothesis 3c: Tie strength will mediate the positive effect of relationship management on product innovation performance.

\section{METHODOLOGY}

\section{Sample and Data Collection}

We chose the German energy sector as the industrial setting of our study and focus on small and medium-sized utilities. We consider the setting to be well suited for examining our research topic. Being confronted with novel technological, market-related, and regulatory challenges, the large number of utilities in Germany are currently striving to enter new market fields and foster product innovation (Müller et al., 2008). Among others, many companies increasingly explore business opportunities in the fields of smart home, energy efficiency optimization, onsite power generation, and electromobility. In this race for innovation, most utilities possess only low resource endowment and financial slack compared to the Big Four (E.ON, Vattenfall, EnBW, RWE) which dominate the market (Kehrel and Sick, 2014). Therefore, smaller utilities 
deploy various forms of inter-firm collaboration to support their innovation endeavors (Kolloch and Reck, 2017).

The proposed hypotheses were tested based on data collected from the members of the largest German cluster network of municipal utilities. The network consists of 84 energy providers with an aggregated annual sales volume ranging between 19.8 and 23.4 billion $€$ in 2013-2015 and the total number of employees 17,100 people as of the end of 2015. Additionally, the cluster comprises an administrative unit for central network management as well as eight specialized service providers that support the cluster members in areas such as energy trade, insurance, renewable energies, smart metering, energy efficiency, and grid operation. The cluster network operates at a national level, still, most member firms are located in the southeastern parts of Germany. In a study by Raynor and Ahmed (2013) that examined the business performance of 25,000 companies over a 40-year period, this cluster network was counted among the 'Miracle Workers', i.e., organizations that consistently outperformed their industry concerning profitability.

Data collection was done in Spring 2016. Thereby, we pursued a key informant approach by using an online survey. First, we developed the questionnaire based on existing scales. We pretested the prototype on 26 senior managers from the energy industry, clarified ambiguous terms, and discussed the scales in detail to ensure face validity. Second, we obtained contact information for key informants in three ways: 1) provision of a list of c-level executives' e-mail addresses by the central network coordination unit; 2) provision of a list of innovation managers' e-mail addresses by the coordinator of a network-wide innovation circle; and 3) telephoning the member organizations to ask for the managers responsible for innovation and inter-organizational relations. Third, we sent the survey link to the identified key informants followed by a reminder at the end of the first half of the survey period. Throughout the whole process, our study was actively promoted by the senior and c-level management of the network coordination unit, as well as by several senior, innovation, and c-level managers from individual member firms.

In all, we obtained 157 completed questionnaires, of which nine were excluded owing to considerable missing data or unidentifiable respondent affiliation, resulting in 148 usable questionnaires. Data was received from 74 member organizations, resulting in a response rate of 88.1 percent on the company level. This value is comparable to other bounded-network studies in the context of organizational research (Costenbader and Valente, 2003). We controlled for non-respondent bias by comparing several observable characteristics of respondents and non-respondents. There were no significant differences in any of them (firm size: $t=1.15, p>.25$; tenure of association membership: $t=0.69, p>.49$; market diversification: $t=0.87, p>.38$; investment-to-sales ratio: $t=1.44, p>.15$; for the exact calculation of these observable indicators, see the later section on control variables). Hence, we are confident that non-response bias does not present a major issue in this study.

\section{Research Variables and Construct Measurement}

For all non-network variables, we collected data based on item scales with seven-point Likert ratings $(1=$ "completely disagree" to $7=$ "completely agree"). The outcome variable product 
innovation performance was measured by three items that asked respondents to rate their firm's product innovation achievements in relation to competitors in the own industry (Yli-Renko et al., 2001). Especially in industries lacking rich patent data or in case of the reluctance of firms to provide objective financial data, it is common and appropriate to rely on managers' evaluations (Zhang and $\mathrm{Li}, 2010$ ). In order to validate the approach, we triangulated our measure by two observable indicators of firms' product innovation performance. First, we analyzed publications in the cluster network's quarterly newsletter between 2014 and 2016 in which firms reported on their product innovation activity and counted the number of product innovation reports for each firm. Correlations with our rating measure were found to be highly significant $(r=.42 ; p<.001)$. Second, we manually scanned the nominees and winners of six major industry-specific innovation awards and four major national innovation awards in Germany between 2014 and 2016. We counted the number of awards and nominations earned by that firm to calculate an index for innovation performance. The correlation with the Likertscale ratings was significant $(r=.23 ; p<.05)$. Thus, we are confident in the validity of our measurement approach for product innovation performance.

Our independent variables portfolio management and relationship management are based on the scales developed by Sarkar et al. (2009) and Schreiner et al. (2009), respectively. In order not to overburden respondents, especially as the network questionnaire is time-consuming, we consolidated the single first-order constructs of their scales, compared them with similar scales in the literature (Schilke and Goerzen, 2010; Kale et al., 2000; Ritter and Gemünden, 2003), and derived six-item measures that indicate firm-level processes for both portfolio management and relationship management.

To depict the intra-cluster knowledge network as well as each firm's ego-network, we applied a sociometric approach (Wasserman and Faust, 1994). In this approach, we used the following name generator question (Borgatti et al., 2013):

From the list below, please select the firms from which your company received knowledge relevant for innovation activity within the last three years. This knowledge receipt may stem from formal exchange during joint $R \& D$ projects, discussions in innovation circles, or informal exchange on the personal level, among others. Feel free to include as many firms as you consider to be relevant knowledge sources.

As a result, we obtained an asymmetric, directed network among the sample organizations. The mean number of indicated ties was 7.5 (standard deviation $=5.7$, minimum $=0$, maximum $=$ 23). In the next step, we asked respondents to indicate the intensity of knowledge exchange associated with the given tie. We created four items to be ranked on a scale from 1 (no exchange) to 7 (highly intensive exchange) in four distinct dimensions comprising technological, market, managerial, and regulatory knowledge.

Network size was measured via Burt's (1992) effective size. As effective size weights ties based on their level of redundancy, it provides a more accurate picture of the volume of knowledge resources that can be accessed through the ego-network (Borgatti et al., 2013; Burt, 1992). We calculated effective size via Burt's (1992) formula for binary data: 


$$
E S_{i}=n-\frac{1}{n} \sum_{j} \sum_{q} m_{j q} q \neq i, j
$$

In the formula, $n$ represents the number of $i$ 's ties while $m_{j q}$ indicates 1 if alter $j$ possesses a tie to $i$ 's alter $q$ and 0 otherwise. The formula calculates $i$ 's degree centrality less the sum of shares of redundant ties (Borgatti et al., 2013). Thus, it captures the aspect that, particularly for innovation, non-redundant ties bear a higher value than redundant ones (Burt, 1992), making effective size an appropriate operationalization of knowledge reach.

In order to operationalize knowledge complementarity, we asked each respondent to rate his or her firm's intellectual capital (Nahapiet and Ghoshal, 1998) across four dimensions: technological knowledge, market knowledge, managerial knowledge, and regulatory knowledge. While the former three have been found in past studies to be important for product innovation (e.g. Sammarra and Biggiero, 2008), the latter knowledge category was added due to the particular importance of regulatory issues for innovation in the energy industry (Beerepot and Beerepot, 2007). Following Subramaniam and Youndt's (2005) conceptualization of intellectual capital as a multidimensional construct, we measured each knowledge dimension with one item displaying human capital and one displaying organizational capital. The knowledge base complementarity between recipient and source was measured by calculating the Pearson correlation coefficient on the intellectual capital profile between both firms (Gilsing et al., 2008). The resulting value can range from -1 to +1 , with the former indicating perfect complementarity and the latter indicating perfect similarity between the recipient's and the source's knowledge profiles. For the sake of presentation clarity, we reversed this scale and calculated the average value across all of the knowledge acquisition ties of the focal firm.

For the operationalization of tie strength (Granovetter, 1973), we calculated the average intensity of a firm's indicated ties (McEvily and Zaheer, 1999) across the four knowledge exchange dimensions. This measure of intensity captures the time commitment and the resource commitment (in terms of the exchanged knowledge) that a firm makes in the given dyadic relationship (Capaldo, 2007).

Several control variables were included into our research model. First, a firm's internal knowledge base, that is, its intellectual capital, is likely to at least partially predict product innovation performance (e.g. Nahapiet and Ghoshal, 1998; Subramaniam and Youndt, 2005). Hence, besides using the four dimensions of intellectual capital to determine knowledge complementarity on the dyadic inter-organizational level, we used them as control variables at the organizational level. Second, an organization's size may lead to resource slack supporting product innovation. We thus include the log of the number of full-time employees as a control variable in the analysis. Third and finally, the general strategic orientations of a firm, such as diversification and expansion, may affect its propensity for innovation. We measured diversification by calculating Blau's Index (Blau, 1977) for the firms' sales across the market sectors of electricity, gas, and heat, which are particularly important for energy companies. Expansion was measured as the mean investment-to-sales ratio of each firm over the last three years. 


\section{Adequacy of Measurement}

Although the inclusion of network measures should reduce the impact of common method bias on our results, we utilized both procedural as well as statistical remedies to prevent variance resulting from the single instrument data collection (Podsakoff et al., 2003). First, procedural steps included ensuring respondent anonymity and reducing evaluation apprehension. Second, we conducted Harman's one-factor test, which subjects all study items to a principal component factor analysis. The unrotated factor solution resulted in six factors explaining 69.6 percent of the variance ( 30.9 percent was the largest variance explained by one factor). Thus, we are confident that common method bias is unlikely to be a problem.

For 62 out of 74 firms, we received data from more than one respondent. Notwithstanding the informational benefits, utilizing multiple key informants, however, might also entail some issues. First, there might be a selection problem resulting in varying degrees of informant knowledge on the topic of investigation. While we are confident that our approach to identify key informants ensures high levels of expertise, different functional backgrounds and hierarchical positions may yield different perspectives, which could result in a systematic informant bias (Kumar et al., 1993). We therefore conducted $t$-tests for mean equality among the two groups of respondents: c-level managers and innovation managers. The values of the variables in our study did not differ significantly among the two groups, indicating that there was no systematic difference in c-level managers' and innovation managers' assessments. As a consequence, we did not exclude the cases with only one respondent per firm from the further analysis.

Furthermore, there is a potential issue of disagreement between informants (Kumar et al., 1993). We followed the approach used by Schilke and Goerzen (2010) to assess inter-rater reliability by calculating the percentage of item ratings in which a pair of respondents differs by one point or less on the seven-point Likert-scale (90.8 percent of ratings). Additionally, we calculated the Pearson correlation across all items for each pair of respondents. The mean correlation across these pairs was .62 and for the majority of pairs the correlation was significant at $p<.01$. However, for the relational data this approach cannot be applied. In order to assess inter-rater reliability for the relational measures, we computed the mean percentage agreement following Tsai and Ghoshal (1998). We divided the number of ties assigned by the respondents from the same firm by the number of all ties that were reported for the particular firm. The average mean agreement was 73.1 percent in our study - a value that is well acceptable. For the Likert scale ratings on ties and partner firms, inter-rater reliability was 76.9 percent (calculated as described above, see Schilke and Goerzen (2010)), average correlation between respondents from the same firm was .55. The high degree of agreement strengthens our confidence in the inter-rater reliability in our sample. Hence, we use averaged informants' data for network and item measures in the further analysis.

\section{RESULTS}

We tested the hypotheses by structural equation modeling (SEM). Among the two most common SEM approaches - covariance-based SEM (CB-SEM) and partial-least-squares SEM (PLS-SEM) - we chose PLS based on three reasons (Hair et al., 2012). First, PLS places 
minimal restrictions on measurement scales and distribution of residuals, which will be advantageous owing to scale differences between network and Likert-scale variables. Second, PLS results are robust for a medium sample size of between 50 and 100 observations. Third, for the examination of new theoretical models encompassing previously untested hypotheses, PLS is more suited as it rather underestimates model paths (Reinartz et al., 2009). In the analysis procedure, we applied SmartPLS 3.2.3 (Ringle et al., 2015). We ran the non-parametric bootstrapping method to examine 5,000 subsamples with the original number of cases and accepted sign changes.

\section{Validity of the Measurement Model}

To test for internal consistency and convergent and discriminant validity, we conducted PLS model estimation in SmartPLS 3.2.3. Our measurement model clearly fulfills all three criteria. Concerning internal consistency, all Cronbach's $\alpha$, composite reliability, and Jöreskog $\rho_{c}$ are well above the required thresholds (Tables 1 and 2). Concerning convergent validity, all factor loadings are significant $(p<.001)$ and above the threshold of .707 (Hulland, 1999) respectively .60 (Bagozzi and Yi, 1988). Furthermore, average variance extracted (AVE) estimates range between .61 and .89 , exceeding the common standard of .50 (Bagozzi and Yi, 1988). Concerning discriminant validity, the criterion established by Fornell and Larckner (1981) is fulfilled as the AVE of each latent variable is greater than the squared correlation between the concerned and the other constructs (Table 3). 
Table III-2-1. Construct specifications and item loadings

\begin{tabular}{|c|c|c|c|c|}
\hline & Item & Load & Mean & SD \\
\hline \multirow{3}{*}{$\begin{array}{l}\text { Product Innovation } \\
\text { Performance } \\
\left(\alpha=.77, C R=.87, \rho_{c}=.77\right)\end{array}$} & We develop and introduce new product/service offerings in the market. & .852 & 4.27 & 1.39 \\
\hline & We regularly improve existing product/service bundles. & .817 & 4.36 & 1.36 \\
\hline & Our product/service offering is based on novel technologies. & .817 & 4.17 & 1.34 \\
\hline \multirow{7}{*}{$\begin{array}{l}\text { Portfolio Management } \\
\left(\alpha=.87, C R=.90, \rho_{c}=.88\right)\end{array}$} & We actively search for new potential knowledge exchange partners. & .742 & 4.27 & 1.33 \\
\hline & $\begin{array}{l}\text { We evaluate interdependencies, conflicts, and synergies between our partners to coordinate our relationship } \\
\text { portfolio holistically. }\end{array}$ & .805 & 3.62 & 1.50 \\
\hline & We develop goals for modifying and using our network based on our company's business strategy. & .787 & 4.06 & 1.32 \\
\hline & We evaluate our benefit from the network portfolio to derive action plans for its modification. & .802 & 3.84 & 1.27 \\
\hline & We observe, document, and assess the development of our industry environment, our network and the & .769 & 3.70 & 1.39 \\
\hline & networks of our partners. & .782 & 4.31 & 1.26 \\
\hline & We present ourself as attractive partners by publishing success stories and referrals. & & & \\
\hline \multirow{6}{*}{$\begin{array}{l}\text { Relationship Management } \\
\left(\alpha=.88, C R=.91, \rho_{c}=.89\right)\end{array}$} & We communicate intensively with our partners to keep each other informed about the current situation and & .821 & 4.58 & 1.16 \\
\hline & In the case of $\mathrm{cc}$ & .812 & 4.41 & 1.15 \\
\hline & mutually. & .809 & 3.97 & 1.27 \\
\hline & We bring together key persons of both organizations, e.g. via social events. & .847 & 3.90 & 1.31 \\
\hline & $\begin{array}{l}\text { We regularly monitor the state and development of our relationships concerning goals, resources, and } \\
\text { potentials of our partners. }\end{array}$ & 673 & 4.29 & 1.37 \\
\hline & $\begin{array}{l}\text { We assign internal responsibles with corresponding competencies to each exchange relation. } \\
\text { We conjointly develop and act on firm-spanning processes and standards of collaboration. }\end{array}$ & .781 & 3.90 & 1.25 \\
\hline
\end{tabular}

Notes: $\alpha=$ Cronbach's $\alpha$; $C R=$ composite reliability; $\rho_{c}=$ Jöreskog‘s $\rho$; $\mathrm{SD}=$ standard deviation. 
Table III-2-2. Construct specifications and item loadings (continued)

\begin{tabular}{|c|c|c|c|c|}
\hline & Item & Load & Mean & SD \\
\hline \multirow{2}{*}{$\begin{array}{l}\text { Intellectual Capital } \\
\text { Technological } \\
\left(\alpha=.88, C R=.94, \rho_{c}=.88\right)\end{array}$} & $\begin{array}{l}\text { Concerning technologies and scientific insights, our employees possess superior knowledge and skills } \\
\text { compared to the rest of our industry. }\end{array}$ & .949 & 4.61 & 1.02 \\
\hline & Our technological knowledge is reflected by internal standards, procedures, and intellectual property. & .942 & 4.35 & 1.05 \\
\hline \multirow{2}{*}{$\begin{array}{l}\text { Intellectual Capital } \\
\text { Market } \\
\left(\alpha=.78, C R=.90, \rho_{c}=.87\right)\end{array}$} & $\begin{array}{l}\text { Our employees possess a high degree of knowledge about customers, understand their preferences and } \\
\text { needs, and develop ideas to satisfy those needs. }\end{array}$ & .941 & 4.66 & 1.07 \\
\hline & We possess a sophisticated repertoire of methods to gain a better in-depth understanding of our customers. & .869 & 4.30 & 1.06 \\
\hline \multirow{2}{*}{$\begin{array}{l}\text { Intellectual Capital } \\
\text { Managerial } \\
\left(\alpha=.80, C R=.91, \rho_{c}=.94\right)\end{array}$} & Our management personnel has profound knowledge on leadership, operative, and strategic management. & .867 & 4.17 & 1.09 \\
\hline & $\begin{array}{l}\text { We have guidelines for management and leadership culture which may be both implicit (e.g. success } \\
\text { stories, "unwritten laws") or explicit (e.g. rules, leadership development programs). }\end{array}$ & .952 & 4.42 & 1.21 \\
\hline \multirow{2}{*}{$\begin{array}{l}\text { Intellectual Capital } \\
\text { Regulatory } \\
\left(\alpha=.84, C R=.93, \rho_{c}=.84\right)\end{array}$} & Our employees are up to speed concerning legal issues, regulation, and political developments. & .929 & 4.72 & 1.08 \\
\hline & $\begin{array}{l}\text { We have systematic methods to interprete our regulatory environment and improve those methods } \\
\text { continuously. }\end{array}$ & .928 & 4.43 & 1.07 \\
\hline
\end{tabular}

Notes: $\alpha=$ Cronbach's $\alpha ; C R=$ composite reliability; $\rho_{c}=$ Jöreskog‘s $\rho$; $\mathrm{SD}=$ standard deviation. 
Table III-2-3. Convergent and discriminant validity

\begin{tabular}{|c|c|c|c|c|c|c|c|c|c|c|c|c|c|}
\hline Variable & 1 & 2 & 3 & 4 & 5 & 6 & 7 & 8 & 9 & 10 & 11 & 12 & 13 \\
\hline 1. Product Innovation Performance & .69 & & & & & & & & & & & & \\
\hline 2. Portfolio Management & .21 & .61 & & & & & & & & & & & \\
\hline 3. Relationship Management & .02 & .11 & .63 & & & & & & & & & & \\
\hline 4. Network Size & .25 & .26 & .01 & 1.00 & & & & & & & & & \\
\hline 5. Knowledge Complementarity & .17 & .14 & .17 & .02 & 1.00 & & & & & & & & \\
\hline 6. Tie Strength & .00 & .01 & .19 & .05 & .07 & 1.00 & & & & & & & \\
\hline 7. Intellectual Capital Technological & .08 & .04 & .07 & .02 & .03 & .01 & .89 & & & & & & \\
\hline 8. Intellectual Capital Market & .15 & .01 & .04 & .01 & .02 & .01 & .08 & .82 & & & & & \\
\hline 9. Intellectual Capital Managerial & .03 & .02 & .01 & .06 & .06 & .00 & .08 & .09 & .83 & & & & \\
\hline 10. Intellectual Capital Regulatory & .14 & .09 & .05 & .01 & .10 & .06 & .12 & .10 & .30 & .86 & & & \\
\hline 11. Firm Size $(\log )$ & .04 & .02 & .00 & .09 & .00 & .02 & .12 & .03 & .10 & .13 & 1.00 & & \\
\hline 12. Diversification & .00 & .00 & .01 & .01 & .01 & .01 & .00 & .02 & .00 & .08 & .03 & 1.00 & \\
\hline 13. Expansion & .01 & .01 & .01 & .00 & .03 & .00 & .01 & .00 & .02 & .01 & .01 & .05 & 1.00 \\
\hline
\end{tabular}

Notes: Bold numbers on the diagonal display the average variance extracted (AVE); numbers below the diagonal display the squared correlations. 


\section{Hypothesis Tests}

Table 4 summarizes the PLS results, whereby Model 0 only includes the control variables, Model 1 is the direct effects model further including the network management variables, and Model 2 represents the hypothesized theoretical model, including the mediation effects between network management and network properties. Over the three models, both predictive accuracy $\left(\mathrm{R}^{2}\right)$ and predictive relevance (Stone-Geisser's $\mathrm{Q}^{2}$ ) increase continuously and significantly. This indicates a higher predictive power of Model 2 compared to the others. The standardized root mean square residual (SRMR) of Model 2 was .72 which indicates sufficient model fit (upper threshold at .80) (Henseler et al., 2016). Hence, the mediation model proposed provides an adequate depiction of variance in the dataset.

To test the research hypotheses, we followed most recent guidelines for determining the significance of direct (Henseler et al., 2016) and mediation effects (Nitzl et al., 2016). The hypothesized effects are largely evident in the structural model. Out of the three network properties, network size (path coefficient $=.400 ; p<.001$; bias-corrected 95\% confidence interval (CI95\%): .223 - .597) and knowledge complementarity (path coefficient $=.303 ; p=$ .006 ; C195\%: .082 - .512) both have a significant positive effect on product innovation performance, whereas the effect of tie strength is positive but insignificant. The $f^{2}$-values are .201 (network size) and .147 (knowledge complementarity), indicating moderate effect size (Cohen, 1988). Hence, H1a and $\mathrm{H} 2 \mathrm{a}$ are supported, while $\mathrm{H} 3 \mathrm{a}$ is rejected. Concerning $\mathrm{H} 1 \mathrm{~b}$ and $\mathrm{H} 2 \mathrm{~b}$, portfolio management influences both network size (path coefficient $=.547 ; p<.001$; CI95\%: .354 - .724) and knowledge complementarity ( path coefficient $=.263 ; p=.008 ;$ CI95\%: $.070-.458$ ) positively and significantly, while having no effect on tie strength. The $f^{2}$-value for the effect on network size is .364 (strong effect), for the effect on knowledge complementarity it is .080 (weak effect). Concerning $\mathrm{H} 2 \mathrm{~d}$ and $\mathrm{H} 3 \mathrm{~b}$, relationship management influences both knowledge complementarity (path coefficient $=.328 ; p=.001 ;$ C195\%: .120 - .491) and tie strength (path coefficient $=.476 ; p<.001 ; C 195 \%: .237-.633$ ) positively and significantly but does not affect network size. Here, $f^{2}$-values are .124 (weak effect on knowledge complementarity) and .253 (moderate effect on tie strength). Thus, all proposed hypotheses on the effects of network management on knowledge network characteristics are supported.

Concerning the mediation effects, $\mathrm{H} 1 \mathrm{c}$ and $\mathrm{H} 2 \mathrm{c}$ suggest that network size respectively knowledge complementarity mediate the effect of portfolio capability on product innovation performance. Both the mediation effect over network size (specific indirect effect $=.219 ; p=$ .004 ; CI95\%: $.090-.411$; variance accountant for $(V A F)=0.640)$ and over knowledge complementarity (specific indirect effect $=.080 ; p=.078 ; C 195 \%: .013-.191 ; V A F=0.394$ ) are significant, though for the latter only at a level of $\mathrm{p}<.10$. Taken together, both mediation paths account for $71.4 \%$ of the total effect of portfolio management on product innovation performance. Hence, both $\mathrm{H} 1 \mathrm{c}$ and $\mathrm{H} 2 \mathrm{c}$ are supported. $\mathrm{H} 2 \mathrm{e}$ and $\mathrm{H} 3 \mathrm{c}$ suggest that the knowledge complementarity respectively tie strength mediate the effect of relationship capability on product innovation performance. The mediation path over knowledge complementarity is significant (specific indirect effect $=.099 ; p=.048 ; C 195 \%: .019-.227 ; V A F=-1.193$ ). As the direct effect of relationship management on product innovation performance is negative (though insignificant) whereas the indirect effect including knowledge complementarity is 
positive, the results indicate an instance of competitive partial meditation in which the direct and indirect effect of an independent variable conflict each other (MacKinnon et al., 2007; Nitzl et al., 2016). Hence, though by itself relationship management has no or even a negative effect on product innovation performance, still, it also explains higher levels of firms' innovativeness due to the positive effect on knowledge complementarity. Nevertheless, H2e is supported. Finally, the mediation path from relationship management over tie strength is insignificant. Hence, $\mathrm{H} 3 \mathrm{c}$ is rejected. 
III. Publications in Focus Area II: Networks and External Partners

Table III-2-4. PLS-SEM results

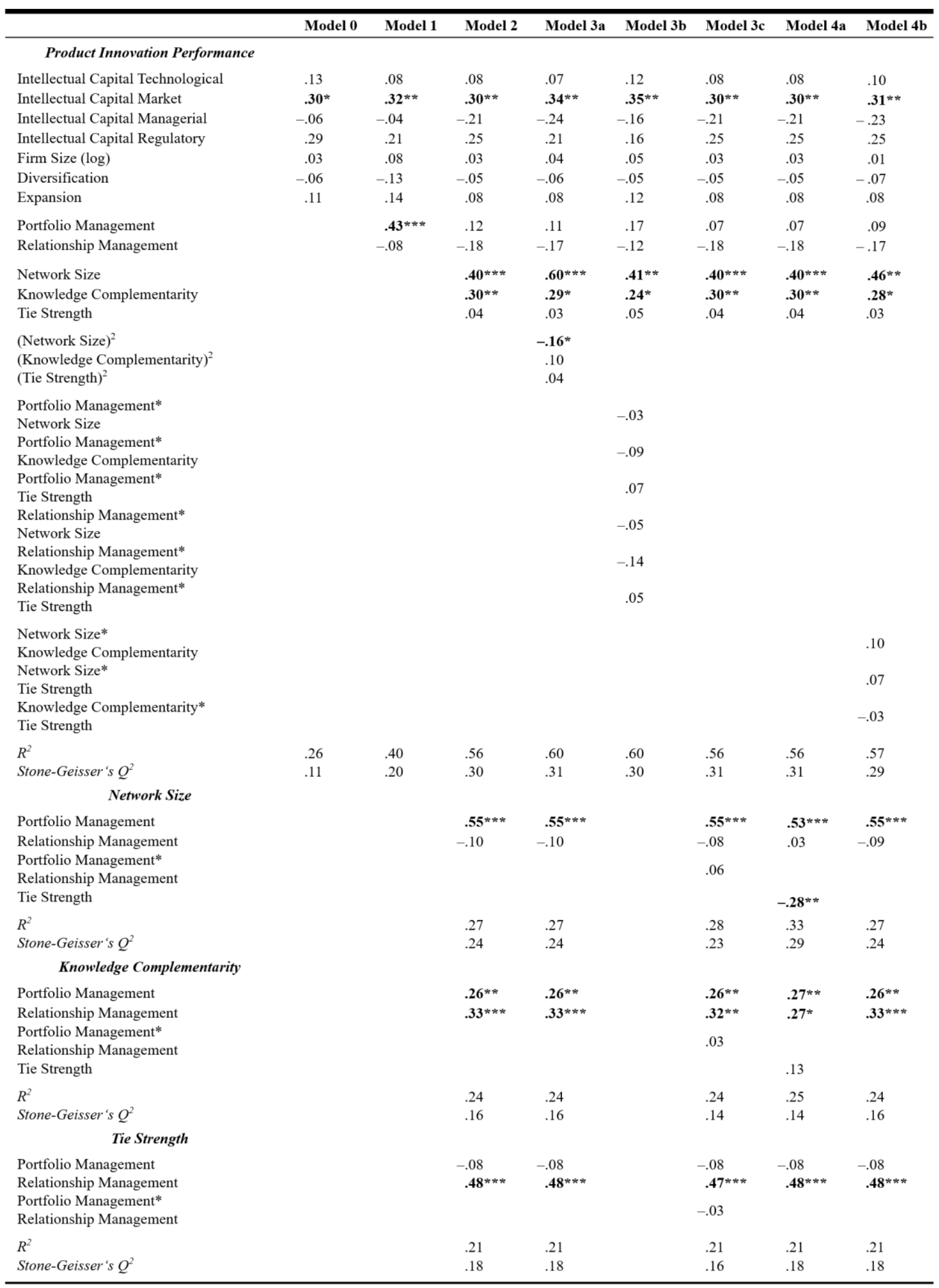

Notes: $\quad * * * \mathrm{p}<.001 * * \mathrm{p}<.01 \quad * \mathrm{p}<.05$ 


\section{Alternative and Additional Models}

In order to solidify the validity of our theory, we further tested three other models representing alternative explanations on how knowledge network properties and network management capabilities might improve product innovation performance. Thereby, Model $3 a$ includes squared term effects of the three network properties. The results of Model $3 a$ indicate that the relation between network size and product innovation performance might be better explained by an inversed U-shaped effect than by a linear one. This insight is consistent with other works that argue that above a certain size, a large network may become too complex to handle while simultaneously, the marginal value added by further ties continuously decreases (e.g. Dong et al., 2017; Rothaermel and Deeds, 2006). Model $3 b$ tests for moderation effects between network management and knowledge network properties, and Model $3 c$ assumes interaction effects of portfolio management and relationship management on the three network characteristics. We found that neither are the included paths in Model $3 b$ and Model $3 c$ significant nor do these models yield a significant increase in predictive accuracy or predictive relevance. Therefore, the mediation model that has been theoretically derived above is adequately valid.

Furthermore, we also examined two additional models in an explorative attempt to investigate whether there are interdependencies or interactions between the knowledge network properties, as noted by several previous works (e.g. Capaldo, 2007; Gulati et al., 2011). In Model 4a, we test the notion that strong ties may be source of inertia that may cause firms to stick with old partners instead of identifying and acquiring new, potentially more valuable, collaborators. Indeed, there is a negative significant effect of tie strength on network size while for knowledge complementarity the effect is positive but insignificant. Following Gulati et al.'s (2011) notion of strong inter-organizational ties as an enabler of the benefits of knowledge reach and access to complementary expertise, we modeled the corresponding interaction effects in Model $4 b$. We found that none of the three interaction effects on product innovation performance were significant.

\section{DISCUSSION AND CONCLUSIONS}

\section{Theoretical Implications}

The objective of this study was to examine if and how the composition of firms' knowledge networks and firm-level network management capabilities explain differences in innovation performance between members of an industry cluster network. Our analysis has revealed several important insights. First, the PLS-SEM results confirm the theoretically driven assumption that the positive effect of network management on innovation performance is mediated by beneficial knowledge network properties. Second, our study revealed different effects of network management processes on the relationship, that is, dyadic and the network portfolio level. Portfolio management enables firms to increase their network size and knowledge complementarity, but not the strength of ties in their ego-network. On the contrary, relationship management helps in achieving partners' complementarity and strengthening interorganizational ties, but not in increasing the network size. Third, both network size and knowledge complementarity have been found to explain variance in product innovation performance between cluster firms. Finally (and contrary to our hypotheses), our study revealed 
that at least in a cluster network, high levels of tie strength in the knowledge network do not explain differences in product innovation performance.

However, the results of the empirical analysis contradict our theoretical assumptions concerning the relational dimension of inter-organizational knowledge networks. On the one hand, there was no significant evidence for a positive effect of tie strength on product innovation performance. On the other hand, all analysis models indicated a negative direct effect (though not significant) and a competitive mediation effect of relationship management on product innovation performance. It thus seems as if investing effort in the intensification of knowledge exchange relationships in the cluster network is futile, unless it helps bind partner firms with complementary knowledge. There might be several plausible explanations for these results. First, in the context of a cluster network, the network-theoretic assumption that a strong interfirm bond is necessary for companies to be receptive to transfer knowledge and learn from each other (e.g. Gulati et al., 2011; McEvily and Marcus, 2005; Rowley et a., 2000; Tiwana, 2008) might not hold true. Instead the firms' embeddedness in the cluster environment might provide a social infrastructure in the form of common goals, sense of identity, codes of conduct, or thought frames (Arikan, 2009; Dai et al., 2018; Dhanaraj and Parkhe, 2006) that is able to substitute for the receptivity benefits provided by close collaboration on the dyadic level. Second, by conceptualizing and operationalizing the variable tie strength as the average value across the overall network, we might have neglected effects stemming from an ego-network's composition concerning strong and weak ties. For instance, firms with dual network architectures, as considered beneficial by Capaldo (2007), might enhance their knowledge receptivity and product innovation performance via a small number of strong ties while only having a low average level of tie strength owing to numerous weak ties.

In summary, the obtained results provide several important contributions to the literature. First, our study contributes to research on industry clusters by shedding light on the issue of performance differentials between cluster firms. A prominent stream of previous research explained such differences based on the size, content, and strength of member firms' egonetworks (e.g. Boschma and Ter Wal, 2007; McCann and Folta, 2011; Owen-Smith and Powell, 2004; Singh, 2005; Zhang and Li, 2010; Zaheer and Bell, 2005), but remained inconclusive concerning the question of what determines if a cluster firm possesses network with beneficial characteristics or not (Phelps et al., 2012; Rowley and Baum, 2008; Salancik, 1995). In order to advance research on this issue, our study builds a conceptual and empirical bridge between two perspectives on the drivers of innovation performance: 1) the network theoretical approach, which highlights superior access to external knowledge sources via networks as an important innovation-enhancing mechanism, and 2) the capability-oriented perspective, which explains differences in innovative performance by the existence of specific firm-level activities that govern inter-organizational collaboration and knowledge transfer. Our findings contribute to the integration of both viewpoints by demonstrating that the effect of network management capabilities on product innovation performance in a cluster environment is mediated rather than direct. Though it is not mainly the management processes themselves that lead to product innovation, these processes are still of high importance as they help firms develop and maintain knowledge networks with beneficial, i.e., innovation-friendly attributes. In doing so, we 
overcome the issue of treating firm-internal and network-level factors as separate realms of enquiry (McCann and Folta, 2011). Rather, our study demonstrates how internal capabilities explain differences in firms' ability to obtain a network of knowledge sources in a cluster environment that is conducive to their ability to develop and commercialize novel products.

Second, our study has advanced the strategic management and organizational capability literature by analyzing and testing distinct effects of network management at both the dyadic level and the entire portfolio level. From the theoretical perspective, we argued that the different effects of these capabilities result from the different constraints associated with specific egonetwork characteristics. These theoretical arguments have been supported empirically. Furthermore, our findings show that both capabilities are complementary in terms of their independent influence on different ego-network characteristics. The additive effect on knowledge complementarity is particularly interesting. It implies that both capabilities independently increase a firm's likelihood for developing a high complementarity network. Hence, there are three ways in which firms can create a portfolio of knowledge sources with a high level of complementarity: either because they excel at identifying, evaluating, and selecting potential knowledge sources (widening the space of partnering opportunities) or because they are proficient in motivating and establish strong partnerships with the most valuable knowledge sources (increasing the share of realized opportunities); the third way is a combination of both options.

Third and finally, this study contributes to strategic network literature (e.g. Hoffmann, 2007; Madhavan et al., 2008; Ozcan and Eisenhardt, 2009; Rowley and Baum, 2008). We provide important empirical evidence that firm-level management processes and routines indeed enable firms to at least partially influence key properties of their ego-networks. Hence, our results support the recent criticism in management literature that challenges the structuralist assumption of networks as exogeneous externalities that influence firm-level outcomes and outlines the influence of firms' network action and their ability to exert such action (Gulati and Srivastava, 2014; Madhavan et al., 2008; Phelps et al., 2012; Stuart and Sorenson, 2007). Moreover, by discussing the constraints associated with three different types of knowledge network properties representing the structural, compositional, and relational dimension of firmlevel ego-networks, we extend literature as we establish a more fine-grained and differentiated perspective on strategic network development than previous works. Particularly, our theoretical reasoning specifies the distinct challenges that firms need to overcome for the achieving size, knowledge complementarity, and tie strength in their ego-network while our empirical results substantiate these considerations. Hence, our study helps understand how networks of different properties can be developed and what it takes from a firm's perspective to do so.

\section{Practical Implications}

Our analysis of the specific effects of network management processes and their transmission mechanisms provides valuable insights on how firms could improve their product performance by developing their knowledge networks. Our data show that 1) knowledge networks within a cluster bear the potential for fostering innovation performance and 2) specific management activities help firms in obtaining and maintaining innovation-enhancing network 
configurations. Thereby, firms may take different approaches to develop beneficial egonetwork characteristics. On the one hand, firms could seek to assemble a large network of knowledge providers; on the other hand, a more focused approach (a smaller number of partners but with high complementarity of knowledge) may likewise foster product innovation performance. Irrespective of the strategic approach taken, firms should put in place processes for developing, coordinating, and monitoring their overall ego-network on the portfolio level. Not seeing the wood for the trees, that is, becoming entangled in managing discrete dyadic relationships while losing sight of the whole pattern can bear significant costs and risks. As portfolio management processes are an important safeguard for preventing this from happening, they are essential for securing innovation benefits from firms' intra-cluster ego-networks. In all, our results thus imply that instead of mere membership in a cluster network, proactivity in intra-cluster network development is likely to sift chaff from the wheat with regard to innovative performance. Hence, managers should dedicate adequate attention to issues related to the firm's partnerships within a cluster network, and, most importantly, strive to systematically develop and extend internal management capabilities related to this issue.

\section{Limitations and Further Research}

Notwithstanding our measures to ensure this study's validity, our work has several limitations, which provide promising avenues for further research. First, networks are dynamic, not static, constructs. By utilizing a cross-sectional design, we were only able to analyze our research setting at one point of inflection. This procedure bears two shortcomings. On the one hand, we have no indications about the lifecycles and change rates of networks and ties. Hence, we had to assume that the same constraints apply for maintaining networks and developing networks, and the same capabilities are necessary. This assumption is quite simplistic and should be challenged in future research. Furthermore, there might be a problem of reversed causality: Specific ego-network characteristics might provide firms with valuable networking experiences, which may then yield organizational learning processes and contribute to the development of network management capabilities (e.g. Heimeriks and Duysters, 2007). While we are confident in our theoretical logic, we cannot fully exclude the possibility of reversed causality in this case. Consequently, we suggest that future studies should conduct longitudinal analyses on this research topic.

Moreover, future research could further specify our approach by including other variables or differentiate some constructs in more detail. For example, we did not differentiate between different types of innovation tasks and activities, such as exploration and exploitation (March, 1991). Furthermore, our study only addressed product innovation and thus has not considered other important forms of innovation, such as business model innovation. Additionally, while we focused on knowledge transfer ties in cluster networks, other types of inter-firm relations might be influenced by network management processes. We will leave the analysis of these multiplex relations for future research. Finally, we argue that the generalizability of our results could be increased by future research examining different types of collaborative organizational settings in different industries. In sum, we believe we have made a valuable contribution to research on industry clusters, network management, knowledge networks, and innovation by 
III. Publications in Focus Area II: Networks and External Partners

gaining a better understanding of the mechanisms through which key organizational capabilities help companies to become more effective network actors and thus more successful innovators. 


\subsection{References}

Abrahamsen, M.H., Henneberg, S.C., and Naudé, P. (2012). 'Using actors' perceptions of network roles and positions to understand network dynamics'. Industrial Marketing Management, 41, 259-69.

Ahuja, G. (2000a). 'Collaboration networks, structural holes, and innovation: A longitudinal study'. Administrative Science Quarterly, 45, 425-55.

Ahuja, G. (2000b). 'The duality of collaboration: Inducements and opportunities in the formation of interfirm linkages'. Strategic Management Journal, 21, 317-43.

Alberti, F.G., and Pizzurno, E. (2015). 'Knowledge exchanges in innovation networks: evidences from an Italian aerospace cluster'. Competitiveness Review, 25, 258-87.

Anand, B.N., and Khanna, T. (2000). 'Do firms learn to create value? The case of alliances'. Strategic Management Journal, 21, 295-315.

Arikan, A.T. (2009). 'Interfirm knowledge exchanges and the knowledge creation capability of clusters.' Academy of Management Review, 34, 658-76.

Bagozzi, R.P., and Yi, Y. (1988). 'On the evaluation of structural equation models'. Journal of the Academy of Marketing Science, 16, 74-94.

Baker, W.E., Grinstein, A., and Harmancioglu, N. (2016). 'Whose innovation performance benefits more from external networks: Entrepreneurial or conservative firms?'. Journal of Product Innovation Management, 33, 104-20.

Baum, J.A.C., Calabrese, T., and Silverman, B.S. (2000). 'Don't go it alone: Alliance network composition and startups' performance in canadian biotechnology'. Strategic Management Journal, 21, 267-94.

Baum, J.A.C., Cowan, R., and Jonard, N. (2010). 'Network-independent partner selection and the evolution of innovation networks'. Management Science, 56, 2094-110.

Beerepoot, M., and Beerepoot, N. (2007). 'Government regulation as an impetus for innovation: Evidence from energy performance regulation in the Dutch residential building sector'. Energy Policy, 35, 4812-25.

Bell, G.G. (2005). 'Clusters, networks, and firm innovativeness'. Strategic Management Journal, 26, 287-95.

Bell, G.G., and Zaheer, A. (2007). 'Geography, networks, and knowledge flow'. Organization Science, 18, 955-72.

Bierly, P.E., Damanpour, F., and Santoro, M.D. (2009). 'The application of external knowledge: Organizational conditions for exploration and exploitation'. Journal of Management Studies, 46, 481-509.

Blau, P.M. (1977). Inequality and Heterogeneity. New York: Free Press.

Blomqvist, K., and Levy, J. (2006). 'Collaboration capability - A focal concept in knowledge creation and collaborative innovation in networks'. International Journal of Management Concepts and Philosophy, 2, 31-48.

Borgatti, S.P., Everett, M.G., and Johnson, J.C. (2013). Analyzing Social Networks. Los Angeles: SAGE Publications.

Borgatti, S.P., and Foster, P.C. (2003). 'The network paradigm in organizational research: A review and typology'. Journal of Management, 29, 991-1013. 
Borgatti, S.P., and Halgin, D.S. (2011). 'On network theory'. Organization Science, 22, $1168-81$.

Boschma, R.A. (2005). 'Proximity and innovation: a critical assessment'. Regional Studies, 39, 61-74.

Boschma, R.A. and ter Wal, A.L.J. (2007). 'Knowledge networks and innovative performance in an industrial district: the case of a footwear district in the South of Italy'. Industry and Innovation, 14, 177-99.

Brown, J.E., and Hendry, C. (1998). 'Industrial districts and supply chains as vehicles for managerial and organizational learning'. International Studies of Management \& Organization, 27, 127-57.

Burt, R.S. (1992). Structural Holes: The Social Structure of Competition. Cambridge: Harvard University Press.

Capaldo, A. (2007). 'Network structure and innovation: The leveraging of a dual network as a distinctive relational capability'. Strategic Management Journal, 28, 585-608.

Cohen, J. (1988). Statistical Power Analysis for the Behavioral Sciences. Mahwah: Lawrence Erlbaum.

Costenbader, E., and Valente, T.W. (2003). 'The stability of centrality measures when networks are sampled'. Social Networks, 25, 283-307.

Dai, Y., Goodale, J.C., Byun, G., and Ding, F. (2018). 'Strategic flexibility in new hightechnology ventures'. Journal of Management Studies, 55, 265-94.

Degener, P., Maurer, I., and Bort, S. (2018). 'Alliance portfolio diversity and innovation: the interplay of portfolio coordination capability and proactive partner selection capability'. Journal of Management Studies, 55, 1386-1422.

Delgado, M., Porter, M.E., and Stern, S. (2014). 'Clusters, convergence, and economic performance'. Research Policy, 43, 1785-99.

Dhanaraj, C., and Parkhe, A. (2006). 'Orchestrating innovation networks'. Academy of Management Review, 31, 659-69.

Dong, J.Q., McCarthy, K.J., and Schoenmakers, W.W. (2017). 'How central is too central? Organizing interorganizational collaboration networks for breakthrough innovation'. Journal of Product Innovation Management, 34, 526-542.

Doreian, P. (2008). 'Actor utilities, strategic action, and network evolution'. In Baum, J.A.C., and Rowley, T.J. (Eds), Network Strategy, Bingley: Emerald, 247-71.

Duysters, G. and Lokshin, B. (2011). 'Determinants of alliance portfolio complexity and its effect on innovative performance of companies'. Journal of Product Innovation Management, 28, 570-85.

Dyer, J.H., and Nobeoka, K. (2000). 'Creating and managing a high-performance knowledgesharing network: The Toyota case'. Strategic Management Journal, 21, 345-67.

Dyer, J.H., and Singh, H. (1998). 'The relational view: Cooperative strategy and sources of interorganizational competitive advantage'. Academy of Management Review, 23, 660-79.

Easterby-Smith, M., Lyles, M.A., and Tsang, E.W.K. (2008). 'Inter-organizational knowledge transfer: Current themes and future prospects'. Journal of Management Studies, 45, 67790.

Edvardsson, B., Holmlund, M., and Strandvik, T. (2008). 'Initiation of business relationships in service-dominant settings'. Industrial Marketing Management, 37, 339-50. 
Eisenhardt, K.M., and Martin, J.A. (2000). 'Dynamic capabilities: what are they?'. Strategic Management Journal, 21, 1105-21.

Elfring, T., and Hulsink, W. (2007). 'Networking by entrepreneurs: patterns of tie-formation in emerging organizations'. Organization Studies, 28, 1849-72.

Faems, D., Janssens, M. and Neyens, I. (2012). 'Alliance portfolios and innovation performance connecting structural and managerial perspectives'. Group \& Organization Management, 37, 241-68.

Fang, E. (2011). 'The effect of strategic alliance knowledge complementarity on new product innovativeness in China'. Organization Science, 22, 158-72.

Fliaster, A., and Spiess, J. (2008). 'Knowledge mobilization through social ties: The cost benefit analysis'. Schmalenbach Business Review, 60, 99-117.

Fornell, C., and Larckner, D.F. (1981). 'Evaluating structural equation models with unobservable variables and measurement error'. Journal of Marketing Research, 18, 3950.

Fund, B.R., Pollock, T.G., Baker, T., and Wowak, A.J. (2008). 'Who is the new kid? The process of developing centrality in venture capitalist deal networks'. In Baum, J.A.C., and Rowley, T.J. (Eds), Network Strategy, Bingley: Emerald, 563-93.

Gilsing, V., Nooteboom, B., Vanhaverbeke, W., Duysters, G., and Van den Oord, A. (2008). 'Network embeddedness and the exploration of novel technologies: Technological distance, betweenness centrality and density'. Research Policy, 37, 1717-31.

Giuliani, E. (2007). 'The selective nature of knowledge networks in clusters: evidence from the wine industry'. Journal of Economic Geography, 7, 139-68.

Granovetter, M.S. (1973). 'The strength of weak ties'. American Journal of Sociology, 78, 1360-80.

Gulati, R., Lavie, D., and Madhavan, R. (2011). 'How do networks matter? The performance effects of interorganizational networks'. Research in Organizational Behavior, 31, 207-24.

Gulati, R., Khanna, T., and Nohria, N. (1994). 'Unilateral commitments and the importance of process in alliances'. MIT Sloan Management Review, 35, 61-69.

Gulati, R., and Srivastava, S.B. (2014). 'Bringing agency back into network research: Constrained agency and network action'. In Brass, D.J., Labianca, G., Mehra, A.J., Halgin, D.S., and Borgatti, S.P. (Eds), Contemporary Perspectives on Organizational Social Networks, Bingley: Emerald, 73-93.

Hagedoorn, J. (2006). 'Understanding the cross-level embeddedness of interfirm partnership formation'. Academy of Management Review, 31, 670-80.

Hargadon, A., and Sutton, R.I. (1997). 'Technology brokering and innovation in a product development firm'. Administrative Science Quarterly, 42, 716-49.

Hair, J.F., Sarstedt, M., Pieper, T.M., and Ringle, C.M. (2012). 'The use of partial least squares structural equation modeling in strategic management research: A review of past practices and recommendations for future applications'. Long Range Planning, 45, 320-40.

Harrison, B., Kelley, M.R., and Grant, J. (1996). 'Innovative firm behavior and local milieu: exploring the intersection of agglomeration, firm effects, and technological change'. Economic Geography, 72, 233-58. 
Heimeriks, K.H., and Duysters, G. (2007). 'Alliance capability as a mediator between experience and alliance performance: An empirical investigation into the alliance capability development process'. Journal of Management Studies, 44, 25-49.

Henseler, J., Hubona, G., and Ray, P.A. (2016). 'Using PLS path modeling in new technology research: updated guidelines'. Industrial Management \& Data Systems, 116, 2-20.

Hoffmann, W.H. (2007). 'Strategies for managing a portfolio of alliances'. Strategic Management Journal, 28, 827-56.

Hulland, J. (1999). 'Use of partial least squares (PLS) in strategic management research: A review of four recent studies'. Strategic Management Journal, 20, 195-204.

Inkpen, A.C., and Pien, W. (2006). 'An examination of collaboration and knowledge transfer: China-Singapore Suzhou Industrial Park'. Journal of Management Studies, 43, 779-811.

Inkpen, A.C., and Tsang, E.W.K. (2005). 'Social capital, networks, and knowledge transfer'. Academy of Management Review, 30, 146-65.

Ireland, R.D., Hitt, M.A., and Vaidyanath, D. (2002). 'Alliance management as a source of competitive advantage'. Journal of Management, 28, 413-46.

Jensen, M., and Roy, A. (2008). 'Staging exchange partner choices: When do status and reputation matter?'. Academy of Management Journal, 51, 495-516.

Kale, P., and Singh, H. (2007). 'Building firm capabilities through learning: The role of the alliance learning process in alliance capability and firm-level alliance success'. Strategic Management Journal, 28, 981-1000.

Kale, P., and Singh, H. (2009). 'Managing strategic alliances: What do we know now, and where do we go from here?'. Academy of Management Perspectives, 23, 45-62.

Kale, P., Singh, H., and Perlmutter, H. (2000). 'Learning and protection of proprietary assets in strategic alliances: Building relational capital'. Strategic Management Journal, 21, $217-$ 37.

Kehrel, U., and Sick, N. (2014). 'Economic and technological forecasting competencies of German energy companies: empirical insights from annual reports'. International Journal of Energy Sector Management, 8, 588-610.

Koka, B.R., and Prescott, J.E. (2002). 'Strategic alliances as social capital: A multidimensional view'. Strategic Management Journal, 23, 795-816.

Kolloch, M., and Reck, F. (2017). 'Innovation networks in the German energy industry: an empirical analysis of inter-organizational knowledge transfer'. International Journal of Energy Sector Management, 11, 268-94.

Kumar, N., Stern, L.W., and Anderson, J.C. (1993). 'Conducting interorganizational research using key informants'. Academy of Management Journal, 36, 1633-51.

Leischnig, A., Geigenmüller, A., and Lohmann, S. (2014). 'On the role of alliance management capability, organizational compatibility, and interaction quality in interorganizational technology transfer'. Journal of Business Research, 67, 1049-57.

Lorenzoni, G., and Lipparini, A. (1999). 'The leveraging of interfirm relationships as a distinctive organizational capability: a longitudinal study'. Strategic Management Journal, 20, 317-38.

Lovas, B., and Sorenson, O. (2008). 'The mobilization of scarce resources'. In Baum, J.A.C., and Rowley, T.J. (Eds), Network Strategy, Bingley: Emerald, 361-89. 
MacKinnon, D.P., Fairchild, A.J., and Fritz, M.S. (2007). 'Mediation analysis'. Annual Review of Psychology, 58, 593-614.

Madhavan, R., Caner, T., Prescott, J.E., and Koka, B.R. (2008). 'Bringing the firm back in: Networking as antecedent to network structure'. In Baum, J.A.C., and Rowley, T.J. (Eds), Network Strategy, Bingley: Emerald, 457-501.

Makadok, R. (2001). 'Toward a synthesis of the resource-based and dynamic-capability views of rent creation'. Strategic Management Journal, 22, 387-401.

Majchrzak, A., Jarvenpaa, S.L., and Bagherzadeh, M. (2015). 'A review of interorganizational collaboration dynamics'. Journal of Management, 41, 1338-60.

March, J.G. (1991). 'Exploration and exploitation in organizational learning'. Organization Science, 2, 71-87.

Mariotti, F., and Delbridge, R. (2012). 'Overcoming network overload and redundancy in interorganizational networks: The roles of potential and latent ties'. Organization Science, 23, 511-28.

McCann, B.T., and Folta, T.B. (2011). 'Performance differentials within geographic clusters'. Journal of Business Venturing, 26, 104-23.

McEvily, B., and Marcus, A. (2005). 'Embedded ties and the acquisition of competitive capabilities'. Strategic Management Journal, 26, 1033-55.

McEvily, B., and Zaheer, A. (1999). 'Bridging ties: A source of firm heterogeneity in competitive capabilities'. Strategic Management Journal, 20, 1133-56.

Michelfelder, I., and Kratzer, J. (2013). 'Why and how combining strong and weak ties within a single interorganizational R\&D collaboration outperforms other collaboration structures'. Journal of Product Innovation Management, 30, 1159-77.

Mitchell, W., and Singh, K. (1996). 'Survival of businesses using collaborative relationships to commercialize complex goods'. Strategic Management Journal, 17, 169-95.

Mitrega, M., Forkmann, S., Ramos, C., and Henneberg, S.C. (2012). 'Networking capability in business relationships - Concept and scale development'. Industrial Marketing Management, 41, 739-51.

Morrison, A. (2008). 'Gatekeepers of knowledge within industrial districts: who they are, how they interact'. Regional Studies, 42, 817-35.

$\mathrm{Mu}$, J., and Di Benedetto, A. (2012). 'Networking capability and new product development'. IEEE Transactions on Engineering Management, 59, 4-19.

Müller, R., Steinert, M., and Teufel, S. (2008). 'Successful diversification strategies of electricity companies'. Energy Policy, 36, 398-412.

Nahapiet, J., and Ghoshal, S. (1998). 'Social capital, intellectual capital, and the organizational advantage'. Academy of Management Review, 23, 242-66.

Nelson, R., and Winter, S.G. (1982). An Evolutionary Theory of Economic Change. Cambridge: Belknap Press.

Nitzl, C., Roldan, J.L., and Cepeda, G. (2016). 'Mediation analysis in partial least squares path modeling: helping researchers discuss more sophisticated models'. Industrial Management \& Data Systems, 116, 1849-64.

Owen-Smith, J., and Powell, W.W. (2004). 'Knowledge networks as channels and conduits: The effects of spillovers in the Boston biotechnology community'. Organization Science, $15,5-21$. 
Ozcan, P., and Eisenhardt, K.M. (2009). 'Origin of alliance portfolios: Entrepreneurs, network strategies, and firm performance. Academy of Management Journal, 52, 246-79.

Ozer, M., and Zhang, W. (2015). 'The effects of geographic and network ties on exploitative and exploratory product innovation'. Strategic Management Journal, 36, 1105-14.

Parise, S., and Casher, A. (2003). 'Alliance portfolios: Designing and managing your network of business-partner relationships'. Academy of Management Executive, 17, 25-39.

Park, S.H., and Ungson, G.R. (2001). 'Interfirm rivalry and managerial complexity: A conceptual framework of alliance failure'. Organization Science, 12, 37-53.

Phelps, C., Heidl, R., and Wadhwa, A. (2012). 'Knowledge, networks, and knowledge networks: A review and research agenda'. Journal of Management, 38, 1115-66.

Podsakoff, P.M., MacKenzie, S.B., Lee, J.Y., and Podsakoff, N.P. (2003). 'Common method biases in behavioral research: A critical review of the literature and recommended remedies. Journal of Applied Psychology, 88, 879-903.

Porter, M.E. (1998). 'Clusters and the new economics of competition'. Harvard Business Review, 76, 77-90.

Pouder, R., and St. John, C.H. (1996). 'Hot spots and blind spots: Geographical clusters of firms and innovation'. Academy of Management Review, 21, 1192-1225.

Powell, W.W., Koput, K.W., and Smith-Doerr, L. (1996). 'Interorganizational collaboration and the locus of innovation: Networks of learning in biotechnology'. Administrative Science Quarterly, 41, 116-45.

Pullen, A.J., Weerd-Nederhof, P.C., Groen, A.J., and Fisscher, O.A. (2012). 'Open innovation in practice: Goal complementarity and closed NPD networks to explain differences in innovation performance for SMEs in the medical devices sector'. Journal of Product Innovation Management, 29, 917-34.

Ramos, C., Henneberg, S.C., and Naudé, P. (2012). 'Understanding network picture complexity: An empirical analysis of contextual factors'. Industrial Marketing Management, 41, 951-72.

Raynor, M.E., and Ahmed, M. (2013). 'Three rules for making a company truly great'. Harvard Business Review, 91, 108-17.

Reagans, R., and McEvily, B. (2003). 'Network structure and knowledge transfer: The effects of cohesion and range'. Administrative Science Quarterly, 48, 240-67.

Reinartz, W., Haenlein, M., and Henseler, J. (2009). An empirical comparison of the efficacy of covariance-based and variance-based SEM'. International Journal of Research in Marketing, 26, 332-44.

Ringle, C.M., Wende, S., and Becker, J.M. (2015). SmartPLS 3.2.3. Hamburg: SmartPLS.

Ritter, T., and Gemünden, H.G. (2003). 'Network competence: Its impact on innovation success and its antecedents'. Journal of Business Research, 56, 745-55.

Rothaermel, F.T., and Deeds, D.L. (2006). 'Alliance type, alliance experience and alliance management capability in high-technology ventures'. Journal of Business Venturing, 21, 429-60.

Rowley, T.J., and Baum, J.A.C. (2008). 'Introduction: Evolving webs in network economies'. In Baum, J.A.C., and Rowley, T.J. (Eds), Network Strategy, Bingley: Emerald, xiii-xxxii. 
Rowley, T.J., Behrens, D., and Krackhardt, D. (2000). 'Redundant governance structures: An analysis of structural and relational embeddedness in the steel and semiconductor industries'. Strategic Management Journal, 21, 369-86.

Salancik, G.R. (1995). 'WANTED: A Good Network Theory of Organization'. Administrative Science Quarterly, 40, 345-49.

Sammarra, A., and Biggiero, L. (2008). 'Heterogeneity and specificity of inter-firm knowledge flows in innovation networks'. Journal of Management Studies, 45, 800-29.

Sampson, R.C. (2007). 'R\&D alliances and firm performance: the impact of technological diversity and alliance organization on innovation'. Academy of Management Journal, 50, 364-86.

Sarkar, M.B., Aulakh, P.S., and Madhok, A. (2009). 'Process capabilities and value generation in alliance portfolios'. Organization Science, 20, 583-600.

Sarkar, M.B., Echambadi, R.A., and Harrison, J.S. (2001). 'Alliance entrepreneurship and firm market performance. Strategic Management Journal, 22, 701-11.

Schilke, O., and Goerzen, A. (2010). 'Alliance management capability: an investigation of the construct and its measurement'. Journal of Management, 36, 1192-1219.

Schreiner, M., Kale, P., and Corsten, D. (2009). 'What really is alliance management capability and how does it impact alliance outcomes and success?'. Strategic Management Journal, 30, 1395-1419.

Shan, W., Walker, G., and Kogut, B. (1994). 'Interfirm cooperation and startup innovation in the biotechnology industry'. Strategic Management Journal, 15, 387-94.

Singh, J. (2005). 'Collaborative networks as determinants of knowledge diffusion patterns'. Management Science, 51, 756-70.

Steier, L., and Greenwood, R. (2000). 'Entrepreneurship and the evolution of angel financial networks'. Organization Studies, 21, 163-92.

Stuart, T.E., and Sorenson, O. (2007). 'Strategic networks and entrepreneurial ventures'. Strategic Entrepreneurship Journal, 1, 211-27.

Subramaniam, M., and Youndt, M.A. (2005). 'The influence of intellectual capital on the types of innovative capabilities'. Academy of Management Journal, 48, 450-63.

Szulanski, G. (1996). 'Exploring internal stickiness: impediments to the transfer of best practices within the firm'. Strategic Management Journal, 17, 27-43.

Tödtling, F., Asheim, B. and Boschma, R. (2013). 'Knowledge sourcing, innovation and constructing advantage in regions of Europe'. European Urban and Regional Studies, 20, 161-69.

Tiwana, A. (2008). 'Do bridging ties complement strong ties? An empirical examination of alliance ambidexterity'. Strategic Management Journal, 29, 251-72.

Tsai, W., and Ghoshal, S. (1998). 'Social capital and value creation: the role of intrafirm networks'. Academy of Management Journal, 41, 464-76.

van Liere, D.W., Koppuis, O.R., and Vervest, P.H.M. (2008). 'Network horizon: an information-based view on the dynamics of bridging positions'. In Baum, J.A.C., and Rowley, T.J. (Eds), Network Strategy, Bingley: Emerald, 595-642.

van Wijk, R., Jansen, J.J.P., and Lyles, M.A. (2008). 'Inter- and intra-organizational knowledge transfer: a meta-analytic review and assessment of its antecedents and consequences'. Journal of Management Studies, 45, 830-53. 
Vesalainen, J., and Hakala, H. (2014). 'Strategic capability architecture: The role of network capability'. Industrial Marketing Management, 43, 938-50.

Walter, A., Auer, M., and Ritter, T. (2006). 'The impact of network capabilities and entrepreneurial orientation on university spin-off performance'. Journal of Business Venturing, 21, 541-67.

Wang, Y., and Rajagopalan, N. (2015). 'Alliance capabilities: review and research agenda'. Journal of Management, 41, 236-60.

Wasserman, S., and Faust, K. (1994). Social Network Analysis: Methods and Applications. Cambridge: Cambridge University Press.

Wassmer, U. (2010). 'Alliance portfolios: a review and research agenda'. Journal of Management, 36, 141-71.

Wassmer, U., and Dussauge, P. (2012). 'Network resource stocks and flows: how do alliance portfolios affect the value of new alliance formations?'. Strategic Management Journal, 33, 871-83.

Yli-Renko, H., Autio, E., and Sapienza, H.J. (2001). 'Social capital, knowledge acquisition, and knowledge exploitation in young technology-based firms'. Strategic Management Journal, 22, 587-613.

Zaefarian, G., Forkmann, S., Mitrega, M., Henneberg, S. C. (2017). 'A capability perspective on relationship ending and its impact on product innovation success and firm performance'. Long Range Planning, 50, 184-99.

Zaheer, A., and Bell, G.G. (2005). 'Benefiting from network position: Firm capabilities, structural holes, and performance'. Strategic Management Journal, 26, 809-25.

Zaheer, A., Gözübüyük, R., and Milanov, H. (2010). 'It's the connections: The network perspective in interorganizational research'. Academy of Management Perspectives, 24, $62-77$.

Zajac, E. J. and Olsen, C. P. (1993). 'From transaction cost to transactional value analysis: Implications for the study of interorganizational strategies'. Journal of Management Studies, 30, 131-45.

Zhang, Y., and Li, H. (2010). 'Innovation search of new ventures in a technology cluster: the role of ties with service intermediaries'. Strategic Management Journal, 31, 88-109.

Zollo, M. and Winter, S.G. (2002). 'Deliberate learning and the evolution of dynamic capabilities'. Organization Science, 13, 339-51. 
III. Publications in Focus Area II: Networks and External Partners

\section{Publication 5: Firms' Network Profiles and Product Innovation Performance - A Configurational Perspective}

\subsection{Note on Submitted Paper}

The following paper on "Firms' Network Profiles and Product Innovation Performance - A Configurational Perspective” was co-authored by my $\mathrm{PhD}$ supervisor Prof. Dr. Alexander Fliaster and myself. As corresponding author, I submitted the paper to a leading international academic journal (VHB: B; ABS: 3) where it is currently under review. An earlier version of the paper was accepted for presentation at the 79th Annual Meeting of the Academy of Management in Boston, USA (date of presentation: August $12^{\text {th }}, 2019$ ) after a double-blind peer-review process. 


\title{
3.2. Academic Paper
}

\begin{abstract}
Previous research has revealed that firms' partner networks essentially affect innovation performance. However, the bulk of past studies has focused on the isolated effects of singular network characteristics, such as size and diversity. Taking the "configurational perspective", we theorize that the effects of these characteristics are likely to be interdependent and investigate the impact of firms' networks as a whole. To address this issue, we collected empirical data from the German energy industry and applied fuzzy-set qualitative comparative analysis (fsQCA). Our study identified four archetypical network profiles that contribute to product innovation: (1) a network with strong ties to partners with complementary resources, (2) a network with strong ties to partners with cutting-edge resources, (3) a large network composed of many complementary partners, and (4) a large network composed of many innovative partners. Furthermore, we show that these four network profiles are particularly instrumental for innovating firms with different characteristics: Large firms are rather successful when they are embedded in large networks, whereas smaller firms are more innovative when they rely on strong relations to their partners. Furthermore, firms with high levels of human capital can profit from ties to highly innovative firms, whereas companies with lower levels of internal expertise benefit from the complementarity of network partners' resources.
\end{abstract}

Keywords: Partner Networks; Inter-organizational Knowledge Transfer; New Product Development; Configuration Theory; fsQCA

\section{PRACTITIONER POINTS}

- There are four "ideal network profiles" that can serve as strategic blueprints for making the firm's network more "governable" and thus innovation-friendly.

- Firms need to configure their network in terms of volume (network size vs. tie strength) and content (innovative partners vs. complementary partners).

- While small firms should try to obtain a close-knit partner network with high strength and in-depth exchange of knowledge, large firms are able to process a broader range of incoming information and thus benefit from large partner networks with rather weak inter-firm ties.

- Firms with higher levels of internal expertise (as measured by human capital) are able to process and learn from cutting-edge knowledge and thus should aim to form relations to highly innovative partners, whereas firms with lower levels of internal expertise should rely more on partners with complementary expertise.

\section{INTRODUCTION}

A firm's partner network represents a decisive success factor for new product development (NPD) (Brettel and Cleven, 2011; Pittaway et al., 2004; Snow et al., 2011). Previous studies 
have revealed several characteristics of networks that are conducive to product innovation. For instance, Ahuja (2000), Baum et al. (2000), and Rothaermel et al. (2006) showed that large network size is beneficial. Furthermore, research found positive effects of other network features, such as partner diversity (e.g. Piening et al., 2016), quality of partner firms' expertise (e.g. Emden et al., 2006; Stuart, 2000; Zaheer and Bell, 2005), complementarity between the focal firm and its partners (e.g. Fang, 2011; Sampson, 2007), and the strength of collaboration with partner firms (e.g. Kale et al., 2000; Tiwana 2008).

However, most previous studies focused on the isolated effects of single network features (Wassmer, 2010). Hence, though the past research has identified plenty of network characteristics that influence a firm's innovative performance individually, the understanding of the interplay of these characteristics and the impact of firms' networks as a whole is still limited (Pullen et al., 2012; Thornton et al., 2019). Admittedly, several past works strived to explain and test the interaction effects between two or more network characteristics (e.g. partner resources and network structure (Bae and Gargiulo, 2004; Operti and Carnabuci, 2014), or tie strength and network structure (Rowley et al., 2000; Tiwana, 2008)). Still, none of these studies have taken a holistic perspective that aims to understand firms' networks as complex, multifaceted entities rather than a collection of network features independent from each other.

In contrast we argue that to explain the effects of networks on firms' innovation performance it is reasonable to assume causal complexity (Fiss, 2011). Hence, rather than being linear and separated, the effects of partner networks on innovation are likely to display three key characteristics: (1) conjunction (i.e., effects do not stem from single network characteristics in isolation but rather from their overall combination); (2) equifinality (i.e., different types of "network profiles" exist that equally enable firms to innovate successfully); and (3) causal asymmetry (i.e., low-performing network profiles may not necessarily be a mirror image of high-performing profiles). As the current literature is predominantly based on variancetheoretical approaches that do not adequately address this causal complexity (Ragin, 2008), the understanding of high-performing networks still remains fragmentary.

Our paper tackles these shortcomings from previous research by applying a configurational perspective (e.g. Kraus et al., 2018; Misangyi et al., 2017) that conceptualizes a firm's partner portfolio as a bundle of different, but interdependent structural, relational, and partner-related network characteristics. Configuration theory shifts the focus from the net effects of single variables to the combinatorial effects of configurations, i.e., specific combinations of the causal variables under study ("causal conditions") that together create an outcome of interest (Fiss, 2011; Ragin, 2008). Thus, rather than trying to explain the impact of firm networks on innovative performance by determining the isolated effects of various network characteristics, our work aims to unveil "ideal", meaning "archetypical", portfolio profiles that are constituted by a variety of network features (Pittaway et al., 2004).

In doing so, this article answers the following research questions: (1) Are there "ideal" network profiles that allow firms to foster their innovative performance? (2) What are the features of these profiles? (3) For which types of firms is each of these profiles effective? To address these questions, we collect empirical data from 93 companies in the German energy industry and 
analyze these data deploying the fsQCA methodology (fuzzy-set qualitative comparative analysis). In sum, this study contributes to network studies and innovation management research in two important ways. On the one hand, we extend theoretical understanding of networks' contribution to innovation by developing a configurational model that allows for an exhaustive depiction of various types of networks that benefit firms' NPD efforts. We uncover four major configurations of the partner network that consistently lead to high levels of product innovation performance. These "ideal profiles" may serve as causal recipes for further research and as strategic blueprints for firms and top-level managers in charge.

On the other hand, we add insights to network research by exploring the interactions between the organization's ego network and key organizational characteristics. While previous research has drawn on contingency theory and included different firm-level variables in order to depict firms' ability to make use of their particular network (e.g. Huggins and Johnston, 2010; Rothaermel and Hess, 2007), we add to this discussion by demonstrating that to innovate successfully, firms with different characteristics need networks with different profiles. By including two organizational variables - the size of the firm and its human capital - into our configurational model, we categorize firms along these two dimensions in a $2 \times 2$ matrix and explain how for the firms in each quadrant, a different type of network promises to be useful.

The rest of the paper is organized as follows. We first lay out the theoretical background on which we base our considerations. We therein review previous literature on firm's partner portfolios and incorporate the gained insights into a research framework that allows for exploring successful network configurations. Next, in the methodology section, we outline our empirical research design as well as the applied fsQCA data analysis approach. The findings are described in the results section, after which the identified configurations are discussed in detail. Finally, we address the limitations of our study and show its implications for management research and practice.

\section{THEORETICAL FRAMEWORK}

\section{Partner Networks and Product Innovation}

In line with previous works, we define the partner network as a focal firm's egocentric network, i.e., the collection of direct ties to other firms (e.g. Baum et al., 2000; Ozcan and Eisenhardt, 2009). Hence, our work takes a perspective that is centered around the focal firm and understands the partner network as a firm-level asset (Lavie, 2007). Since there are different types of ties between firms (e.g. buyer-supplier transactions, research collaboration agreements, etc.), the conceptualization and operationalization of networks depends on the specific definition of the interorganizational ties under investigation (Borgatti and Halgin, 2011). As in the context of innovation knowledge flows between firms are of critical importance, this paper focuses on the knowledge network of a focal firm (ego), i.e., its set of contacts (alters) that are connected to the focal firm by ties that enable the firm's efforts to acquire and create new knowledge and thus drive innovation (Phelps et al., 2012).

Previous research has largely drawn on two theoretical lenses in order to explain the impact of partner networks on firms' product innovation performance: the resource-based view and the 
social network theory. The resource-based view assumes that innovation performance is a result of the resource endowment of the firm (Barney, 1991). Thereby, the firm does not have to own valuable resource by itself but may use its relations to partner firms in order to access expertise, skills, and information (Hoffmann, 2007; Lavie, 2007). The social network theory adds to this theoretical perspective by pointing out that the quantity and quality of resources (e.g. innovation-related knowledge) that a firm can access depend on the characteristics of its partner network (Borgatti and Halgin, 2011; Gulati et al., 2011). The value of a firm's network is thus determined by its composition, i.e., the content and arrangement of the relationships to its partners (Wassmer, 2010). Consequently, the bulk of previous studies examined the effects of different network characteristics and strived to explain the causal mechanisms at work.

\section{Characteristics of Partner Networks}

The partner network can be described by several characteristics that fall into three dimensions: structural characteristics, relational characteristics, and partner-related characteristics (Wassmer, 2010; Phelps et al., 2012; Pittaway et al., 2004). In particular, past research specified the following five network characteristics that are relevant for the focal firm's innovation endeavors: network size (structural), tie strength (relational), as well as partner innovativeness, partner complementarity, and partner diversity (partner-related).

Network Size. Network size refers to the number of contacts from whom the focal firm can acquire knowledge, expertise, and other resources (Ahuja, 2000; Shan et al., 1994). A large network size grants the firm a high reach on potentially valuable resources (Gulati et al., 2011). A higher reach has several positive effects on innovative performance. On the one hand, the reach increases the volume of knowledge and resources that a firm can access in its NPD projects (Koka and Prescott, 2002; Rothaermel and Hess, 2007). Hence, with a growing network size firms will be able to draw from a larger pool of technologies and applicable solutions so that it is more likely to develop new products that address important customer needs and solve these needs effectively and efficiently (Baker et al., 2016). On the other hand, research has shown that networks play an important role when it comes to obtaining timely access to information (Ahuja, 2000). A firm's relationships serve as antennas for ideas; the more of these antennas the firm possesses, the more likely it is to become aware of new technological developments or changed customer needs early (Owen-Smith and Powell, 2004).

Partner Innovativeness. This network feature describes the degree to which a firm's network is composed of highly innovative partners. In contrast to network size, partner innovativeness influences the quality (and not the quantity) of resources that a firm can access via its network (Gulati et al., 2011). Hence, studies that include this variable take into account that some partners are more valuable than others when it comes to innovation (Emden et al., 2006; Zaheer and Bell, 2005). Cooperative relationships with highly innovative firms will most likely grant access to ideas and solutions of high usefulness and topicality (Bae and Gargiulo, 2004; Operti and Carnabuci, 2014; Zaheer and Bell, 2005). Hence, by developing a network with high level of partner innovativeness a focal firm obtains more opportunities to learn from its innovative partners, profit from knowledge spillovers, imitate ideas, and thus create own product innovations based on the transferred knowledge (Nahapiet and Ghoshal, 1998). Supporting 
these notions, studies from different industrial contexts like semiconductors (Stuart, 2000), biotechnology (Baum et al., 2000), and software (Lavie, 2007) provide empirical evidence for the positive effect of a network with highly innovative partners on innovative performance.

Partner Complementarity. Past research demonstrated that a high complementarity of resources within the firm's partner network is desirable. In other words, studies indicate that the accessible network resources should complement and add to the resources that the focal firm possesses internally (Fang, 2011). Hence, the value of resources accessible from the partners is not fully objective but depends on the focal firm's perspective (Gulati et al., 2011). Product innovation and NPD projects often require a diverse and broad bandwidth of skills and know-how (Garcia and Calantone, 2002). A network portfolio with a high degree of complementarity allows the focal firm to access the partners' resources and thereby eliminate own deficiencies (Lambe et al., 2002). Therefore, the focal firm might concentrate on its own core competencies in the innovation process while simultaneously benefit from the externally acquired resources (Becker and Dietz, 2004).

Partner Diversity. Partner diversity describes the degree to which a firm's partners differ with regard to resources that they provide to the firm (Gulati et al., 2011). Diversity may be a result of the partner firms operating in different industries or market segments, different geographical locations, serving different customers, using different technologies, or taking different roles along the value chain (Koka and Prescott, 2002; Lavie and Miller, 2008). If the diversity of partner firms is high, there is only a low degree of redundancy of resources, e.g. the knowledge available from the network (Burt, 1992). A partner portfolio of high diversity opens up a larger bandwidth of accessible expertise and skills as well as a larger number of different perspectives on technological or market-related challenges (Piening et al., 2016). Consequently, the firm obtains more opportunities to learn and develop new product concepts and designs (Koka and Prescott, 2002; Hargadon and Sutton, 1997). Especially in situations of high environmental volatility, a diverse partner portfolio might help leaving old trajectories, experiment with new solutions, and outpace competitors in the innovation game (Levinthal and March, 1993).

Tie Strength. Tie strength describes the level of trust, reciprocity, intensity and proximity of interaction within a firm's portfolio of relationships (Kale et al., 2000; Michelfelder and Kratzer, 2013). Research has shown that the stronger the relationship between two firms, the easier and more effective knowledge can be transferred. Strong ties entail high levels of relational capital (Dyer and Singh, 1998), social cohesion (Tiwana, 2008), and mutual understanding (Nahapiet and Ghoshal, 1998). This strengthens the involved partners' capacity for knowledge transfer, so that the depth and scope of the exchanged knowledge increases (Rowley et al., 2000). Especially when an innovative effort requires tacit and complex expertise, strong ties improve the mutual receptivity so that both partners are likely to profit (McEvily and Marcus, 2005). Therefore, with a network of strong ties, a firm will be more likely to learn from its partners, create new knowledge in cooperative efforts, and develop innovative products (Capaldo, 2007; Michelfelder and Kratzer, 2013; Sampson, 2007). 


\section{Toward a Configurational Perspective on Partner Networks}

We argue that because partner networks are multidimensional entities, they are likely to display causal complexity (Pullen et al., 2012; Wassmer, 2010), particularly regarding their impact on innovation performance. Such causal complexity can be depicted by drawing on configurational theory (Misangyi et al., 2017). Configurational theory promotes the assumption that "parts of a social entity take their meaning from the whole and cannot be understood in isolation" (Meyer et al., 1993: 1178). Therefore, complex concepts such as partner networks also must be examined holistically as "variables found to be causally related in one configuration may be unrelated or even inversely related in another" (Meyer et al., 1993: 1178). A configurational perspective thus implies that causal conditions (a term analogous to the "independent" variables for describing explanatory variables in configurational studies) cannot be treated in isolation but as parts of whole configurations, i.e., specific combinations of causal conditions (Fiss, 2011).

Configurational theory takes a fundamentally different perspective on causality and causal effects than variance theories that prevail in management science. In particular, configurational theory lifts major assumptions of variance theories, namely symmetric relations between predictor and outcome variable, limited covariance between predictors, and the absence of spurious effects not captured by research models (Van de Ven and Huber, 1990). Consequently, causal relations between conditions and outcome variables may display three characteristics.

First, conjunction means that outcomes are produced by a combination of variables rather than variables in isolation. In configurational theory, theoretical propositions are thus formulated as causal recipes that capture overall configurations predicting an outcome of interest (Misangyi et al., 2017). This notion of conjunction entails that in certain configurations, variables that otherwise would be positively related to an outcome might be harmful and vice versa (Greckhamer et al., 2008). Second, causation may be equifinal, i.e., different configurations may lead to similar positive or negative outcomes (Doty et al., 1993). Hence, in most managerial tasks there is not a single recipe for success but a number of ways to reach a desired outcome (Ketchen et al., 1993). Third, configurational theory embraces the notion of causal asymmetry, i.e., a situation where a configuration that predicts the presence of an outcome does not likewise predict the absence of this outcome (Fiss, 2011; Ragin, 2008). Hence, causal conditions can be either necessary (i.e., they must be present for a certain outcome to occur, but do not guarantee its occurrence), sufficient (i.e., they guarantee the occurrence of a certain outcome but must not be present for it to occur), or both (Greckhamer et al., 2008).

Taking into considerations the causal mechanisms proposed in network research, we argue that due to the three assumptions on causality presented above, configuration theory is likely to depict the reality of inter-firm networks more accurately than variance theories. First, network literature extensively discusses interactive effects between different types of network characteristics (e.g. Borgatti and Halgin, 2011; Gulati et al., 2011; Nahapiet and Ghoshal, 1998). Though previous research theorizes on more complex interactions between network variables, the bulk of empirical studies effectively examine isolated effects or one-way interactions so that research results may suffer from reductionism and be considerably distorted 
(Pullen et al., 2012). Second, previous research has produced inconsistent results and academic arguments on which network variables actually determine organizational performance (Phelps et al., 2012). Taking the lens of configurational theory, such different perspectives and explanations might not necessarily conflict with each other, so that either/or arguments are unlikely to result in consistent explanations (Ragin, 2008). Rather, networks with different characteristics are likely to depict different, but equally effective pathways to high performance, just depending on their internal fit (i.e., the fit between the network variables forming the overall network profile) and external fit (i.e., the fit between the network profile and the situational context in which a firm operates) (Fiss, 2011). Third, literature demonstrates that network features like network size, tie strength, or partner resources might entail benefits, but also come at costs and risks (Hoffmann, 2007; Ozcan and Eisenhardt, 2009; Wassmer, 2010). Due to such costs, certain combinations of network characteristics might be conflicting rather than synergistic. For instance, a firm that tries to form deep and trusting relationships to many diverse partners might suffer from overloading its capacity for processing information and managing relationships (Fliaster and Spiess, 2008; Mariotti and Delbridge, 2012). By taking a configurational perspective, such potential conflicts can be identified and explained.

Hence, we propose that configuration theory is likely to capture causal mechanisms in the network field more holistically and accurately and thus help to enrich existing theories on firms' partner networks and innovative performance (Misangyi and Acharya, 2014). In order to elaborate such a configurational perspective on firms' partner networks, we suggest a theoretical framework that includes the most relevant network characteristics in terms of their influence on innovation performance that have been discussed above: network size, partner innovativeness, partner complementarity, partner diversity, and tie strength. We argue that, taken together, these five characteristics provide an adequately exhaustive picture (Wagemann and Schneider, 2010) of a firm's partner portfolio as well as the network-theoretical mechanisms that may be at play (Pittaway et al., 2004; Pullen et al., 2012). Furthermore, we consider these five characteristics to be mutually exclusive as all cover different aspects of firms' networks (Phelps et al., 2012; Wassmer, 2010). The interdependent nature of these key network characteristics is depicted by the five-element Venn diagram in Figure 1. 


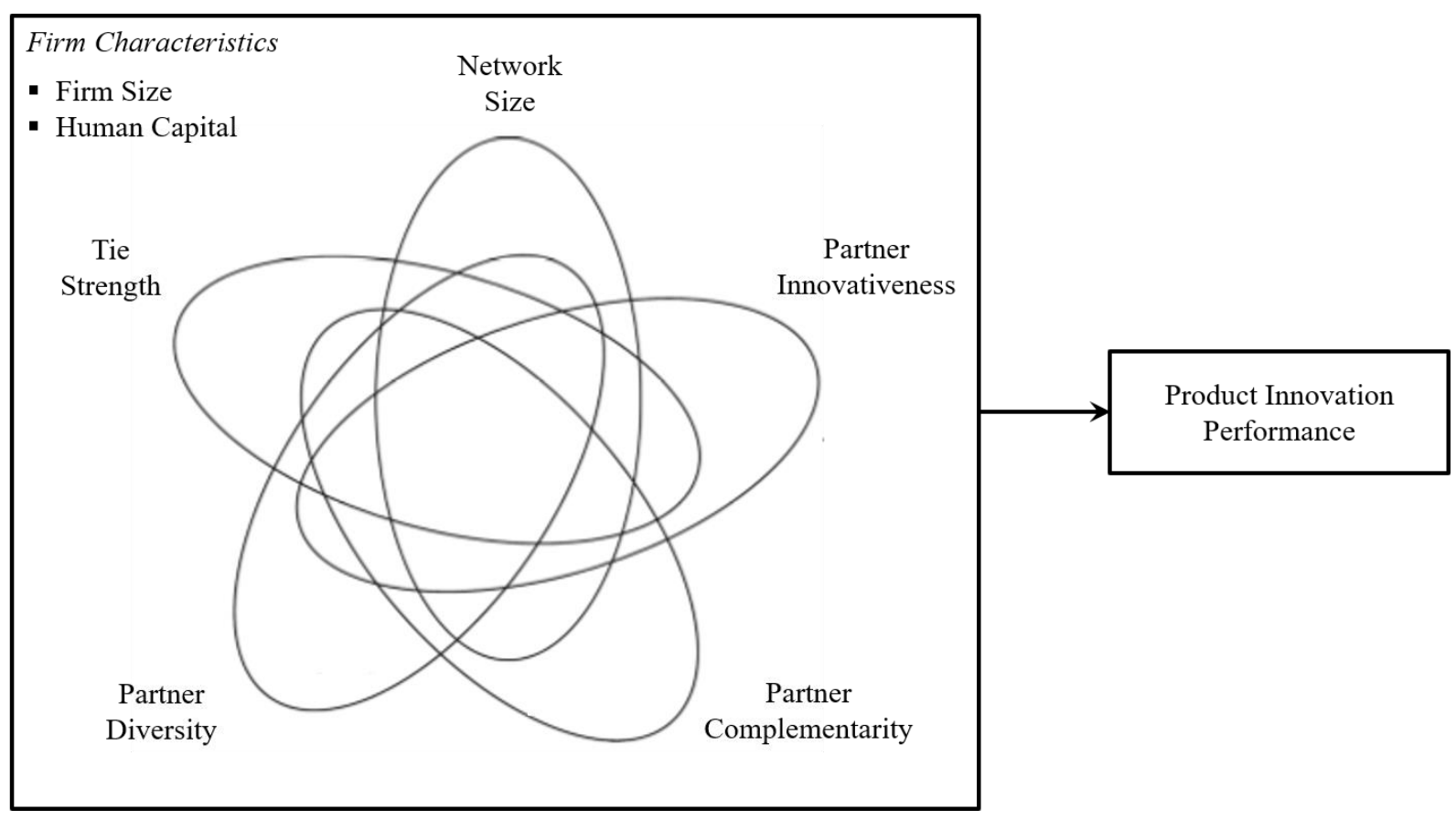

Figure III-3-1. Research framework (own illustration)

In the next step, we extend the research framework by including two firm-level variables. This allows us to examine, whether certain network profiles are instrumental for different types of firms. The first variable is firm size. Firm size is linked to resource slack and access to resources in general, but also to the capacity for processing different innovation initiatives (Ettlie and Rubenstein, 1987). Thus, it has been shown that different networking strategies might be promising for small and large firms (Huggins and Johnston, 2010). The second firm-level variable that we include is human capital. Human capital has been shown to be a predictor of firms' innovative performance (Rupietta and Backes-Gellner, 2019), but also a predictor of how well firms are able to learn from external sources (Rothaermel and Hess, 2007). Hence, human capital determines the volume and content of novel knowledge that a firm is able to absorb effectively (Ritala and Hurmelinna-Laukanen, 2013). In summary, both variables depict different types of internal resources that may combine with externally acquired expertise and ideas, but also be required for a firm to realize innovation-related benefits from its network.

\section{METHODOLOGY}

\section{Research Setting and Data Collection}

We tested the hypotheses based on data collected from the German energy industry, particularly from municipal utilities. We consider this industrial setting as an attractive research context for investigating the effects of network profiles on product innovation performance. Being confronted with several challenges in their business environment, municipal utilities in Germany are currently striving to enter new market fields and foster product innovation (Müller et al., 2008). Major fields of innovation in which many utilities engage are smart home, energy efficiency optimization, on-site power generation, and electromobility, among others (Edelmann, 2015). In this race for innovation, most utilities fall short of the Big Four (E.ON, 
Vattenfall, EnBW, RWE) with regard to resource endowment and financial slack (Kehrel and Sick, 2014; Nikogosian and Veith, 2012). Therefore, cooperative initiatives between two or more utilities play an important role in their NPD strategies, and the relationships to other firms become enablers of firms' product innovation performance (Kolloch and Reck, 2017).

As population for data collection, we chose 300 of the largest municipal utilities in Germany. This sample includes mostly SMEs, but also larger firms (ranging from 30 full-time employees to 9,134 and from around 25 million $€$ of sales to 8.3 billion $€$ in 2017). We limited the sample to 300 utilities in order to ensure that all firms under investigation were at least potentially able to actively engage in product innovation. There exist a much larger number of utilities in Germany, however, the smallest of them are often mere administrators of small plants (such as photovoltaics) owned by the municipality. In contrast to the firms in our sample, these smallest utilities do not actively compete for market shares and thus are unlikely to engage in innovative efforts (Edelmann, 2015).

In a key informant approach, we collected data by online survey conducted in Autumn 2016. We first used existing scales to develop the research questionnaire. The questionnaire was pretested by 26 senior managers from the energy industry. Within the process, ambiguous terms were clarified, and face validity was ensured by discussing the employed scales. We advanced in three steps in order to acquire contact data of the potential key informants. First, company pages in the business network XING (the German counterpart to LinkedIn) were scanned for managers that occupied a position in the ranks of vice presidents, directors or top management and stated work contents related to NPD, such as "innovation management", "product management", "R\&D", or similar. Second, we searched company websites for the presentation of top management, and scanned press releases and annual reports for topics and articles that point to NPD efforts in order to find mentioning or quotes of further top managers. Third, in case that we were not able to identify potential contact through the previous steps, we contacted the company via e-mail or telephone and asked for the manager who is majorly responsible for product innovation. By this approach, we identified at least two contacts for each of the sample firms, at least one in general management and one in innovation management. In all, there were 661 potential respondents, at least two from each utility. We sent an invitation to participate including the survey link to all key informants and followed up with a reminder at the end of the first half of the survey period (after 30 days).

In all, 144 completed questionnaires were collected. Of these 16 had to be excluded due to considerable missing data or missing information on the respondent's affiliation with one of the sample companies. Hence, 128 questionnaires were usable. The data came from 93 firms, so that the response rate was 31.00 percent at the firm level and 19.21 percent for the individual respondents. We controlled for non-respondent bias by comparing several observable characteristics (number of employees, sales, geographical region) of respondent and nonrespondent firms. In most of them, there were no significant differences between respondents and non-respondents, however, larger firms (number of employees: $\mathrm{t}=2.04, \mathrm{p}<.05$, sales: $\mathrm{t}=$ $2.02, p<.05)$ seem to be overrepresented in the final data. Larger firms with more than 1,000 employees are the minority in our overall population, still from most of these firms we received completed questionnaires. However, the analysis procedure in configurational studies requires 
exhaustive covering of cases with theoretically meaningful differences rather than sample representativeness (Greckhamer et al., 2018). As our final data is composed of firms of a wide range of sizes, this requirement is fulfilled. Hence, we are confident that non-response bias does not present a major issue in this study.

\section{Research Variables and Construct Measurement}

Data on most research variables was collected based on item scales with seven-point Likert ratings $(1=$ "completely disagree" to $7=$ "completely agree"). The outcome variable product innovation performance was assessed based on three items that indicate the firms' innovation achievements in relation to its competitors in the industry (Yli-Renko et al., 2001). As the energy industry lacks rich patent data and financial data that may serve as an indication for product innovation performance is most often not available, we followed the common approach of using managers' evaluations (e.g. Zhang and Li, 2010). In order to ensure the validity of this approach, however, we also drew on objective data for triangulation. Manually, we scanned the nominees and award winners of the four most important innovation awards in Germany as well as six major industry-specific innovation awards for the five-year timespan between 2014 and 2018. In all, the firms in the sample were awarded with 29 nominations and awards in this period. For each firm, we calculated a count measure that added up awards and nominations earned by that firm. The Pearson correlation between this count measure and the self-ratings were significant and adequately large $(\mathrm{r}=.42, \mathrm{p}<.01)$. Thus, we are confident in the validity of our item-based measure.

In order to depict each firm's partner network, a sociometric approach was employed (Wasserman and Faust, 1994). Thereby, inter-firm network ties were elicited via the following name generator question (Borgatti et al., 2013):

Please name the firms from which your company received knowledge relevant for innovation activity within the last three years. This knowledge receipt may stem from formal exchange during joint $R \& D$ projects, discussions in innovation circles, etc., or from informal exchange on the personal level, among others. Please include as many firms as you consider to be relevant knowledge sources.

As a result, we obtained the partner network of each firm in the sample. The variable network size is represented by the number of ties that were stated by the respondents. In a further step, we used interpreter questions in order to rate each partner and relationship: partner innovativeness ("Please rate the innovativeness of this partner (i.e., the success of this partner's efforts to develop and introduce new products, services, processes, and business models)!") (Zaheer and Bell, 2005), partner complementarity ("Please rate the complementarity between you and this partner firm (i.e., the degree to which this partner's resources, skills, and expertise differ from your own resource base and add to it)!") (Fang, 2011; Pullen et al., 2012), and partner diversity ("Please rate the uniqueness of this partner's resources, skills and expertise (i.e., the degree to which this partner's resources differ from those of your other partner firms)!") (Rodan and Galunic, 2004), were assessed via single items. The use of single item scales is common in network studies, as this approach is often necessary to keep the time the respondents invest to complete the sociometric questionnaire in a reasonable range (Borgatti 
et al., 2013). As tie strength in interfirm relations is a construct that comprises several different dimensions and meanings (Capaldo, 2007; Granovetter, 1973), we used a three-item measure based on Kale et al. (2000). For each of these four variables, we aggregated and averaged the ratings across all partners for each firm in order to obtain measures for the overall innovativeness, complementarity, diversity, and tie strength of the whole partner network.

In order to determine the firm size, we used data on the number of employees, the size of the utility's distribution area, and sales volume in 2016. Data on these three variables was obtained by the company presentation and the annual reports published by the firms. The variable human capital was computed by the respondents' ratings on a four-item scale that was based on Subramaniam and Youndt (2005). For all research variables in our study, Table 1 depicts means, standard deviations and correlations; Table 2 summarizes the items used in the scales. 
Table III-3-1. Means, standard deviations, and correlations

\begin{tabular}{|c|c|c|c|c|c|c|c|c|c|c|c|c|}
\hline & Variable & Mean & S. D. & 1 & 2 & 3 & 4 & 5 & 6 & 7 & 8 & 9 \\
\hline 1. & Product Innovation Performance & 4.08 & 1.08 & & & & & & & & & \\
\hline 2. & Firm Size (No. of Employees) & 580.59 & 1350.01 & .14 & & & & & & & & \\
\hline 3. & Firm Size (People in Distribution Area) ${ }^{\dagger}$ & 131.92 & 211.12 & .03 & $.70 * * *$ & & & & & & & \\
\hline 4. & Firm Size (Sales) ${ }^{\dagger \dagger}$ & 416.92 & 1196.49 & .15 & $.94 * * *$ & $.69 * * *$ & & & & & & \\
\hline 5. & Human Capital & 4.43 & 1.28 & $.46^{* * *}$ & -.01 & -.17 & .02 & & & & & \\
\hline 6. & Network Size & 10.15 & 5.81 & $.43^{* * *}$ & .18 & .07 & .17 & $.23^{*}$ & & & & \\
\hline 7. & Partner Innovativeness & 4.07 & 1.42 & $.59 * * *$ & .04 & -.08 & .02 & $.43 * * *$ & -.01 & & & \\
\hline 8. & Partner Complementarity & 4.32 & 1.23 & $.54 * * *$ & .13 & .02 & .11 & $.32 * *$ & .09 & $.32 * *$ & & \\
\hline 9. & Partner Diversity & 4.02 & 1.11 & $.29 * *$ & -.06 & .01 & -.07 & .12 & $.22 *$ & .02 & $.26^{*}$ & \\
\hline & Tie Strength & 4.13 & 1.33 & $.34 * *$ & .08 & .08 & .09 & .11 & -.02 & $.41 * * *$ & $.21^{*}$ & .04 \\
\hline
\end{tabular}


Table III-3-2. Construct specifications and item loadings

\begin{tabular}{|c|c|c|c|c|}
\hline & Item & Load & Mean & S.D. \\
\hline Product & We develop and introduce new product-/service offerings in the market. & .761 & 3.97 & 1.37 \\
\hline Innovation & We regularly improve existing product-/service bundles. & .802 & 4.53 & 1.33 \\
\hline $\begin{array}{l}\text { Performance } \\
(\alpha=.76, \\
\mathrm{CR}=.82 \\
\mathrm{AVE}=.61)\end{array}$ & Our product-/service offering is based on novel technologies. & .777 & 3.75 & 1.25 \\
\hline Human Capital & Our employees are experts in their particular jobs and functions. & .725 & 4.54 & 1.53 \\
\hline$(\alpha=.84$ & Our employees develop new ideas and knowledge. & .793 & 4.31 & 1.57 \\
\hline $\mathrm{CR}=.87$ & Our employees are widely considered among the most skilled in our industry. & .844 & 4.34 & 1.60 \\
\hline $\mathrm{AVE}=.63)$ & Our employees are creative and bright. & .817 & 4.52 & 1.54 \\
\hline $\begin{array}{l}\text { Tie Strength } \\
(\alpha=.81\end{array}$ & $\begin{array}{l}\text { In this relationship, we strive to create a win-win situation in which both firms have opportunities to learn and profit from } \\
\text { each others expertise. }\end{array}$ & .840 & 4.20 & 1.54 \\
\hline $\mathrm{CR}=.88$ & This relationship is characterized by personal communication and personal friendships at multiple levels. & .838 & 3.98 & 1.63 \\
\hline $\mathrm{AVE}=.70)$ & This relationship is characterized by frequent interaction and intensive mutual knowledge transfer. & .838 & 4.19 & 1.49 \\
\hline
\end{tabular}

Notes: $\alpha=$ Cronbach's $\alpha$; $\mathrm{CR}=$ Composite Reliability; AVE = Average Variance Extracted 


\section{Adequacy of Measurement}

We validated our measurement instrument based on the conventional quality criteria. Cronbach's alpha, composite reliability, average variance extracted (AVE) as well as all factor loadings surpassed the thresholds that are proposed in literature (Bagozzi and Yi, 1988). Discriminant validity is also adequate as AVE of each latent variable is greater than the squared correlation between the concerned and the other constructs so that the criterion by Fornell and Larcker (1981) is fulfilled. Finally, to test for common-method bias, we conducted Harman's one-factor test (Podaskoff et al., 2003). The unrotated factor solution indicated the existence of seven factors explaining $68.4 \%$ of the variance $(30.1 \%$ was the largest variance explained by a single factor). Thus, common method bias is unlikely a problem in our empirical data.

For 33 firms, two or more respondents completed the questionnaire. As we reached out to multiple key informants from each firm, there might be lack of agreement when there are multiple informants per firm (Kumar et al., 1993). We therefore assessed inter-rater reliability by calculating the percentage of item ratings in which a pair of respondents differs one point or less on the 7-point Likert-scale (78.3\% of ratings) (Schilke and Goerzen, 2010). In addition, for each pair of respondents from the same firm, the Pearson correlation across all items was calculated. The mean correlation was .53. However, this approach cannot be applied for the relational data, where respondents state to which partners their firm has a relationship. Here, we calculated the mean percentage agreement as proposed by Tsai and Ghoshal (1998), by dividing the number of ties that were named by both respondents by the number of all ties that were reported for the particular firm. The average mean percentage agreement was .78 in our study - a value that is well acceptable. For the Likert scale ratings on partner innovativeness, complementarity, diversity, and tie strength, inter-rater reliability was 75.5 percent (calculated analogous to Schilke and Goerzen's (2010) approach described above). Here, average Pearson correlation between the answers of respondents from the same firm was .65. Based on these tests for respondent bias, we are confident that both for firms with only one respondent as well as for those with more than one, the acquired data is robust and valid. For firms with more than one respondent we thus averaged the ratings.

\section{Set-theoretic Analysis}

For data analysis, we applied fsQCA methodology. This set-theoretic method of analysis treats research cases as combinations of causal conditions and outcomes and allows to extract configurations that consistently lead to the presence or absence of an outcome of interest (in our case product innovation performance) (Ragin, 2008). In the process of analysis, we deployed fsQCA software version 3.0 (Ragin and Davey, 2016). The procedure and the underlying assumptions of fsQCA differ considerably from those of regression analysis and other variance-based approaches that dominate empirical studies in management science. Instead of a statistical procedure of parameter estimation, fsQCA uses means of Boolean analysis in order to identify and extract high- or low-performing configurations (Ragin, 2008).

The fsQCA procedure does not treat data on research variables as absolute numbers but as indicators of set membership (e.g. if a firm is member in the set of highly innovative firms or if it is not). By comparing the set membership of the cases under study in the high respectively 
low outcome group, researchers can assess if a particular configuration of antecedent variables is necessary and/or sufficient for the outcome of interest to occur (Fiss, 2011; Ragin, 2008). This assessment is achieved in a three-phase procedure including the following steps of analysis: calibration, truth table refinement, and truth table analysis.

Calibration. In the first step, all construct measures need to be transformed into fuzzy-set membership scores, i.e., scores that determine the degree to which the research case at hand is a member in the set of firms that display the causal condition or the outcome in question (Ragin, 2008). This is achieved by defining a cross-over point that marks the borderline between setmembership and non-membership as well as thresholds for full membership and full nonmembership for all research variables (Fiss, 2011). Our survey measures were calibrated based on existing guidelines for the treatment of multi-item scales in fsQCA (Misangyi and Archarya, 2014). Thus, minimum, midpoint, and maximum of the seven-point Likert scale served as our calibration anchors $(1=$ full non-membership; $4=$ cross-over point; $7=$ full membership $)$. Fuzzy-set membership scores for each research case and research variable were then assigned using the formula developed by Fiss (2011).

As neither network size nor firm size are measured on Likert scales, we could not rely on this procedure of calibration for these two variables. For network size we lack congruent statements in literature that determine when a firm network is large and when it is not. Hence, we needed to rely on sample statistics for determining reasonable calibration anchors. We started by analyzing the distribution of the variable network size in the sample (see Figure 2). Research has shown that the number of network partners typically is distributed according to a power law (Baum et al., 2004). The power law assumes that in most networks observed empirically, differences in activity and popularity will lead to most actors in network possessing only a small number of partners ("tail" of the distribution), a smaller number of actors possessing a medium number of partners ("body"), whereas only very actors possess a high number of partners ("head") (Albert and Barabàsi, 2002). The distribution of our data on network size shows the skewedness to the right that is typical for power law distributions, and all three categories of firms in the distribution are also observable. Hence, we used the transition points to the "tail", "body", and "head" category as calibration anchors for network size ( 2 = full non-membership; $11.5=$ cross-over point; $19=$ full membership). As we did with the Likert scale ratings, we used these anchors to compute the fuzzy membership scores. 


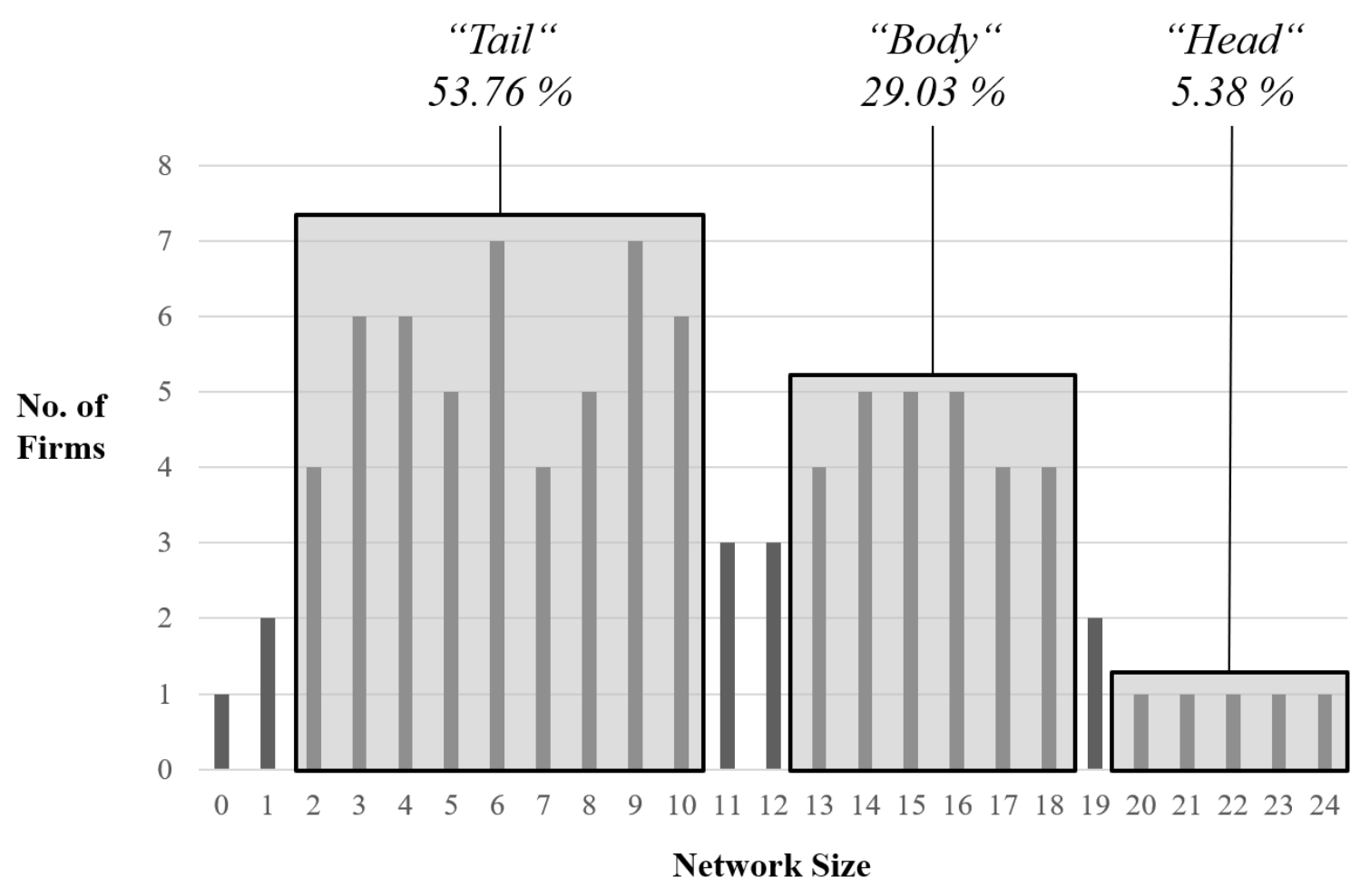

Figure III-3-2. Distribution of network size (own illustration)

Following the principle that calibration should be based on anchors that are universal and grounded in theory or contextual insight (Ragin, 2008), we assigned membership scores for the three indicators that measure firm size based on quantitative and qualitative data on the industry structure and the characteristics of municipal utilities (e.g. Berlo and Wagner, 2013; Doleski, 2016; Edelmann, 2015; Schlüter and Rottmann, 2017). For all three indicators of firm size, we used a scale with four degrees of membership $(0=$ full non-membership, $0.33=$ rather nonmembership, 0.67 = rather membership, $1=$ full membership) (Ragin, 2008) and assigned values to each firm accordingly (number of employees: $0 \hat{=}<100$ employees, $0.33 \hat{=}<300$, $0.67 \hat{=}<1000,1 \hat{=}>1000 ;$ size of distribution area: $0 \hat{=}<50,000$ inhabitants, $0.33 \hat{=}<$ $200,000,0.67 \hat{=}<500,000,1 \hat{=}>500,000$; sales: $0 \hat{=}<100$ million $€, 0.33 \hat{=}<250,0.67 \hat{=}<$ $800,1 \hat{=}>800)$. As all three indicators cover different aspects of firm size and are used to determine the utility's size in official statistics, we assigned the overall membership score when the firm surpassed the particular threshold for at least two of the three indicators.

Truth Table Refinement. In the second step of fsQCA, a truth table is constructed that depicts all potential combinations of the antecedent variables in the research model (i.e., $2^{\mathrm{k}}$ combinations with $\mathrm{k}=$ number of antecedent variables) (Ragin, 2008). Subsequently, all research cases are sorted into that truth table, before lines with little empirical relevance are eliminated based on a defined frequency threshold and the performance of the remaining configurations is coded based on a defined consistency threshold. In line with advice on how to handle samples with $N<100$, we set the frequency threshold to 1 , making sure that all combinations that were observed empirically were also included in the analysis (Greckhamer et al., 2013). Out of the 128 entries in the truth table ( $2^{7}$ for seven causal conditions in the 
model), 56 of these configurations were present in our data (43.8\%). Limited diversity is thus unlikely to be a problem. Concerning the consistency threshold, literature suggests values of at least .8 for raw consistency and .75 for PRI consistency (Misangyi and Acharya, 2014). Hence, we used both values for assigning high-performing and low-performing configurations.

Truth Table Analysis. Based on this refined truth table, fsQCA extracts the configurations that consistently lead to the outcome of interest on the basis of the Quine-McCluskey algorithm (Ragin, 2008). In the procedure, fsQCA identifies which configurations consistently lead to a particular outcome, compares the configurations identified, and eliminates redundant or unnecessary variables. The Quine-McCluskey algorithm thereby produces two different solutions based on which the causal relevance of all antecedent variables in a given configuration can be assessed, the parsimonious and the intermediate solution (Fiss, 2011). If a research variable appears both in the parsimonious and the intermediate solution, this variable is termed a "core condition" of a specific configuration. That is to say, there is stronger evidence for this variable to impact the outcome of interest so that the variable can be seen as causally essential for the effect of the configuration in which it is part (Fiss, 2011). In contrast, if a variable appears only in the intermediate solution, it is termed a "peripheral condition". Hence, in the particular configuration, the variable supports the effect of the core conditions but is rather expandable or exchangeable for explaining the outcome of interest (Fiss, 2011).

\section{RESULTS}

\section{High Performance Configurations}

Using fsQCA, we analyzed whether there are sufficient solutions that consistently lead to high product innovation performance. Table 3 illustrates the results of this analysis. In all, there are four major solutions, meaning network profiles that are sufficient for high levels of product innovation performance. Solution 1 involves high levels of partner complementarity and tie strength as well as low level of partner diversity as core conditions. This configuration is only successful for small firms with low levels of human capital. The causal core of solution 2 is represented by high levels of partner innovativeness and tie strength. This network profile is effective for companies with small size but high level of human capital. Solution 3 depicts a large network with highly innovative partners and weak ties. This network profile works well for firms with high human capital, both small and large. Solution 4 combines large network size with high level of partner complementarity as core conditions. For this configuration to be instrumental for product innovation, the firm has to be of large size.

The consistency of the single solutions ranges between .97 and .99. The consistency of the combined solution is .96 , which indicates a high quality of the results (Ragin, 2008). Raw coverage that computes the link between solution set and outcome set independently for all configurations varies between .21 and .50 whereas unique coverage that controls for overlap between the configurations in the solution set ranges between .01 and .06 . Solution $2 \mathrm{a}$ and $2 \mathrm{~b}$ have the highest coverage scores, which means that these configurations occur most frequently in the sample. The coverage of the overall solution is .78. Hence, the identified configurations explain 78 percent of the instances in which the research cases achieve high innovation performance, which is a good level of overall coverage (Ragin, 2008). 
Table III-3-3. Sufficient solutions for high product innovation performance

\begin{tabular}{|c|c|c|c|c|c|c|c|c|}
\hline & \multicolumn{6}{|c|}{ Solution } & \multirow[b]{2}{*}{$4 a$} & \multirow[b]{2}{*}{$4 b$} \\
\hline & 1 & 2a & $2 \mathbf{b}$ & $2 c$ & $3 \mathbf{a}$ & $3 \mathbf{b}$ & & \\
\hline \multicolumn{9}{|l|}{ Context } \\
\hline \multicolumn{9}{|l|}{ Firm Size } \\
\hline Human Capital & $\otimes$ & & & & & & $\otimes$ & $\bullet$ \\
\hline \multicolumn{9}{|l|}{ Network } \\
\hline Network Size & $\otimes$ & & ? & $\otimes$ & & & & \\
\hline Partner Innovativeness & $\otimes$ & & & & & & $\otimes$ & \\
\hline Partner Complementarity & & & $\otimes$ & $\bullet$ & $\bullet$ & & 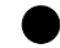 & 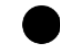 \\
\hline Partner Diversity & & $\bullet$ & & & $\otimes$ & & & $\bullet$ \\
\hline Tie Strength & & & & & $\otimes$ & $\bigotimes$ & $\otimes$ & $\otimes$ \\
\hline Consistency & .98 & .99 & .97 & .98 & .98 & .97 & .99 & .99 \\
\hline Raw Coverage & .33 & .50 & .32 & .46 & .35 & .27 & .21 & .27 \\
\hline Unique Coverage & .05 & .04 & .01 & .06 & .01 & .02 & .01 & .02 \\
\hline Overall Solution Consistency & & & & 96 & & & & \\
\hline Overall Solution Coverage & & & & 78 & & & & \\
\hline
\end{tabular}

Notes: Black circles indicate the presence of a condition, circles with " $x$ " indicate its absence. Large circles indicate core conditions, small ones indicate peripheral conditions. Blank spaces indicate that the condition may be either present or absent.

\section{Low Performance Configurations}

Furthermore, the deployment of the fsQCA methodology also allows to identify six major configurations that consistently lead to a low performance outcome (see Table 4). As in the case of the high-performing configurations the consistency and coverage values of the overall as well as the single solutions of low-performing configurations are high. In line with the notion of causal asymmetry, it can be observed that some (Solutions 1b, 3a, 3b, 4, 6) but not all lowperforming configurations are partial mirror images of one of the high-performing configurations. Moreover, we have three additional interesting findings: (1) There are solutions in which high levels of partner innovativeness may harm innovation performance rather than enhance it - namely, when the human capital of the firm is low (Solutions 2, 3, 4, 6). (2) In most solutions pairing two partner-related network characteristics (partner innovativeness, partner complementarity, and partner diversity) does not work well for innovation (Solutions 1a, 2, 3b, 4, 5, 6). (3) All solutions, without any exception, depict partner networks of low size. 
Table III-3-4. Sufficient solutions for low product innovation performance

\begin{tabular}{|c|c|c|c|c|c|c|c|c|c|}
\hline & \multicolumn{6}{|c|}{ Solution } & \multirow[b]{2}{*}{$5 \mathbf{a}$} & \multirow[b]{2}{*}{$\mathbf{5 b}$} & \multirow[b]{2}{*}{6} \\
\hline & 1a & $1 \mathrm{~b}$ & 2 & 3a & $3 \mathbf{b}$ & 4 & & & \\
\hline \multicolumn{10}{|l|}{ Context } \\
\hline $\begin{array}{l}\text { Firm Size } \\
\text { Human Capital }\end{array}$ & $\otimes$ & $\otimes$ & \multicolumn{2}{|l|}{$\otimes$} & $\otimes$ & \multicolumn{2}{|l|}{$\otimes$} & • & $\otimes$ \\
\hline \multicolumn{10}{|l|}{ Network } \\
\hline Network Size & $\otimes$ & $\otimes$ & $\bigotimes$ & $\otimes$ & $\otimes$ & $\otimes$ & $\otimes$ & $\otimes$ & $\otimes$ \\
\hline Partner Innovativeness & $\otimes$ & $\otimes$ & $\bullet$ & & $\bullet$ & & $\otimes$ & $\otimes$ & \\
\hline Partner Complementarity & & $\otimes$ & $\otimes$ & $\otimes$ & $\otimes$ & & $\bullet$ & $\bullet$ & $\otimes$ \\
\hline Partner Diversity & & $\otimes$ & $\bullet$ & $\otimes$ & $\bullet$ & $\otimes$ & & $\bullet$ & \\
\hline Tie Strength & $\otimes$ & & $\otimes$ & $\bullet$ & & & $\otimes$ & & $\otimes$ \\
\hline Consistency & .98 & .99 & .99 & .98 & .99 & .98 & .99 & 1.00 & .99 \\
\hline Raw Coverage & .50 & .44 & .32 & .40 & .22 & .22 & .39 & .21 & .39 \\
\hline Unique Coverage & .04 & .01 & .01 & .02 & .01 & .01 & .01 & .01 & .02 \\
\hline Overall Solution Consistency & \multicolumn{9}{|c|}{.97} \\
\hline Overall Solution Coverage & \multicolumn{9}{|c|}{.67} \\
\hline
\end{tabular}

Notes: Black circles indicate the presence of a condition, circles with " $\mathrm{x}$ " indicate its absence. Large circles indicate core conditions, small ones indicate peripheral conditions. Blank spaces indicate that the condition may be either present or absent.

\section{Sensitivity Analyses}

In line with previous studies that employ fsQCA, we did several tests to ensure the robustness of our results. First, we reran the analysis with changed calibration anchors (Fiss, 2011). Thereby, we changed the thresholds for full non-membership and full membership from 1 to 2 and from 7 to 6 respectively and varied the cross-over point to 3.5 and 4.5 for the Likert scale variables. For firm size and network size, we also tested different calibration. For instance, for network size, we tested a sample-based calibration procedure using the sample mean as crossover point, the 90-percent-quantile for determining full membership, and the 10-percentquantile for determining full non-membership. Second, in the truth table refinement procedure, we varied the frequency threshold and conducted the analysis by including only configurations that had at least two and at least three empirical instances in the data. Finally, in the truth table refinement, we also varied the criterion for raw and PRI consistency. In all, the robustness checks conducted brought about only minor variations in the results (especially concerning the number of solutions and neutral permutations). Overall, the results exhibited the same general patterns. The results of the robustness checks can be obtained from the authors on request.

\section{DISCUSSION}

\section{Interpretation of the Identified Configurations}

The purpose of this study was to understand through the lenses of configurational theory how complex multidimensional network profiles affect firms' product innovation performance. Based on previous research literature, we developed a configurational model that integrates five 
key network characteristics and two firm-level variables. Using this holistic model as a settheoretic framework for an empirical study in the German energy industry, we identified four different configurations that consistently lead to high innovation performance.

Solution 1: Focused and Complementary Strong-Tie-Network. The first innovation-fostering network combines high partner complementarity, high tie strength, and low partner diversity in its causal core. Low network size and low partner innovativeness complement this configuration as peripheral conditions. In this case, the focal firm has built a closely-knit group of partners that are able to compensate the firm's knowledge and competence deficiencies. Small network size and low partner diversity point towards a rather selective approach by which partners are carefully assessed concerning their fit. We argue that this network profile is likely to provide several benefits for innovation. It enables an efficient transfer of relevant, complementary and non-redundant knowledge and expertise with low transaction costs thanks to the similarity between the partners and high access security due to the strong ties to them. This finding creates more insight concerning the results of previous studies as Gilsing et al. (2008) and Bae and Gargiulo (2004) also advocated an interaction between complementary resources and strong cohesion in a firm's network but reported mixed evidence for this effect.

Furthermore, our analysis shows that this portfolio only works well for small firms that possess low internal expertise and small amount of human capital. These firms do not have the capacity to deal with large information volume, they cannot afford to engage in resource-consuming adventures, and might be exposed to considerable risks when a partnership goes wrong (Ettlie and Rubinstein, 1987; Huggins and Johnston, 2010). Moreover, due to low human capital these small firms may simply not be able to profit from cutting-edge external expertise (Rothaermel and Hess, 2007) or might lose learning races with more innovative partners (Kale et al., 2000). Hence, this network profile could represent the only chance for this type of firms to access the required resources and realize potential benefits during NPD projects.

Solution 2: Innovative Strong-Tie-Network. The second network profile is mainly characterized by high partner innovativeness and high tie strength. This portfolio enables a continuous access to external sources of highly valuable and novel knowledge and is associated with low relational risk (Das and Teng, 1996). Such an "elite circle" (Pisano and Verganti, 2008) of capable innovators might lead to the creation of cutting-edge knowledge and boost the innovative output for all partners. While networks with similar characteristics have already been described in case studies (Filieri et al., 2014; Ojasalo, 2008), our work stands out by creating a more comprehensive empirical evidence for the beneficial effects of the combination of partner innovativeness and tie strength. Moreover, our results also demonstrate that these two key network features must be complemented with at least one of the three other examined network characteristics in order to foster product innovation performance. Hence, either the large resource volume that is associated with big network size, or the precise fit of resources provided by partner complementarity, or the bandwidth of resources provided by partner diversity constitute needed peripheral conditions for enabling the beneficial effects.

Furthermore, we found that this network profile benefits only one category of firms - small companies that are highly knowledgeable. In contrast to organizations with low human capital, 
firms of this type do not only receive expertise and insights from "elite partners" but are also able to actively contribute high quality knowledge on their own (Pisano and Verganti, 2008). As the cohesion and retention of such networks strongly depend on mutual benefits (Ojasalo, 2008), only firms with profound internal knowledge base will be able to uphold collaborative relationships with innovative partners. Moreover, as small firms might lack the capacity for compensating failed partnerships or mitigate the relational risks of choosing the wrong partners (Filieri et al., 2014; Das and Teng, 1996), the collaborative advantages of strong ties (Nahapiet and Ghoshal, 1998) are highly important for this type of firm.

Solution 3: Large and Innovative Weak-Tie-Network. Large network size, high partner innovativeness, and low tie strength are the main features of this profile. This network is likely to deliver a large volume of new and useful knowledge and expertise. The focal firm can thus keep informed about the newest developments in technological and market environment. Hence, it is likely to be able to react more effectively and timelier to external changes and outpace the competition in NPD (Ozcan and Eisenhardt, 2009). Furthermore, weak ties cause smaller costs for maintenance and reciprocal services compared to strong ties, which helps the firms to use more time and resources to expand the network (Fliaster and Spiess, 2008).

Past quantitative studies that investigated the interactions between the causal effects of partner innovativeness and network size produced inconsistent results as both positive (Zaheer and Bell, 2005) and negative interactions (Operti and Carnabuci, 2014) have been reported. Our findings shed more light on this issue: one reason for the inconsistency might be that previous studies did not include specific firm characteristics in the interaction effect. Our results indicate that this type of network only works for firms with high level of human capital. Only firms with profound internal expertise possess the absorptive capacity for gaining the benefits from innovative knowledge acquired from external sources (Ritala and Hurmelinna-Laukanen, 2013). On the other hand, when a firm has superior human capital, partners may be more likely to tolerate the firm's "polygamy because of the firm's superior information" (Ozcan and Eisenhardt, 2009: 264). When we add firm size to the equation, the results indicate that small firms can only profit from such a network when partner complementarity is high and partner diversity is low. For large firms, those characteristics are not causally relevant.

Solution 4: Large Network with Complementary Resources. The fourth innovation-fostering network profile is characterized by large network size and high partner complementarity as core elements. Interaction effects between these two network characteristics have been rarely investigated in previous works. However, the case studies presented by Ojasalo (2008), Taylor and Levitt (2007), and Gann and Salter (1998) indicate that such a network profile can result from a series of innovation projects: for every initiated NPD project, the focal firm scans the external environment selecting potential partners who are likely to contribute the required resources that it does not possess internally. As these relations have a defined functional and temporal scope, most of them remain weak ties. This line of reasoning is also supported by our finding that revealed low tie strength as peripheral condition within this solution. Consequently, over time the firm develops a network portfolio that is composed of many specialized collaborators with complementary resources. 
Our analysis shows that this portfolio works well for large firms, independent of human capital. Large firms may be able to profit more from this type of network as they usually have numerous innovative projects in place simultaneously so that the usage rate of a large network with complementary partners is likely to be high (Rothaermel and Deeds, 2004). Small firms may lack the capacity to deal with a big network of this type (Alvarez and Barney, 2001). Comparing firms with high and low human capital, we observe that for low human capital, low partner innovativeness, whereas for high human capital, high partner diversity complements the causal core. This finding provides an additional support for the above conclusion that companies with low human capital seem to be better off dealing with less innovative partner firms.

\section{Theoretical Implications}

By identifying the four innovation-fostering configurations, that is, bundles of network characteristics that exert conjunctural effects on product innovation performance, our results bring about several insights that contribute to a better theoretical understanding of firms' partner networks in the context of innovation management.

First, our results shed light on the general question of what characterizes an innovation-fostering partner network, that is, which network variables actually explain differences in firm innovation performance and which theoretical mechanisms prevail (Borgatti and Foster, 2003; Borgatti and Halgin, 2011; Phelps et al., 2012; Pittaway et al., 2004). All innovation-fostering solutions build on combinations of either large network size or high tie strength with high partner innovativeness or with high partner complementarity. In countercheck, for the innovationhindering configurations such a combination is missing. In other words, all four possible combinations of network size and tie strength on the one hand, and partner innovativeness and partner complementarity on the other hand appear as the causal core of innovation-fostering configurations. This finding indicates that the causal mechanisms that these network characteristics induce are strongly synergistic.

On a more abstract level, we observe that in each successful configuration there is one causal mechanism that is linked to resource volume and one causal mechanism that is linked to resource content (Gulati et al., 2011; Wassmer, 2010). On the volume dimension, network size benefits product innovation especially by the large amount of resources that network partners provide to the focal firm, whereas high tie strength allows for deep and comprehensive access to rich resources of the partner firms, such as tacit knowledge (Nahapiet and Ghoshal, 1998). On the content dimension, high partner innovativeness grants access to resources that are valuable and novel for the recipient, whereas partner complementarity fosters innovation thanks to the resource fit. Neither of these mechanisms is sufficient for predicting innovation performance. Rather, it is a synergistic interplay between these both dimensions that represents as a key feature of innovation-fostering partner networks: To foster innovation performance firms must combine large network size or high tie strength with high partner innovativeness or with high partner complementarity (see Figure 3). 


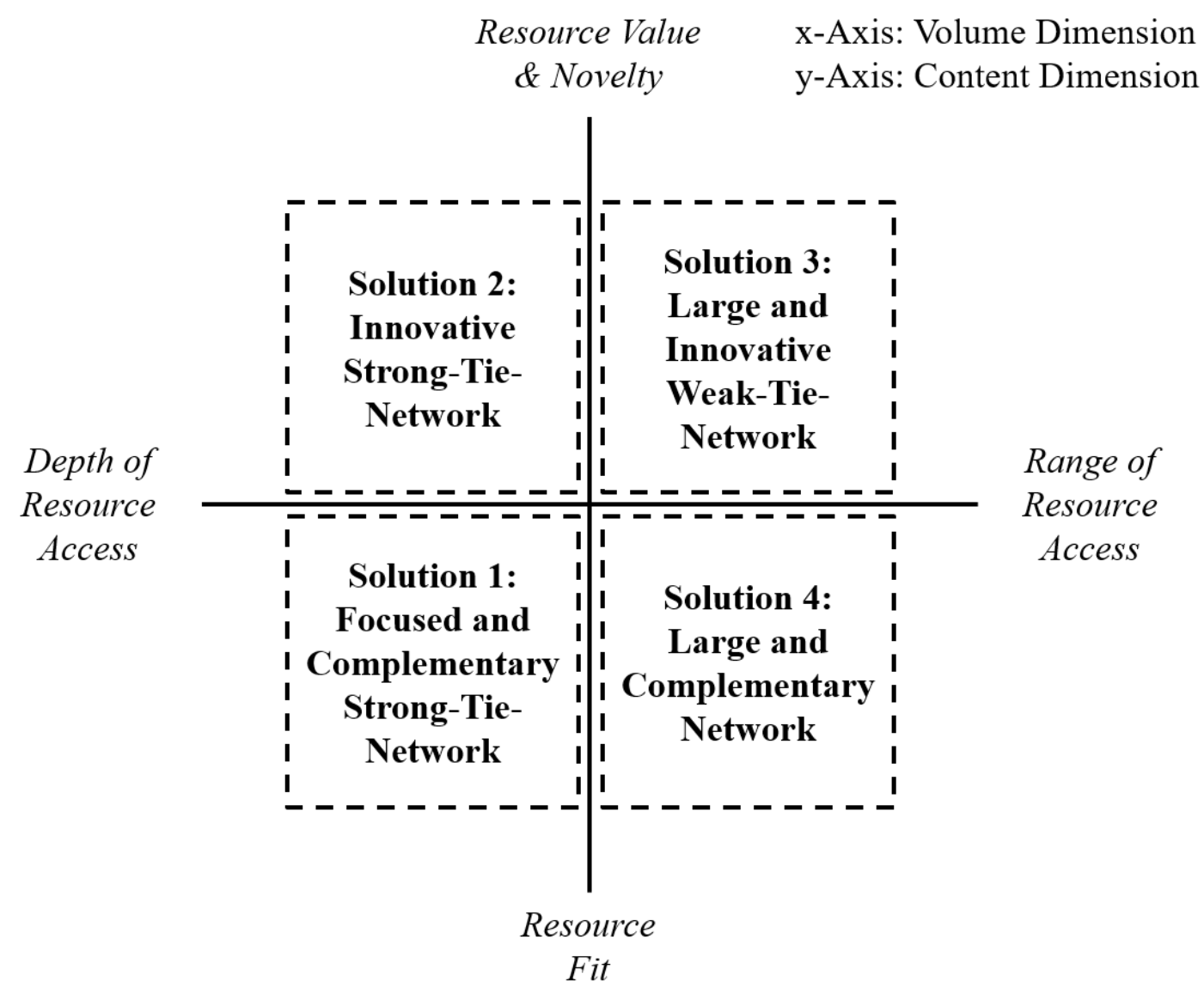

Figure III-3-3. Summary of innovation-fostering configurations (own illustration)

Second, we contribute to literature by providing evidence that different network characteristics may not only produce positive, but also negative interactive effects. Most interestingly, our results demonstrate that valence reversals, that is, causal conditions that are beneficial in some configurations also are detrimental to the outcome of interest in at least one other configuration (Ragin, 2008), are quite prominent in the observed network profiles. Except for Solution 2a, all other profiles require the absence of at least one of the examined network characteristics. Hence, our results contradict the assumptions of previous configurational studies on firms' partner networks, which assume innovation-fostering networks to follow a "the-more-the-better" logic (Pullen et al., 2012; Zaefarian et al., 2013). Our analysis reveals that depending on the configuration, certain network characteristic may add no value to the conjunctural effect. As many network characteristics, such as network size and tie strength, are difficult and costly to obtain and maintain (Hoffmann, 2007; Ozcan and Eisenhardt, 2009; Wassmer, 2010), the absence of useless characteristics is thus more beneficial than their presence.

In particular, we observe such detrimental or even conflicting effects in the interplay between network size and tie strength. Except for Solutions $2 \mathrm{a}$ and $2 \mathrm{~b}$, either of these network characteristics is absent when the other is present. This finding supports previous network research which argues that strong ties are costly, e.g. time-consuming, and accumulating too many of these ties might harm innovators rather than benefit them (e.g. Fliaster and Spiess, 2008; Mariotti and Delbridge, 2012). Our results indicate that to innovate successfully firms 
must choose between two alternatives - building either a small but cohesive network or a large network with a high number of weak ties (Capaldo, 2007). In doing so, firms can prevent that costs of network maintenance outweigh the benefits provided by these network characteristics.

Finally, our results add insight to research on the interaction between firm-level and networklevel variables (e.g. Huggins and Johnston, 2010; Rothaermel and Hess, 2007). Our data reveal that various network profiles foster product innovations only if particular firm-level characteristics (e.g. firm size and its human capital) are at play. In order to provide a better overview on which configurations are effective for which type of firms, Table 5 structures the firm context in a 2-by-2 matrix and fills in the innovation-fostering configurations in the corresponding quadrants.

Table III-3-5. Solutions for high product innovation performance: Contingency perspective

\begin{tabular}{|c|c|c|c|}
\hline & & \multicolumn{2}{|c|}{ Human Capital } \\
\hline & & Low & High \\
\hline \multirow[t]{2}{*}{ Firm Size } & Low & $\sim$ NWSIZE* ${ }^{*}$ INNO*COMPL* DIVERS*TIESTR & $\begin{array}{c}\text { INNO*DIVERS*TIESTR }+ \\
\text { NWSIZE*INNO* } * \text { COMPL*TIESTR }+ \\
\sim \text { NWSIZE*INNO*COMPL*TIESTR }+ \\
\text { NWSIZE*INNO*COMPL* DIVERS* } * \text { TIESTR }\end{array}$ \\
\hline & High & NWSIZE* ${ }^{*}$ INNO*COMPL* TIESTR & $\begin{array}{l}\text { NWSIZE*INNO* TIESTR }+ \\
\text { NWSIZE*COMPL*DIVERS* TIESTR }\end{array}$ \\
\hline
\end{tabular}

Notes: NWSIZE $=$ Network Size; INNO = Partner Innovativeness; COMPL = Partner Complementarity; DIVERS = Partner

Diversity; TIESTR $=$ Tie Strength

$\sim=$ logical NOT; $+=$ logical OR; * = logical AND

Bold font indicates core conditions

For both high and low values on the firm size and on the human capital dimensions, there exists a preference for particular network characteristics. For firms of different size, different volumerelated network characteristics are preferable. In contrast, for firms with different amounts of human capital, different content-related network characteristics are effective in supporting innovation. Available capacity, slack, and possible risk mitigation allow large firms to operate large networks (Damanpour, 1991), while the higher number of initiatives and projects in these firms may even necessitate larger networks and higher volumes of resource input (Huggins and Johnston, 2010). In contrast, while small firms also might be successful with a large network (Solution 2a, 2b), a small circle of trusted partners will more likely meet their specific needs and capabilities. Concerning human capital, only high amount of own knowledge and expertise allows firms to benefit from partnerships to highly innovative partners. With low human capital, firms must rather aim to close their existing resource deficiencies by their partner network.

\section{Managerial Implications}

Our findings provide several implications for managerial practice. First, our configurational model that includes five different network characteristics may serve as a framework for firms to systematically analyze and monitor their current network. This analysis allows for the unveiling of innovation-related strengths and weaknesses and the developing of network 
interventions, such as the establishment of new or the cancellation of existing collaborative relationships and the strengthening of dyadic ties. Furthermore, as the key network characteristics are quantified, the success of interventions can be also measured and monitored. In sum, the "ideal profiles" uncovered by the configurational analysis may serve as strategic blueprints for making the firm's network more "governable" and thus innovation-friendly. Second, our research highlights the value of human capital and outlines that also from the network perspective, the development of this internal asset should be high on the strategic agenda of each firm. Not only does human capital influence innovation performance directly, but it also opens up the scope of choices and actions for firm's networking and portfolio strategies. Finally, our study shows that for small and big firms, networks with different configurations of attributes are instrumental. This insight might help firms define more customized collaboration strategies adapting their networks to organizational growth (or even decline).

\section{Limitations and Further Research}

Our work has several limitations that indicate promising avenues for further research. First, our empirical study is located in the context of the German energy industry. The energy sector is of high economic weight, faces important innovation challenges, and partner networks represent an important means for conducting innovation projects and initiatives. Nevertheless, it might represent a special case, and our findings may be specific to this industry context. Further research should conduct similar studies in other industries in order to test whether the identified network profiles and the underlying causal mechanisms are robust across empirical settings. Second, our research focused at egocentric networks, i.e., the collection of direct ties that a firm possesses. This conceptualization was appropriate with regard to our research objective. Nevertheless, it leaves out the effect of larger network structures and the positioning of the firm within these structures (see Provan et al., 2007 for an overview). Previous research has shown that the firm's position in the whole network (e.g. within an industry segment) might considerably influence its innovation performance (Phelps, 2010). Hence, future research should extend the configurational approach presented here to the network level of analysis. Third, by conceptualizing the firm's network as a collection of ties, we operationalized all partner-related and relational network characteristics as mean values across all ties in the network. Consequently, in this research approach a firm that has an equal number of very strong and very weak ties would have been treated like a firm with all moderately strong ties. Past research indicates that such compositional differences might indeed lead to different performance outcomes (e.g. Capaldo, 2007). Therefore, we suggest that future works should incorporate a more fine-grained perspective on this issue in the subsequent configurational models. Finally, some methodological limitations have to be mentioned. In particular, we relied on cross-sectional data and used self-report measures. Though we took several measures that we consider appropriate to deal with potential biases that might stem from our data collection approach, we suggest that future research should draw on longitudinal data and consult a larger range of data sources. In sum, we hope that the results of our study have contributed to a better understanding of the complex interplay of the firms' internal characteristics and their network profiles in fostering innovation and encouraged future research on this intriguing and important issue. 


\subsection{References}

Ahuja, G. 2000. Collaboration networks, structural holes, and innovation: a longitudinal study. Administrative Science Quarterly 45 (3): 425-455.

Albert, R. and A. L. Barabási. 2002. Statistical mechanics of complex networks. Reviews of Modern Physics 74 (1): 47-99.

Alvarez, S. A. and J. B. Barney. 2001. How entrepreneurial firms can benefit from alliances with large partners. Academy of Management Perspectives 15 (1): 139-148.

Bae, J. and M. Gargiulo. 2004. Partner substitutability, alliance network structure, and firm profitability in the telecommunications industry. Academy of Management Journal 47 (6): 843-859.

Bagozzi, R. P. and Y. Yi. 1988. On the evaluation of structural equation models. Journal of the Academy of Marketing Science 16 (1): 74-94.

Baker, W. E., A. Grinstein and N. Harmancioglu. 2016. Whose innovation performance benefits more from external networks: entrepreneurial or conservative firms?. Journal of Product Innovation Management 33 (1): 104-120.

Barney, J. 1991. Firm resources and sustained competitive advantage. Journal of Management 17 (1): 99-120.

Baum, J. A. C., T. Calabrese and B. Silverman. 2000. Don't go it alone: alliance network composition and startups' performance in Canadian biotechnology. Strategic Management Journal 21 (3): 267-294.

Baum, J. A. C., T. J. Rowley and A. V. Shipilov. 2004. The small world of Canadian capital markets: statistical mechanics of investment bank syndicate networks, 1952-1989. Canadian Journal of Administrative Sciences 21 (4): 307-325.

Becker, W. and J. Dietz. 2004. R\&D cooperation and innovation activities of firms - Evidence for the German manufacturing industry. Research Policy 33 (2): 209-223.

Berlo, K. and O. Wagner. 2013. Stadtwerke-Neugründungen und Rekommunalisierungen. Wuppertal: Wuppertal Institut für Klima, Umwelt, Energie.

Borgatti, S. P., M. G. Everett and J. C. Johnson. 2013. Analyzing Social Networks. Los Angeles: SAGE Publications.

Borgatti, S. P. and D. S. Halgin. 2011. On network theory. Organization Science 22 (5): 11681181.

Brettel, M. and N. J. Cleven. 2011. Innovation culture, collaboration with external partners and NPD performance. Creativity \& Innovation Management 20 (4): 253-272.

Burt, R. S. 1992. Structural holes: the social structure of competition. Cambridge: Harvard University Press.

Capaldo, A. 2007. Network structure and innovation: the leveraging of a dual network as a distinctive relational capability. Strategic Management Journal 28 (6): 585-608.

Damanpour, F. 1991. Organizational innovation: a meta-analysis of effects of determinants and moderators. Academy of Management Journal 34 (3): 555-590.

Das, T. K. and B. Teng. 1996. Risk types and inter-firm alliance structures. Journal of Management Studies 33: 827-843

Doleski, O. 2016. Utility 4.0. Wiesbaden: Springer Vieweg. 
Doty, D. H., W. H. Glick and G. P. Huber. 1993. Fit, equifinality, and organizational effectiveness: a test of two configurational theories. Academy of Management Journal 36 (6): 1196-1250.

Dyer, J. H. and H. Singh. 1998. The relational view: cooperative strategy and sources of interorganizational competitive advantage. Academy of Management Review 23 (4): 660-679.

Edelmann, H. 2015. Gewohnte Wege verlassen - Innovation in der Energiewirtschaft. Düsseldorf: Ernst \& Young.

Emden, Z., R. J. Calantone and C. Droge. 2006. Collaborating for new product development: selecting the partner with maximum potential to create value. Journal of Product Innovation Management 23 (4): 330-341.

Ettlie, J. E. and A. H. Rubenstein. 1987. Firm size and product innovation. Journal of Product Innovation Management 4 (2): 89-108.

Fang, E. 2011. The effect of strategic alliance knowledge complementarity on new product innovativeness in China. Organization Science 22 (1): 158-172.

Filieri, R., R. C. McNally, M. O'Dwyer and L. O'Malley. 2014. Structural social capital evolution and knowledge transfer: evidence from an Irish pharmaceutical network. Industrial Marketing Management 43 (3): 429-440.

Fiss, P. C. 2011. Building better causal theories: a fuzzy set approach to typologies in organization research. Academy of Management Journal 54 (2): 393-420.

Fliaster, A. and J. Spiess. 2008. Knowledge mobilization through social ties: the cost benefit analysis. Schmalenbach Business Review 60 (1): 99-117.

Fornell, C. and D. F. Larckner. 1981. Evaluating structural equation models with unobservable variables and measurement error. Journal of Marketing Research 18 (1): 39-50.

Gann, D. M. and A. Salter. 1998. Learning and innovation management in project-based, service-enhanced firms. International Journal of Innovation Management 2 (4): 431-454.

Garcia, R. and R. Calantone. 2002. A critical look at technological innovation typology and innovativeness terminology: a literature review. Journal of Product Innovation Management 19 (2): 110-132.

Gilsing, V., B. Nooteboom, W. Vanhaverbeke, G. Duysters and A. van den Oord. 2008. Network embeddedness and the exploration of novel technologies: technological distance, betweenness centrality and density. Research Policy 37 (10): 1717-1731.

Granovetter, M. S. 1973. The strength of weak ties. American Journal of Sociology 78 (6): 1360-1380.

Greckhamer, T., S. Furnari, P. C. Fiss, and R. V. Aguilera. 2018. Studying configurations with qualitative comparative analysis: best practices in strategy and organization research. Strategic Organization 16 (4): 482-495.

Greckhamer, T., V. F. Misangyi, H. Elms and R. Lacey. 2008. Using qualitative comparative analysis in strategic management research. Organizational Research Methods 11 (4): 695726.

Greckhamer, T., V. F. Misangyi and P. C. Fiss. 2013. The two QCAs: from a small-N to a large$\mathrm{N}$ set theoretic approach. In Configurational theory and methods in organizational research, ed. P. C. Fiss, B. Cambré and A. Marx, 49-75. Bingley: Emerald.

Gulati, R., D. Lavie and R. Madhavan. 2011. How do networks matter? The performance effects of interorganizational networks. Research in Organizational Behavior 31: 207-224. 
Hargadon, A. and R. I. Sutton. 1997. Technology brokering and innovation: evidence from a product design firm. Administrative Science Quarterly 42 (4): 716-749.

Hoffmann, W. H. 2007. Strategies for managing a portfolio of alliances. Strategic Management Journal 28 (8): 827-856.

Huggins, R. and A. Johnston. 2010. Knowledge flow and inter-firm networks: the influence of network resources, spatial proximity and firm size. Entrepreneurship \& Regional Development 22 (5): 457-484.

Kale, P., H. Singh and H. Perlmutter. 2000. Learning and protection of proprietary assets in strategic alliances: building relational capital. Strategic Management Journal 21 (3): 217237.

Kehrel, U. and N. Sick. 2014. Economic and technological forecasting competencies of German energy companies: empirical insights from annual reports. International Journal of Energy Sector Management 8 (4): 588-610.

Ketchen, D. J., J. B. Thomas and C. C. Snow. 1993. Organizational configurations and performance. Academy of Management Journal 36 (6): 1278-1313.

Koka, B. R. and J. E. Prescott. 2002. Strategic alliances as social capital: a multidimensional view. Strategic Management Journal 23 (9): 795-816.

Kolloch, M. and F. Reck. 2017. Innovation networks in the German energy industry: an empirical analysis of inter-organizational knowledge transfer. International Journal of Energy Sector Management 11 (2): 268-294.

Kraus, S., D. Ribeiro-Soriano and M. Schüssler. 2018. Fuzzy-set qualitative comparative analysis (fsQCA) in entrepreneurship and innovation research - The rise of a method. International Entrepreneurship and Management Journal 14 (1): 15-33.

Kumar, N., L. W. Stern and J. C. Anderson. 1993. Conducting interorganizational research using key informants. Academy of Management Journal 36 (6): 1633-1651.

Lambe, C. J., R. E. Spekman and S. D. Hunt. 2002. Alliance competence, resources, and alliance success: conceptualization, measurement, and initial test. Journal of the Academy of Marketing Science 30 (2): 141-158.

Lavie, D. 2007. Alliance portfolios and firm performance: a study of value creation and appropriation in the US software industry. Strategic Management Journal 28 (12): 1187-1212.

Lavie, D. and S. R. Miller. 2008. Alliance portfolio internationalization and firm performance. Organization Science 19 (4): 623-646.

Levinthal, D. A. and J. G. March. 1993. The myopia of learning. Strategic Management Journal 14 (S2): 95-112.

McEvily, B., and A. Marcus. 2005. Embedded ties and the acquisition of competitive capabilities. Strategic Management Journal 26 (11): 1033-1055.

McEvily, B., and A. Zaheer. 1999. Bridging ties: a source of firm heterogeneity in competitive capabilities. Strategic Management Journal 20 (12): 1133-1156.

Meyer, A. D., A. S. Tsui and C. R. Hinings. 1993. Configurational approaches to organizational analysis. Academy of Management Journal 36 (6): 1175-1195.

Michelfelder, I., and J. Kratzer. 2013. Why and how combining strong and weak ties within a single interorganizational R\&D collaboration outperforms other collaboration structures. Journal of Product Innovation Management 30 (6): 1159-1177. 
Misangyi, V. F. and A. G. Acharya. 2014. Substituting or complements? A configurational examination of corporate governance mechanisms. Academy of Management Journal 57 (6): 1681-1705.

Misangyi, V. F., T. Greckhamer, S. Furnari, P. C. Fiss, D. Crilly and R. Aguilera. 2017. Embracing causal complexity: the emergence of a neo-configurational perspective. Journal of Management 43 (1): 255-282.

Mitchell, W. and K. Singh. 1996. Survival of businesses using collaborative relationships to commercialize complex goods. Strategic Management Journal 17 (3): 169-195.

Müller, R., M. Steinert and S. Teufel. 2008. Successful diversification strategies of electricity companies. Energy Policy 36 (1): 398-412.

Nahapiet, J. and S. Ghoshal. 1998. Social capital, intellectual capital, and the organizational advantage. Academy of Management Review 23 (2): 242-266.

Nikogosian, V. and T. Veith. 2012. The impact of ownership on price-setting in retail-energy markets - The German case. Energy Policy 41 (2): 161-172.

Ojasalo, J. 2008. Management of innovation networks: A case study of different approaches. European Journal of Innovation Management 11 (1): 51-86.

Operti, E. and G. Carnabuci. 2014. Public knowledge, private gain: the effect of spillover networks on firms' innovative performance. Journal of Management 40 (4): 1042-1074.

Owen-Smith, J. and W. W. Powell. 2004. Knowledge networks as channels and conduits. Organization Science 15 (1): 5-21.

Ozcan, P. and K. M. Eisenhardt. 2009. Origin of alliance portfolios: entrepreneurs, network strategies, and firm performance. Academy of Management Journal 52 (2): 246-279.

Phelps, C. C. 2010. A longitudinal study of the influence of alliance network structure and composition on firm exploratory innovation. Academy of Management Journal 53 (4): 890-913.

Phelps, C., R. Heidl and A. Wadhwa. 2012. Knowledge, networks, and knowledge networks: a review and research agenda. Journal of Management 38 (4): 1115-1166.

Piening, E. P., T. O. Salge and S. Schäfer. 2016. Innovating across boundaries: a portfolio perspective on innovation partnerships of multinational corporations. Journal of World Business 51 (3): 474-485.

Pisano, G. P. and R. Verganti. 2008. Which kind of collaboration is right for you. Harvard Business Review 86 (12): 78-86.

Pittaway, L., M. Robertson, K. Munir, D. Denyer and A. Neely. 2004. Networking and innovation: a systematic review of the evidence. International Journal of Management Reviews 5 (3-4): 137-168.

Podsakoff, P. M., S. B. MacKenzie, J.-Y. Lee and N. P. Podsakoff. 2003. Common method biases in behavioral research: a critical review of the literature and recommended remedies. Journal of Applied Psychology 88 (5): 879-903.

Provan, K. G., A. Fish and J. Sydow. 2007. Interorganizational networks at the network level. Journal of Management 33 (3): 479-516.

Pullen, A. J., P. C. Weerd-Nederhof, A. J. Groen and O. A. Fisscher. 2012. Open innovation in practice: goal complementarity and closed NPD networks to explain differences in innovation performance for SMEs in the medical devices sector. Journal of Product Innovation Management 29 (6): 917-934. 
Ragin, C. C. 2006. Set relations in social research: evaluating their consistency and coverage. Political Analysis 14 (3): 291-310.

Ragin, C. C. 2008. Redesigning social inquiry. Chicago: University of Chicago Press.

Ragin, C. C. and P. C. Fiss. 2008. Net effects analysis vs. configurational analysis. In Redesigning social inquiry, ed. C. C. Ragin, 190-212. Chicago: University of Chicago Press.

Ragin, C. C. and S. Davey. 2016. Fuzzy-set/qualitative comparative analysis 3.0. Irvine: Department of Sociology, University of California.

Ritala, P. and P. Hurmelinna-Laukkanen. 2013. Incremental and radical innovation in coopetition - The role of absorptive capacity and appropriability. Journal of Product Innovation Management 30 (1): 154-169.

Rodan, S. and C. Galunic. 2004. More than network structure: how knowledge heterogeneity influences managerial performance and innovativeness. Strategic Management Journal 25 (6): 541-562.

Rothaermel, F. T. and D. L. Deeds. 2004. Exploration and exploitation alliances in biotechnology: a system of new product development. Strategic Management Journal 25 (3): 201-221.

Rothaermel, F. T. and D. L. Deeds. 2006. Alliance type, alliance experience and alliance management capability in high-technology ventures. Journal of Business Venturing 21 (4): 429-460.

Rothaermel, F. T. and A. M. Hess. 2007. Building dynamic capabilities: innovation driven by individual-, firm-, and network-level effects. Organization Science 18 (6): 898-921.

Rothaermel, F. T., M. A. Hitt and L. A. Jobe. 2006. Balancing vertical integration and strategic outsourcing: effects on product portfolio, product success, and firm performance. Strategic Management Journal 27 (11): 1033-1056.

Rowley, T., D. Behrens and D. Krackhardt. 2000. Redundant governance structures: an analysis of structural and relational embeddedness in the steel and semiconductor industries. Strategic Management Journal 21 (3): 369-386.

Rupietta, C. and U. Backes-Gellner. 2019. Combining knowledge stock and knowledge flow to generate superior incremental innovation performance: evidence from Swiss manufacturing. Journal of Business Research 94 (1): 209-222.

Sampson, R. C. 2007. R\&D alliances and firm performance: the impact of technological diversity and alliance organization on innovation. Academy of Management Journal 50 (2): 364-386.

Schilke, O. and A. Goerzen. 2010. Alliance management capability: an investigation of the construct and its measurement. Journal of Management 36 (5): 1192-1219.

Schlüter, K. and O. Rottmann, O. 2017. Stadtwerke - Fit für die Zukunft?. Frankfurt a. M.: Frankfurt Business Media.

Schneider, C. Q. and C. Wagemann. 2012. Set-theoretic methods for the social sciences: a guide to qualitative comparative analysis. Cambridge: Cambridge University Press.

Shan, W., G. Walker and B. Kogut. 1994. Interfirm cooperation and startup innovation in the biotechnology industry. Strategic Management Journal 15 (5): 387-394.

Snow, C. C., Ø. D. Fjeldstad, C. Lettl and R. E. Miles. 2011. Organizing continuous product development and commercialization: The collaborative community of firms model. Journal of Product Innovation Management 28 (1): 3-16. 
Stuart, T. E. 2000. Interorganizational alliances and the performance of firms: a study of growth and innovation rates in a high-technology industry. Strategic Management Journal 21 (8): 791-811.

Subramaniam, M. and M. A. Youndt. 2005. The influence of intellectual capital on the types of innovative capabilities. Academy of Management Journal 48 (3): 450-463.

Taylor, J. E. and R. Levitt. 2007. Innovation alignment and project network dynamics: an integrative model for change. Project Management Journal 38 (3): 22-35.

Thornton, S. C., S. C. Henneberg, A. Leischnig and P. Naudé. 2019. It's in the mix: how firms configure resource mobilization for new product success. Journal of Product Innovation Management 36 (4): 513-531.

Tiwana, A. 2008. Do bridging ties complement strong ties? An empirical examination of alliance ambidexterity. Strategic Management Journal 29 (2): 251-272.

Tsai, W. and S. Ghoshal. 1998. Social capital and value creation: the role of intrafirm networks. Academy of Management Journal 41 (4): 464-476.

Van de Ven, A. H. and G. P. Huber. 1990. Longitudinal field research methods for studying processes of organizational change. Organization Science 1 (3): 213-219.

Wagemann, C. and C. Q. Schneider. 2010. Standards of good practice in qualitative comparative analysis (QCA) and fuzzy-sets. Comparative Sociology 9 (3): 397-418.

Wasserman, S. and K. Faust. 1994. Social network analysis. Methods and applications. Cambridge: Cambridge University Press.

Wassmer, U. 2010. Alliance portfolios: a review and research agenda. Journal of Management 36 (1): 141-171.

Yli-Renko, H., E. Autio and H. J. Sapienza. 2001. Social capital, knowledge acquisition, and knowledge exploitation in young technology-based firms. Strategic Management Journal 22 (6-7): 587-613.

Zaefarian, G., S. C. Henneberg and P. Naudé. 2013. Assessing the strategic fit between business strategies and business relationships in knowledge-intensive business services. Industrial Marketing Management 42 (2): 260-272.

Zaheer, A. and G. G. Bell. 2005. Benefiting from network position: firm capabilities, structural holes, and performance. Strategic Management Journal 26 (9): 809-825.

Zhang, Y. and H. Li. 2010. Innovation search of new ventures in a technology cluster: the role of ties with service intermediaries. Strategic Management Journal 31 (1): 88-109. 


\section{Synopsis (Epilogue)}

The following epilogue serves to summarize and aggregate the findings of the five publications and put those findings into the larger context of top management and network research as well as innovation management literature in general. Section IV.1 discusses the results and implications of the two publications in focus area I ("Top Management and Leadership"), section IV.2 covers focus area II ("Networks and External Partners"). In both sections, I will first refer back to the research gaps identified in the synopsis and demonstrate how the key findings of my research publications help to close those research gaps. Second, I will discuss the implications of those key findings for the major theoretical streams in each focus area, namely upper echelon theory and strategic leadership theory ("Top Management and Leadership") as well as the strategic network perspective ("Networks and External Partners"). Third, I will present conceptual and empirical limitations of my work and make according suggestions for further research. To conclude this dissertation, section IV.3 will explain how the results in both focus areas relate back to the broader innovation management literature and the challenges of "organizing for innovation in the digitized world".

\section{Key Findings and Implications in Focus Area I: Top Management and Leadership}

Focus area I comprised two publications that aim to explain how top managers influence outcomes of innovation and business digitalization at the firm level. Drawing on configuration theory and aiming to build conceptual bridges between the dominant theoretical perspectives on the topic (upper echelon theory and leadership theory), both publications provide novel empirical findings which enrich current perspectives on how top managers affect organizational innovation. In sum, my research advocates a comprehensive theoretical perspective on top management and innovation leadership that acknowledges "that the antecedents and consequences of CEO-related [and, in a broader sense, top management-related] phenomena are best understood by exploring interrelationships of theories from each of the domains [i.e. a top manager's person and personal relationships, the managerial position, and the firm and environmental context] rather than from just one" (Busenbark et al., 2016, p. 238).

\subsection{Research Gaps and Key Findings}

In the prologue of this dissertation, I identified and described five important gaps in current research on the influence of top management and leadership on organizational innovation: (1) prevailing theoretical endogeneity; (2) focus on isolated net effects of individual variables rather than causal complexity; (3) lack of knowledge on what top managers "actually do" to promote innovation; (4) lack of research on the relations between top managers' personal characteristics and leadership behaviors; (5) neglect of top management positions besides the CEO. The two studies presented in this dissertation provide important empirical evidence that helps to shed light on each of those research gaps and thus make highly relevant contributions to top management and leadership literature. The key findings concerning each of the identified research gaps are presented in Figures 1, 2, and 3.

Concerning gap (1) (“prevailing theoretical endogeneity”), publication 1 demonstrates that top managers' personal characteristics, skills, networks, and behaviors influence firm-level 
innovation in conjunction rather than in isolation. Thereby, the paper provides evidence that mechanisms of human capital (e.g. Hoffman \& Hegarty, 1993), social capital (e.g. Cao et al., 2015), leadership (e.g. Elenkov et al., 2005), or job demands (e.g. Barker \& Mueller, 2002) proposed by different research streams under the umbrella of upper echelon theory are likely to interact when it comes to explaining the influence of top managers on firm-level outcomes (Busenbark et al., 2016). Concerning gap (2) ("focus on isolated net effects of individual variables rather than causal complexity"), both papers identify a number of comprehensive profiles of top managers that integrate theoretical approaches and help creating a more complete picture of top managers' influence on organizational innovation.

Concerning gap (3) ("lack of knowledge on what top managers "actually do" to promote innovation"), publication 2 develops a conceptual framework for categorizing top managers' different behaviors to "instigate, sponsor, and steer innovation in their organization" (Deschamps, 2008, p. 19), and identifies eight different types of top managers with regard to their innovation leadership behaviors. Concerning gap (4) ("lack of research on the relations between top managers' personal characteristics and leadership behaviors"), the same paper demonstrates that factors related to a top manager's person and position determine in which leadership behaviors he/she engages. Furthermore, publication 1 provides evidence that the effectiveness of a top manager's behaviors towards innovation and change depends on the personal resources in the form of skills and personal relationships that the manager possesses (e.g. Busenbark et al., 2016; Garms \& Engelen, 2019). Finally, concerning gap (5) ("neglect of top management positions besides the CEO"), both papers use an important but underresearched group of executives as unit of analysis: functional top managers that are "responsible for one or more functional areas in their organizations" (Menz, 2012, p. 46) and play a key role in strategic decision-making and determining the direction of a firm's future development (e.g. Hambrick \& Cannella, 2004; Marcel, 2009; Menz \& Scheef, 2014). 


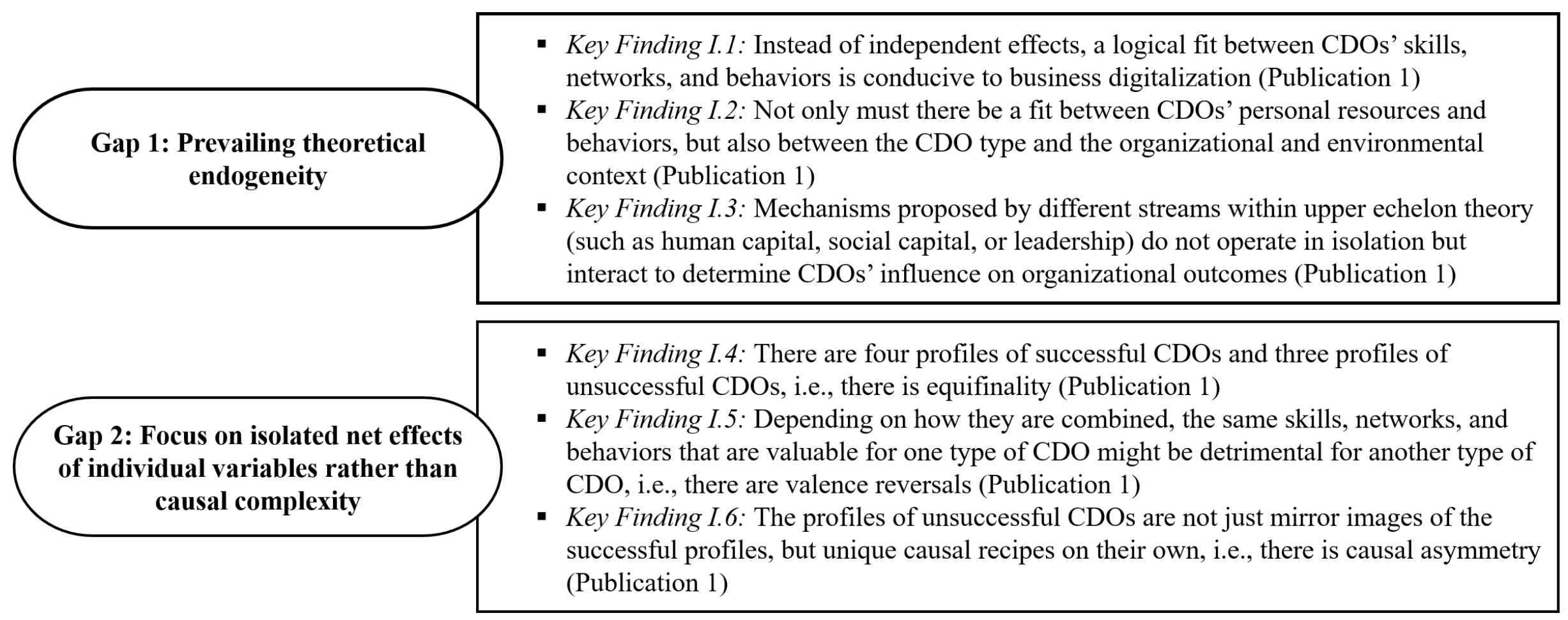

Figure IV-1. Key findings in focus area I with regard to research gaps 1 and 2 (own illustration) 

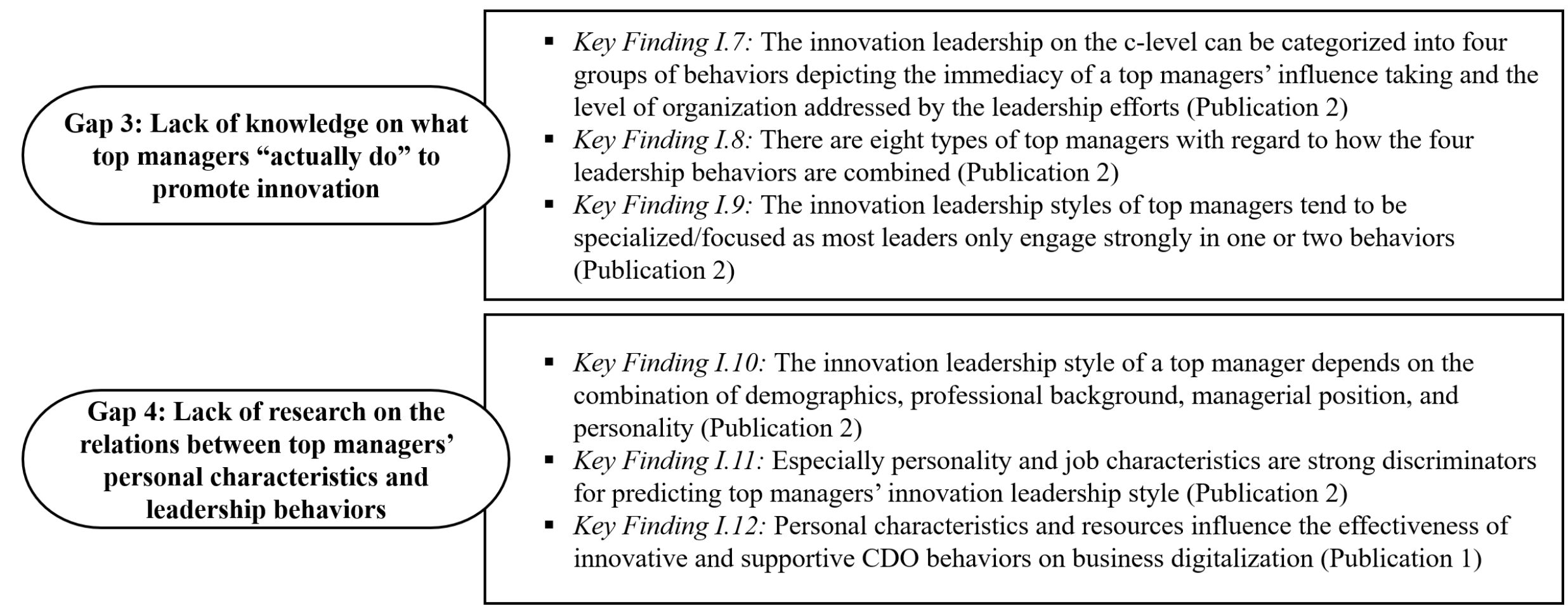

Figure IV-2. Key findings in focus area I with regard to research gaps 3 and 4 (own illustration) 
- Key Finding I.13: CDOs and other functional top managers may influence innovation and business digitization in the firm in a number of ways (Publications $1 \& 2$ )

- Key Finding I.14: CIOs, CMOs, CTOs, COOs, CHROs, and CFOs take different

Gap 5: Neglect of top management positions besides the CEO

Figure IV-3. Key findings in focus area I with regard to research gap 5 (own illustration) 


\subsection{Theoretical Implications}

By providing insights to pressing research gaps in top management research, the two papers make important contributions to upper echelon theory and strategic leadership theory. First, both publications add to the small but growing number of studies that employ configurational perspectives for explaining the impact of top managers on organizational outcomes (e.g. Greckhamer, 2016; Lewellyn \& Fainshmidt, 2017). In publication 1, for instance, we identify four clearly different skill, network, and behavior profiles of effective CDOs and three profiles of CDOs failing in their managerial task. Furthermore, our results help to link those profiles to four different situational contexts that top managers may face depending on the power they hold in their firm and the external pressure the firm receives from its market environment. Though upper echelon research discusses interaction effects between top manager characteristics as well, our configurational research goes beyond such approaches of merely "arguing that a relationship between two constructs is dependent on a third" (Busenbark et al., 2016, p. 238).

Instead, our findings indicate equifinality and valence reversal as two integral elements in explaining the complex causal relations that underlie the effects of top managers on firms' innovation performance. On the one hand, equifinality describes that "a system can reach the same final state, from different initial conditions and by a variety of different paths" (Katz \& Kahn, 1978, p. 30). Analogous to Busenbark et al. (2016) who describe three different types of CEOs that might each benefit a firm's M\&A performance in clearly different but nonetheless effective ways, our results on CDOs demonstrate that there is not one type of effective top manager with one specific set of personal characteristics and resources, but a number of different configurations leading to success. On the other hand, related to the notion of equifinality, valence reversals "refer to situations in which a specific factor has opposite effects (i.e., positive and negative effects) on an outcome, depending on how this factor combines with other factors to form a configuration" (Geigenmueller \& Leischnig, 2017, p. 80). In the context of top management research, the notion of valence reversals denotes that while a certain skill or characteristic of a top manager might generally be beneficial for innovation, for certain types of top managers that factor might be of little value or even detrimental to performance outcomes (for instance, strong strategic IT knowledge of "evangelist" type CDOs might "entrench" (Dane, 2010) their perspective on digital technologies, lead to less experimentation and creativity, and in turn to lower levels of business digitalization).

In sum, the notions of equifinality and valence reversals supported by the results of my doctoral research imply that upper echelon theory should refrain from still quite popular perspectives that paint the ideal picture of top managers as "great men", "superstars", or "superheroes" (e.g. Deschamps, 2008; Hoffman, Woehr, Madhagen-Youngjohn, \& Lyons, 2011; Khurana, 2002). Likewise, the "the-more-the-better" assumption with regard to top managers' personal characteristics and resources for explaining organizational outcomes must be questioned (Busenbark et al., 2016). Rather, based on the results of my research, I argue that a "jack-ofall-trades" perspective on organizational leaders is both unrealistic and ineffective. Top managers are likely to take a more focused and differentiated role so that upper echelon theory should develop a more comprehensive and multi-faceted viewpoint on $\mathrm{CxOs}$ ' influence on organizational outcomes. 
In a similar vein, my research puts forth a perspective on innovation leadership as a multifaceted phenomenon. Most research on the basis of strategic leadership theory discusses the impact of top managers' visionary, charismatic, and transformational leadership styles and behaviors on organizational innovation (e.g. Elenkov et al., 2005; Jung et al., 2008; Ling et al., 2008; Mumford \& Licuanan, 2004). Outcome-oriented behaviors like getting involved in idea generation, mentoring innovators and innovation projects, or formulating innovation strategies have been mentioned in some works, but not adequately conceptualized and operationalized (Deschamps, 2008; Hunter \& Cushenbery, 2011; Makri \& Scandura, 2010). By developing a framework that helps capturing what top managers "actually do" in order to promote innovation as well as an empirically-grounded taxonomy of different managerial roles, publication 2 enriches the innovation leadership concept and demonstrates that there are many different ways in which top managers can contribute to organizational innovation.

Moreover, the study builds an important bridge between top managers' characteristics and leadership behaviors. Management research most often assumed personal characteristics to impact top managers behaviors and involvement in innovation but did not adequately substantiate and test this central mechanism in its chain of explanation (e.g. Cannella \& Monroe, 1997; Carpenter et al., 2004; Elenkov et al., 2005; Geletkanycz \& Boyd, 2011). By demonstrating that the personal characteristics of top managers as well as the managerial position they hold affect the type and magnitude of top managers' engagement in organizational innovation, my research provides evidence for that centerpiece in the reasoning of upper echelon and strategic leadership theory and might serve as a basis for further research on the determinants of top managers' innovation leadership behaviors.

\subsection{Limitations and Further Research}

Conceptually, my research focuses on the personal characteristics, personal resources, and leadership behaviors of single top managers. While research demonstrates that single top managers can significantly affect firm-level outcomes (e.g. Garms \& Engelen, 2019; Hambrick, 2007; Menz, 2012), upper echelon theory also notes that corporate management essentially involves teamwork and coordination between the different members of the TMT (e.g. Buyl, Boone, Hendriks, \& Matthyssens, 2011; Talke et al., 2011). Hence, the findings of my publications open up a range of questions of how to group and coordinate different types of leaders in the organizational structure of the c-suite. Future research could thus examine, if the coexistence of different types of leaders in the TMT yields complementing or conflicting effects on organizational outcomes, in particular innovation performance.

Methodologically, the research design of both publications entails several limitations. First, data was collected exclusively in manufacturing firms in German-speaking countries. Hence, the publications did not account for sectoral and cultural differences. Future works should test the robustness of my findings across industry and national contexts. Second, data collection was cross-sectional so that endogeneity cannot fully be ruled out. Future works should incorporate longitudinal or time-lagged data, especially for testing the effects on organizational performance. Third and finally, I used self-report data. Though I relied on multiple informants where it was possible and took several appropriate measures to account for potential biases 
stemming from my approach of data collection, future research might employ archival or observational data to further triangulate and solidify self-report measures on personal characteristics, leadership behaviors, and innovation outcomes.

\section{Key Findings and Implications in Focus Area II: Networks and External Partners}

Focus area II comprised three publications that shed light on the mechanisms by which interorganizational networks impact firm-level innovation performance. Extending the strategic network perspective, my publications in this focus area employ configurational theory and multi-level perspectives in order to close some pressing gaps in current research. In sum, my research in focus area II promotes a view of inter-organizational networks that goes beyond traditional notions by acknowledging that a firm's network of inter-firm relationships should be perceived as an entity comprising multiple network characteristics that shape firm performance in interaction rather than in isolation (Gulati et al., 2011; Pullen et al., 2012; Zaefarian et al., 2013), and that at least partially "firms and managers take actions to influence the structure of relationships around them, constructing networks that facilitate innovation" (Rowley \& Baum, 2008, p. xix).

\subsection{Research Gaps and Key Findings}

In section 6.2 of the prologue, I identified four major research gaps in focus area II: (1) focus on the effect of single network characteristics and neglect of the interplay and fit between different network resources; (2) neglect of firm characteristics and the interplay and fit between network resources and internal resources; (3) missing link between structural and managerial perspectives on inter-organizational networks; (4) focus on a limited set of network and resource types. Like in the section on top management and leadership, I will link the key findings of my three publications in focus area II to the identified research gaps on the topic. Figures 4 and 5 summarize the research gaps and key findings of my research on interorganizational networks.

Concerning research gap (1) ("focus on the effect of single network characteristics and neglect of the interplay and fit between different network resources"), publication 5 identified four distinct network profiles that lead to high levels of innovation performance. Those profiles display the overarching pattern, that in each of them, exactly one network characteristic that reflects the volume dimension of resource access (network size and tie strength) is combined with exactly one that reflects the content dimension of resource access (partner innovativeness and partner complementarity). This result specifies complementary effects between resource volume and resource quality that have been previously suggested by various authors (e.g. Gulati et al., 2011; Nahapiet \& Ghoshal, 1998; Pullen et al., 2012), but also demonstrates substitutive effects between both volume and content-related network characteristics. Concerning research gap (2) ("neglect of firm characteristics and the interplay and fit between network resources and internal resources"), publication 5 furthermore demonstrates that each of the identified network profiles is particularly beneficial for one of four combinations of internal firm resources (slack related to firm size and absorptive capacity related to human capital). This finding thus not only supports the notion "that an organization needs sufficient internal 
resources to create value from its network resources" (Gulati et al., 2011, p. 221), but also informs on which network resources fit which internal resource constellations.

Concerning gap (3) ("missing link between structural and managerial perspectives on interorganizational networks"), publication 4 demonstrates that network management capabilities help firms in industry clusters develop three potentially innovation-enhancing network characteristics, namely network size, knowledge complementarity, and tie strength. Moreover, the results indicate that each of the three network characteristics is associated with specific constraints so that firms require either management activities and routines on the portfolio level, on the relationship level, or both, in order to overcome those constraints and develop a network with beneficial structural, relational, and compositional features.

Finally, concerning gap (4) ("focus on a limited set of network and resource types"), publication 4 provides an analysis of four different knowledge exchange networks in the above-mentioned industry cluster. In line with Alberti \& Pizzurno (2015) and Sammarra \& Biggiero (2008), we provide evidence that all four types of knowledge are exchanged in clearly different patterns. Furthermore, the results indicate that especially technology and market knowledge as well as regulatory and managerial knowledge are likely to be exchanged simultaneously in the same knowledge transfer relation and, that firms that acquire a relatively smaller amount of regulatory knowledge but more of the other knowledge types outperform their peers with regard to product, process, and administrative innovation. 
- Key Finding II.1: There are four different "ideal" network profiles that enable high levels of product innovation performance (Publication 5)

Gap 1: Focus on the effect of single network characteristics and neglect different network resources of the interplay and fit between

- Key Finding II.2: Each of those four profiles represents a combination of one network characteristic related to resource volume (network size vs. tie strength) and the resource content (partner innovativeness vs. partner complementarity) (Publication 5)

- Key Finding II.3: The addition of further network characteristics does either not improve or even detriment (e.g. combining tie strength and network size) the positive effect (Publication 5)

- Key Finding II.4: The four different "ideal" network profiles each fit a different configuration of internal resources (Publication 5)

- Key Finding II.5: Large firms are able to profit from large networks whereas small firms rather profit from strong tie networks (Publication 5)

characteristics and the interplay and fit between network resources and internal resources

- Key Finding II.6: Firms with profound internal human capital are able to profit from innovative partners whereas firms with less-developed internal human capital rather profit from complementary partners (Publication 5)

Figure IV-4. Key findings in focus area II with regard to research gaps 1 and 2 (own illustration) 
- Key Finding II.7: Network management allows firms in industry clusters to shape the local network structure to benefit their capacity for generating product innovations (Publication 4)

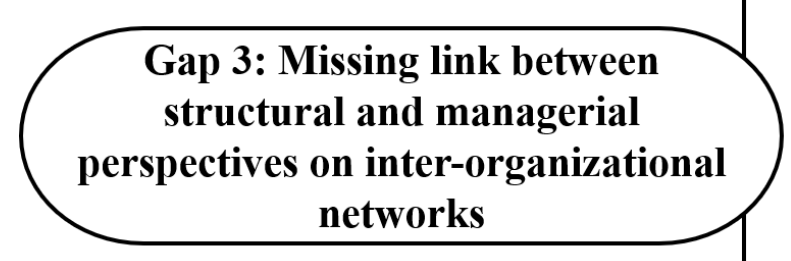

Gap 4: Focus on a limited set of network and resource types

Figure IV-5. Key findings in focus area II with regard to research gaps 3 and 4 (own illustration)
- Key Finding II.8: In order to develop different network characteristics, different combinations of portfolio management and relationship management routines are required (Publication 4)

- Key Finding II.9: Particularly, portfolio management helps firms develop a large network, portfolio and relationship management help firms establish relations to complementary partners, and relationship management helps developing strong ties (Publication 4)

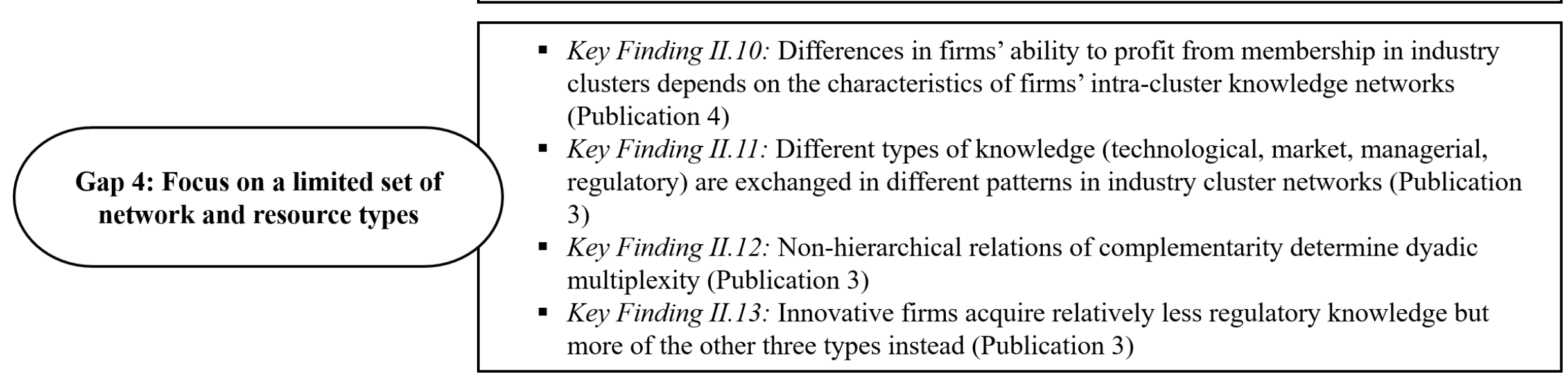




\subsection{Theoretical Implications}

The key findings of the three publications provide several important implications to the strategic network perspective. First, my research aligns with the small but growing stream of literature that promotes a perspective of "fit" to explain the mechanisms by which network resources and the network characteristics that grant access to those network resources impact organizational performance (e.g. Gulati et al., 2011; Pullen et al., 2012; Zaefarian et al., 2013). Publication 5 shows that the four permutational combinations of the two resource volume-related network characteristics "network size" and "tie strength" on the one hand and the two resource contentrelated characteristics "partner innovativeness" and "partner complementarity" on the other hand all represent equifinal configurations leading to increased innovation performance.

This finding demonstrates that it is the combination of network characteristics that is likely to differentiate highly innovative from less innovative firms. Furthermore, the results indicate that for different firm characteristics reflecting different internal resource combinations, the "ideal" network profile varies. Instead of getting entangled into arguments on which network characteristics actually are conducive to high innovation performance, theories on the effects of inter-organizational networks should thus incorporate configurational perspectives and aim to identify "ideal" network profiles. Also, the strategic network perspective should be enhanced by explanations on why some combinations of network characteristics (and the corresponding network resources) appear to be complementary with each other as well as with the characteristics and internal resources of the firm (i.e., are internally and externally consistent) whereas other combinations fail to deliver the desired effects.

Second, the findings of my research coincide with calls for a network theory that does not merely treats firms as "black boxes" (Phelps et al., 2012) but rather acknowledges active and strategic efforts of firms to shape the local network structures surrounding them (Rowley \& Baum, 2008). Publication 4 argues that the development of beneficial local network structures (i.e., ego-networks (Borgatti \& Halgin, 2011)) is afflicted with constraints specific to the network characteristics that a focal firm aims to develop. Drawing on this notion of constraints, the paper explains and tests the effects of firms' network management capabilities on the portfolio and the relationship level. Thereby, it substantiates and further specifies the notion that intra-firm management activities, practices, and routines are likely to determine a firm's ability to obtain and maintain a beneficial ego-network, i.e., to shape the local network structures to achieve resource benefits and foster the own capacity for generating innovative solutions (e.g. Anand \& Khanna, 2000; Lorenzoni \& Lipparini, 1999; Thornton et al., 2015; Vesalainen \& Hakala, 2014). Publication 4 thus contributes to current efforts in literature to overcome the fragmentation of the strategic network perspective by examining "the interaction between [...] network management and structural [...] network characteristics (e.g. network centrality, network density) in influencing innovation performance" (Faems et al., 2012, p. 262).

Third and finally, my research in focus area II enriches the literature on inter-organizational networks by demonstrating that knowledge transfer between firms is multi-dimensional. Though the argument of the knowledge-based view that innovation requires firms to acquire 
and recombine knowledge from different domains is well established (e.g. Grant, 1996; Hargadon \& Sutton, 1997; Kogut \& Zander, 1992), only few network studies actually differentiate between knowledge types such as technological, market, and managerial knowledge (Alberti \& Pizzurno, 2015; Sammarra \& Biggiero, 2008). In their literature review on knowledge exchange networks, Phelps et al. (2012) thus aptly remark that with rare exceptions most works limit themselves to considering only one type of knowledge exchange relationship in their attempt to represent inter-organizational network structures. Consequently, "[t]he simultaneous consideration of different types of knowledge in the context of inter-firm innovation collaboration has not yet received proper conceptual or empirical elaboration" (Sammarra \& Biggiero, 2008, p. 801).

Publication 3 extends the ideas of pioneering works on that issue (e.g. Alberti \& Pizzurno, 2015; Boschma \& Ter Wal, 2007; Sammarra \& Biggiero, 2008; Schulz, 2001; Tanriverdi \& Venkatraman, 2005) by comparing the patterns on the network, dyad, and firm level that describe the exchange of four different knowledge types (technological, market, managerial, regulatory). The findings demonstrate that firms exchange the four knowledge types in different ways. Hence, the paper emphasizes the need for network research to adopt a multiplexity perspective on knowledge transfer in inter-organizational networks, i.e., a perspective that captures the extent to which two firms maintain more than one type of knowledge exchange relationship with each other (e.g. Minor, 1983; Phelps et al., 2012; Simpson, 2015). As "the complexification of modern technologies is actually increasing the salience of nontechnological types of knowledge" (Sammarra \& Biggiero, p. 820), a multiplexity perspective on knowledge exchange might considerably strengthen the validity of prevailing theories on inter-organizational networks and help uncover the mechanisms by which firms "integrate and recombine technological, market and managerial knowledge [...] to identify and exploit new innovation opportunities" (ibid., p. 820).

\subsection{Limitations and Further Research}

Conceptually, me and my coauthors had to take several restrictive measures to condense the obtained network data, to allow for statistical testing procedures, and to ensure interpretability of the data and the observed effects. As all three publications include the firm as a unit of analysis, conversions had to be made in order to obtain firm-level indicators from relational data (Tsai \& Ghoshal, 1998). In particular, we aggregated the partner-related and relational properties of network ties into mean values for each firm. Though such conversions of network data are common in management research (e.g. Lechner, Frankenberger, \& Floyd, 2010; Pullen et al., 2012; Tsai, 2001; Tsai \& Ghoshal, 1998), information on single ties and relationships is not included in the statistical analysis. Still, this information might be of relevance to explain the observed effects. For instance, several authors posit that a concurrence of certain partnerrelated and relational characteristics in a single tie (for instance partner innovativeness and tie strength) might benefit firms' performance more than if those qualities are spread across different ties (e.g. Capaldo, 2007; Gulati et al., 2011). Therefore, firms with the same mean values for partner-related or relational variables across their ego-network may still differ due to differences in the degree to which those characteristics concur or dispense across ties. Future 
works might conduct a more detailed analysis of such differences on the dyad level and use the results to further elaborate and specify my theoretical claims.

Contextually, my research in focus area II was conducted in the energy sector. The energy sector provides a rich setting for studying innovation and inter-organizational networks, due to major turbulences in the market and the advent of technological trends such as smart home, energy efficiency optimization, on-site power generation, and electromobility, among others (Edelmann, 2015). Still, by the empirical approach underlying my research publications, the effects of sectoral differences and specificities could not be controlled for. Analogous to focus area I, future works should conduct network studies in other innovation- and collaborationintensive industry sectors such as software, manufacturing, mobility, or medical engineering and test the generalizability of my findings.

Finally, the data collection of my work relied on cross-sectional self-reports. I was able to triangulate data on innovation performance by the help of multi-year archival data and conducted several other measures to prevent and control for informant biases, but such distortions cannot fully be ruled out. Also, the possibility of endogeneity cannot fully be dismissed. Analogous to focus area I, I suggest future works to incorporate longitudinal or timelagged data and employ archival or observational data to replicate the effects observed in my research.

\section{Concluding Remarks: Implications for "Organizing for Innovation" in the Digital Age}

While "organizing for innovation" has always been a challenging and complex task (e.g. Chesbrough \& Teece, 2009; Dougherty, 1999; Tushman \& Nadler, 1986; Van de Ven et al., 2007), the digital age brings about unprecedented levels of unpredictability, dynamism, and decentralization (e.g. Benner \& Tushman, 2015; Nambisan et al., 2017; Yoo et al., 2010b; Yoo et al., 2012). Due to these unique features of digital innovation, management and organizational research must adjust both the theoretical and methodological approaches previously used to examine and explain innovation outcomes at the firm level.

Concerning theoretical approaches, the features of digital innovation challenge the "key assumptions that underlie extant theories informing innovation management" (Nambisan et al., 2017 , p. 224). Innovation can no longer be perceived as a well-bounded phenomenon that is managed centrally by the firm and its R\&D department (e.g. Dougherty \& Dunne, 2012; Hess et al., 2016; Rindfleisch et al., 2017; Yoo et al., 2012). Instead, digital innovation is boundaryspanning and requires transformational efforts across the whole organization (e.g. Hess et al., 2016; Matt et al., 2015; McDonald \& Rowsell-Jones, 2012; Yoo et al., 2010b) as well as the capability to orchestrate viable partner networks and engage in a variety of collaborative forms of organization such as innovation networks, industry clusters, or platform ecosystems (e.g. Adner \& Kapoor, 2010; Lee \& Berente, 2012; Lyytinen et al., 2016; Tiwana et al., 2010). Concerning methodological approaches, Nambisan et al. (2017) argue that "[c]lassic variance based studies are often too static and make too simplistic assumptions about the nature of the phenomenon so the use of such methodologies does not easily get at the heart of the matter" ( $p$. 231). Hence, they argue innovation management research should increasingly employ 
methodologies such as configurational analysis that are able to adequately represent complex emergent phenomena.

Collectively, the publications presented in this doctoral dissertation address aspects of both the theoretical and methodological issues of studying digital innovation management. On the one hand, I refine and extend existing theories on two of the most relevant organizational elements that determine a firm's capacity for successfully generating and commercializing digital innovations: "top management and leadership" as well as "networks and external partnerships". On both topics, my research suggests that the prevailing theories like upper echelon theory and strategic network perspective should be further elaborated by incorporating notions of "fit" (Doty et al., 1993), "causal complexity" (Misangyi, Greckhamer, Furnari, Fiss, Crilly, \& Aguilera, 2017), and "conjunctural causation" (Fiss, 2011). Also, my research follows the suggestion that organizational phenomena are context-dependent in that the effects of firmlevel or individual-level variables most likely will vary across organizational and environmental settings (Meyer et al., 1993).

In doing so, I promote the use of either multi-level research models or typological/taxonomic frameworks as core elements in theories on the determinants of organizational innovation. Such models "acknowledge the complex and interdependent nature of organizations, in which fit and competitive advantage frequently rest not on a single attribute but instead on the relationships and complementarities between multiple characteristics" (Fiss, 2011, p. 393) and allow for developing and testing "complex theories that describe the causal relationships of contextual, structural, and strategic factors, thus offering configurations that can be used to predict variance in an outcome of interest" (ibid., p. 393). Contrary to the "correlational theorizing" that dominates most management and innovation research (Delbridge \& Fiss, 2013; Fiss, 2011), my research thus demonstrates that there are different but nonetheless theoretically sound ways in which organizational elements can be combined to foster innovation performance. I thus suggest innovation research to intensify the use of this "particularly attractive form of theorizing" (Delbridge \& Fiss, 2013, p. 329) when trying to explain differences in innovation performance between firms.

On the other hand, with regard to methodology, I follow calls that urge a need for methodologies that are able to grasp complex interdependent organizational phenomena rather than relying on variance explanation (Nambisan et al., 2017) for explaining innovation outcomes in the digital world. Configurational methods such as fsQCA are able to examine such richer forms of causal complexity than more traditional analytical methods such as regression analysis (El Sawy, 2010). This "helps open the black box of configurations, explores the fused interactions among elements, and uncovers rich, multifaceted causalities" (El Sawy, 2010, p. 845). In line with my suggestions on the advantages of multi-level models and typological/taxonomic frameworks in theory development and evaluation, I thus concur with works that advocate an increased use of configurational analysis to study innovation in the digital age (e.g. El Sawy et al., 2010; Kraus, Ribeiro-Soriano, \& Schüssler, 2017; Nambisan et al., 2017). I hope that by this doctoral thesis, I was able to contribute to the development of "better causal theories" (Fiss, 2011, p. 393) on what determines organizational innovation in the digital age and inspire further research on this highly relevant and exciting topic. 


\section{References (Synopsis)}

Adner, R. (2017). Ecosystem as structure: An actionable construct for strategy. Journal of Management, 43(1), 39-58.

Adner, R., \& Kapoor, R. (2010). Value creation in innovation ecosystems: How the structure of technological interdependence affects firm performance in new technology generations. Strategic Management Journal, 31(3), 306-333.

Ahuja, G. (2000). Collaboration networks, structural holes, and innovation: A longitudinal study. Administrative Science Quarterly, 45(3), 425-455.

Alberti, F. G., \& Pizzurno, E. (2015). Knowledge exchanges in innovation networks: Evidences from an Italian aerospace cluster. Competitiveness Review, 25(3), 258-287.

Alexiev, A. S., Jansen, J. J., Van den Bosch, F. A., \& Volberda, H. W. (2010). Top management team advice seeking and exploratory innovation: The moderating role of TMT heterogeneity. Journal of Management Studies, 47(7), 1343-1364.

Anand, B. N., \& Khanna, T. (2000). Do firms learn to create value? The case of alliances. Strategic Management Journal, 21(3), 295-315.

Anderson, N., Potočnik, K., \& Zhou, J. (2014). Innovation and creativity in organizations: A state-of-the-science review, prospective commentary, and guiding framework. Journal of Management, 40(5), 1297-1333.

Andrew, J., Manget, J., Michael, D., Taylor, A., \& Zablit, H. (2010). Innovation 2010: BCG report. Retrieved from http://www.bcg.com/documents/file42620.pdf

Antonakis, J., \& House, R. J. (2014). Instrumental leadership: Measurement and extension of transformational-transactional leadership theory. The Leadership Quarterly, 25(4), 746771.

Arikan, A. T. (2009). Interfirm knowledge exchanges and the knowledge creation capability of clusters. Academy of Management Review, 34(4), 658-676.

Arthur, W. B. (2009). The nature of technology: What it is and how it evolves. New York: Free Press.

Atuahene-Gima, K., \& Ko, A. (2001). An empirical investigation of the effect of market orientation and entrepreneurship orientation alignment on product innovation. Organization Science, 12(1), 54-74.

Austin, R. D., Devin, L., Sullivan, E. E. (2012). Accidental innovation: Supporting valuable unpredictability in the creative process. Organization Science, 23(5), 1505-1522.

Bae, J., \& Gargiulo, M. (2004). Partner substitutability, alliance network structure, and firm profitability in the telecommunications industry. Academy of Management Journal, 47(6), 843-859.

Baker, W. E., Grinstein, A., \& Harmancioglu, N. (2016). Whose innovation performance benefits more from external networks: Entrepreneurial or conservative firms? Journal of Product Innovation Management, 33(1), 104-120.

Balkin, D. B., Markman, G. D., \& Gomez-Mejia, L. R. (2000). Is CEO pay in high-technology firms related to innovation? Academy of Management Journal, 43(6), 1118-1129.

Barczak, G., Griffin, A., \& Kahn, K. B. (2009). Trends and drivers of success in NPD practices: Results of the 2003 PDMA best practices study. Journal of Product Innovation Management, 26(1), 3-23. 
Barker, V. L., \& Mueller, G. C. (2002). CEO characteristics and firm R\&D spending. Management Science, 48(6), 782-801.

Barney, J. B. (2001). Resource-based theories of competitive advantage: A ten-year retrospective on the resource-based view. Journal of Management, 27(6), 643-650.

Baron, R. A., \& Markman, G. D. (2000). Beyond social capital: How social skills can enhance entrepreneurs' success. Academy of Management Perspectives, 14(1), 106-116.

Barrett, M., Davidson, E., Prabhu, J., \& Vargo, S. L. (2015). Service innovation in the digital age: Key contributions and future directions. MIS Quarterly, 39(1), 135-154.

Barrett, M., Oborn, E., Orlikowski, W. J., \& Yates, J. (2012). Reconfiguring boundary relations: Robotic innovations in pharmacy work. Organization Science, 23(5), 1448-1466.

Bass, B. M. (1985). Leadership and performance beyond expectations. New York: The Free Press.

Bhattacharyya, S. C. (2007). Energy sector management issues: An overview. International Journal of Energy Sector Management, 1(1), 13-33.

Baum, J. A., Calabrese, T., \& Silverman, B. S. (2000). Don't go it alone: Alliance network composition and startups' performance in Canadian biotechnology. Strategic Management Journal, 21(3), 267-294.

Becker, W. (2018). Digitale Transformation von Geschäftsmodellen - Ein konzeptioneller Bezugsrahmen. In W. Becker, B. Eierle, A. Fliaster, B. Ivens, A. Leischnig, A. Pflaum, \& E. Sucky (Eds.), Geschäftsmodelle in der digitalen Welt - Strategie, Prozesse und Praxiserfahrungen (pp. 15-33). Wiesbaden: Springer Gabler.

Becker, W., \& Pflaum, A. (2018). Begriff der Digitalisierung - Extension und Intension aus betriebswirtschaftlicher Perspektive. In W. Becker, B. Eierle, A. Fliaster, B. Ivens, A. Leischnig, A. Pflaum, \& E. Sucky (Eds.), Geschäftsmodelle in der digitalen Welt - Strategie, Prozesse und Praxiserfahrungen (pp. 3-13). Wiesbaden: Springer Gabler.

Beckman, C. M., \& Haunschild, P. R. (2002). Network learning: The effects of partners' heterogeneity of experience on corporate acquisitions. Administrative Science Quarterly, 47(1), 92-124.

Bell, G. G. (2005). Clusters, networks, and firm innovativeness. Strategic Management Journal, 26(3), 287-295.

Benner, M. J., \& Tushman, M. L. (2015). Reflections on the 2013 decade award - 'Exploitation, exploration, and process management: The productivity dilemma revisited' ten years later. Academy of Management Review, 40(4), 497-514.

Berson, Y., Oreg, S., \& Dvir, T. (2008). CEO values, organizational culture and firm outcomes. Journal of Organizational Behavior, 29(5), 615-633.

Bierly, P. E., Damanpour, F., \& Santoro, M. D. (2009). The application of external knowledge: Organizational conditions for exploration and exploitation. Journal of Management Studies, 46(3), 481-509.

Blindenbach-Driessen, F., \& Van den Ende, J. (2014). The locus of innovation: The effect of a separate innovation unit on exploration, exploitation, and ambidexterity in manufacturing and service firms. Journal of Product Innovation Management, 31(5), 1089-1105.

Boal, K. B., \& Hooijberg, R. (2000). Strategic leadership research: Moving on. The Leadership Quarterly, 11(4), 515-549. 
Boeker, W. (1997). Strategic change: The influence of managerial characteristics and organizational growth. Academy of Management Journal, 40(1), 152-170.

Boland, R. J., Lyytinen, K., \& Yoo, Y. (2007). Wakes of innovation in project networks: The case of digital 3-D representations in architecture, engineering, and construction. Organization Science, 18(4), 631-647.

Boone, C., De Brabander, B., \& Hellemans, J. (2000). Research note: CEO locus of control and small firm performance. Organization Studies, 21(3), 641-646.

Borgatti, S. P., \& Foster, P. C. (2003). The network paradigm in organizational research: A review and typology. Journal of Management, 29(6), 991-1013.

Borgatti, S. P., \& Halgin, D. S. (2011). On network theory. Organization Science, 22(5), 1168 1181.

Boschma, R. (2005). Proximity and innovation: A critical assessment. Regional Studies, 39(1), 61-74.

Boschma, R. A., \& Ter Wal, A. L. (2007). Knowledge networks and innovative performance in an industrial district: The case of a footwear district in the South of Italy. Industry \& Innovation, 14(2), 177-199.

Brenner, T. (2007). Local knowledge resources and knowledge flows. Industry \& Innovation, 14(2), 121-128.

Bromiley, P., \& Rau, D. (2016). Social, behavioral, and cognitive influences on upper echelons during strategy process: A literature review. Journal of Management, 42(1), 174-202.

Brynjolfsson, E., Hu, Y., \& Smith, M. D. (2010). Long tails vs. superstars: The effect of information technology on product variety and sales concentration patterns. Information Systems Research, 21(4), 736-747.

Busenbark, J. R., Krause, R., Boivie, S., \& Graffin, S. D. (2016). Toward a configurational perspective on the CEO: A review and synthesis of the management literature. Journal of Management, 42(1), 234-268.

Buyl, T., Boone, C., Hendriks, W., \& Matthyssens, P. (2011). Top management functional diversity and firm performance. Journal of Management Studies, 48(1), 151-177.

Calantone, R. J., Cavusgil, S. T., \& Zhao, Y. (2002). Learning orientation, firm innovation capability, and firm performance. Industrial Marketing Management, 31(6), 515-524.

Cannella, A. A., \& Monroe, M. J. (1997). Contrasting perspectives on strategic leaders: Toward a more realistic view of top managers. Journal of Management, 23(3), 213-237.

Cao, Q., Simsek, Z., \& Jansen, J. J. (2015). CEO social capital and entrepreneurial orientation of the firm: Bonding and bridging effects. Journal of Management, 41(7), 1957-1981.

Capaldo, A. (2007). Network structure and innovation: The leveraging of a dual network as a distinctive relational capability. Strategic Management Journal, 28(6), 585-608.

Capozzi, M. M., Gregg, B., \& Howe, A. (2010). McKinsey Global Survey results: Innovation and commercialization. Retrieved from https:/www.innovationmanagement.se/wpcontent/uploads/2010/09/Innovation-and-commercialization-2010-McKinsey-GlobalSurvey-results.pdf

Carpenter, M. A., \& Fredrickson, J. W. (2001). Top management teams, global strategic posture, and the moderating role of uncertainty. Academy of Management Journal, 44(3), $533-545$. 
Carpenter, M. A., Geletkanycz, M. A., \& Sanders, W. G. (2004). Upper echelons research revisited: Antecedents, elements, and consequences of top management team composition. Journal of Management, 30(6), 749-778.

Chesbrough, H. W., \& Teece, D. J. (2009). Organizing for innovation. In D. A. Klein (Ed.), The strategic management of intellectual capital (pp. 27-40). Boston: ButterworthHeinemann.

Chesbrough, H., Vanhaverbeke, W., \& West, J. (2006). Open innovation: Researching a new paradigm. New York: Oxford University Press.

Christensen, C. M., Kaufman, S. P., \& Shih, W. C. (2008). Innovation killers: How financial tools destroy your capacity to do new things. Harvard Business Review, 86(1), 98-105.

Chua, R. Y., Roth, Y., \& Lemoine, J. F. (2015). The impact of culture on creativity: How cultural tightness and cultural distance affect global innovation crowdsourcing work. Administrative Science Quarterly, 60(2), 189-227.

Cohen, W. M., \& Levinthal, D. A. (1990). Absorptive capacity: A new perspective on learning and innovation. Administrative Science Quarterly, 35(1), 128-152.

Collins, C. J., \& Clark, K. D. (2003). Strategic human resource practices, top management team social networks, and firm performance: The role of human resource practices in creating organizational competitive advantage. Academy of Management Journal, 46(6), 740-751.

Cooper, R. G. (2005). Product leadership: Pathways to profitable innovation. Reading: Perseus Books.

Cooper, R. G. (2013). New products - What separates the winners from the losers and what drives success. In K. B. Kahn, S. E. Kay, R. J. Slotegraaf, \& S. Uban (Eds.), The PDMA handbook of new product development (pp. 3-34). Hoboken: Wiley.

Cooper, R. G. (2017). We've come a long way baby. Journal of Product Innovation Management, 34(3), 387-391.

Cooper, R. G., \& Edgett, S. J. (2012). Best practices in the idea-to-launch process and its governance. Research-Technology Management, 55(2), 43-54.

Cooper, R. G., Edgett, S. J., \& Kleinschmidt, E. J. (2004a). Benchmarking best NPD practices - I. Research-Technology Management, 47(1), 31-43.

Cooper, R. G., Edgett, S. J., \& Kleinschmidt, E. J. (2004b). Benchmarking best NPD practices - II. Research-Technology Management, 47(3), 50-59.

Cooper, R. G., Edgett, S. J., \& Kleinschmidt, E. J. (2004c). Benchmarking best NPD practices - III. Research-Technology Management, 47(6), 43-55.

Cooper, R. G., \& Mills, M. (2005). Succeeding at new products the P\&G way: A key element is using the innovation diamond. PDMA Visions, 29(4), 9-13.

Cooper, R. G., \& Kleinschmidt, E. J. (1995a). Benchmarking firms' new product performance and practices. Engineering Management Review, 23(3), 112-120.

Cooper, R. G., \& Kleinschmidt, E. J. (1995b). Benchmarking the firm's critical success factors in new product development. Journal of Product Innovation Management, 12(5), 374-391.

Crossan, M. M., \& Apaydin, M. (2010). A multi-dimensional framework of organizational innovation: A systematic review of the literature. Journal of Management Studies, 47(6), 1154-1191.

Cyert, R. M., \& March, J. G. (1963). A behavioral theory of the firm. Englewood Cliffs: Prentice-Hall. 
Dai, Y., Goodale, J. C., Byun, G., \& Ding, F. (2018). Strategic flexibility in new hightechnology ventures. Journal of Management Studies, 55(2), 265-294.

Dalziel, M. (2006). The impact of industry associations: Evidence from statistics Canada data. Innovation, 8(3), 296-306.

Damanpour, F. (1991). Organizational innovation: A meta-analysis of effects of determinants and moderators. Academy of Management Journal, 34(3), 555-590.

Damanpour, F. (1992). Organizational size and innovation. Organization Studies, 13(3), 375402.

Damanpour, F., \& Aravind, D. (2006). Product and process innovations: A review of organizational and environmental determinants. In J. Hage, \& M. Meeus (Eds.), Innovation, science, and industrial change: A research handbook (pp. 38-66). Oxford: Oxford University Press.

Damanpour, F., \& Schneider, M. (2009). Characteristics of innovation and innovation adoption in public organizations: Assessing the role of managers. Journal of Public Administration Research and Theory, 19(3), 495-522.

Dane, E. (2010). Reconsidering the trade-off between expertise and flexibility: A cognitive entrenchment perspective. Academy of Management Review, 35(4), 579-603.

Deeds, D. L., \& Hill, C. W. (1996). Strategic alliances and the rate of new product development: An empirical study of entrepreneurial biotechnology firms. Journal of Business Venturing, 11(1), 41-55.

Degener, P., Maurer, I., \& Bort, S. (2018). Alliance portfolio diversity and innovation: The interplay of portfolio coordination capability and proactive partner selection capability. Journal of Management Studies, 55(8), 1386-1422.

Delbridge, R., \& Fiss, P. C. (2013). Editors' comments: Styles of theorizing and the social organization of knowledge. Academy of Management Review, 38(3), 325-331.

Deschamps, J. P. (2008). Innovation leaders: How senior executives stimulate, steer and sustain innovation. Chichester: Wiley.

Dhanaraj, C., \& Parkhe, A. (2006). Orchestrating innovation networks. Academy of Management Review, 31(3), 659-669.

Doty, D. H., Glick, W. H., \& Huber, G. P. (1993). Fit, equifinality, and organizational effectiveness: A test of two configurational theories. Academy of Management Journal, 36(6), 1196-1250.

Dougherty, D. (1999). Organizing for Innovation. In S. R. Clegg, C. Hardy, \& W. R. Nord (Eds.), Managing organizations: Current issues (pp. 174-189). London: Sage.

Dougherty, D., \& Dunne, D. D. (2012). Digital science and knowledge boundaries in complex innovation. Organization Science, 23(5), 1467-1484.

Downes, L., \& Nunes, P. (2014). Big bang disruption: Business survival in the age of constant innovation. New York: Penguin.

Drazin, R., \& Van de Ven, A. H. (1985). Alternative forms of fit in contingency theory. Administrative Science Quarterly, 30(4), 514-539.

Dusonchet, L., \& Telaretti, E. (2010). Economic analysis of different supporting policies for the production of electrical energy by solar photovoltaics in western European Union countries. Energy Policy, 38(7), 3297-3308. 
Dutton, J. E., Ashford, S. J., O’Neill, R. M., \& Lawrence, K. A. (2001). Moves that matter: Issue selling and organizational change. Academy of Management Journal, 44(4), 716-736.

Dyer, J. H., \& Nobeoka, K. (2000). Creating and managing a high-performance knowledgesharing network: The Toyota case. Strategic Management Journal, 21(3), 345-367.

Edelmann, H. (2015). Gewohnte Wege verlassen - Innovation in der Energiewirtschaft. Düsseldorf: Ernst \& Young.

Edgett, S. J. (2011). New product development: Process benchmarks and performance metrics. Houston: American Productivity \& Quality Center.

Edwards, J. S. (2008). Knowledge management in the energy sector: Review and future directions. International Journal of Energy Sector Management, 2(2), 197-217.

Eisenhardt, K. M., \& Martin, J. A. (2000). Dynamic capabilities: What are they? Strategic Management Journal, 21(10-11), 1105-1121.

El Sawy, O. A., Malhotra, A., Park, Y., \& Pavlou, P. A. (2010). Seeking the configurations of digital ecodynamics: It takes three to tango. Information Systems Research, 21(4), 835-848.

Elenkov, D. S., Judge, W., \& Wright, P. (2005). Strategic leadership and executive innovation influence: An international multi-cluster comparative study. Strategic Management Journal, 26(7), 665-682.

Emden, Z., Calantone, R. J., \& Droge, C. (2006). Collaborating for new product development: Selecting the partner with maximum potential to create value. Journal of Product Innovation Management, 23(4), 330-341.

Ettlie, J. E., \& Elsenbach, J. M. (2007). Modified Stage-Gate ${ }^{\circledR}$ regimes in new product development. Journal of Product Innovation Management, 24(1), 20-33.

Faems, D., Janssens, M., \& Neyens, I. (2012). Alliance portfolios and innovation performance: Connecting structural and managerial perspectives. Group \& Organization Management, $37(2), 241-268$.

Fang, E. (2011). The effect of strategic alliance knowledge complementarity on new product innovativeness in China. Organization Science, 22(1), 158-172.

Faraj, S., Jarvenpaa, S. L., \& Majchrzak, A. (2011). Knowledge collaboration in online communities. Organization Science, 22(5), 1224-1239.

Felekoglu, B., \& Moultrie, J. (2014). Top management involvement in new product development: A review and synthesis. Journal of Product Innovation Management, 31(1), 159-175.

Ferrier, W. J. (2001). Navigating the competitive landscape: The drivers and consequences of competitive aggressiveness. Academy of Management Journal, 44(4), 858-877.

Fiol, C. M. (1996). Squeezing harder doesn't always work: Continuing the search for consistency in innovation research. Academy of Management Review, 21(4), 1012-1021.

Fiss, P. C. 2011. Building better causal theories: A fuzzy set approach to typologies in organization research. Academy of Management Journal, 54(2), 393-420.

Fitzgerald, M., Kruschwitz, N., Bonnet, D., \& Welch, M. (2014). Embracing digital technology: A new strategic imperative. MIT Sloan Management Review, 55(2), 1-12.

Fleishman, E. A., Mumford, M. D., Zaccaro, S. J., Levin, K. Y., Korotkin, A. L., \& Hein, M. B. (1991). Taxonomic efforts in the description of leader behavior: A synthesis and functional interpretation. The Leadership Quarterly, 2(4), 245-287. 
Ford, D., \& Mouzas, S. (2013). The theory and practice of business networking. Industrial Marketing Management, 42(3), 433-442.

Galaskiewicz, J., \& Zaheer, A. (1999). Networks of competitive advantage. Research in the Sociology of Organizations, 16(1), 237-261.

Galasso, A., \& Simcoe, T. S. (2011). CEO overconfidence and innovation. Management Science, 57(8), 1469-1484.

Garcia, R., \& Calantone, R. (2002). A critical look at technological innovation typology and innovativeness terminology: A literature review. Journal of Product Innovation Management, 19(2), 110-132.

Garms, F. P., \& Engelen, A. (2019). Innovation and R\&D in the upper echelons: The association between the CTO's power depth and breadth and the TMT's commitment to innovation. Journal of Product Innovation Management, 36(1), 87-106.

Gawer, A., \& Cusumano, M. A. (2014). Industry platforms and ecosystem innovation. Journal of Product Innovation Management, 31(3), 417-433.

Geigenmüller, A., \& Leischnig, A. (2017). A configurational perspective on alliance management capabilities. Managing alliance portfolios and networks. In T. K. Das (Ed.), Managing alliance portfolios and networks (pp. 71-90). Charlotte: Information Age Publishing.

Geletkanycz, M. A., \& Boyd, M. K. (2011). CEO outside directorships and firm performance: A reconciliation of agency and embeddedness views. Academy of Management Journal, 54(2), 335-352.

Geletkanycz, M. A., \& Hambrick, D. C. (1997). The external ties of top executives: Implications for strategic choice and performance. Administrative Science Quarterly, 42(4), 654-681.

George, G., Haas, M. R., \& Pentland, A. (2014). Big data and management. Academy of Management Journal, 57(2), 321-326.

Gerstner, W. C., König, A., Enders, A., \& Hambrick, D. C. (2013). CEO narcissism, audience engagement, and organizational adoption of technological discontinuities. Administrative Science Quarterly, 58(2), 257-291.

Gesing, J., Antons, D., Piening, E. P., Rese, M., \& Salge, T. O. (2015). Joining Forces or Going It Alone? On the Interplay among External Collaboration Partner Types, Interfirm Governance Modes, and Internal R \& D. Journal of Product Innovation Management, 32(3), 424-440.

Gnyawali, D. R., \& Madhavan, R. (2001). Cooperative networks and competitive dynamics: A structural embeddedness perspective. Academy of Management Review, 26(3), 431-445.

Goerzen, A., \& Beamish, P. W. (2005). The effect of alliance network diversity on multinational enterprise performance. Strategic Management Journal, 26(4), 333-354.

Grant, R. M. (1996). Toward a knowledge-based theory of the firm. Strategic Management Journal, 17(S2), 109-122.

Greckhamer, T. (2016). CEO compensation in relation to worker compensation across countries: The configurational impact of country-level institutions. Strategic Management Journal, 37(4), 793-815.

Grigoriou, K., \& Rothaermel, F. T. (2014). Structural microfoundations of innovation: The role of relational stars. Journal of Management, 40(2), 586-615. 
Guadalupe, M., Li, H., \& Wulf, J. (2014). Who lives in the C-suite? Organizational structure and the division of labor in top management. Management Science, 60(4), 824-844.

Gulati, R. (1999). Network location and learning: The influence of network resources and firm capabilities on alliance formation. Strategic Management Journal, 20(5), 397-420.

Gulati, R. (2007). Managing network resources: Alliances, affiliations, and other relational assets. New York: Oxford University Press.

Gulati, R., \& Higgins, M. C. (2003). Which ties matter when? The contingent effects of interorganizational partnerships on IPO success. Strategic Management Journal, 24(2), 127 144.

Gulati, R., Lavie, D., \& Madhavan, R. R. (2011). How do networks matter? The performance effects of interorganizational networks. Research in Organizational Behavior, 31, 207-224.

Gulati, R., Nohria, N., \& Zaheer, A. (2000). Strategic networks. Strategic Management Journal, 21(3), 203-215.

Haffke, I., Kalgovas, B., \& Benlian, A. (2017). Options for transforming the IT function using bimodal IT. MIS Quarterly Executive, 16(2), 101-120.

Hambrick, D. C. (2007). Upper echelons theory: An update. Academy of Management Review, $32(2), 334-343$.

Hambrick, D. C., \& Cannella, A. A. (2004). CEOs who have COOs: Contingency analysis of an unexplored structural form. Strategic Management Journal, 25(10), 959-979.

Hambrick, D. C., Finkelstein, S., \& Mooney, A. C. (2005). Executive job demands: New insights for explaining strategic decisions and leader behaviors. Academy of Management Review, 30(3), 472-491.

Hambrick, D. C., \& Mason, P. A. (1984). Upper echelons: The organization as a reflection of its top managers. Academy of Management Review, 9(2), 193-206.

Hargadon, A., \& Sutton, R. I. (1997). Technology brokering and innovation in a product development firm. Administrative Science Quarterly, 42(4), 716-749.

Hauser, J., Tellis, G. J., \& Griffin, A. (2006). Research on innovation: A review and agenda for marketing science. Marketing Science, 25(6), 687-717.

Hegarty, W. H., \& Hoffman, R. C. (1990). Product/market innovations: A study of top management involvement among four cultures. Journal of Product Innovation Management, 7(3), 186-199.

Heidenreich, S., Landsperger, J., \& Spieth, P. (2016). Are innovation networks in need of a conductor? Examining the contribution of network managers in low and high complexity settings. Long Range Planning, 49(1), 55-71.

Heimeriks, K. H., \& Duysters, G. (2007). Alliance capability as a mediator between experience and alliance performance: An empirical investigation into the alliance capability development process. Journal of Management Studies, 44(1), 25-49.

Helfat, C. E., \& Martin, J. A. (2015). Dynamic managerial capabilities: Review and assessment of managerial impact on strategic change. Journal of Management, 41(5), 1281-1312.

Henfridsson, O., Mathiassen, L., \& Svahn, F. (2014). Managing technological change in the digital age: The role of architectural frames. Journal of Information Technology, 29(1), $27-$ 43.

Hess, T., Matt, C., Benlian, A., \& Wiesböck, F. (2016). Options for formulating a digital transformation strategy. MIS Quarterly Executive, 15(2), 123-139. 
Hofman, E., Faems, D., \& Schleimer, S. C. (2017). Governing collaborative new product development: Toward a configurational perspective on the role of contracts. Journal of Product Innovation Management, 34(6), 739-756.

Hoffman, B. J., Woehr, D. J., Maldagen-Youngjohn, R., \& Lyons, B. D. (2011). Great man or great myth? A quantitative review of the relationship between individual differences and leader effectiveness. Journal of Occupational and Organizational Psychology, 84(2), 347381.

Hoffman, R. C., \& Hegarty, W. H. (1993). Top management influence on innovations: Effects of executive characteristics and social culture. Journal of Management, 19(3), 549-574.

Hoffmann, W. H. (2007). Strategies for managing a portfolio of alliances. Strategic Management Journal, 28(8), 827-856.

Horbach, J., Rammer, C., \& Rennings, K. (2012). Determinants of eco-innovations by type of environmental impact - The role of regulatory push/pull, technology push and market pull. Ecological Economics, 78(1), 112-122.

Huggins, R., \& Johnston, A. (2010). Knowledge flow and inter-firm networks: The influence of network resources, spatial proximity and firm size. Entrepreneurship \& Regional Development, 22(5), 457-484.

Hult, G. T. M., Hurley, R. F., \& Knight, G. A. (2004). Innovativeness: Its antecedents and impact on business performance. Industrial Marketing Management, 33(5), 429-438.

Hunt, J. G. (2004). Task leadership. In G. R. Goethels, G. J. Sorensen, \& J. M. Burns (Eds.), Encyclopedia of leadership (pp. 1524-1529). Thousand Oaks: Sage.

Hunter, S. T., \& Cushenbery, L. (2011). Leading for innovation: Direct and indirect influences. Advances in Developing Human Resources, 13(3), 248-265.

Iansiti, M., \& Lakhani, K.R. (2014). Digital ubiquity: How connections, sensors, and data are revolutionizing business. Harvard Business Review, 92(11), 90-99.

Inkpen, A. C., \& Pien, W. (2006). An examination of collaboration and knowledge transfer: China-Singapore Suzhou Industrial Park. Journal of Management Studies, 43(4), 779-811.

Inkpen, A. C., \& Tsang, E. W. (2005). Social capital, networks, and knowledge transfer. Academy of Management Review, 30(1), 146-165.

Ireland, D., \& Hitt, M. A. (1999). Achieving and maintaining strategic competitiveness in the 21st century: The role of strategic leadership. Academy of Management Executive, 13(1), 43-57.

Ireland, R. D., Hitt, M. A., \& Vaidyanath, D. (2002). Alliance management as a source of competitive advantage. Journal of Management, 28(3), 413-446.

Jacobsson, S., \& Bergek, A. (2004). Transforming the energy sector: The evolution of technological systems in renewable energy technology. Industrial and Corporate Change, 13(5), 815-849.

Jaruzelski, B., Chwalik, R., \& Goehle, B. (2018). What the top innovators get right. Retrieved from https:/www.strategy-business.com/feature/What-the-Top-Innovators-Get-Right?gko $=\mathrm{e} 7 \mathrm{cf} 9$

Jung, D. D., Wu, A., \& Chow, C. W. (2008). Towards understanding the direct and indirect effects of CEOs' transformational leadership on firm innovation. The Leadership Quarterly, $19(5), 582-594$. 
Kale, P., \& Singh, H. (2007). Building firm capabilities through learning: The role of the alliance learning process in alliance capability and firm-level alliance success. Strategic Management Journal, 28(10), 981-1000.

Kale, P., Singh, H., \& Perlmutter, H. (2000). Learning and protection of proprietary assets in strategic alliances: Building relational capital. Strategic Management Journal, 21(3), 217237.

Katz, D., \& Kahn, R. L. (1978). The social psychology of organizations. New York: Wiley.

Kay, S. E., Boike, D., Fisher, W., Hustad, T., Jankowski, S., Mills, D. A., Novotny, B. J., Page, A., \& Riggs, W. M. (2013). Lessons Learned from Outstanding Corporate Innovators. In K. B. Kahn, S. E. Kay, R. J. Slotegraaf, \& S. Uban (Eds.), The PDMA handbook of new product development (pp. 387-404). Hoboken: Wiley.

Keil, T., Maula, M., Schildt, H., \& Zahra, S. A. (2008). The effect of governance modes and relatedness of external business development activities on innovative performance. Strategic Management Journal, 29(8), 895-907.

Khurana, R. (2002). The curse of the superstar CEO. Harvard Business Review, 80(9), 60-67.

Kitchell, S. (1995). Corporate culture, environmental adaptation, and innovation adoption: A qualitative/quantitative approach. Journal of the Academy of Marketing Science, 23(3), 195205.

Klomp, L., \& Van Leeuwen, G. (2001). Linking innovation and firm performance: A new approach. International Journal of the Economics of Business, 8(3), 343-364.

Kogut, B., \& Zander, U. (1992). Knowledge of the firm, combinative capabilities, and the replication of technology. Organization Science, 3(3), 383-397.

Koka, B. R., \& Prescott, J. E. (2008). Designing alliance networks: The influence of network position, environmental change, and strategy on firm performance. Strategic Management Journal, 29(6), 639-661.

Kolloch, M., \& Golker, O. (2016). Staatliche Regulierung und Digitalisierung als Antezedenzien für Innovationen in der Energiewirtschaft am Beispiel von REMIT. Zeitschrift für Energiewirtschaft, 40(1), 41-54.

Kolloch, M., \& Reck, F. (2018). Kundengetriebene Innovation und Digitalisierung. In W. Becker, B. Eierle, A. Fliaster, B. Ivens, A. Leischnig, A. Pflaum, \& E. Sucky (Eds.), Geschäftsmodelle in der digitalen Welt - Strategie, Prozesse und Praxiserfahrungen (pp. 123-143). Wiesbaden: Springer Gabler.

Kraaijenbrink, J., Spender, J. C., \& Groen, A. J. (2010). The resource-based view: A review and assessment of its critiques. Journal of Management, 36(1), 349-372.

Kraft, P., \& Bausch, A. (2016). How do transformational leaders promote exploratory and exploitative innovation? Examining the black box through MASEM. Journal of Product Innovation Management, 33(6), 687-707.

Kraus, S., Ribeiro-Soriano, D., \& Schüssler, M. (2018). Fuzzy-set qualitative comparative analysis (fsQCA) in entrepreneurship and innovation research - The rise of a method. International Entrepreneurship and Management Journal, 14(1), 15-33.

Lam, A. (2005). Organizational innovation. In J. Fagerberg, D. C. Mowery, \& R. R. Nelson (Eds.), The Oxford Handbook of Innovation (pp. 115-147). Oxford: Oxford University Press. 
Lambe, C. J., Spekman, R. E., \& Hunt, S. D. (2002). Alliance competence, resources, and alliance success: Conceptualization, measurement, and initial test. Journal of the Academy of Marketing Science, 30(2), 141-158.

Lane, P. J., Salk, J. E., \& Lyles, M. A. (2001). Absorptive capacity, learning, and performance in international joint ventures. Strategic Management Journal, 22(12), 1139-1161.

Lavie, D. (2006). The competitive advantage of interconnected firms: An extension of the resource-based view. Academy of Management Review, 31(3), 638-658.

Lavie, D. (2007). Alliance portfolios and firm performance: A study of value creation and appropriation in the US software industry. Strategic Management Journal, 28(12), 11871212.

Lavie, D., Lechner, C., \& Singh, H. (2007). The performance implications of timing of entry and involvement in multipartner alliances. Academy of Management Journal, 50(3), 578604.

Lavie, D., \& Miller, S. R. (2008). Alliance portfolio internationalization and firm performance. Organization Science, 19(4), 623-646.

Lechner, C., Frankenberger, K., \& Floyd, S. W. (2010). Task contingencies in the curvilinear relationships between intergroup networks and initiative performance. Academy of Management Journal, 53(4), 865-889.

Lee, J., \& Berente, N. (2012). Digital innovation and the division of innovative labor: Digital controls in the automobile industry. Organization Science, 23(5), 1428-1447.

Leifer, R., O'Connor, G. C., \& Rice, M. (2001). Implementing radical innovation in mature firms: The role of hubs. Academy of Management Executive, 15(3), 102-113.

Leischnig, A., Geigenmueller, A., \& Lohmann, S. (2014). On the role of alliance management capability, organizational compatibility, and interaction quality in interorganizational technology transfer. Journal of Business Research, 67(6), 1049-1057.

Lessig, L. (2008). Remix: Making art and commerce thrive in the hybrid economy. New York: Penguin.

Levinthal, D. A., \& Warglien, M. (1999). Landscape design: Designing for local action in complex worlds. Organization Science, 10(3), 342-357.

Lewellyn, K. B., \& Fainshmidt, S. (2017). Effectiveness of CEO power bundles and discretion context: Unpacking the 'fuzziness' of the CEO duality puzzle. Organization Studies, 38(11), $1603-1624$.

Li, M., \& Patel, P. C. (2019). Jack of all, master of all? CEO generalist experience and firm performance. The Leadership Quarterly, 30(3), 320-334.

Li, Q., Maggitti, P. G., Smith, K. G., Tesluk, P. E., \& Katila, R. (2013). Top management attention to innovation: The role of search selection and intensity in new product introductions. Academy of Management Journal, 56(3), 893-916.

Li, T., \& Calantone, R. J. (1998). The impact of market knowledge competence on new product advantage: conceptualization and empirical examination. Journal of Marketing, 62(4), $13-$ 29.

Li, Y., \& Tan, C. H. (2013). Matching business strategy and CIO characteristics: The impact on organizational performance. Journal of Business Research, 66(2), 248-259. 
Ling, Y. A. N., Simsek, Z., Lubatkin, M. H., \& Veiga, J. F. (2008). Transformational leadership's role in promoting corporate entrepreneurship: Examining the CEO-TMT interface. Academy of Management Journal, 51(3), 557-576.

Lorenzoni, G., \& Lipparini, A. (1999). The leveraging of interfirm relationships as a distinctive organizational capability: A longitudinal study. Strategic Management Journal, 20(4), 317 338.

Lubatkin, M. H., Simsek, Z., Ling, Y., \& Veiga, J. F. (2006). Ambidexterity and performance in small-to medium-sized firms: The pivotal role of top management team behavioral integration. Journal of Management, 32(5), 646-672.

Lusch, R. F., \& Nambisan, S. (2015). Service innovation: A service-dominant logic perspective. MIS Quarterly, 39(1), 155-176.

Lyytinen, K., Yoo, Y., \& Boland, R. J. (2016). Digital product innovation within four classes of innovation networks. Information Systems Journal, 26(1), 47-75.

Madhavan, R., Caner, T., Prescott, J. E., \& Koka, B. R. (2008). Bringing the firm back in: Networking as antecedent to network structure. In J. A. C: Baum \& T. J. Rowley (Eds.), Network strategy (pp. 457-501). Bingley: Emerald.

Majchrzak, A., \& Malhotra, A. (2013). Towards an information systems perspective and research agenda on crowdsourcing for innovation. Journal of Strategic Information Systems, 22(4), 257-268.

Makri, M., \& Scandura, T. A. (2010). Exploring the effects of creative CEO leadership on innovation in high-technology firms. The Leadership Quarterly, 21(1), 75-88.

Marcel, J. J. (2009). Why top management team characteristics matter when employing a chief operating officer: A strategic contingency perspective. Strategic Management Journal, 30(6), 647-658.

Matt, C., Hess, T., \& Benlian, A. (2015). Digital transformation strategies. Business \& Information Systems Engineering, 57(5), 339-343.

Maurer, I. (2010). How to build trust in inter-organizational projects: The impact of project staffing and project rewards on the formation of trust, knowledge acquisition and product innovation. International Journal of Project Management, 28(7), 629-637.

Maurer, I., Bartsch, V., \& Ebers, M. (2011). The value of intra-organizational social capital: How it fosters knowledge transfer, innovation performance, and growth. Organization Studies, 32(2), 157-185.

McCann, B. T., \& Folta, T. B. (2011). Performance differentials within geographic clusters. Journal of Business Venturing, 26(1), 104-123.

McDonald, M.P., \& Rowsell-Jones, A. (2012). The digital edge: Exploiting information \& technology for business advantage. Stamford: Gartner.

McEvily, B., \& Marcus, A. (2005). Embedded ties and the acquisition of competitive capabilities. Strategic Management Journal, 26(11), 1033-1055.

McEvily, B., Soda, G., \& Tortoriello, M. (2014). More formally: Rediscovering the missing link between formal organization and informal social structure. Academy of Management Annals, 8(1), 299-345.

McEvily, B., \& Zaheer, A. (1999). Bridging ties: A source of firm heterogeneity in competitive capabilities. Strategic Management Journal, 20(12), 1133-1156. 
McKinsey (2019). Growth \& Innovation. Retrieved from https://www.mckinsey.com/businessfunctions/strategy-and-corporate-finance/how-we-help-clients/growth-and-innovation/

Menz, M. (2012). Functional top management team members: A review, synthesis, and research agenda. Journal of Management, 38(1), 45-80.

Menz, M., \& Scheef, C. (2014). Chief strategy officers: Contingency analysis of their presence in top management teams. Strategic Management Journal, 35(3), 461-471.

Meuer, J. (2014). Archetypes of inter-firm relations in the implementation of management innovation: A set-theoretic study in China's biopharmaceutical industry. Organization Studies, 35(1), 121-145.

Meyer, A. D., Tsui, A. S., \& Hinings, C. R. (1993). Configurational approaches to organizational analysis. Academy of Management Journal, 36(6), 1175-1195.

Milgrom, P., \& Roberts, J. (1995). Complementarities and fit strategy, structure, and organizational change in manufacturing. Journal of Accounting and Economics, 19(2-3), 179-208.

Minor, M. J. (1983). New directions in multiplexity analysis. In R. S. Burt \& M. J. Minor (Eds.), Applied network analysis (pp. 223-244). Beverly Hills: Sage.

Misangyi, V. F., Greckhamer, T., Furnari, S., Fiss, P. C., Crilly, D., \& Aguilera, R. (2017). Embracing causal complexity: The emergence of a neo-configurational perspective. Journal of Management, 43(1), 255-282.

Mitrega, M., \& Pfajfar, G. (2015). Business relationship process management as company dynamic capability improving relationship portfolio. Industrial Marketing Management, 46(2), 193-203.

Mowery, D. C., Oxley, J. E., \& Silverman, B. S. (1996). Strategic alliances and interfirm knowledge transfer. Strategic Management Journal, 17(S2), 77-91.

$\mathrm{Mu}$, J., \& Di Benedetto, A. (2012). Networking capability and new product development. IEEE Transactions on Engineering Management, 59(1), 4-19.

Mugge, P., \& Markham, S. K. (2013). An innovation management framework: A model for managers who want to grow their business. In K. B. Kahn, S. E. Kay, R. J. Slotegraaf, \& S. Uban (Eds.), The PDMA handbook of new product development (pp. 35-50). Hoboken: Wiley.

Müller, R., Steinert, M., \& Teufel, S. (2008). Successful diversification strategies of electricity companies: An explorative empirical study on the success of different diversification strategies of German electricity companies in the wake of the European market liberalization. Energy Policy, 36(1), 398-412.

Mumford, M. D., \& Licuanan, B. (2004). Leading for innovation: Conclusions, issues, and directions. The Leadership Quarterly, 15(1), 163-171.

Mumford, M. D., Scott, G. M., Gaddis, B., \& Strange, J. M. 2002. Leading creative people: Orchestrating expertise and relationships. The Leadership Quarterly, 13(6), 705-750.

Nahapiet, J., \& Ghoshal, S. (1998). Social capital, intellectual capital, and the organizational advantage. Academy of Management Review, 23(2), 242-266.

Nambisan, S., Lyytinen, K., Majchrzak, A., \& Song, M. (2017). Digital Innovation Management: Reinventing innovation management research in a digital world. MIS Quarterly, 41(1), 223-238. 
Nath, P., \& Mahajan, V. (2008). Chief marketing officers: A study of their presence in firms' top management teams. Journal of Marketing, 72(1), 65-81.

Naudé, P., Zaefarian, G., Tavani, Z. N., Neghabi, S., \& Zaefarian, R. (2014). The influence of network effects on SME performance. Industrial Marketing Management, 43(4), 630-641.

Niebuhr, J., Röder, H., Seyfferth, J., Eberle, D., Schwarz, K., \& Skritek, B. (2019). A strategic guide to digital innovation: How to transform and scale up models and mindsets. Retrieved from https://www.strategyand.pwc.com/gx/en/insights/strategists-guide-to-digitalinnovation.html

Nylén, D., \& Holmström, J. (2015). Digital innovation strategy: A framework for diagnosing and improving digital product and service innovation. Business Horizons, 58(1), 57-67.

O'Brien, J. P. (2003). The capital structure implications of pursuing a strategy of innovation. Strategic Management Journal, 24(5), 415-431.

O'Connor, G. C. (2012). Innovation: From process to function. Journal of Product Innovation Management, 29(3), 361-363.

O'Connor, G. C., \& Ayers, A. D. (2005). Building a radical innovation competency. ResearchTechnology Management, 48(1), 23-31.

O’Connor, G. C., \& DeMartino, R. (2006). Organizing for radical innovation: An exploratory study of the structural aspects of RI management systems in large established firms. Journal of Product Innovation Management, 23(6), 475-497.

Owen-Smith, J., \& Powell, W. W. (2004). Knowledge networks as channels and conduits: The effects of spillovers in the Boston biotechnology community. Organization Science, 15(1), 5-21.

Oxley, J., \& Wada, T. (2009). Alliance structure and the scope of knowledge transfer: Evidence from US-Japan agreements. Management Science, 55(4), 635-649.

Ozer, M., \& Zhang, W. (2015). The effects of geographic and network ties on exploitative and exploratory product innovation. Strategic Management Journal, 36(7), 1105-1114.

Papadakis, V., \& Bourantas, D. (1998). The chief executive officer as corporate champion of technological innovation: An empirical investigation. Technology Analysis \& Strategic Management, 10(1), 89-110.

Parthasarthy, R., \& Hammond, J. (2002). Product innovation input and outcome: Moderating effects of the innovation process. Journal of Engineering and Technology Management, 19(1), 75-91.

Péladeau, P., Acker, O., \& Müller, K. (2019). The 2019 Chief Digital Officer (CDO) study: Global findings. Retrieved from https://www.strategyand.pwc.com/media/file/2019-CDOStudy_Global-findings.pdf

Phelps, C. C. (2010). A longitudinal study of the influence of alliance network structure and composition on firm exploratory innovation. Academy of Management Journal, 53(4), 890913.

Phelps, C., Heidl, R., \& Wadhwa, A. (2012). Knowledge, networks, and knowledge networks: A review and research agenda. Journal of Management, 38(4), 1115-1166.

Pisano, G. P. (2015). You need an innovation strategy. Harvard Business Review, 93(6), 4454. 
Pittaway, L., Robertson, M., Munir, K., Denyer, D., \& Neely, A. (2004). Networking and innovation: A systematic review of the evidence. International Journal of Management Reviews, 5(3-4), 137-168.

Porter, M. E., \& Heppelmann, J. E. (2014). How smart, connected products are transforming competition. Harvard Business Review, 92(11), 64-88.

Pouder, R., \& St. John, C. H. (1996). Hot spots and blind spots: Geographical clusters of firms and innovation. Academy of Management Review, 21(4), 1192-1225.

Powell, W. W., Koput, K. W., \& Smith-Doerr, L. (1996). Interorganizational collaboration and the locus of innovation: Networks of learning in biotechnology. Administrative Science Quarterly, 41(1), 116-145.

Pullen, A. J., de Weerd-Nederhof, P. C., Groen, A. J., \& Fisscher, O. A. (2012). Open innovation in practice: Goal complementarity and closed NPD networks to explain differences in innovation performance for SMEs in the medical devices sector. Journal of Product Innovation Management, 29(6), 917-934.

Richter, M. (2013). Business model innovation for sustainable energy: German utilities and renewable energy. Energy Policy, 62(11), 1226-1237.

Rijsdijk, S. A., \& Hultink, E. J. (2009). How today's consumers perceive tomorrow's smart products. Journal of Product Innovation Management, 26(1), 24-42.

Rindfleisch, A., O'Hern, M., \& Sachdev, V. (2017). The digital revolution, 3D printing, and innovation as data. Journal of Product Innovation Management, 34(5), 681-690.

Ringel, M., Grassl, F., Baeza, R., Kennedy, D., \& Manly, J. (2019). Innovation in 2019: The most innovative companies 2019. Retrieved from https://www.bcg.com/publications/2019/most-innovative-companies-innovation.aspx

Ringel, M., \& Zablit, H. (2018). Innovation in 2018. Retrieved from https://www.bcg.com/publications/2018/most-innovative-companies-2018-innovation.aspx

Ritala, P., \& Hurmelinna-Laukkanen, P. (2013). Incremental and radical innovation in coopetition - The role of absorptive capacity and appropriability. Journal of Product Innovation Management, 30(1), 154-169.

Ritter, T., \& Gemünden, H. G. (2003). Network competence: Its impact on innovation success and its antecedents. Journal of Business Research, 56(9), 745-55.

Rivkin, J. W. (2000). Imitation of complex strategies. Management Science, 46(6), 824-844.

Rohrbeck, R., Hölzle, K., \& Gemünden, H. G. (2009). Opening up for competitive advantage - How Deutsche Telekom creates an open innovation ecosystem. R\&D Management, 39(4), 420-430.

Rost, K., Hölzle, K., \& Gemünden, H. G. (2007). Promotors or champions? Pros and cons of role specialisation. Schmalenbach Business Review, 59(4), 340-363.

Rothaermel, F. T., \& Deeds, D. L. (2006). Alliance type, alliance experience and alliance management capability in high-technology ventures. Journal of Business Venturing, 21(4), 429-460.

Rothaermel, F. T., \& Hess, A. M. (2007). Building dynamic capabilities: Innovation driven by individual-, firm-, and network-level effects. Organization Science, 18(6), 898-921.

Rothwell, R. (1991). External networking and innovation in small and medium-sized manufacturing firms in Europe. Technovation, 11(2), 93-112. 
Rowley, T. J., \& Baum, J. A. C. (2008). Introduction: Evolving webs in network economies. In J. A. C. Baum \& T. J. Rowley (Eds.), Network strategy (pp. xiii-xxxii). Bingley: Emerald.

Rowley, T., Behrens, D., \& Krackhardt, D. (2000). Redundant governance structures: An analysis of structural and relational embeddedness in the steel and semiconductor industries. Strategic Management Journal, 21(3), 369-386.

Rupietta, C., \& Backes-Gellner, U. (2019). Combining knowledge stock and knowledge flow to generate superior incremental innovation performance - Evidence from Swiss manufacturing. Journal of Business Research, 94(1), 209-222.

Salancik, G. R. (1995). Wanted: A good network theory of organization. Administrative Science Quarterly, 40(2), 345-349.

Sammarra, A., \& Biggiero, L. (2008). Heterogeneity and specificity of inter-firm knowledge flows in innovation networks. Journal of Management Studies, 45(4), 800-829.

Sampson, R. C. (2007). R\&D alliances and firm performance: The impact of technological diversity and alliance organization on innovation. Academy of Management Journal, 50(2), 364-386.

Sarkar, M. B., Aulakh, P. S., \& Madhok, A. (2009). Process capabilities and value generation in alliance portfolios. Organization Science, 20(3), 583-600.

Sarkar, M. B., Echambadi, R. A. J., \& Harrison, J. S. (2001). Alliance entrepreneurship and firm market performance. Strategic Management Journal, 22(6-7), 701-711.

Sarros, J. C., Cooper, B. K., \& Santora, J. C. (2008). Building a climate for innovation through transformational leadership and organizational culture. Journal of Leadership \& Organizational Studies, 15(2), 145-158.

Schilke, O., \& Goerzen, A. (2010). Alliance management capability: An investigation of the construct and its measurement. Journal of Management, 36(5), 1192-1219.

Schilling, M. A., \& Phelps, C. C. (2007). Interfirm collaboration networks: The impact of largescale network structure on firm innovation. Management Science, 53(7), 1113-1126.

Schreiner, M., Kale, P., \& Corsten, D. (2009). What really is alliance management capability and how does it impact alliance outcomes and success? Strategic Management Journal, 30(13), 1395-1419.

Schulz, M. (2001). The uncertain relevance of newness: Organizational learning and knowledge flows. Academy of Management Journal, 44(4), 661-681.

Sethi, R., \& Iqbal, Z. (2008). Stage-gate controls, learning failure, and adverse effect on novel new products. Journal of Marketing, 72(1), 118-134.

Shan, W., Walker, G., \& Kogut, B. (1994). Interfirm cooperation and startup innovation in the biotechnology industry. Strategic Management Journal, 15(5), 387-394.

Simon, E., McKeough, D., Ayers, A., Rinehart, E., \& Alexia, B. (2003). How do you best organize for radical innovation? Research-Technology Management, 46(5), 17-20.

Simonin, B. L. (1999a). Ambiguity and the process of knowledge transfer in strategic alliances. Strategic Management Journal, 20(7), 595-623.

Simonin, B. L. (1999b). Transfer of marketing know-how in international strategic alliances: An empirical investigation of the role and antecedents of knowledge ambiguity. Journal of International Business Studies, 30(3), 463-490.

Simpson, C. R. (2015). Multiplexity and strategic alliances: The relational embeddedness of coalitions in social movement organisational fields. Social Networks, 42(7), 42-59. 
Singh, A., \& Hess, T. (2017). How Chief Digital Officers promote the digital transformation of their companies. MIS Quarterly Executive, 16(1), 1-17.

Slater, S. F., Mohr, J. J., \& Sengupta, S. (2014). Radical product innovation capability: Literature review, synthesis, and illustrative research propositions. Journal of Product Innovation Management, 31(3), 552-566.

Stieglitz, N., \& Heine, K. (2007). Innovations and the role of complementarities in a strategic theory of the firm. Strategic Management Journal, 28(1), 1-15.

Stuart, T. E. (2000). Interorganizational alliances and the performance of firms: A study of growth and innovation rates in a high-technology industry. Strategic Management Journal, 21(8), 791-811.

Stuart, T. E., Hoang, H., \& Hybels, R. C. (1999). Interorganizational endorsements and the performance of entrepreneurial ventures. Administrative Science Quarterly, 44(2), 315-349.

Stuart, T. E., \& Sorenson, O. (2007). Strategic networks and entrepreneurial ventures. Strategic Entrepreneurship Journal, 1(3-4), 211-227.

Subramaniam, M., \& Youndt, M. A. (2005). The influence of intellectual capital on the types of innovative capabilities. Academy of Management Journal, 48(3), 450-463.

Svahn, F., Mathiassen, L., \& Lindgren, R. (2017). Embracing digital innovation in incumbent firms: How Volvo Cars managed competing concerns. MIS Quarterly, 41(1), 239-254.

Talke, K., Salomo, S., \& Kock, A. (2011). Top management team diversity and strategic innovation orientation: The relationship and consequences for innovativeness and performance. Journal of Product Innovation Management, 28(6), 819-832.

Tanriverdi, H., \& Venkatraman, N. (2005). Knowledge relatedness and the performance of multibusiness firms. Strategic Management Journal, 26(2), 97-119.

Teece, D. J. (1998). Design issues for innovative firms: Bureaucracy, incentives, and industrial structure. In A. D. Chandler, P. Hagstrom, \& O. Solvell (Eds.), The Dynamic Firm (pp. 134165). Oxford: Oxford University Press.

Teece, D. J. (2007). Explicating dynamic capabilities: The nature and microfoundations of (sustainable) enterprise performance. Strategic Management Journal, 28(13), 1319-1350.

Thomson Reuters (2015). 2015 Top 100 global innovators: Honoring the world leaders in innovation. Retrieved from https:/www.solectria.com/site/assets/files/1954/thomson reuters_top100_global_innovators_jan2016.pdf

Thorelli, H. B. (1986). Networks: between markets and hierarchies. Strategic Management Journal, 7(1), 37-51.

Thornton, S. C., Henneberg, S. C., Leischnig, A., \& Naudé, P. (2019). It's in the mix: How firms configure resource mobilization for new product success. Journal of Product Innovation Management, 36(4), 513-531.

Thornton, S. C., Henneberg, S. C., \& Naudé, P. (2015). An empirical investigation of networkoriented behaviors in business-to-business markets. Industrial Marketing Management, 49(1), 167-180.

Tilson, D., Lyytinen, K., \& Sørensen, C. (2010). Digital infrastructures: The missing IS research agenda. Information Systems Research, 21(4), 748-759.

Tiwana, A. (2008). Do bridging ties complement strong ties? An empirical examination of alliance ambidexterity. Strategic Management Journal, 29(3), 251-272. 
Tiwana, A., Konsynski, B., Bush, A. A. (2010). Platform evolution: Coevolution of platform architecture, governance, and environmental dynamics. Information Systems Research, 21(4), 675-687.

Tortoriello, M., \& Krackhardt, D. (2010). Activating cross-boundary knowledge: The role of Simmelian ties in the generation of innovations. Academy of Management Journal, 53(1), 167-181.

Tripsas, M., \& Gavetti, G. (2000). Capabilities, cognition, and inertia: Evidence from digital imaging. Strategic Management Journal, 21(10-11), 1147-1161.

Tsai, W. (2001). Knowledge transfer in intraorganizational networks: Effects of network position and absorptive capacity on business unit innovation and performance. Academy of Management Journal, 44(5), 996-1004.

Tsai, W., \& Ghoshal, S. (1998). Social capital and value creation: The role of intrafirm networks. Academy of Management Journal, 41(4), 464-476.

Tsoukas, H. (1989). The validity of idiographic research explanations. Academy of Management Review, 14(4), 551-561.

Tumbas, S., Berente, N., \& Brocke, J. V. (2018). Digital innovation and institutional entrepreneurship: Chief Digital Officer perspectives of their emerging role. Journal of Information Technology, 33(3), 188-202.

Tushman, M. L., \& Nadler, D. (1986). Organizing for innovation. California Management Review, 28(3), 74-92.

Tushman, M. L., \& Rosenkopf, L. (1996). Executive succession, strategic reorientation and performance growth: A longitudinal study in the US cement industry. Management Science, 42(7), 939-953.

Van de Ven, A. H., \& Huber, G. P. (1990). Longitudinal field research methods for studying processes of organizational change. Organization Science, 1(3), 213-219.

Van de Ven, A., Polley, D., Garud, S., \& Venkataraman, S. (2007). The innovation journey. New York: Oxford University Press.

Van de Ven, A. H., \& Poole, M. S. (1995). Explaining development and change in organizations. Academy of Management Review, 20(3), 510-540.

Vesalainen, J., \& Hakala, H. (2014). Strategic capability architecture: The role of network capability. Industrial Marketing Management, 43(6), 938-950.

Vis, B. (2012). The comparative advantages of fsQCA and regression analyses for moderately large-N analyses. Sociological Methods \& Research, 41(1), 168-198.

Voss, G. B., Sirdeshmukh, D., \& Voss, Z. G. (2008). The effects of slack resources and environmental threat on product exploration and exploitation. Academy of Management Journal, 51(1), 147-164.

Walter, A., Auer, M., \& Ritter, T. (2006). The impact of network capabilities and entrepreneurial orientation on university spin-off performance. Journal of Business Venturing, 21(4), 541-567.

Wang, Y., \& Rajagopalan, N. (2015). Alliance capabilities: Review and research agenda. Journal of Management, 41(1), 236-260.

Wassmer, U. (2010). Alliance portfolios: A review and research agenda. Journal of Management, 36(1), 141-171. 
Watts, S., \& Henderson, J. C. (2006). Innovative IT climates: CIO perspectives. Journal of Strategic Information Systems, 15(2), 125-151.

Weill, P., \& Woerner, S. L. (2015). Thriving in an increasingly digital ecosystem. MIT Sloan Management Review, 56(4), 27-34.

West, J., \& Bogers, M. (2014). Leveraging external sources of innovation: A review of research on open innovation. Journal of Product Innovation Management, 31(4), 814-831.

Wheelwright, S. C., \& Clark, K. B. (1992). Revolutionizing product development: Quantum leaps in speed, efficiency, and quality. New York: Simon and Schuster.

Williams, C. (2007). Transfer in context: Replication and adaptation in knowledge transfer relationships. Strategic Management Journal, 28(9), 867-889.

Winter, S. G. (2000). The satisficing principle in capability learning. Strategic Management Journal, 21(10-11), 981-996.

Wolfe, R. A. (1994). Organizational innovation: Review, critique and suggested research directions. Journal of Management Studies, 31(3), 405-431.

Xie, X., Fang, L., \& Zeng, S. (2016). Collaborative innovation network and knowledge transfer performance: A fsQCA approach. Journal of Business Research, 69(11), 5210-5215.

Yadav, M. S., Prabhu, J. C., \& Chandy, R. K. (2007). Managing the future: CEO attention and innovation outcomes. Journal of Marketing, 71(4), 84-101.

Yoo, Y., Boland, R. J., Lyytinen, K., \& Majchrzak, A. (2012). Organizing for innovation in the digitized world. Organization Science, 23(5), 1398-1408.

Yoo, Y., Lyytinen, K. J., Boland, R., Berente, N., Gaskin, J., Schutz, D., \& Srinivasan, N. (2010a). The next wave of digital innovation: Opportunities and challenges - A report on the research workshop 'Digital Challenges in Innovation Research'. Philadelphia: Temple University.

Yoo, Y., Henfridsson, O., \& Lyytinen, K. (2010b). The new organizing logic of digital innovation: An agenda for information systems research. Information Systems Research, 21(4), 724-735.

Young, G. J., Charns, M. P., \& Shortell, S. M. (2001). Top manager and network effects on the adoption of innovative management practices: A study of TQM in a public hospital system. Strategic Management Journal, 22(10), 935-951.

Zaefarian, G., Henneberg, S. C., \& Naudé, P. (2013). Assessing the strategic fit between business strategies and business relationships in knowledge-intensive business services. Industrial Marketing Management, 42(2), 260-272.

Zaheer, A., \& Bell, G. G. (2005). Benefiting from network position: firm capabilities, structural holes, and performance. Strategic Management Journal, 26(9), 809-825.

Zaheer, A., Gözübüyük, R., \& Milanov, H. (2010). It's the connections: The network perspective in interorganizational research. Academy of Management Perspectives, 24(1), $62-77$.

Zaheer, A., McEvily, B., \& Perrone, V. (1998). Does trust matter? Exploring the effects of interorganizational and interpersonal trust on performance. Organization Science, 9(2), 141159.

Zammuto, R. F., Griffith, T. L., Majchrzak, A., Dougherty, D. J., \& Faraj, S. (2007). Information technology and the changing fabric of organization. Organization Science, 18(5), 749-762. 
Zhang, Y., \& Li, H. (2010). Innovation search of new ventures in a technology cluster: The role of ties with service intermediaries. Strategic Management Journal, 31(1), 88-109.

Zhou, K. Z., Yim, C. K., \& Tse, D. K. (2005). The effects of strategic orientations on technology-and market-based breakthrough innovations. Journal of Marketing, 69(2), 4260 . 